Illinois State University

ISU ReD: Research and eData

Theses and Dissertations

$11-18-2015$

\title{
Synthesis And Characterization Of Neo-Confused Porphyrins And Related Systems
}

Arwa Salem Almejbel

Illinois State University, arwa-3112@hotmail.com

Follow this and additional works at: https://ir.library.illinoisstate.edu/etd

Part of the Organic Chemistry Commons

\section{Recommended Citation}

Almejbel, Arwa Salem, "Synthesis And Characterization Of Neo-Confused Porphyrins And Related Systems" (2015). Theses and Dissertations. 486.

https://ir.library.illinoisstate.edu/etd/486

This Thesis is brought to you for free and open access by ISU ReD: Research and eData. It has been accepted for inclusion in Theses and Dissertations by an authorized administrator of ISU ReD: Research and eData. For more information, please contact ISUReD@ilstu.edu. 


\section{SYNTHESIS AND CHARACTERIZATION OF NEO-CONFUSED PORPHYRINS AND RELATED SYSTEMS}

Arwa S. Almejbel

\section{Pages}

Carbaporphyrins have been the focus of many studies, and a wide variety of related carbaporphyrinoid systems have been reported. N-Confused porphyrins are a class of carbaporphyrins where one pyrrole unit has been inverted. In this work, a newly discovered family of porphyrin isomers where one of the pyrrolic subunits is connected to the meso-bridge in a 1,3-fashion, called neo-confused porphyrins, has been investigated.

Reaction of pyrrole-3-carbaldehydes with acetoxymethylpyrroles 39and $\mathrm{NaH}$ in DMF gave neo-confused dipyrrylmethanedialdehydes. The resulting dialdehydes underwent an acid catalyzed condensation with a dipyrrylmethane to give neo-confused phlorins, and following oxidation with $\mathrm{FeCl}_{3}$ afforded new neo-confused porphyrins. These porphyrinoids differ from previous neo-confused porphyrins in that they do not possess fused benzo- units or electron withdrawing ester substituents. Instead, the neoconfused ring is substituted with a phenyl or bromo group. Reaction of neo-confused porphyrins with nickel(II) or palladium(II) acetate afforded the organometallic complexes. The aromaticity of the neo-confused porphyrins and their derivatives were 
assessed by proton NMR spectroscopy and UV-Vis spectroscopy.

KEYWORDS: Carbaporphyrins, N-confused porphyrins, Neo-confused porphyrins. 
SYNTHESIS AND CHARACTERIZATION OF NEO-CONFUSED PORPHYRINS

AND RELATED SYSTEMS

ARWA S. ALMEJBEL

A Thesis Submitted in Partial

Fulfillment of the Requirements

for the Degree of

MASTER OF SCIENCE

Department of Chemistry

ILLINOIS STATE UNIVERSITY

2016 
(C) 2016 Arwa S. Almejbel 
SYNTHESIS AND CHARACTERIZATION OF NEO-CONFUSED PORPHYRINS AND RELATED SYSTEMS

ARWA S. ALMEJBEL

COMMITTEE MEMBERS:

Timothy D. Lash, Chair

Shawn R. Hitchcock

Christopher Hamaker 


\section{ACKNOWLEDGMENTS}

I would first like to acknowledge Saudi Cultural Mission (SACM) for the generous scholarship. I also would like to thank Chemistry Department faculty members and my colleagues for their advice and support, as well as my committee members, Dr. Shawn Hitchcock and Dr. Christopher Hamaker. A special thanks to my awesome research adviser Dr. Timothy Lash for the generous guidance, patience and endless support for the past two years. I would also thank my family and friends for their unwavering love and support.

A. S. A. 


\section{CONTENTS}

Page

ACKNOWLEDGMENTS $\quad$ i

$\begin{array}{ll}\text { CONTENTS } & \text { ii }\end{array}$

$\begin{array}{ll}\text { TABLES } & \text { iii }\end{array}$

FIGURES

SCHEMES Vi

CHAPTER

I. PORPHYRINS AND RELATED SYSTEMS 1

Introduction 1

Porphyrins as Photosensitizers $\quad 6$

Synthesis of Porphyrinoids 7

Theoretical Studies of N- and Neo-confused Porphyrins 21

Conclusion 23

II. RESULTS AND DISCUSSION 24

$\begin{array}{ll}\text { Conclusions } & 62\end{array}$

III. EXPERIMENTAL 63

$\begin{array}{ll}\text { REFERENCES } & 88\end{array}$

APPENDIX: Selected NMR spectra $\quad 92$ 


\section{TABLES}

Table $\quad$ Page

1. Thermal rearrangment of vinyl oxime $\mathbf{5 7}$ to pyrrole $\mathbf{5 8}$ 


\section{FIGURES}

Figure $\quad$ Page

1. Porphyrin structure $\quad 2$

2. Ring currents in porphyrins 4

3. Structures of heme (left) and chlorophyll (right) 5

4. Porphyrin tautomers 5

5. Carbaporphyrin, N-confused porphyrin and neo-confused porphyrin 12

6. Tetraphenylporphyrin (TPP) (4) and N-Confused Porphyrin (NCP) (17) 14

7. N-confused porphyrin (17) and N-fused porphyrin (22) 15

$\begin{array}{ll}\text { 8. Neo-confused porphyrins } & 17\end{array}$

9. Metal complexes of neo-confused porphyrins 20

10. Structures of neo-confused porphyrin and benzo-neo-confused porphyrin tautomers and their relative energies $(\mathrm{kcal} / \mathrm{mol})$ compared to porphyrin and benzoporphyrin, respectively

11. $500 \mathrm{MHz}$ proton NMR spectrum of bromo neo-confused dipyrrylmethane37a

12. $500 \mathrm{MHz}$ proton NMR spectrum of bromo neo-confused porphyrin 36a

13. UV-vis spectrum of bromo neo-confused porphyrin $\mathbf{3 6 a}$ in $\mathrm{CH}_{2} \mathrm{Cl}_{2}$

14. Protonation of bromo neo-confused porphyrin 36a

15. $500 \mathrm{MHz}$ proton NMR spectrum of neo-confused porphyrin dication $36 \mathbf{a H}_{2}{ }^{2+}$ in TFA-CDCl 3 
16. UV-vis spectrum of neo-confused porphyrin 36a in dichloromethane (red line) and $2 \%$ TFA- $\mathrm{CH}_{2} \mathrm{Cl}_{2}$ (blue line)

17. $500 \mathbf{M H z}$ proton NMR spectrum of nickel(II) complex $\mathbf{5 3}$

18. UV-vis spectrumof the nickel(II) complex $\mathbf{5 3} \mathrm{inCH}_{2} \mathrm{Cl}_{2}$

19. $500 \mathrm{MHz}$ proton NMR spectrum of palladium(II) complex $\mathbf{5 4}$

20. UV-vis spectrum of the palladium(II) complex 54in $\mathrm{CH}_{2} \mathrm{Cl}_{2}$

21. $500 \mathrm{MHz}$ proton NMR spectrum of phenyl neo-confused

Dipyrrylmethane 37b 48

22. $500 \mathrm{MHz}$ proton NMR spectrum of phenyl neo-confused porphyrin 36b $\quad 50$

23. UV-vis spectrum of phenyl neo-confused porphyrin $\mathbf{3 6 b}$ in $\mathrm{CH}_{2} \mathrm{Cl}_{2}$

24. Protonation of phenyl neo-confused porphyrin $\mathbf{3 6} \mathbf{b H}_{2}{ }^{2+}$

25. $500 \mathrm{MHz}$ proton NMR spectrum of phenyl neo-confused porphyrindication 36 $\mathrm{bH}_{2}{ }^{2+}$ in TFA-CDCl 3

26. UV-vis spectrum of neo-confused porphyrin $\mathbf{3 6} \mathbf{b}$ in dichloromethane (purple line) and $2 \% \mathrm{TFA}-\mathrm{CH}_{2} \mathrm{Cl}_{2}$ (green line)

27. $500 \mathrm{MHz}$ proton NMR spectrum of palladium(II) complex 61 in $\mathrm{CDCl}_{3}$

28. $500 \mathrm{MHz}$ proton NMR spectrum of nickel(II) complex 62 in $\mathrm{CDCl}_{3}$

29. $500 \mathrm{MHz}$ proton NMR spectrum of aza neo-confused dipyrrylmethane 63 in $\mathrm{CDCl}_{3}$

30. $500 \mathrm{MHz}$ proton NMR spectrum of methyl aza neo-confused dipyrrylmethane70 in $\mathrm{CDCl}_{3}$ 


\section{SCHEMES}

$\begin{array}{lll}\text { Scheme } & \text { Page }\end{array}$

1. Rothemund method for synthesis of meso-tetraphenylporphyrin

2. Conversion of chlorin to porphyrin 8

3. One-pot synthesis of meso-substituted porphyrins 9

4. "2+2" MacDonald condensation reaction 10

5. Synthesis of tripyrranes 11

6. “3+1” MacDonald condensation reaction 11

7. Synthesis of benzocarbaporphyrins 13

8. Synthesis of N-fused porphyrins 16

9. N-confused corrole and neo-confused corrole (norrole) 17

10. Method developed for the synthesis of neo-confused porphyrin esters 18

11. Retrosynthetic analysis of neo-confused porphyrins using MacDonald's" $2+2$ " condensation approach 25

12. Retrosynthetic analysis of the key intermediary dipyrroledialdehydes 25

13. Synthesis of 5-acetoxymethyl-3,4-dimethylpyrrole-2-carbaldehyde 39

14. Synthesis of 5-bromo pyrrole-3-carbaldehyde 40a 28

15. Synthesis of bromo-neo-confused dipyrrylmethane 37a 29

16. Synthesis of bromo neo-confused porphyrin using a "2+2" condensation 31 
17. Attempted synthesis of neo-fused porphyrin $\mathbf{5 2} 38$

18. Synthesis of nickel(II) neo-confused porphyrin $\mathbf{5 3}$

19. Synthesis of the palladium(II) complex of bromo neo-confused Porphyrin 54

20. Proposed synthesis of phenyl neo-confused porphyrin 36b

21. Synthesis of 5-phenyl pyrrole-3-carbaldehyde 40b 45

22. Synthesis of phenyl neo-confused dipyrrylmethanedialdehyde 37b $\quad 47$

23. Synthesis of phenyl neo-confused porphyrin $\mathbf{3 6 b}$

24. Synthesis of palladium(II) complex 61

25. Synthesis of nickel(II) complex 62

26. Attempted synthesis of aza neo-confused porphyrin 64

27. Synthesis of methyl formyl imidazole $69 \quad 60$

28. Attempted synthesis of methyl aza neo-confused porphyrin 71 


\section{CHAPTER I}

\section{PORPHYRINS AND RELATED SYSTEMS}

\section{Introduction}

The majority of complex animal and plant life that exists on our planet today relies on a class of aromatic heterocycles known as porphyrins. Photosynthesis and respiration are at the heart of what makes life possible. During the Archean period,life on earth was dominated by bacteria and archaeaand the atmosphere was devoid of free oxygen. The evolution of oxygenic photosynthesis from cyanobacteria changed the earth and its atmosphere forever. The process involves the oxidation of water to form molecular

oxygen which is released into the atmosphere. ${ }^{1}$ Eventually the earth's atmosphere changed from anaerobic to aerobic leading to a dramatic increase in biodiversity. Life has since evolved to utilize oxygen, leading to eukaryotic organisms and plants containing chloroplasts for photosynthesis and eventually hemoglobin in the red blood cells for oxygen transportationin vertebrates. ${ }^{1}$ 
Porphyrins are organic molecules that play very important roles in the metabolism of living organisms such as bacteria, animals and plants. The term Porphyrin derives from The Greek word porphura meaning reddish-purple. ${ }^{2}$ Hematoporphyrin was isolated in 1871 by the German chemist Hoppe-Seyler. When he treated dried blood with concentrated $\mathrm{H}_{2} \mathrm{SO}_{4}(\mathrm{aq})$, a purple colored compound was formed that was named hematoporphyrin, from a Greek words for blood and purple. ${ }^{1,2}$

Porphyrins have a characteristic square shape (Figure 1) built up from four pyrrole subunits. The porphyrins are pigments that are either naturally found in living organisms or synthetically formed. ${ }^{1}$

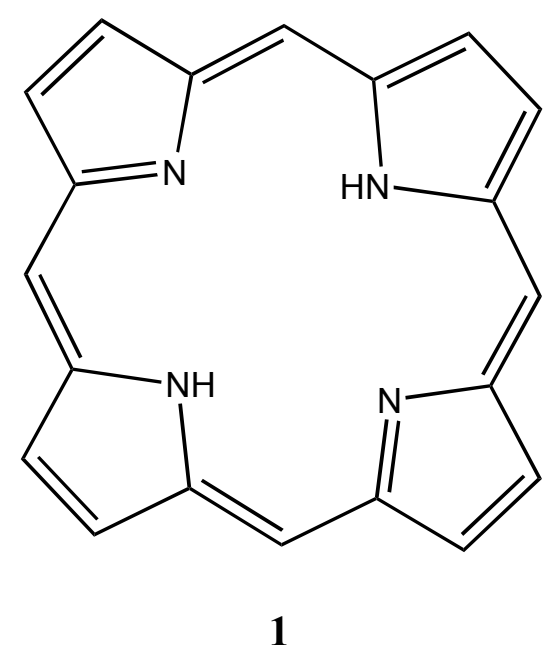

Figure 1: Porphyrin structure

Porphyrins are highly aromatic due in part to the presence of a $\pi$-electron pathway that obeys Hückel's rule of aromaticity, where the number of $\pi$ electrons is[4n +2$]$. In 
porphyrins, the continuous $\pi$ electron delocalization pathway involves $18 \pi$ electrons ( $\mathrm{n}=$ 4). ${ }^{1,2}$

The aromatic character of porphyrins can be confirmed by proton NMR spectroscopy. Studies performed over the last fifty years have demonstrated that ${ }^{1} \mathrm{H}$ NMR spectra are very informative and adequately reflect the structural features of porphyrins. The presence of the extended delocalized $\pi$-electron system of the porphyrin macrocycle gives rise to a strong ring current in molecules that have been placed in a magnetic field.

The ring current causes anisotropic shielding of the protons located in the field of its action and together with the diamagnetic component of paired $\sigma$-electrons leads to a substantial shift of their signals in the ${ }^{1} \mathrm{H}$ NMR spectra. It can be stated that the ring current and the aromaticity of porphyrins change in a similar way in response to the analogous changes in the molecular structure of the porphyrin and the medium, which is most clearly seen in comparisons of the spectra of porphyrins and their precursors. Due to the anisotropic effect from the porphyrin ring current, the NMR signals for the deshieldedmeso-protons (protons on the bridging methine carbons) show up at low field (the external protons usually show up near $+10 \mathrm{ppm}$ ), whereas the signals for the shielded protons on the inner nitrogen atoms show up at very high field (commonly at -4 ppm).Figure 2 illustrates the effects due to the diamagnetic ring current, which results in shielding and deshielding regions. ${ }^{1}$ 


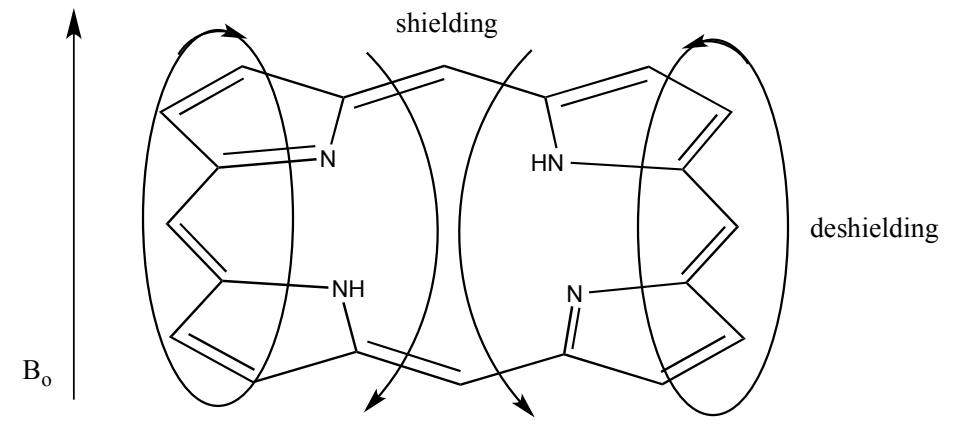

Figure 2: Ring currents in porphyrins

As mentioned above, porphyrins are highly conjugated structures, and have characteristic UV-vis spectra. A strong absorption appears around $400 \mathrm{~nm}$, which is known as the Soret band, and smaller peaks show up between $500 \mathrm{~nm}$ to $700 \mathrm{~nm}$ that are called $\mathrm{Q}$ bands. The $\mathrm{Q}$ bands are responsible for the intense red or green color of porphyrins in solutions. ${ }^{1}$

The study of porphyrin chemistry includes synthesis, structural characterization and the formation of numerous derivatives. The most common derivatives of porphyrins are metal complexes, in which a metal ion is present in the interior of the cavity. The best known example of a metallic complex in humans and other mammals is the heme group in hemoglobin. In this case, the metal ion in the center is iron(II), and heme gives blood its characteristic red color (Figure 3). In plants, the most important porphyrin derivative is chlorophyll, where the coordinated metal is magnesium (Figure 3). Porphyrins and their derivatives are crucial structures in virtually all living organisms. ${ }^{1}$ 


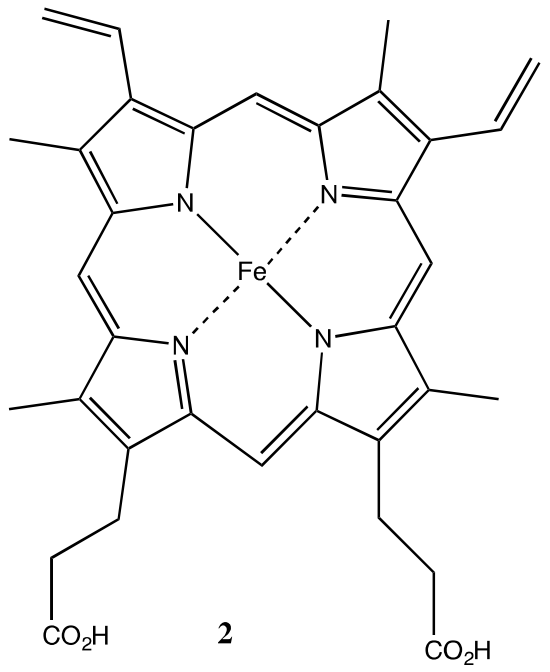

Heme

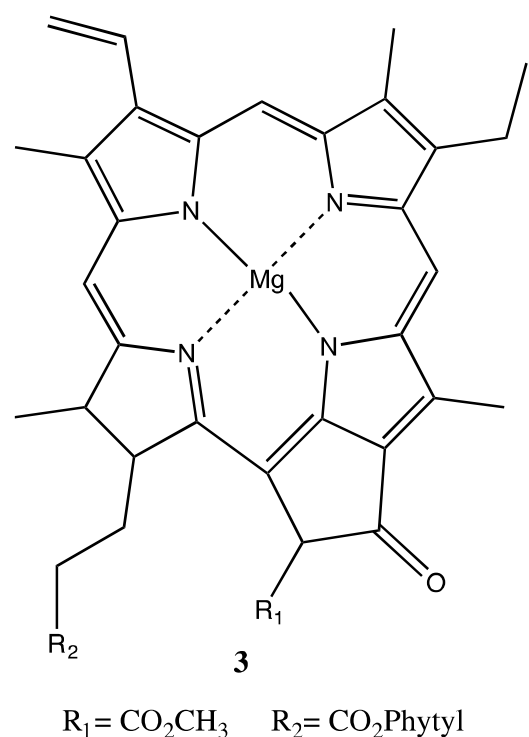

Chlorophyll a

Figure 3: Structures of heme (left) and chlorophyll (right)

The porphyrin structure was first proposed by Küster in 1912, and was confirmed more than 10 years later by Hans Fischer's pioneering synthetic studies. ${ }^{4}$ The presence of two internal hydrogens could potentially lead to isomers $\mathbf{1}, \mathbf{1 a}$ and $\mathbf{1 b}$ (Figure 4), but it is now known that these tautomers rapidly interconvert at room temperature. ${ }^{1}$

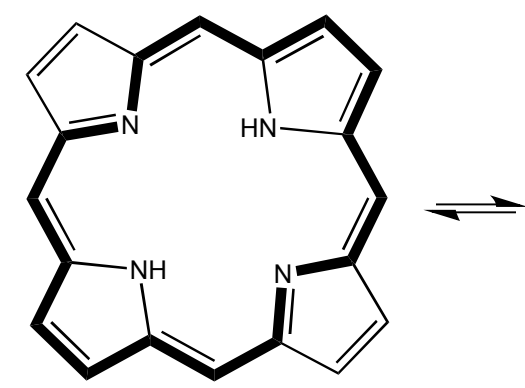

1

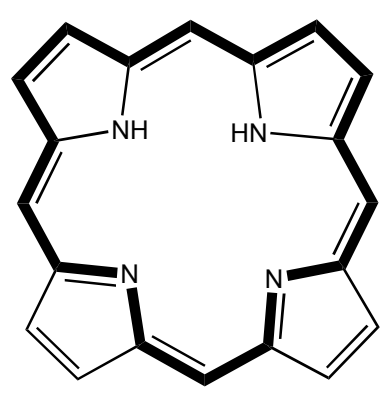

1a

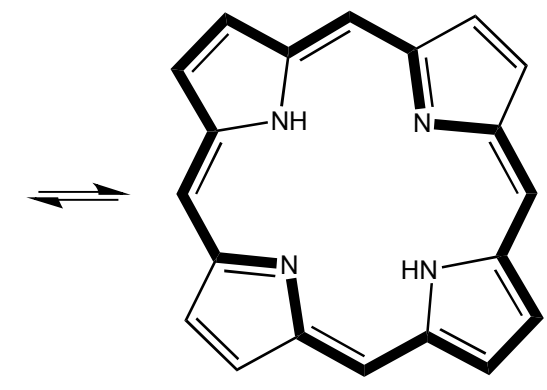

1b

Figure 4: Porphyrin tautomers 


\section{Porphyrins as Photosensitizers}

Photosensitisers have the ability to absorb light at a specific wavelength, transforming it into energy, which is transferred to a substrate or molecular oxygen, leading to the production of ROS (Reactive Oxygen Species). Thus, a good photosensitiser should absorb light efficiently, forming a high quantum yield of photosensitiser in the excited triplet state. The excited triplet state should also be relatively stable, increasing the probability of reacting with either oxygen or a suitable substrate. Compounds that have the ability to form excited triplet states generally possess conjugated systems; hence porphyrin type structures have been utilized as photosensitisers. $^{5}$

As noted above, free base porphyrins have a UV/visible spectrum consisting of one intense absorption band, referred to as the Soret band, at 380-430 nm, and four less intense Q bands at higher wavelengths. ${ }^{5}$ The optical properties of different porphyrin derivatives are dependent on the functional groups that are present on the porphyrin core. Porphyrins absorb photons efficiently at wavelengths corresponding to their absorption peaks, leading to high excited triplet state yields, which efficiently produce ROS. ${ }^{5}$ 


\section{Synthesis of Porphyrinoids}

In 1935, Rothemund investigated a route to synthesize symmetrical porphyrins such as tetraphenylporphyrin (TPP) (Scheme 1). ${ }^{6}$ Initially, acetaldehyde and pyrrole were heated with methanol in a sealed vessel at different temperatures and similar studies were performed employing different aldehydes. The porphyrins generated were observed spectroscopically and shown to be contaminated with other porphyrinic substances. One of these was later isolated by column chromatography and shown to

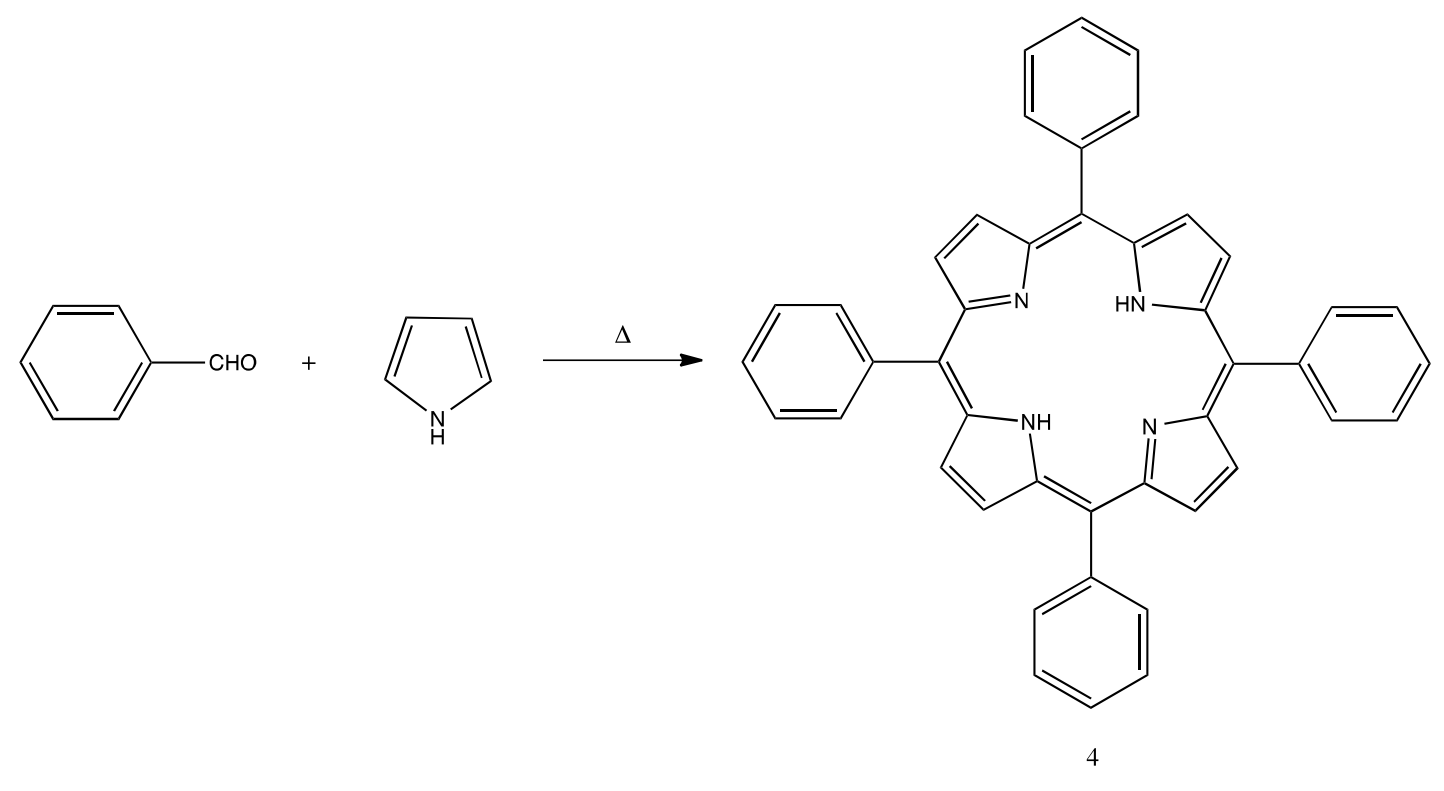

Scheme 1: Rothemund method for synthesis of meso-tetraphenylporphyrin.

be the related dihydroporphyrin or chlorin (Scheme 2). The chlorin can be converted to the porphyrin via an oxidation step. A few years later, Rothemundimproved the preparation of TPP by changing some of the conditions. In the developed procedure, pyrrole and benzaldehyde were heated in pyridine in a sealed vessel and following 
cooling over an $18 \mathrm{~h}$ period afforded blue needles in $9 \%$ yield. ${ }^{6,7}$ During an investigation of the chlorin isolated by Rothemund, Calvin and coworkers found that addition of zinc acetate to the reaction mixture significantly increased the yield to above $11 \%$. However, this method was time consuming. ${ }^{7}$
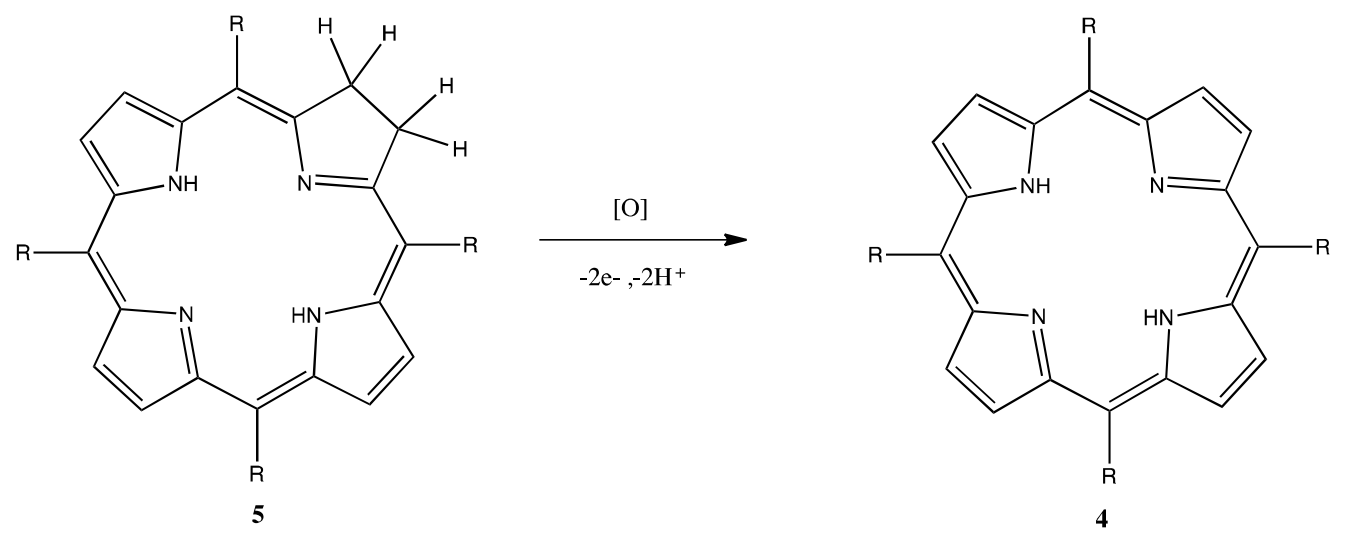

Scheme 2: Conversion of chlorin to porphyrin

In the later 1960s, Adler, Longo and coworkers reported a greatly improved procedure based on Rothemund's method. They condensed benzaldehyde and pyrrole in acidic solvents at reflux and open to air. The solvents employed in this method were: acetic acid, acetic acid in the presence of metal salts, and benzene containing chloroacetic acid or propionic acid. This alternative route for preparing TPP can give $>20 \%$ yield. ${ }^{7,8}$ In addition, this method did not require an oxygen free environment and required shorter reaction times. However, both the Rothemund and Adler-Longo methods are only suitable for symmetrical porphyrins. ${ }^{6,7,8}$ Further improvements to the synthesis of tetraphenyl porphyrins were reported by Lindseyetal.using milder conditions (Scheme 3). In these reactions, dilute solutions of pyrrole and benzaldehyde in dichloromethane are 
reacted at room temperature in the presence of a Lewis acid catalyst such as boron trifluorideetherate.Oxidation, usually with 2,3-dichloro-5,6-dicyano-1,4-benzoquinone (DDQ), furnishes TPP in 40-60\% yield. ${ }^{9}$

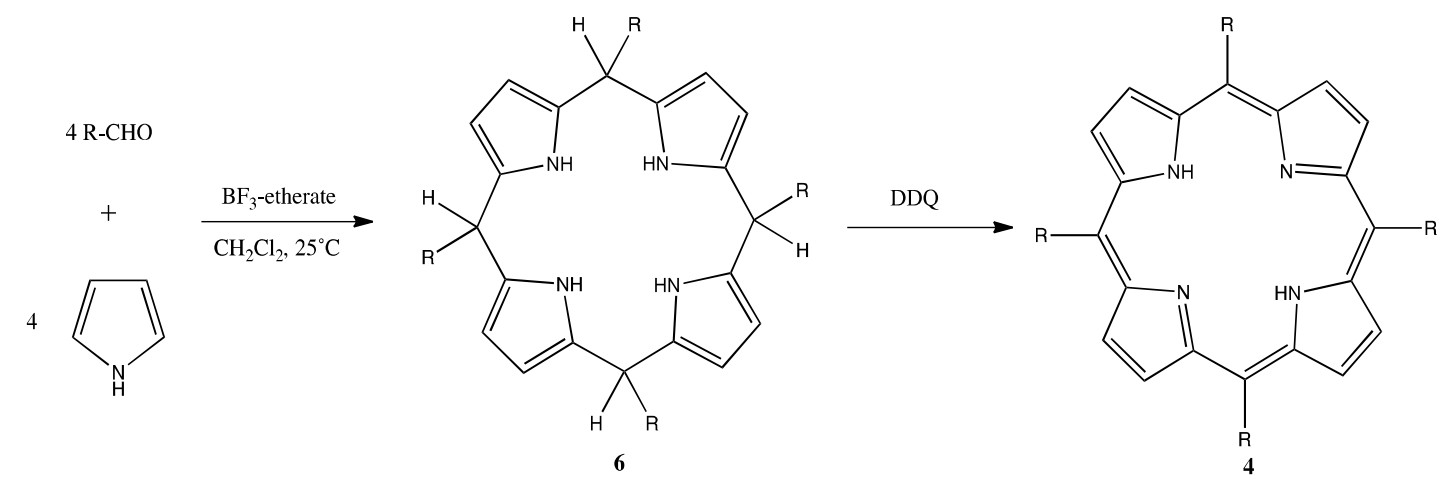

Scheme 3: One-pot synthesis of meso-substituted porphyrins

Hans Fischer developed routes to synthesize asymmetrical porphyrins in the 1920 s, but these methods required harsh conditions and gave low yields. In 1960, MacDonald published a new method for porphyrin synthesis. A 5,5'-dipyrrylmethane dialdehyde7 was condensed with $\alpha$-unsubstituteddipyrrylmethane 8 in the presence of an acid catalyst to generate a porphodimethene intermediate $\mathbf{9}$, and following air oxidation the final porphyrin product $\mathbf{1 0}$ was obtained(Scheme 4). ${ }^{7,10}$ The MacDonald reaction has been one of the important methods for synthesizing meso-unsubstituted porphyrins. Moreover, a variation on MacDonald's condensation was an important step in the total synthesis of chlorophyll a. $^{7}$ 


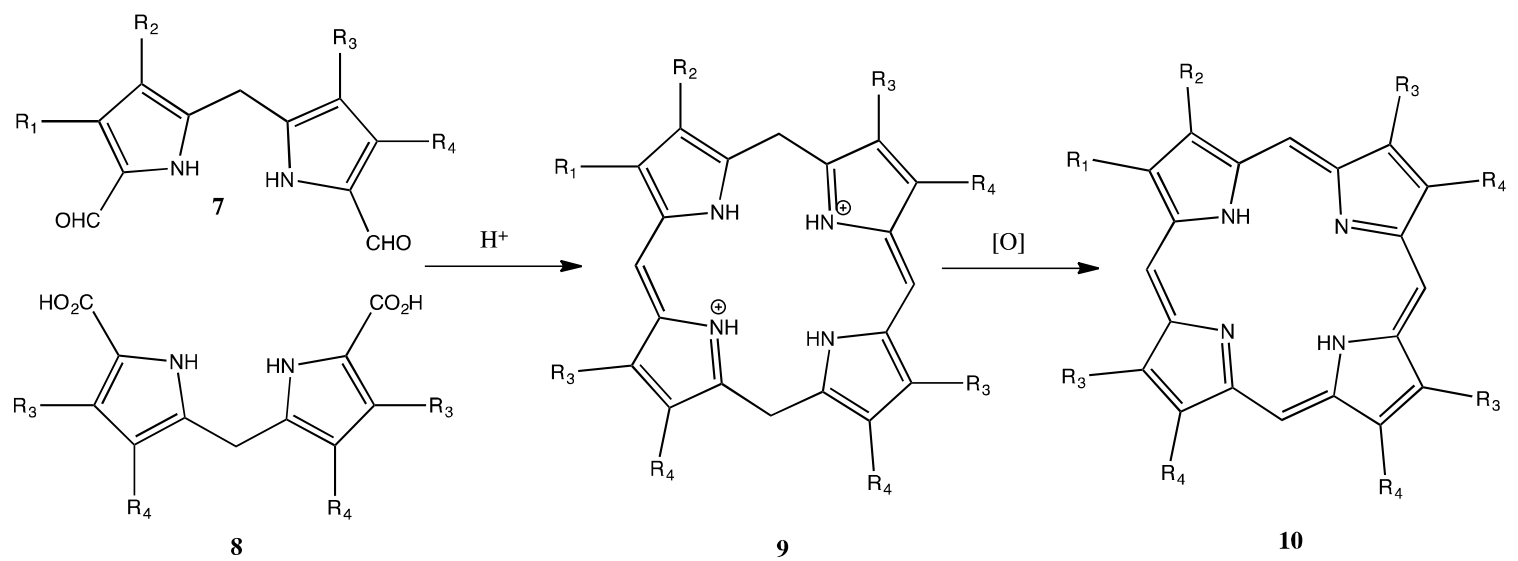

Scheme 4: "2+2" MacDonald condensation reaction

In the mid 1990s, the " $3+1$ " approach was shown to be the method of choice for the synthesis of porphyrin analogues. ${ }^{7}$ Thedevelopment of a straightforward approach for preparing tripyrranes facilitated the success of this approach. ${ }^{7,11}$ This was accomplished by reacting a 2,5-diunsubstituted pyrrole with two equivalents of an acetoxymethylpyrrole11 under acidic conditions to afford protected tripyrrane12. The tripyrrolic products are usually prepared as dibenzyl esters 12 (Scheme 5).

Hydrogenolysis over palladium-charcoal affords the corresponding dicarboxylic acids $\mathbf{1 4}$ and these condense with pyrrole dialdehydes13 to give, following an oxidation step, the corresponding porphyrins $\mathbf{1 5}$ (Scheme 6). ${ }^{11}$ 


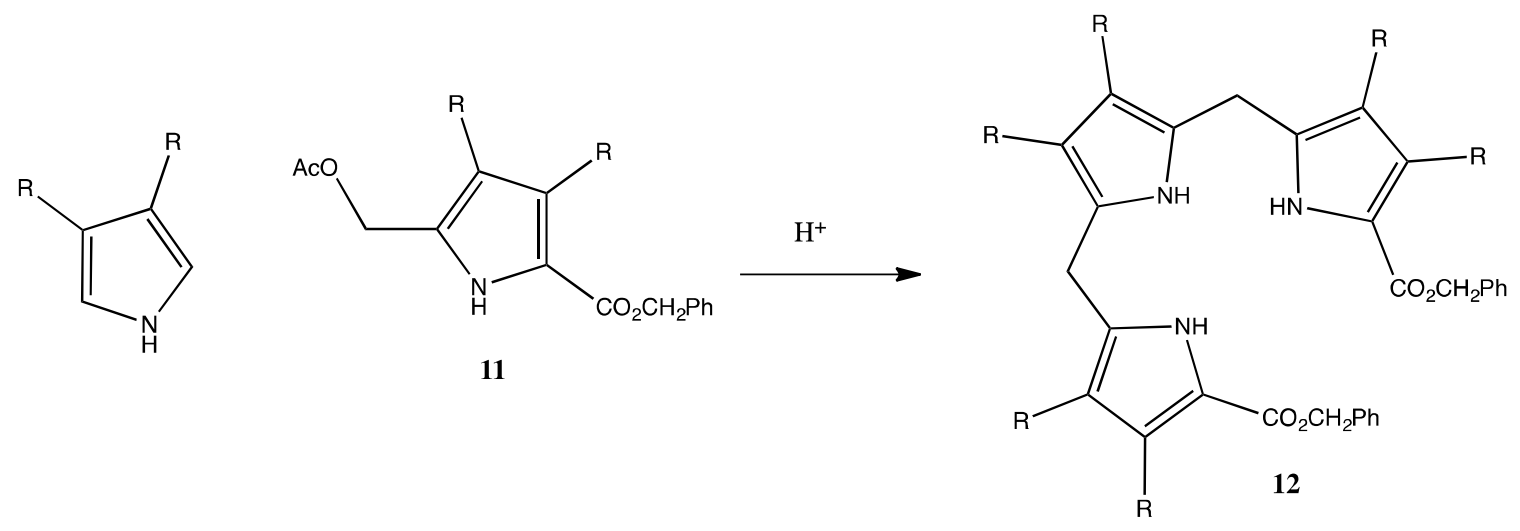

Scheme 5: Synthesis of tripyrranes

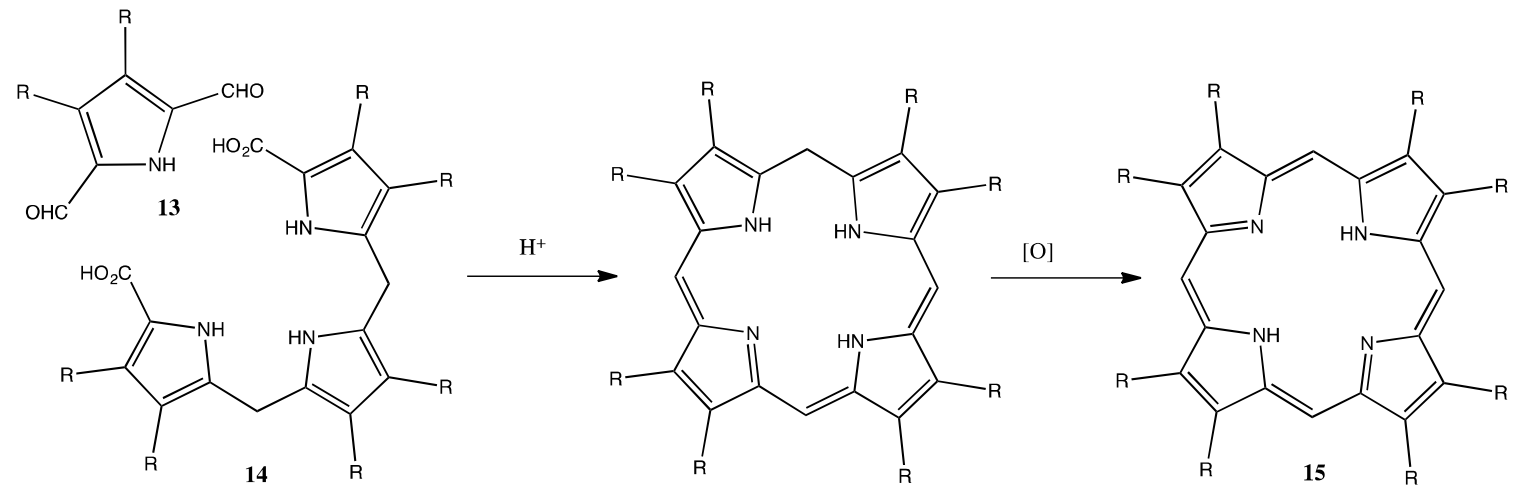

Scheme 6: “3+1" MacDonald condensation reaction 


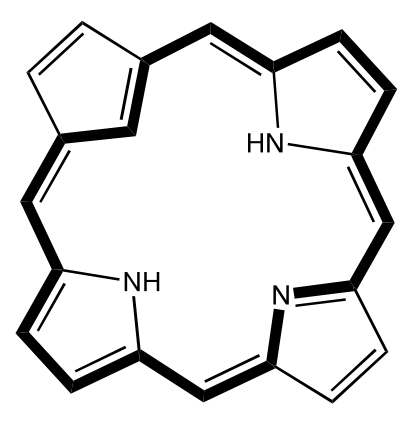

Carbaporphyrin

16

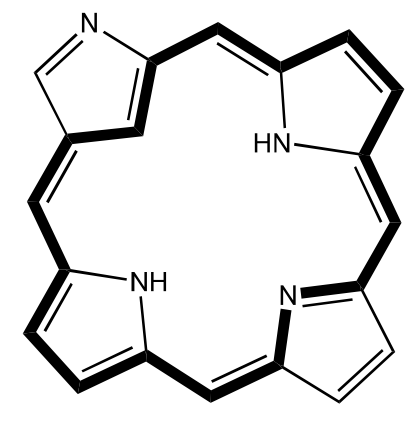

$\mathrm{N}$-confused porphyrin

17

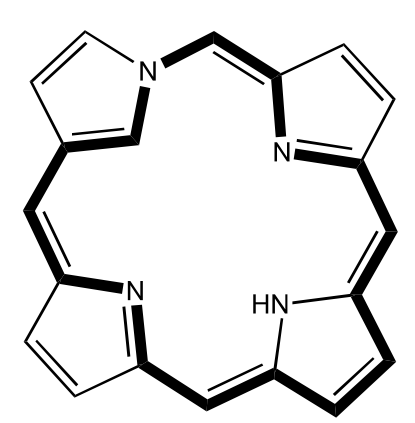

neo-confused porphyrin

18

Figure 5: Carbaporphyrin, N-confused porphyrin and neo-confused porphyrin

Carbaporphyrins16 are porphyrin analogues where one of the internal nitrogens has been replaced with a carbon atom. This class of porphyrin has been widely investigated due to their unusual reactivity such as forming organometallic complexes under mild conditions. Examples of related carbaporphyrinoidsystems are N-confused porphyrins 17 and neo-confused porphyrins 18 (Figure 5). ${ }^{13,14}$

Most of the work that has been carried out on carbaporphyrins has dealt with benzocarbaporphyrins because of the straightforward synthesis of this type of porphyrin analogue. This system can easily be synthesized from indenedicarbaldehyde19 and tripyrrane20 in the presence of an acid catalyst, and following oxidation with DDQ the conjugated porphyrinoid 21 is obtained in $>40 \%$ yield (Scheme 7). ${ }^{14}$ 

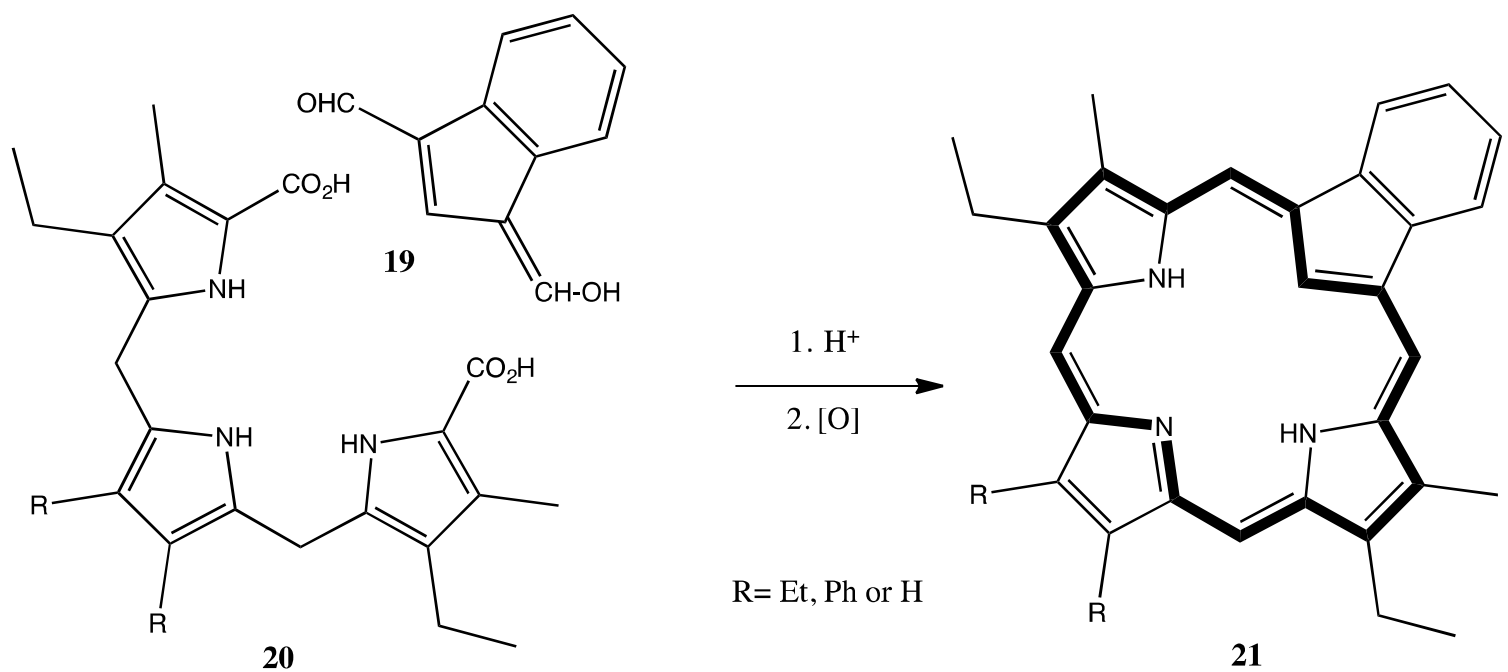

Scheme 7: Synthesis of benzocarbaporphyrins

N-confused porphyrin (NCP) 17, an isomer of tetraphenylporphyrin (TPP) 4 (Figure 6), was discovered in 1994. NCP differs from true porphyrins because one of the pyrrole units is inverted so that nitrogen appears on the periphery (Figure 6). Furutaet al. (1994) ${ }^{14}$ reported that NC-TPP 17 was obtained through the well-known condensation reaction between benzaldehyde and pyrrole, but instead of the usual propionic acid, a mixture of $\mathrm{HBr}$ and tert-Butanol/dichloromethanewas used. Information about the structure of NCTPP was ascertained using NMR spectroscopy and single-crystal X-ray diffraction; the results showed that the molecule was less planar than TPP. Furutaet al. (1994) hypothesized that the ring distortion was due to repulsion by the three inner hydrogens. Latos-Grazynski and coworkers also reported an independent synthesis of NCP in $1994 .{ }^{15}$ 


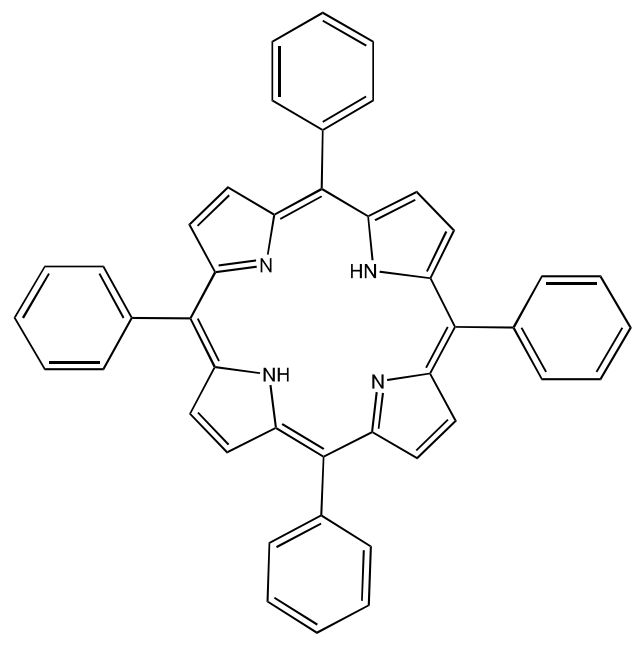

4

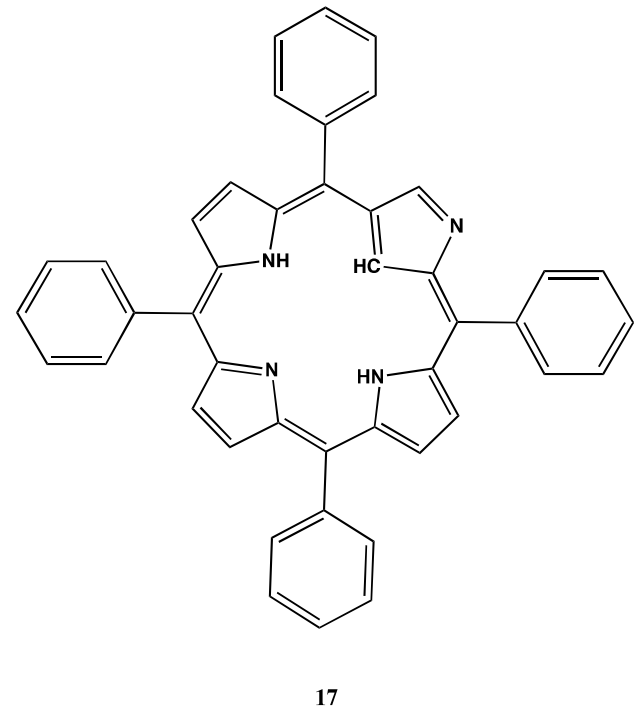

Figure 6:Tetraphenylporphyrin (TPP) (4) and N-Confused Porphyrin (NCP) (17)

Following the discovery of NCPs, hundreds of papers have been published on these unusual porphyrin isomers. In addition, doubly N-confused porphyrins with two inverted pyrrole units have been prepared, as well as expanded $\mathrm{N}$-confused systems. N-Confused porphyrins form coordinated complexes within the porphyrinoid cavity and at the peripheral nitrogen. The NCP core can generate stable organometallic derivatives and may stabilize high oxidation state complexes such as Ag(III) derivatives. The N-confused porphyrins display high reactivity towards electrophilic substitution reactions such as bromination and nitration compared to regular porphyrins. Moreover, NCPs are more flexible than ordinary porphyrins and can exist as an aromatic tautomer or less aromatic form with an external $\mathrm{NH} .{ }^{14,15}$ 


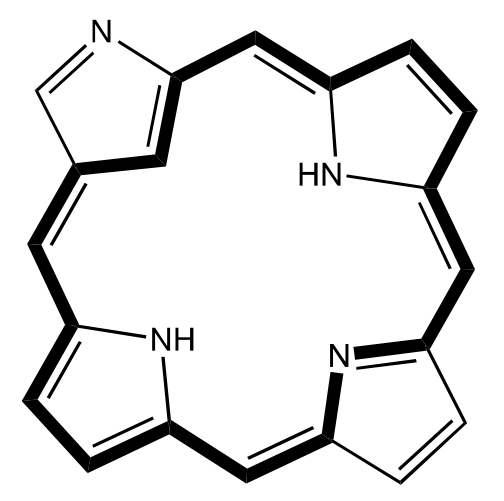

$\mathrm{N}$-confused porphyrin 17

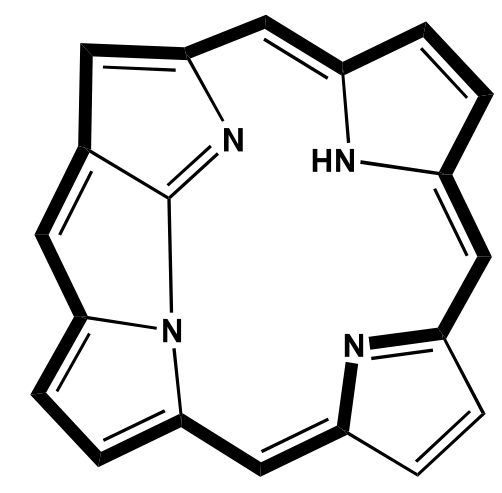

N-Fused porphyrin

Figure 7:N-confused porphyrin (17) and N-fused porphyrin (22)

N-Fused porphyrin (NFP) 22 was discovered by Furutaet al. (1999) and (2000)

(Figure 7). NFP 22 can be made from N-confused porphyrins 17 by several pathways including spontaneous production from a bromo-substituted $\mathrm{N}$-confused tetraarylporphyrin23 in a pyridine solution (Scheme 8). ${ }^{15,16}$ The formation of NFP 22 involves inversion of the "confused" pyrrole unit, followed by generation of a carbonnitrogen bond (Scheme 8). ${ }^{16}$ X-ray diffraction studies (Furutaet al., 2000) showed that the resulting fused tri-pentacyclic ring at the center is almost planar, although the remaining structure is highly distorted and the aryl units on the periphery tilt from $12.4^{\circ}$ to $64.4^{\circ}$ from the plane of the center ring. ${ }^{16}$ Proton NMR and UV/Vis spectroscopy indicated a) three-centered $\mathrm{H}$ bonding in the NFP ring, b) UV-Vis transitions near 360, 500, and $550 \mathrm{~nm}$, and c) weak bands near $650,700,850$, and $940 \mathrm{~nm}$ for a solution $\mathrm{inCH}_{2} \mathrm{Cl}_{2}$. 
Addition of base to the $\mathrm{N}$-fused porphyrin resulted in ring opening to regenerate the NCP system. ${ }^{16}$
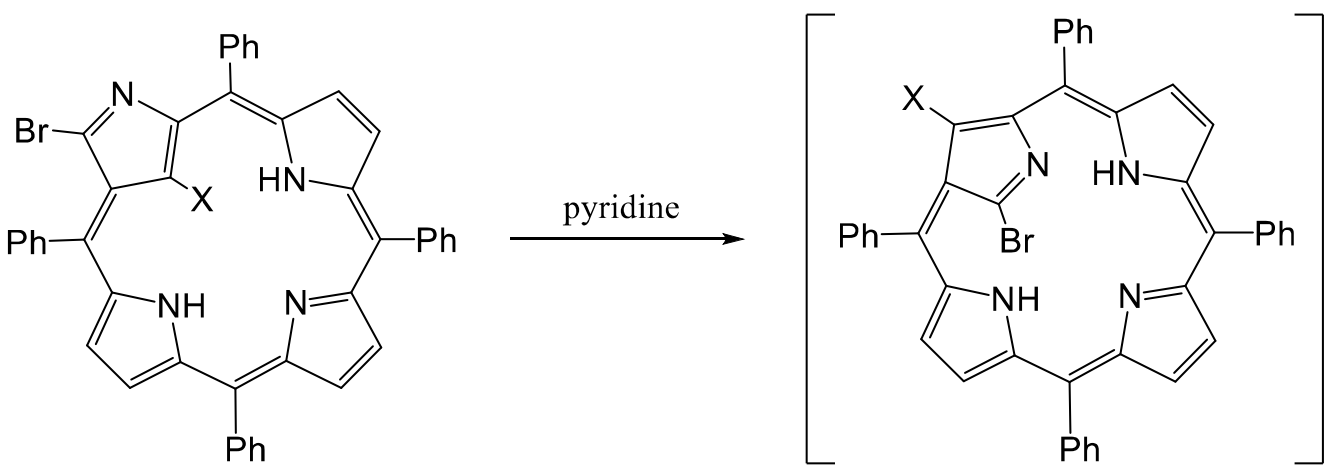

$$
\mathrm{X}=\mathrm{NO}_{2}, \mathrm{Br}, \mathrm{Cl}, \mathrm{I} \text { or } \mathrm{H}
$$

23

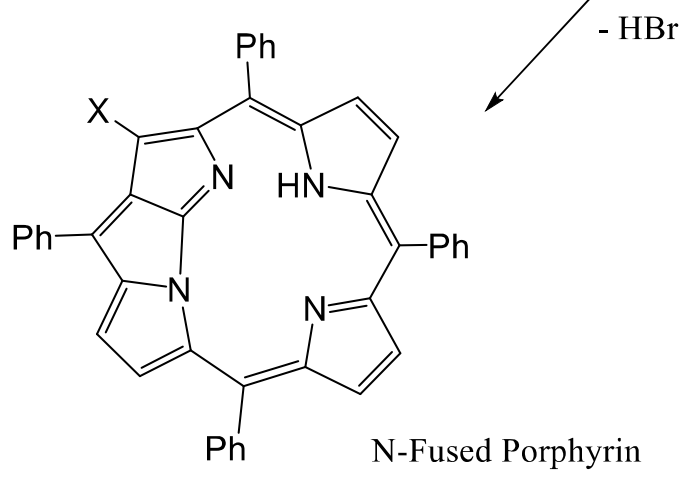

22

Scheme 8: Synthesis of N-fused porphyrins

In 2011, Furuta and coworkers oxidized N-confused bilane24 with DDQ which gave $\mathrm{N}$-confused corrole25, with a direct carbon-carbon link between two pyrrole units, in $18 \%$ yield. In addition, a minor product with a direct carbon-nitrogen link was isolated in $1 \%$ yield, and the new system was named neo-confused corrole or norrole26 (Scheme 9). ${ }^{17}$ 


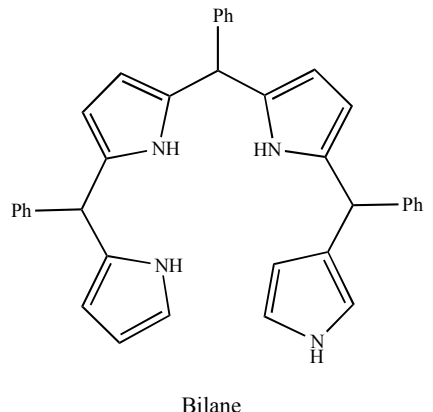

24

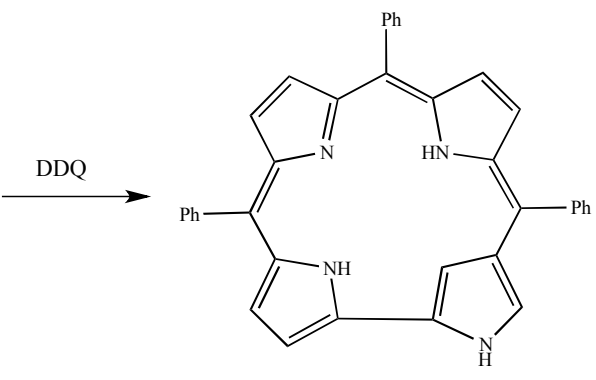

$\mathrm{N}$-confused corrole

25

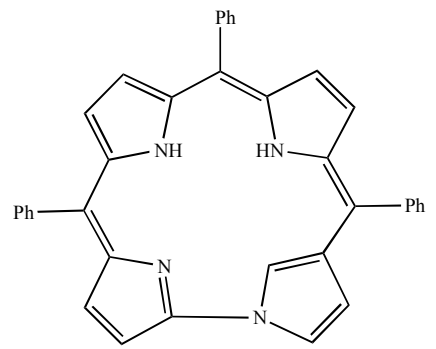

Neo-confused corrole (norrole)

26

$1 \%$

Scheme 9: N-confused corrole and neo-confused corrole (norrole)

Recently, a third class of porphyrin isomers was proposed (Figure 8). In this new proposed variation, one of the pyrrole rings is linked to a methine carbon via a nitrogen atom. This new variation was called a neo-confused porphyrin. Neo-confused porphyrins 18 can potentially take on aromatic characteristics due to the presence of a 17 -atom $18-\pi$ electron delocalization pathway. ${ }^{18}$

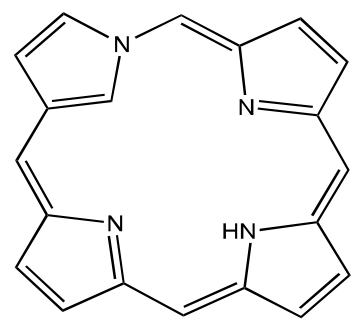

18

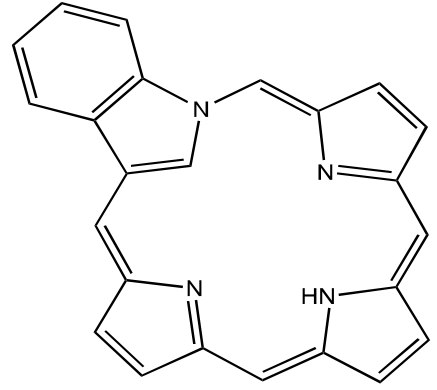

27

Figure 8: Neo-confused porphyrins 
Several examples of this new class of porphyrin analogues were prepared using dipyrrolicdialdehydes as intermediates. The neo-confused porphyrins demonstrated remarkably similar UV-vis spectral profiles to porphyrins. The proton NMR spectra for neo-confused porphyrins demonstrated that they are significantly less aromatic than true porphyrins and carbaporphyrins. The internal $\mathrm{CH}$ for benzo-neo-confused porphyrins was observed upfield near $-0.5 \mathrm{ppm}$, but benzocarbaporphyrinsmethine proton show this resonance substantially further upfield near $-7 \mathrm{ppm} .{ }^{18,19}$

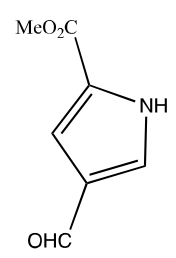

28

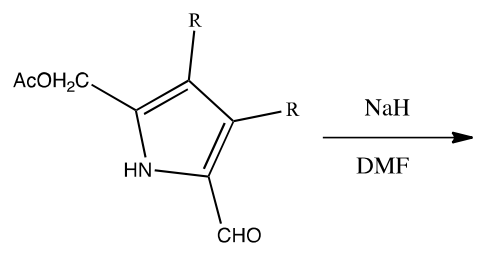

29

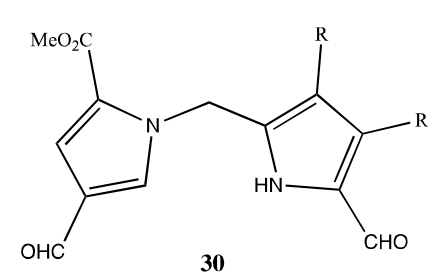

30

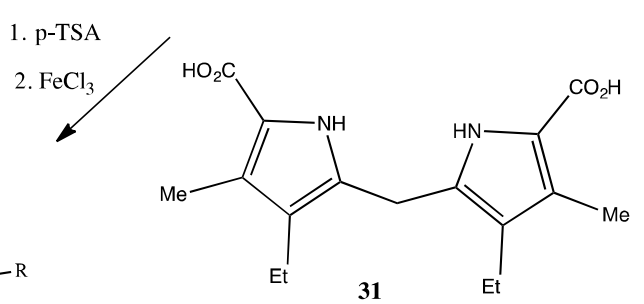

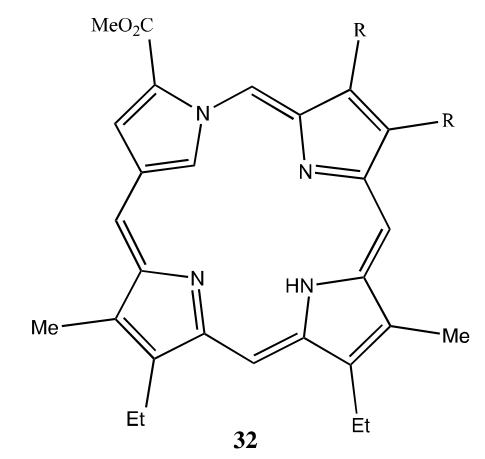

$\mathrm{R}=\mathrm{Me}$ or $\mathrm{Et}$

Scheme 10: Method developed for the synthesis of neo-confused porphyrin esters 
Attempts to synthesize neo-confused porphyrins using a "3 +1 " approach resulted in decomposition of the material under acidic conditions, with no identifiable products. The " $2+2$ " method yielded more favorable results, but in the initial study the desired product was only obtained in $25 \%$ yield. This was subsequently improved when the oxidation step was carried out with aqueous $\mathrm{FeCl}_{3}$ instead of DDQ (Scheme 10). ${ }^{19}$

In 2014, Lash and coworkers reported an efficient method for the synthesis of neoconfused porphyrins without fused benzo-units. In the synthesis of neo-confused porphyrin 32 described by Lash et al. (2014), the intermediate dipyrrolicdialdehydes 30 were formed by reacting pyrrole-3-carbaldehyde $\mathbf{2 8}$ with 5-acetoxymethypyrrole-2carbaldehyde 29 and sodium hydride in DMF (Scheme 10). The next step involved MacDonald "2+2" condensations of the dialdehydes with dipyrromethanes to produce dihydroporphyrinoids, and finally oxidation with ferric chloride produced neo-confused porphyrins 32. These molecules reacted with nickel(II) or palladium(II) acetate to give the organometallic derivatives of neo-confused porphyrin $\mathbf{3 3}$ and $\mathbf{3 4}$ (Figure 9). ${ }^{19}$ This study investigated the unique spectral and synthetic properties of this new class of porphyrin isomers. This research forms the groundwork for future investigations into these porphyrin isomers. Neo-confused porphyrins show surprisingly similar characteristics to regular porphyrins, exhibiting significant aromatic character and the ability to form metallo-derivatives. However, far more work will be required to understand how the structural modification due to the neo-confused ring affects the properties of these macrocycles. ${ }^{19}$ 

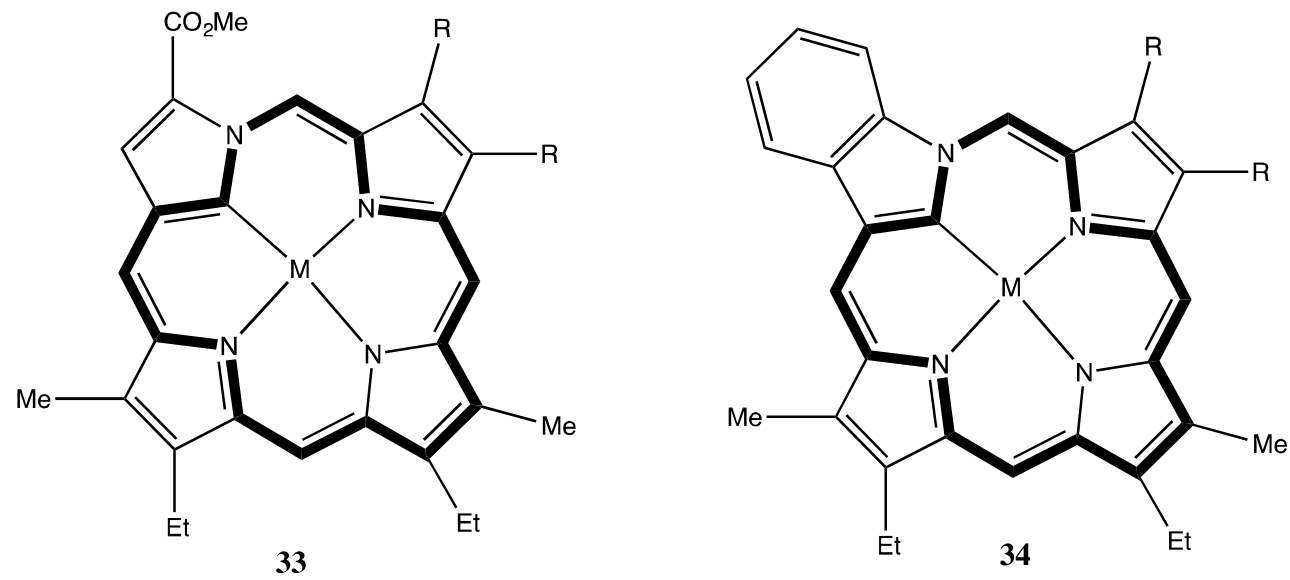

$\mathrm{R}=\mathrm{Me}$ or $\mathrm{Et} ; \mathrm{M}=2 \mathrm{H}, \mathrm{Ni}$ or $\mathrm{Pd}$

Figure 9: Metal complexes of neo-confused porphyrins 


\section{Theoretical Studies of N- and Neo-confused Porphyrins}

In order to gain further insights into $\mathrm{N}$-confused and neo-confused porphyrin systems, computational studies have been performed. ${ }^{20}$ In a study by AbuSalim and Lash in 2013, tautomers of $\mathrm{N}$-confused porphyrin, neo-confused porphyrin and regular porphyrins were investigated using standard density functional theory calculations (Figure 10). The neo-confused tautomers differed from one another by the placement of a single hydrogen atom. In N-confused porphyrin, the ring is tilted at an angle of $16.55^{\circ}$ relative to the macrocyclic plane, which agrees with previous X-ray structure studies. ${ }^{20} \mathrm{In}$ neo-confused tautomers, the structures end up in an almost planar state, because the cavity only has to accommodate one or two hydrogen atoms. Within the study, four tautomers with methylene bridges, which interupt the conjugation of the macrocycle, were also investigated. These were found to have relative energies of 64.28 to $66.25 \mathrm{kcal}$ mol $^{-1}$ compared to porphyrins which means that they are not stable enough to isolate. ${ }^{20}$ 

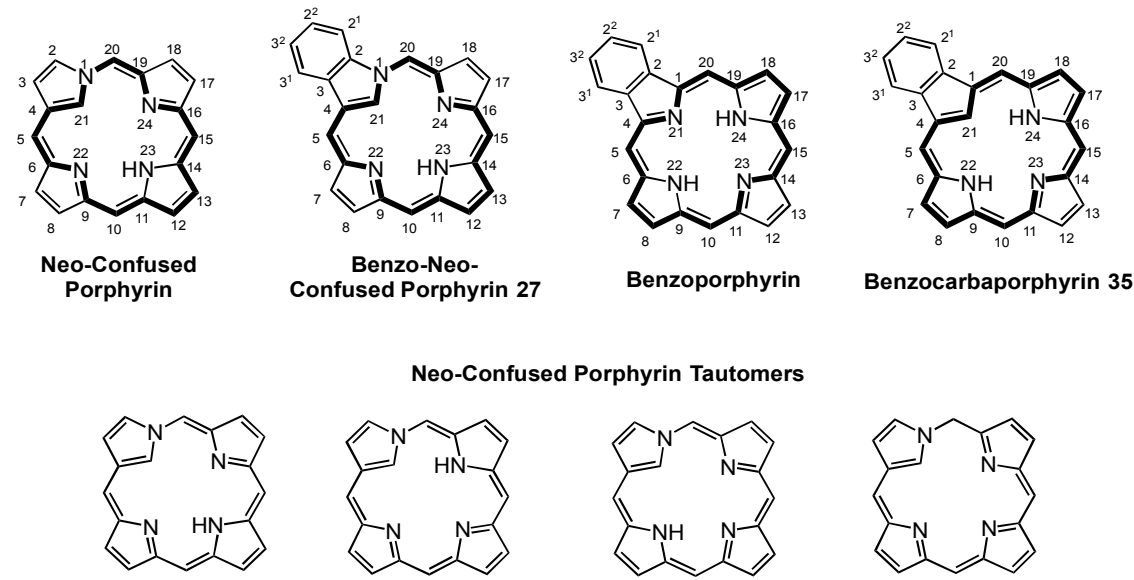

18

27.039
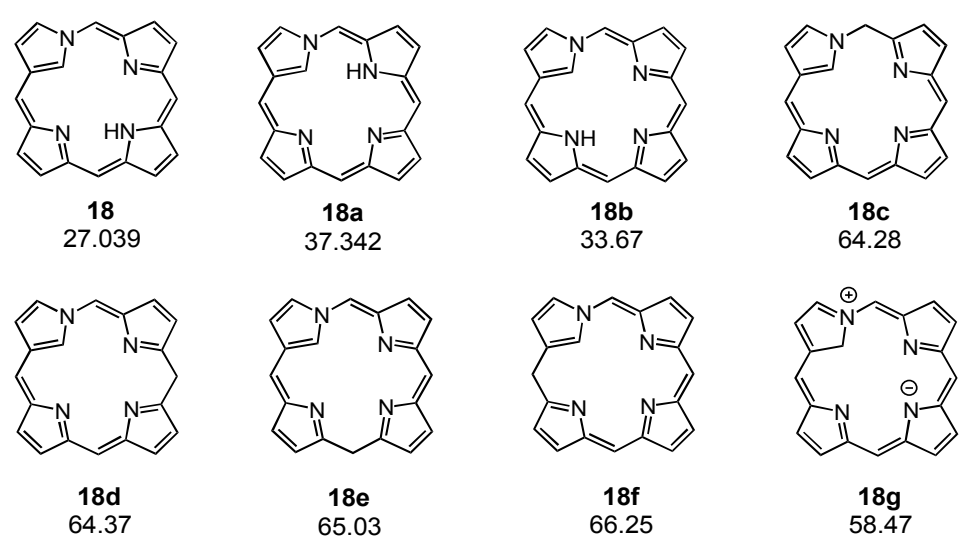

Benzo-Neo-Confused Porphyrin Tautomers
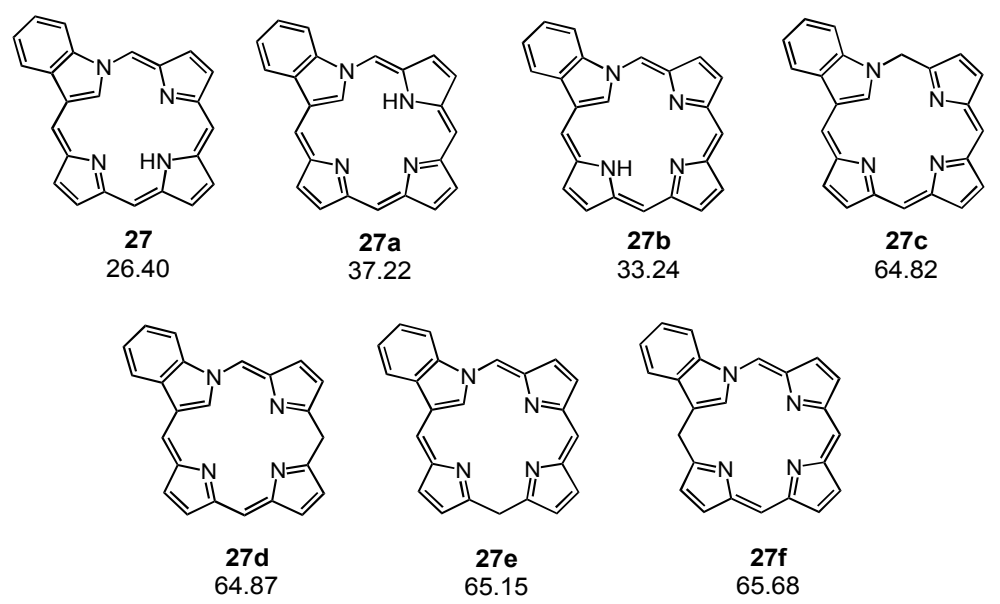

Figure 10: Structures of neo-confused porphyrin and benzo-neo-confused porphyrin tautomers and their relative energies $(\mathrm{kcal} / \mathrm{mol})$ compared to porphyrin and benzoporphyrin, respectively 
Eight neo-confused porphyrin (neo-CP) and seven benzo-neo-confused porphyrin (B-neo-CP) tautomers were studied. In addition, twelve benzoporphyrintautomers and twelve benzocarbaporphyrintautomers, were used for comparison (Figure 10). It was found that the most stable tautomer of neo-CP was $27.04 \mathrm{kcal} \mathrm{mol}^{-1}$ higher in energy than porphyrin, and the most stable B-neo-CP was $26.40 \mathrm{kcal} \mathrm{mol}^{-1}$ higher than benzoporphyrin. Nucleus independent chemical shifts showed that the fully conjugated neo-CP and B-neo-CP tautomers had a significant amount of diatropic character, but this value is lower than for porphyrins. ${ }^{20}$ It should also be noted that $18 \pi$ electron delocalization pathways that pass through a fused benzene ring are less favorable than alternative delocalization pathways that bypass this unit. ${ }^{20}$

\section{$\underline{\text { Conclusion }}$}

In this thesis, the synthesis of neo-confused porphyrins with bromo- or phenylsubstituents is presented. These new porphyrinoids are the first neo-confused porphyrins to be prepared that lack an ester substituent or a fused benzo- unit. The aromatic properties of these macrocycles have been assessed by proton NMR spectroscopy and organometallic derivatives have been prepared. 


\section{CHAPTER II}

\section{RESULTS AND DISCUSSION}

A great deal of interest has been directed towards N-confused porphyrins 17 since they were first discovered in $1994 .{ }^{14}$ This type of porphyrin analogue is different from true porphyrins 1 because one of the pyrrole subunits is connected via $\alpha$ and $\beta$ positions, which results in the nitrogen being relocated to the outside of the macrocycle. NCPs are true porphyrin isomers as the only difference is the arrangement of one pyrrole unit. Another type of porphyrin isomer $\mathbf{1 8}$ has been proposed where the nitrogen atom of the

pyrrole ring is connected to the adjacent meso-carbon. ${ }^{18}$ However, until recently there had been no literature reports on the system, and it was unclear whether structures of this type would retain overall aromatic character. This type of porphyrin isomer, like N-confused porphyrins, can be considered to be a carbaporphyrinoid system as an internal methine unit has replaced by core nitrogen atom. Lash and coworkers successfully generated a benzo-fused version of this type of porphyrin isomer and named it neo-confused porphyrin. ${ }^{18}$ The proton NMR spectra for benzo-fused neo-confused porphyrins showed that they retained diatropic character, although this was somewhat reduced compared to true porphyrins or carbaporphyrins. In this work, bromo and phenyl neo-confused porphyrins have been successfully synthesized. The proton NMR spectra for this type of porphyrin analogue showed that bromo and phenyl neo-confused porphyrins retained diatropic character, although this was significantly reduced compared to true porphyrins. 

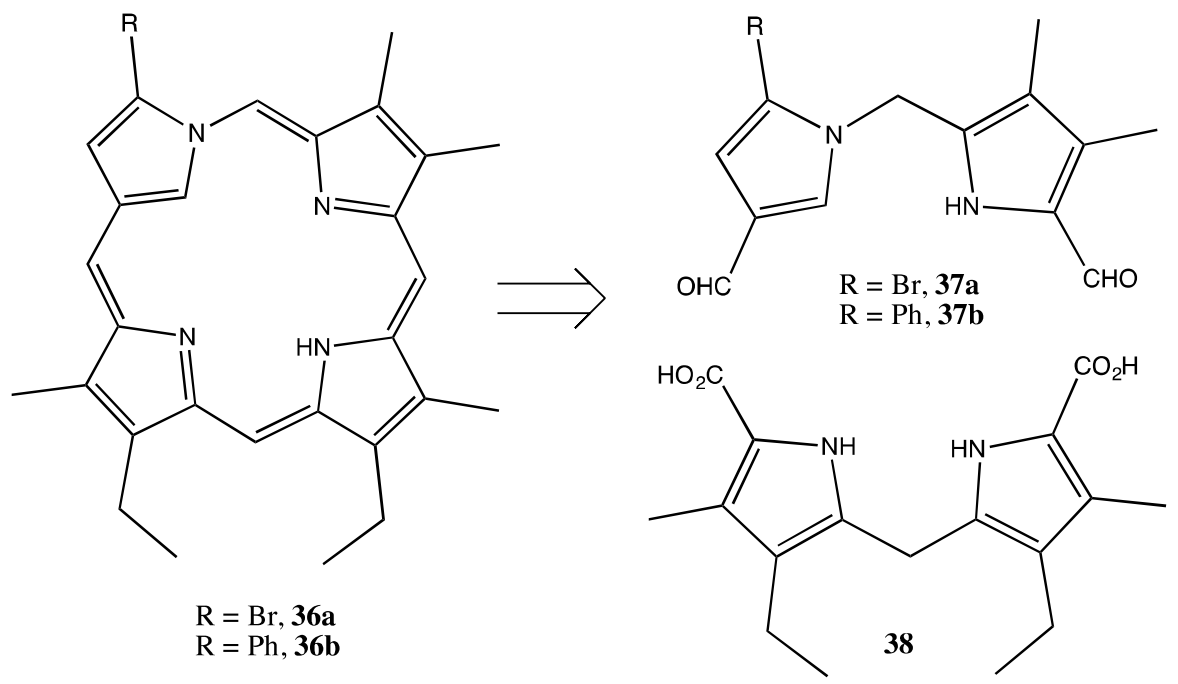

Scheme 11: Retrosynthetic analysis of neo-confused porphyrins using MacDonald's " $2+2$ " condensation approach
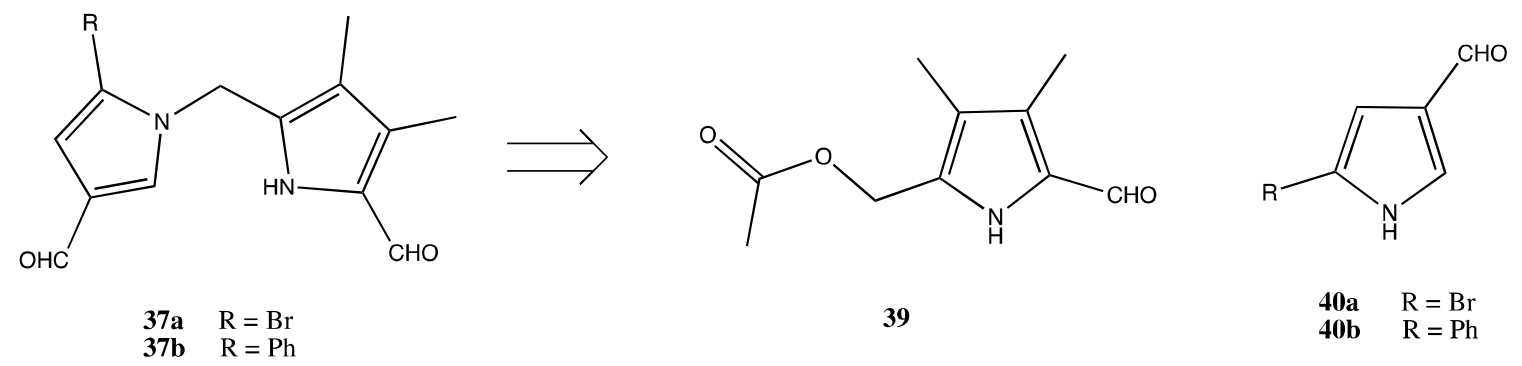

Scheme 12: Retrosynthetic analysis of the key intermediary dipyrroledialdehydes 
MacDonald's “2+2” approach was selected to prepare this system (Scheme 11). This required three dipyrrolic intermediates, the known dipyrrylmethanedicarboxylic acid 38 and 1,2'-dipyrrylmethane dialdehydes $37 \mathbf{a}$ and $\mathbf{3 7} \mathbf{b}$. The synthesis of the key intermediates 37a and $\mathbf{3 7 b}$ was crucial for these investigations. It was anticipated that these dialdehydes could be constructed from acetoxymethylpyrrolecarbaldehyde39 and 3pyrrole carbaldehydes40a and 40b (Scheme 12).

The synthesis first targeted acetoxymethylpyrrole aldehyde 39, which was prepared by adapting literature procedures. ${ }^{21} N$-Formylglycine ethyl ester $\mathbf{4 1}$ was reacted with freshly distilled phosphorus oxychloride in the presence of triethylamine to afford ethyl isocyanoacetate42. Using the Barton- Zard method, ethyl isocyanoacetate42 was reacted with 3-acetoxy-2-nitro-butane $\mathbf{4 3}$ in the presence of tetramethylguanidine to give ethyl 3,4-dimethylpyrrole-2-carboxylate 44 (Scheme 13). Following hydrolysis with sodium hydroxide, 3,4-dimethylpyrrole-2-carboxylic acid $\mathbf{4 5}$ was isolated. In order to form dimethylpyrroledicarbaldehyde $\mathbf{4 6}$, carboxylic acid $\mathbf{4 5}$ was dissolved in TFA and triethylorthoformate was added slowly to the solution. The reaction appeared to be temperature sensitive, and was controlled using a salt-ice bath. The dialdehyde 46 was isolated as brown solid in $97 \%$ yield, which was a significant improvement over the $49 \%$ reported in the earlier literature ${ }^{21}$ and the $71 \%$ yield reported by $\mathrm{Li}^{21,22}$ Conversion of the dialdehyde to mono-alcohol $\mathbf{4 7}$ required the selective reduction of one aldehyde unit. The mono-alcohol 47 was generated by reducing the dialdehyde 46 with 0.25 equivalents of the mild reducing agent $\mathrm{NaBH}_{4}$ and afforded 3,4-dimethyl pyrrole-2-carbaldehyde-5carbinol 47 in $98 \%$ yield as a brown solid. The acetylation of mono-alcohol 47 was temperature and time dependent. Pyrrole carbinol47 was reacted with acetic anhydride 
and pyridine at $\quad-3^{\circ} \mathrm{C}$ for $1 \mathrm{~h}$, and this gave the desired acetoxymethylpyrrolecarbaldehyde39 in $85 \%$ yield (Scheme 13 ).<smiles>CCOC(=O)CN(CC)CC</smiles>

41<smiles>Cc1c[nH]c(C(=O)O)c1C(=O)OC(C(C)C)C(C)C(C)C</smiles><smiles>Cc1c(C=O)[nH]c(CO)c1C</smiles>

47<smiles></smiles>

42

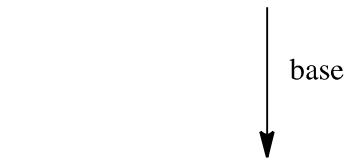

$\underset{\text { Pyridine }}{\stackrel{\text { Acetic anhydride }}{\longrightarrow}}$

(1)

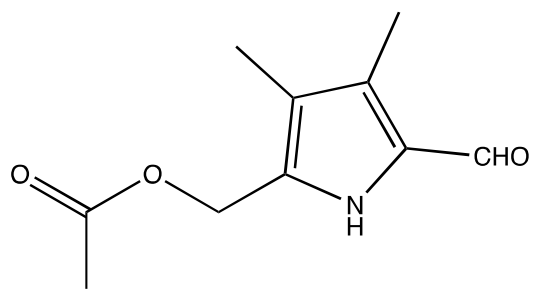

39

Scheme 13: Synthesis of 5-acetoxymethyl-3,4-dimethylpyrrole-2-carbaldehyde 39 

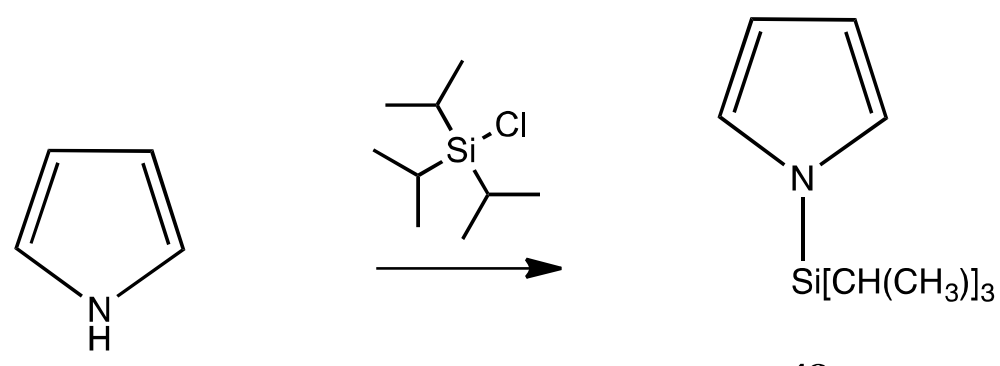

48

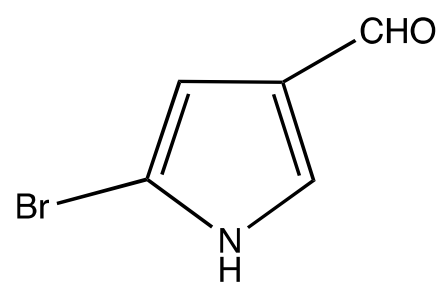

40a

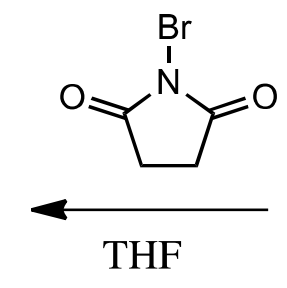

THF
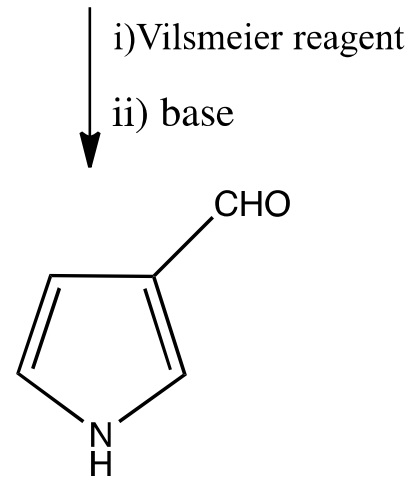

49

Scheme 14: Synthesis of 5-bromopyrrole-3-carbaldehyde40a

In order to synthesize 5-bromo-3-pyrrolecarbaldehyde 40a, a bulky triisopropylsilyl group was introduced at the 1-position of pyrrole to give 48. This allowed Vilsmeierformylation to occur virtually exclusively at the 3-position, and subsequent deprotection gave pyrrole-3-carbaldehyde 49. ${ }^{24}$ Bromination of pyrrole-3-carbaldehyde 49 with N-bromosuccinimide gave 5-bromopyrrole-3-carbaldehyde 40a (Scheme 14). ${ }^{23,24}$ 


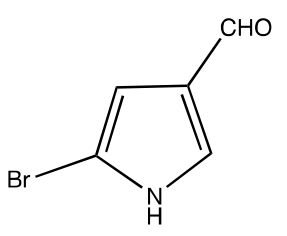

40a

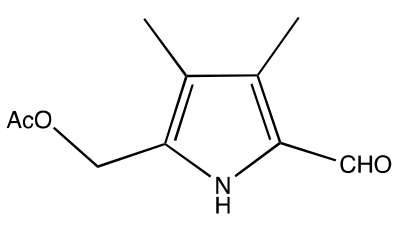

39

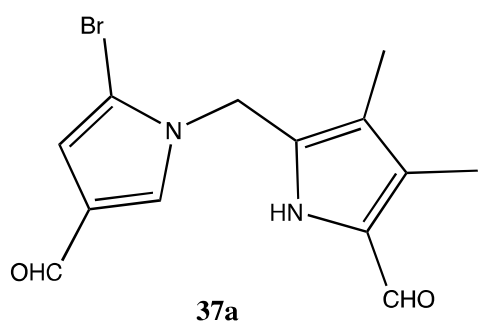

Scheme 15: Synthesis of bromo-neo-confused dipyrrylmethane37a

Reaction of 5-bromopyrrole-3-carbaldehyde 40a with sodium hydride in DMF, followed by addition of acetoxymethylpyrrole39, gave the neo-confused dipyrrylmethane 37a in 65\% yield (Scheme 15). Initially, THF was used as a solvent, but gave very low yields. After numerous trials, the best results were obtained when the reaction was carried out at $30^{\circ} \mathrm{C}$. However, greatly improved results were obtained when DMF was used as the solvent (Figure 11). ${ }^{22}$ 


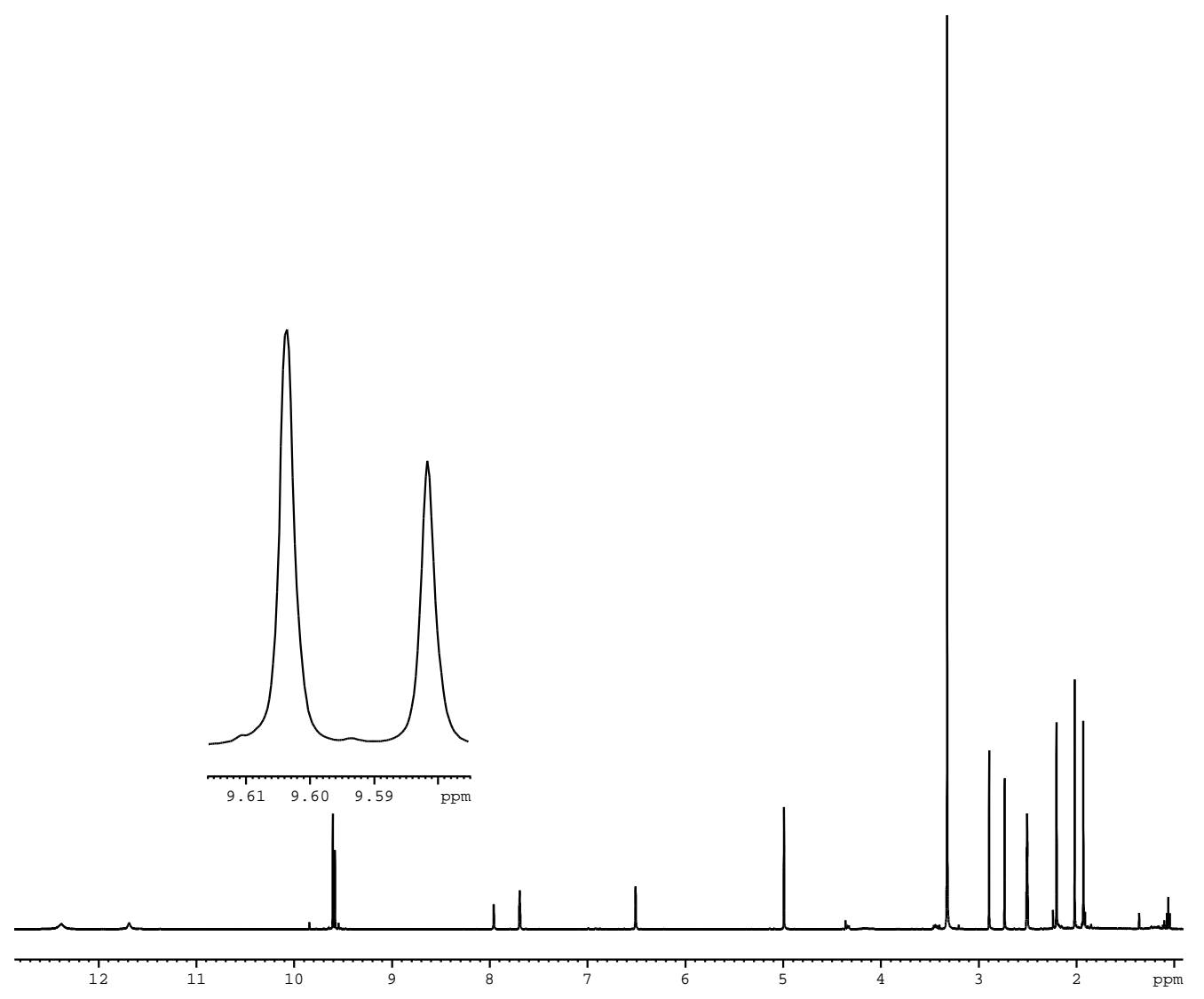

Figure 11: $500 \mathrm{MHz}$ proton NMR spectrum of bromo neo-confused dipyrrylmethane37a

The novel dialdehyde37a was carried on through a MacDonald's " $2+2$ "

condensation with dipyrrylmethane 38 in methanol and dichloromethane in the presence of $p$-toluenesulfonic acid at room temperature for $16 \mathrm{~h}$. Before the oxidation process, a bright blue fraction corresponding to phlorin50 was observed. This phlorin was unstable and exposure to air spontaneously led to the formation of neo-confused porphyrin $36 \mathbf{a}$. When the reaction mixture was stirred with a $0.2 \%$ aqueous ferric chloride solution for 2 hours, neo-confused porphyrin 36a was generated in $45 \%$ yield after purification by 
grade 3 aluminacolumn chromatography. However, the bromoporphyrinoid was somewhat unstable. Attempts to recrystallize bromo neo-confused porphyrin 36a led to decomposition. To further purify bromo neo-confused porphyrin 33a, a second column was performed (Scheme 16).

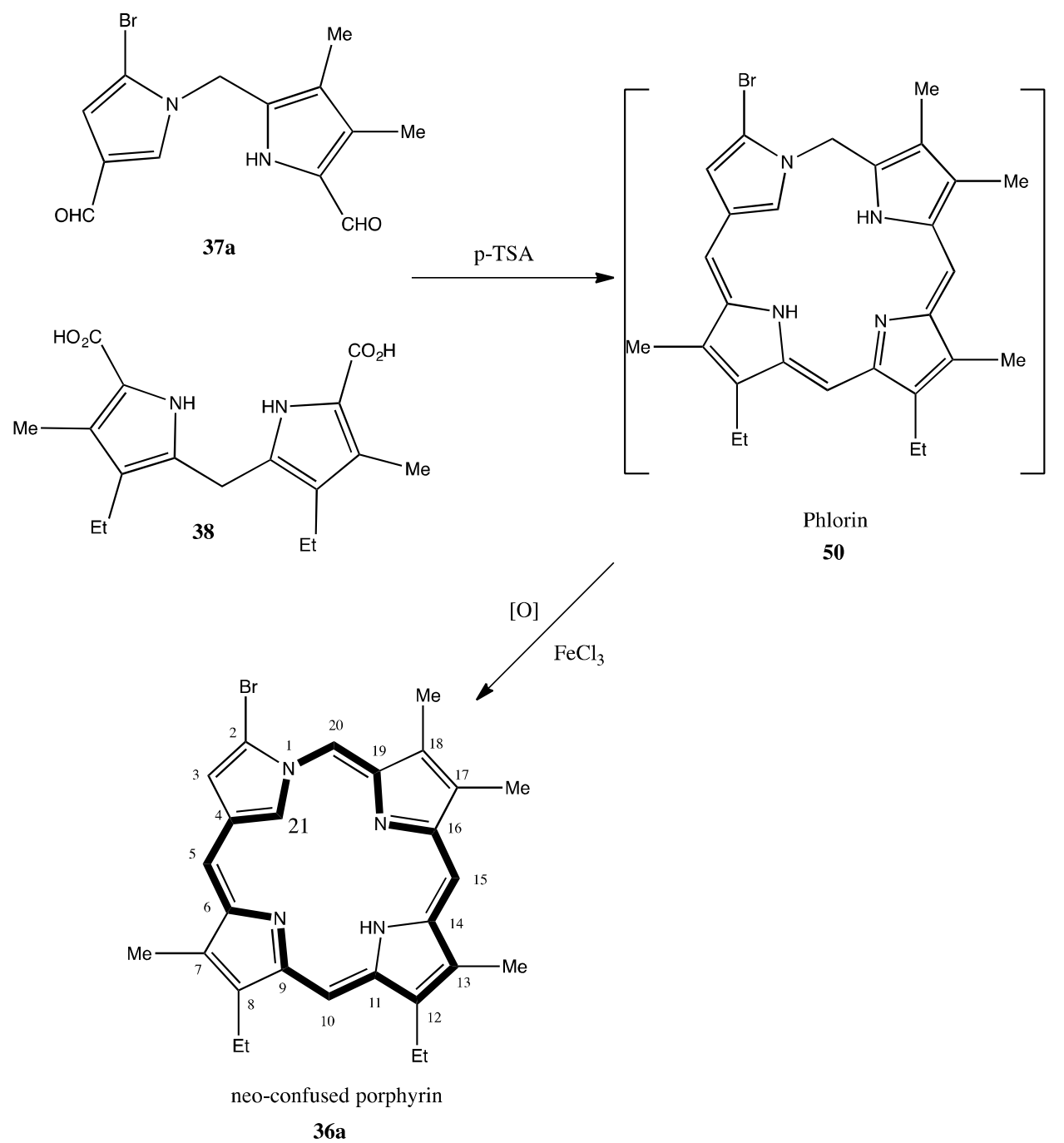

Scheme 16: Synthesis of bromo neo-confused porphyrin using a "2+2" condensation

The spectroscopic data for the fully conjugated neo-confused porphyrin $\mathbf{3 6 a}$ was consistent with an aromatic system. The proton NMR spectrum for 33a shows a moderate 
diatropic ring current, with the meso protons being observed as four singlets at 8.20, 8.35, 8.70 and $9.09 \mathrm{ppm}$ (Figure 12). One of the meso protons showed a substantial downfield shift compared to the other three protons because the $\mathrm{CH}$ is connected to the neoconfused nitrogen. In addition, the external pyrrolic $\mathrm{CH}$ gave rise to a doublet at 8.10 ppm due to coupling to the 21-CH. However, the peak for $\mathrm{CH}-21$, which appeared upfield at $-1.3 \mathrm{ppm}$, only showed this interaction as a slight broadening of the resonance. The internal NH was also shifted upfieldto $-0.02 \mathrm{ppm}$. The diamagnetic ring current in 36a appears to be comparable to the benzo-fused neo-confused porphyrin 27 . In the proton NMR spectrum of 27, the meso-protons appeared at 9.09, 9.33, 9.83 and 9.91 ppm, values that are further downfield compared to the corresponding resonances in 36a with the exception of the $\mathrm{CH}$ that is connected to the nitrogen. However, the internal NH and $\mathrm{CH}$ for 27 were reported to show up at -0.33 and $-0.74 \mathrm{ppm}$, respectively, values that indicate a slightly reduced diatropic ring current compared to 36a.Although neoconfused porphyrins do not possess an [18]annulene $\pi$ delocalization pathway, a 17-atom $18 \pi$ electron delocalization pathway which includes the pair of electrons on the neoconfused nitrogen atom appears to be responsible for the aromatic characteristics of this system. ${ }^{19}$ 


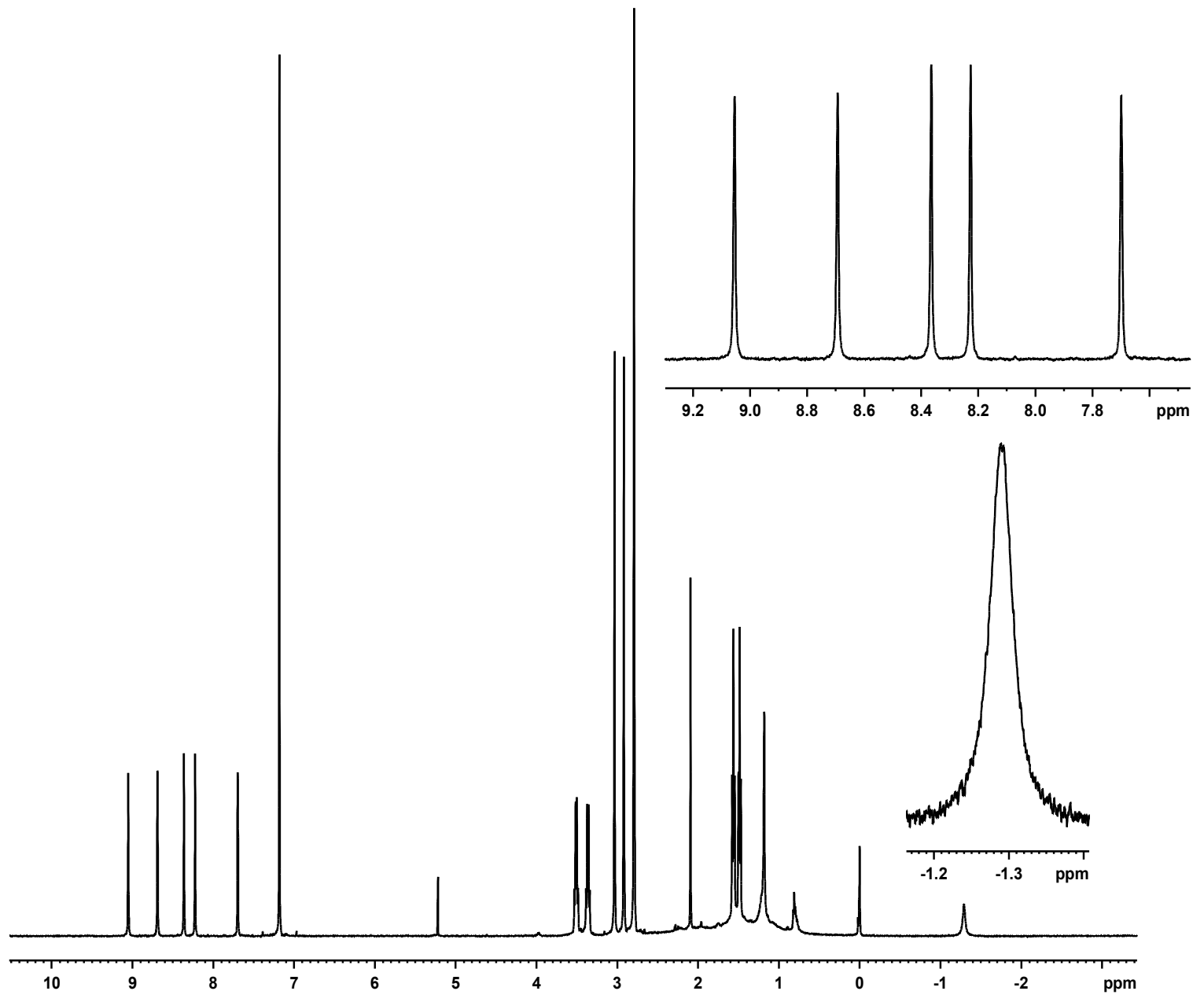

Figure 12: $500 \mathrm{MHz}$ proton NMR spectrum of bromo neo-confused porphyrin 36a 


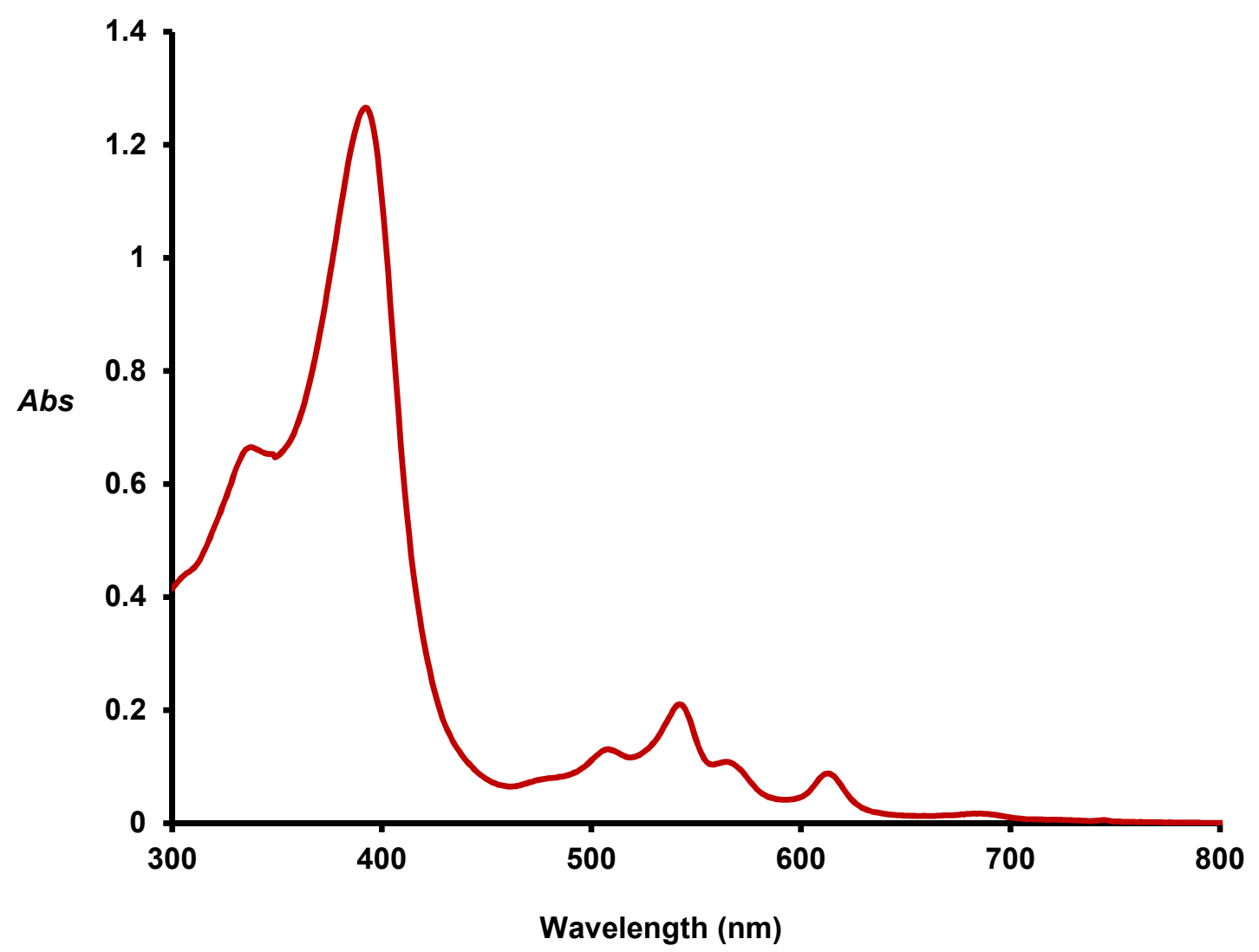

Figure 13: UV-vis spectrum of bromo neo-confused porphyrin 36a in $\mathrm{CH}_{2} \mathrm{Cl}_{2}$

The UV-vis spectrum of bromo neo-confused porphyrin 36a had similar characteristics to true porphyrins. A strong Soret band was present at $392 \mathrm{~nm}$ with several Q bands following at higher wavelengthvaluesof508, 542, 564, 613 and $682 \mathrm{~nm}$ (Figure $13)$.

In TFA-CDCl 3 , the corresponding dication $36 \mathbf{a H}_{2}{ }^{2+}$ (Figure 14) showed a significantly enhanced diatropic ring current and the internal $\mathrm{CH}$ shifted upfield to -1.96 
ppm, while the meso-proton resonances moved downfield to give four $1 \mathrm{H}$ singlets at 8.92, 9.01, 9.58 and $9.95 \mathrm{ppm}$ (Figure 15).
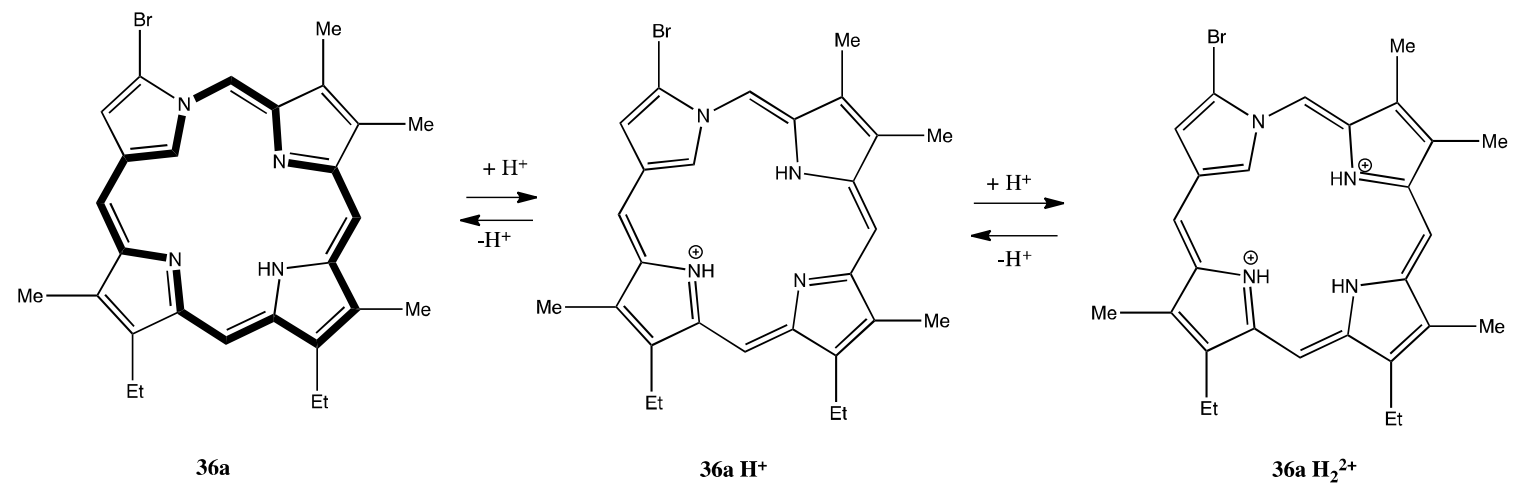

Figure 14: Protonation of bromo neo-confused porphyrin 36a

Addition of TFA also gave rise to changes in the UV-vis spectrum for 36a. At higher concentrations of TFA, a new species was generated with a Soret band at $377 \mathrm{~nm}$ corresponding to the dication $36 \mathbf{a H}_{2}{ }^{2+}$ (Figure 16). 


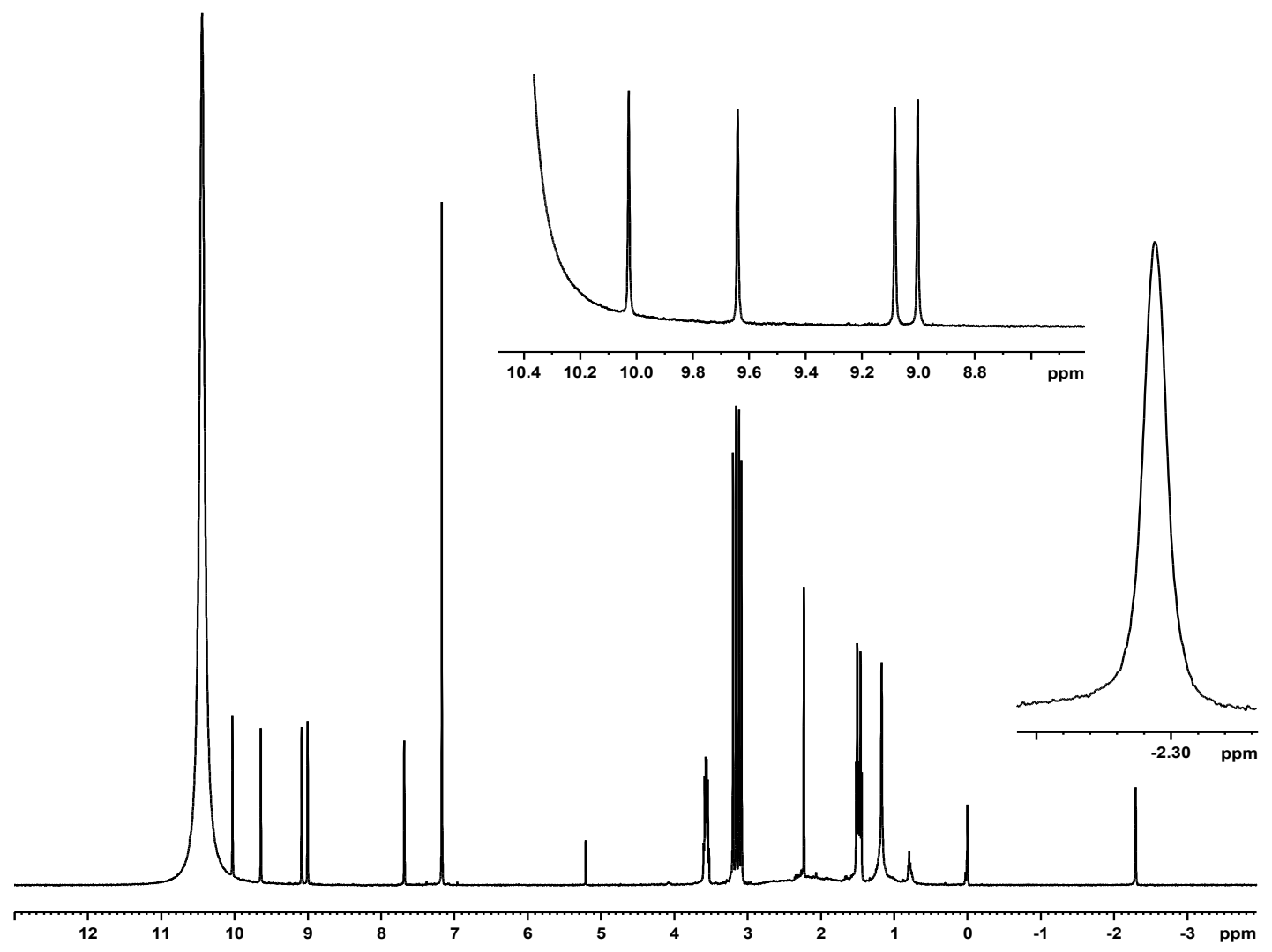

Figure 15: $500 \mathrm{MHz}$ proton NMR spectrum of neo-confused porphyrin dication36a $\mathrm{H}_{2}{ }^{2+}$ in TFA-CDCl 3 


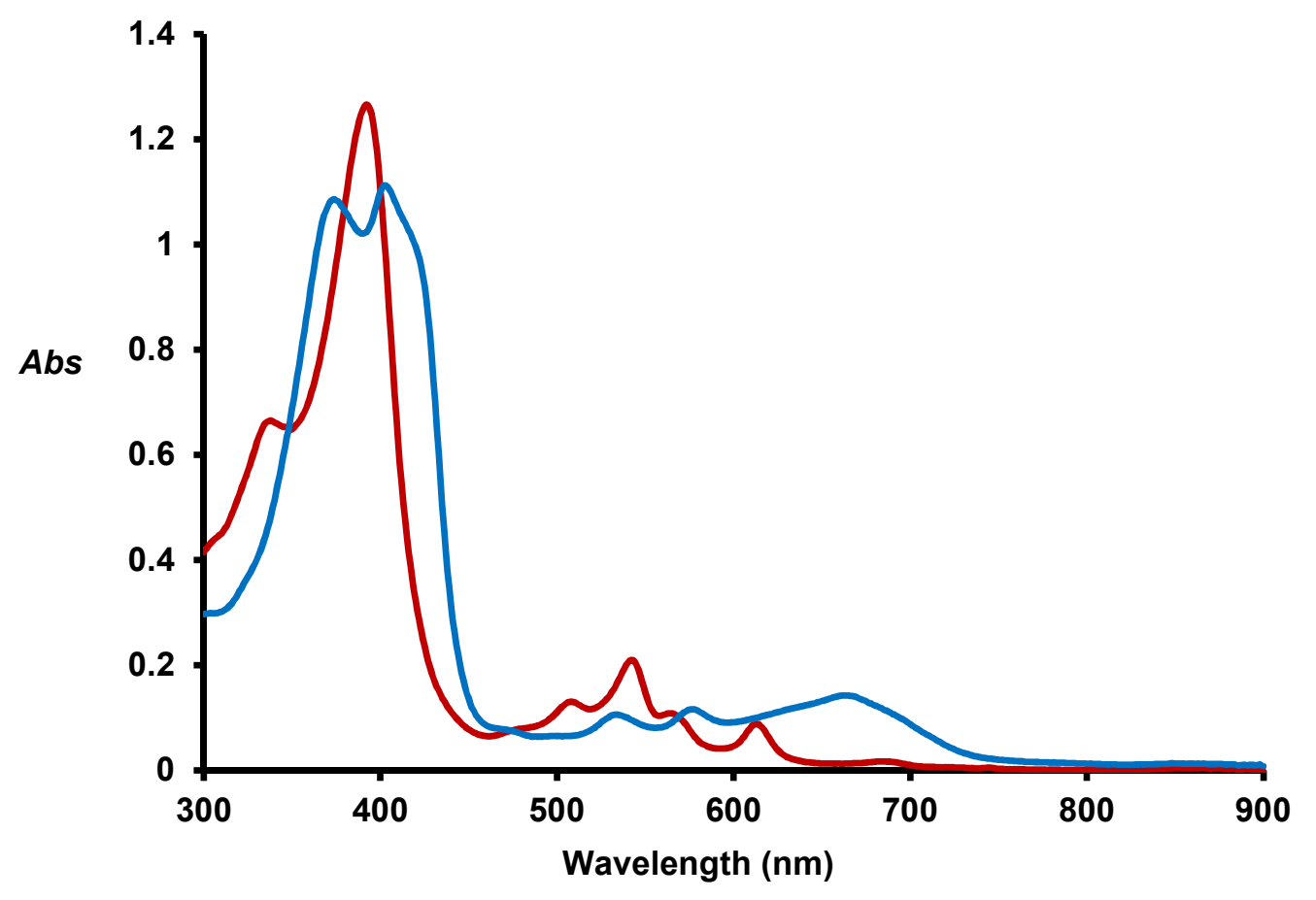

Figure 16: UV-vis spectrum of neo-confused porphyrin 36a in dichloromethane (red line) and $2 \%$ TFA- $\mathrm{CH}_{2} \mathrm{Cl}_{2}$ (blue line)

The possibility of forming a neo-fused porphyrin $\mathbf{5 2}$ from bromo neo-confused porphyrin 36a was investigated (Scheme 17). A second bromination at the inner carbon seemed to be beneficial for the ring fusing process that leads to $\mathrm{N}$-fused porphyrins and the same strategy was attempted for the neo-confused series. Bromo neo-confused porphyrin 36a was treated with 1 equivalent of $N$-bromosuccinimide (NBS)for 5 minutes at room temperature, followed by refluxing in pyridine for $12 \mathrm{hr}$. However, no ring fused products could be identified. Refluxing bromo neo-confused porphyrin 36a in pyridine 
without first treating it with NBS did not lead to decomposition, but gave back the starting material 36a rather than the desired fused system $\mathbf{5 2} .{ }^{16}$ This is surprising as 36a decomposed when recrystallization was attempted and the system appears to be stabilized under these basic conditions. Nevertheless, the formation of neo-fused porphyrin $\mathbf{5 2}$ could not be achieved.

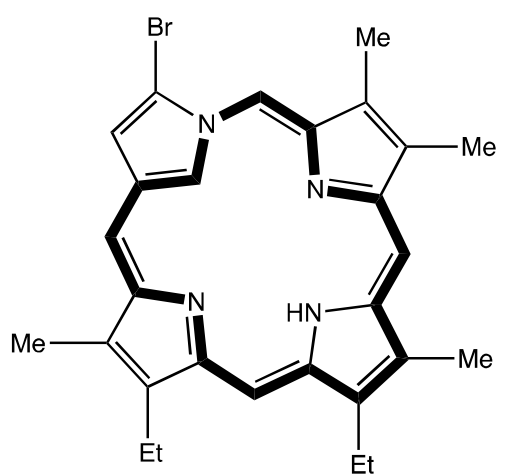

36a

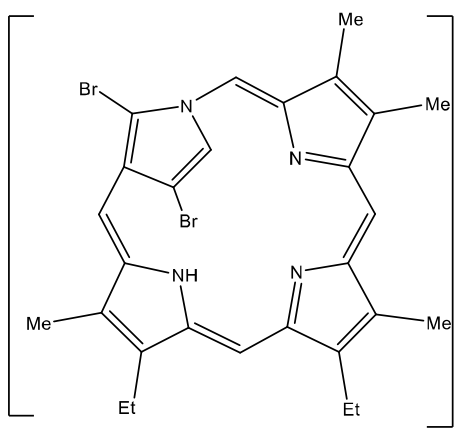

51
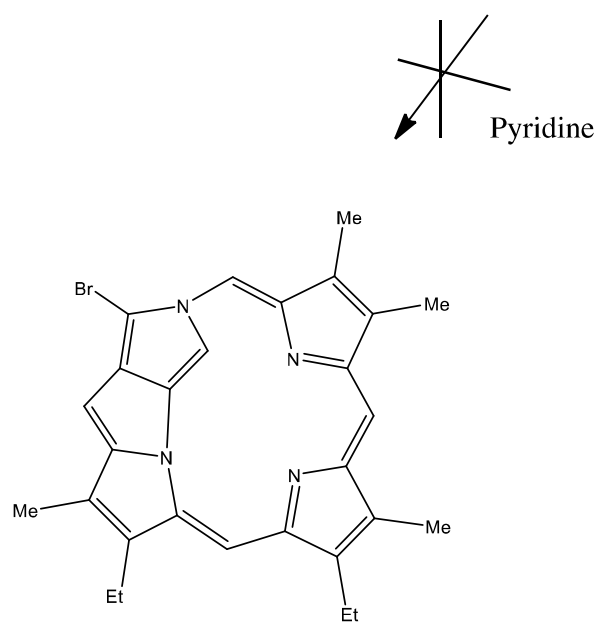

52

Scheme 17: Attempted synthesis of neo-fused porphyrin 52 


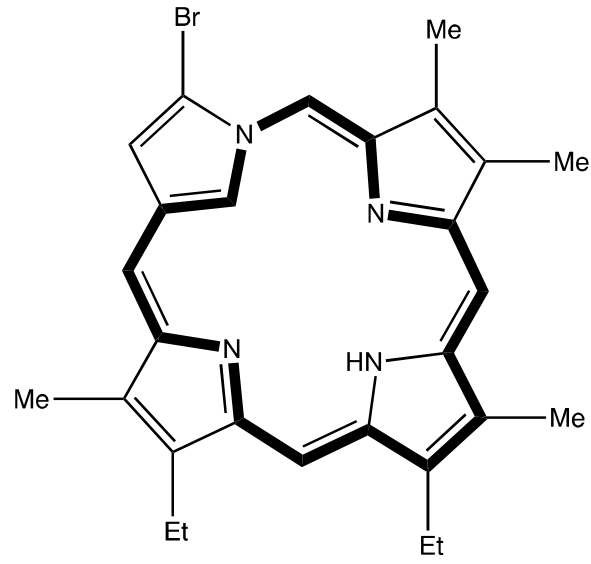

36a

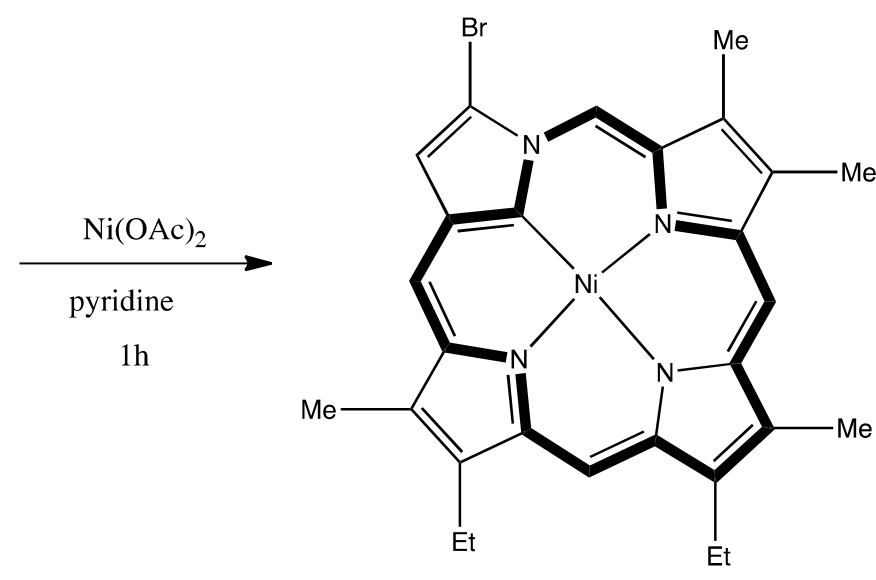

53

Scheme 18: Synthesis of nickel(II) neo-confused porphyrin $\mathbf{5 3}$

Metalation of bromo neo-confused porphyrin 36a was also investigated. Although bromo neo-confused porphyrin 36a appeared to be somewhat unstable and decomposed when heated, when pyridine was used as solvent in an attempt to form neo-fused porphyrin 52, 36a appeared to be far more stable. Hence, pyridine was used as the solvent for metalation reaction. Reaction of $\mathbf{3 6 a}$ with nickel(II) acetate in refluxing pyridine afforded the nickel(II) derivative $\mathbf{5 3}$ in 60\% yield(Scheme 18).

The proton NMR spectrum for $\mathbf{5 3}$ showed that the metal complex had similar diatropic character to the free base form of neo-confused porphyrin $\mathbf{3 6 a}$, although the meso-protons were shifted slightly further downfield. In addition, the external pyrrolic proton showed up as a singlet because there is no longer an internal $\mathrm{CH}$ to couple to this unit. As the internal $\mathrm{NH}$ and $\mathrm{CH}$ units are no longer present, there are no longer any upfield resonances (Figure 17). 


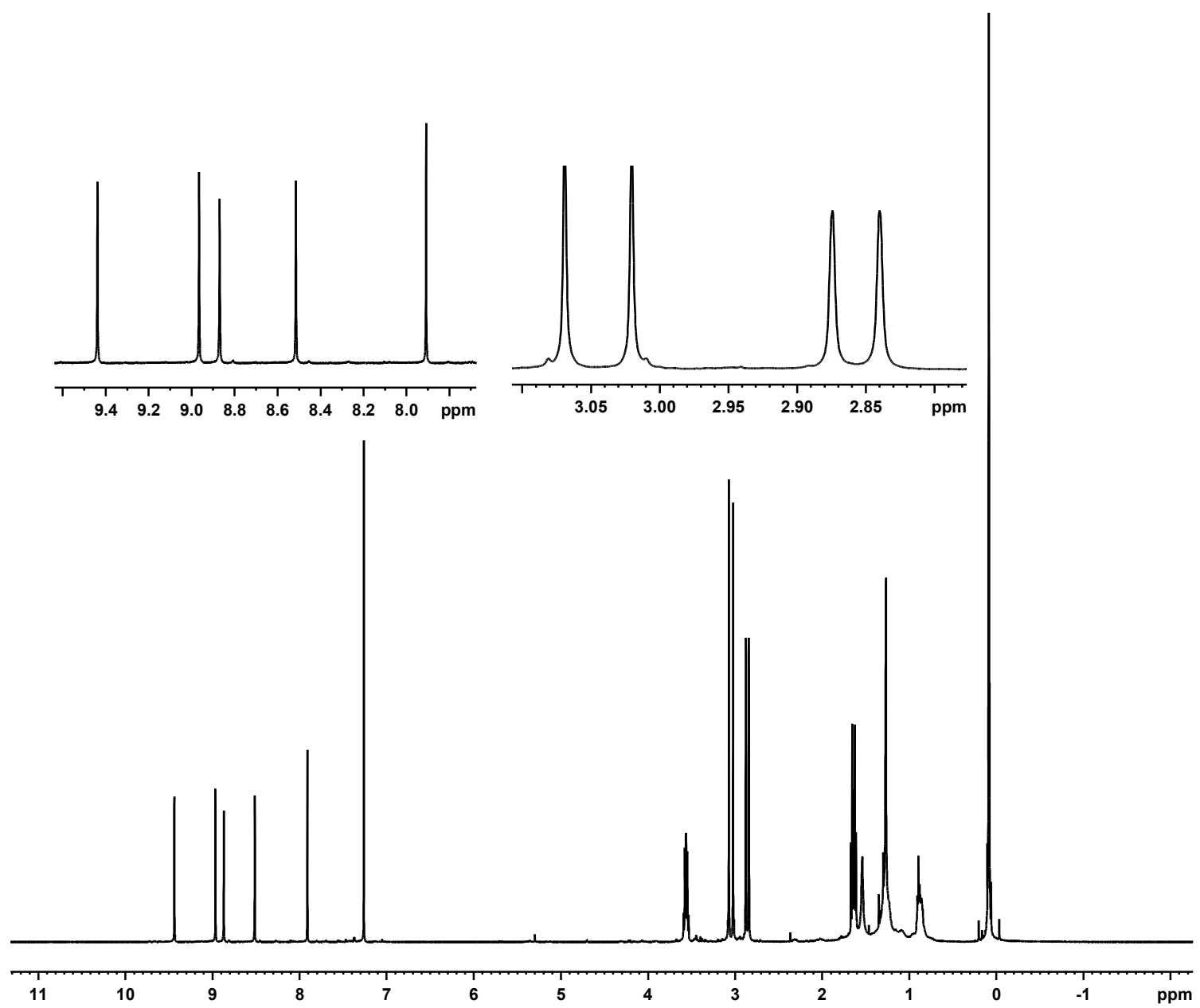

Figure 17: $500 \mathrm{MHz}$ proton NMR spectrum of the nickel(II) complex 53 


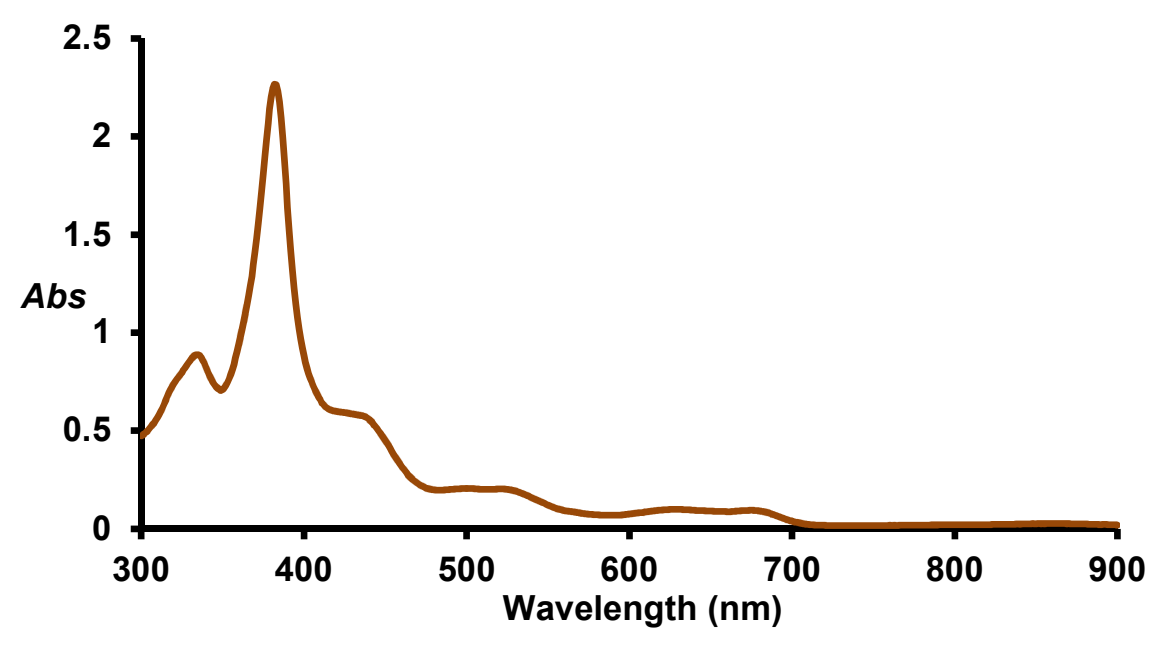

Figure 18: UV-vis spectrumof the nickel(II) complex 53 in $\mathrm{CH}_{2} \mathrm{Cl}_{2}$

The UV-vis spectrum of the nickel(II) complex of bromo neo-confused porphyrin 53 had similar characteristics to true porphyrins. A strong Soret band was present at 382 $\mathrm{nm}$ with several Q bands following at higher wavelengths of 524, 629 and $676 \mathrm{~nm}$ (Figure 18). 


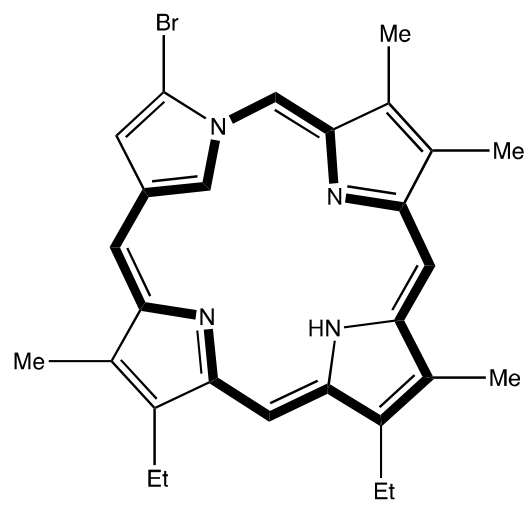

36a

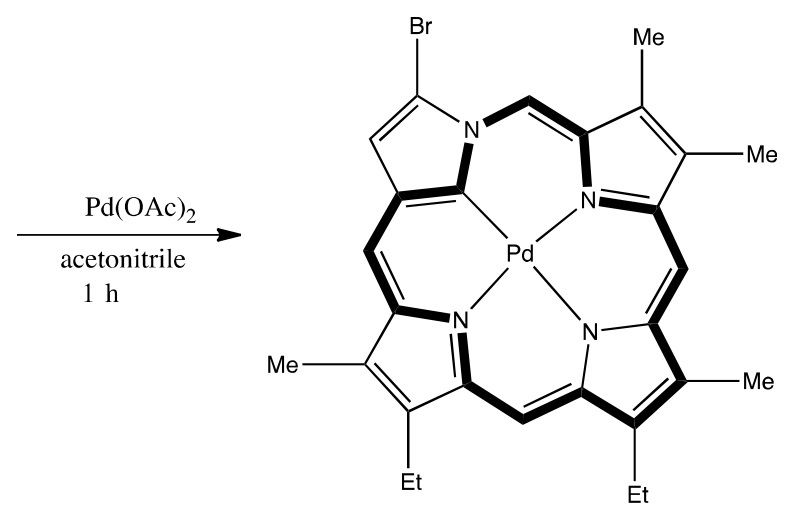

54

Scheme 19: Synthesis of the palladium(II) complex 54

The synthesis of a related palladium(II) complex 54 was also performed. Initial attempts to prepare the palladium complex of bromo neo-confused porphyrin $\mathbf{5 4}$ in acetonitrile for 3 hours were unsuccessful. However, when 36a was reacted with palladium(II) acetate in acetonitrile under reflux for 1 hour, the palladium(II) derivative 54 was isolated as dark green solid in $80 \%$ yield (Scheme 19). 
The proton NMR spectrum for $\mathbf{5 4}$ showed that the palladium complex has slightly increased diamagnetic character compared to bromo neo-confused porphyrin 36a (Figure 19). The meso-protons were observed at $8.63,8.92,9.05$ and $9.50 \mathrm{ppm}$, which is shifted slightly downfield compared to the free base 36a. In addition, the external pyrrolic proton

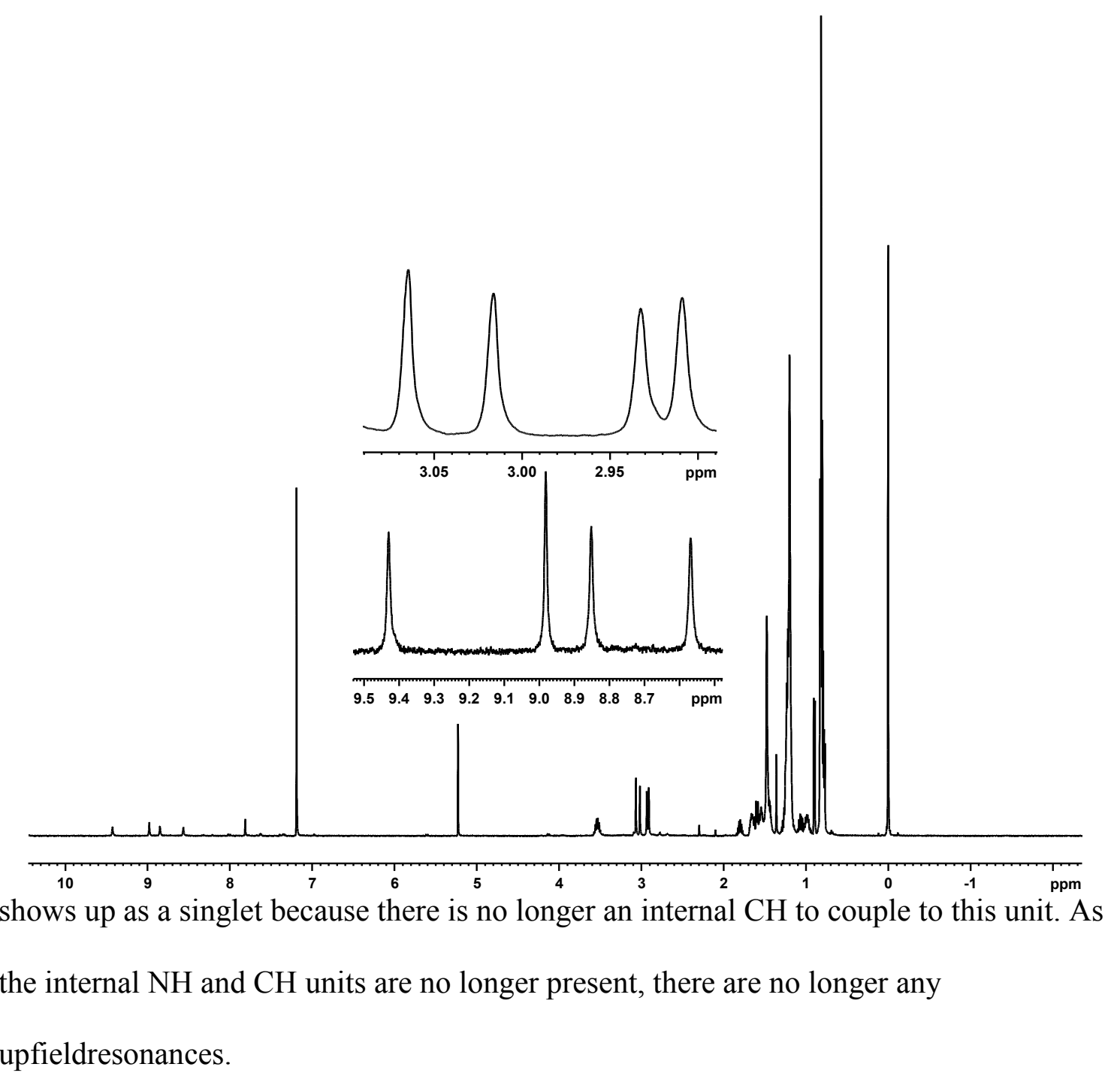

Figure 19: $500 \mathrm{MHz}$ proton NMR spectrum of the palladium(II) complex 54 
The UV-vis spectrum of the palladium(II) complex of bromo neo-confused porphyrin $\mathbf{5 4}$ had similar characteristics to true porphyrins. A strong Soret band was present at $370 \mathrm{~nm}$ with several Q bands following at higher wavelengths of 500, 531, 602, 646 and $856 \mathrm{~nm}$ (Figure 20).

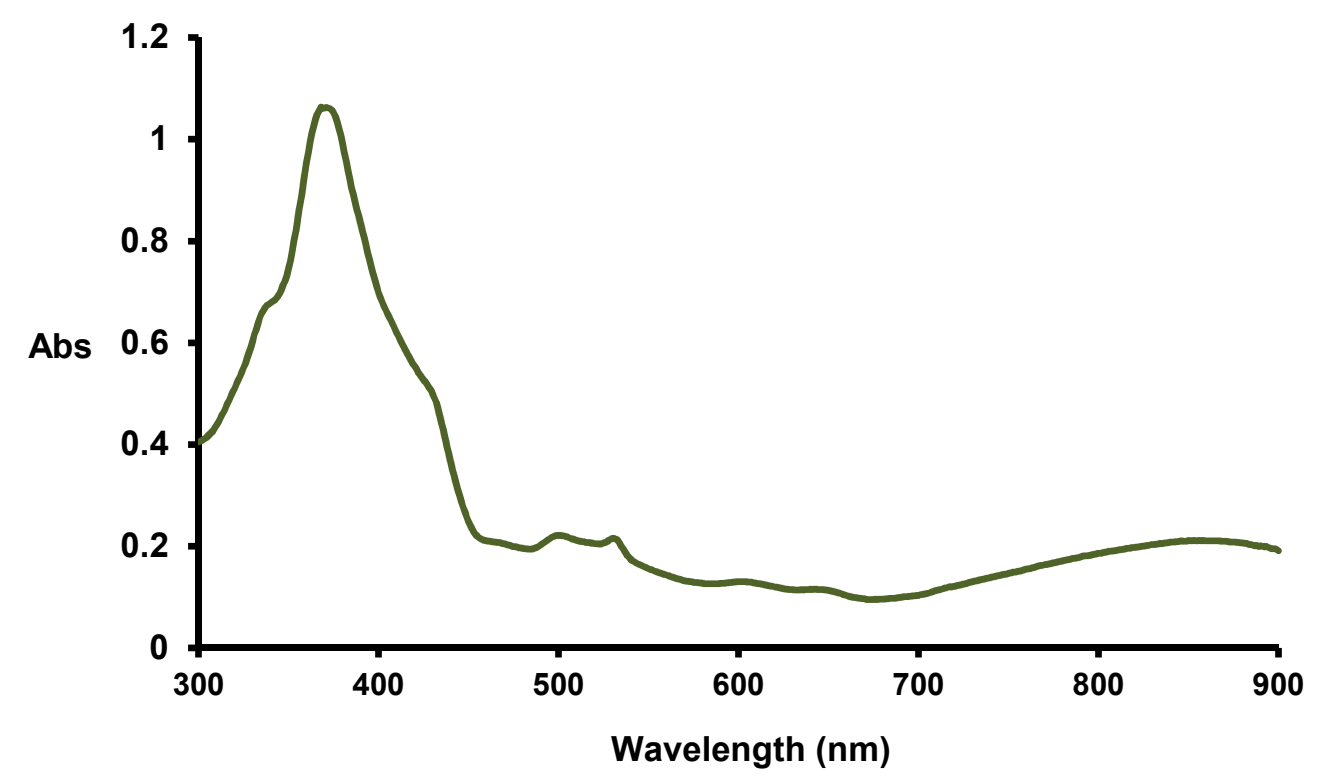

Figure 20: UV-vis spectrum of the palladium(II) complex 54 in $\mathrm{CH}_{2} \mathrm{Cl}_{2}$

Given the success in synthesizing bromo neo-confused porphyrin 36a, the synthesis of related phenyl porphyrinoid36b was also investigated (Scheme 20). 

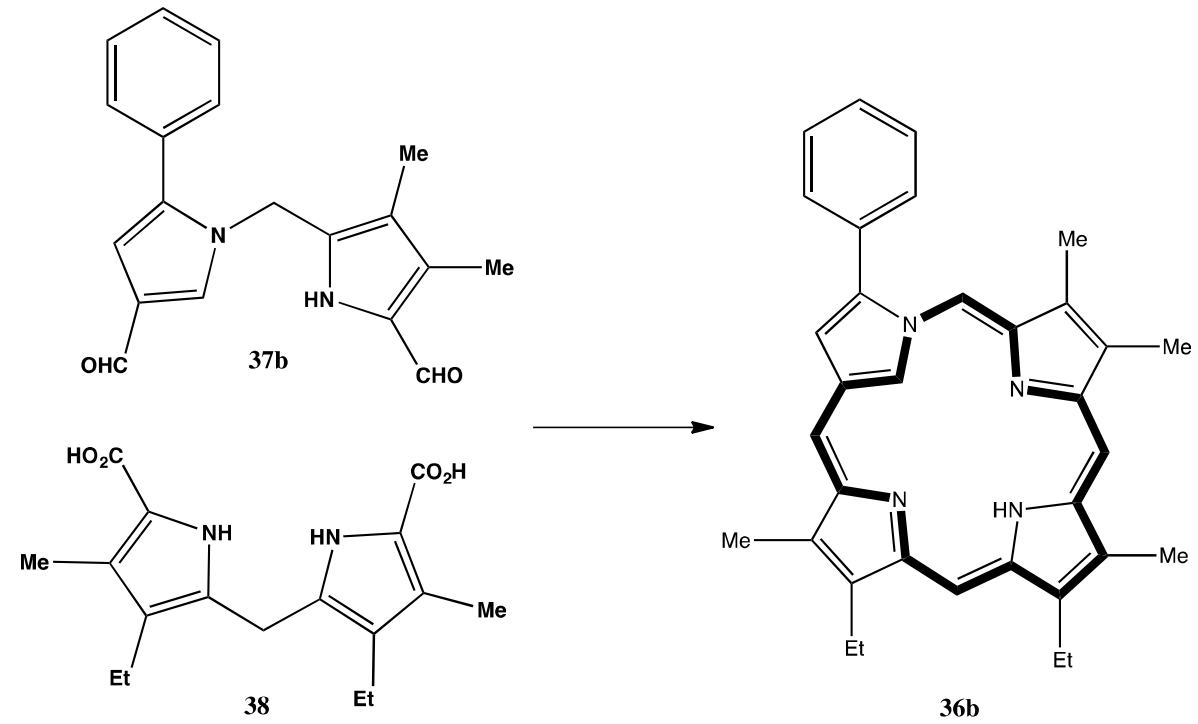

Scheme 20: Proposed synthesis of phenyl neo-confused porphyrin 36b

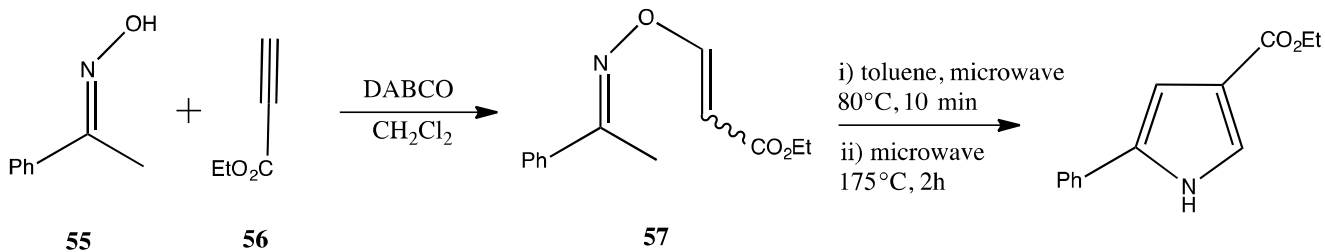
55 56 57

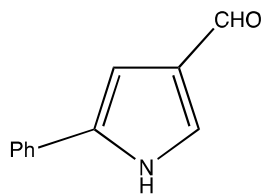

40b

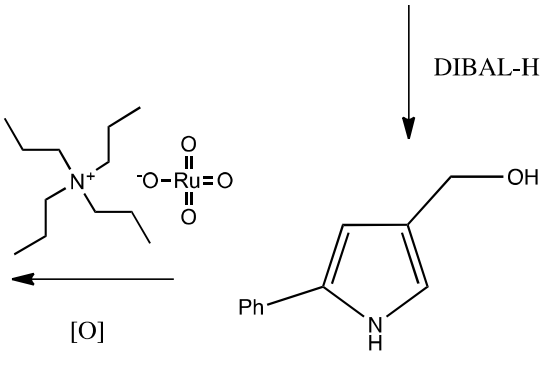

59

Scheme 21: Synthesis of 5-phenylpyrrole-3-carbaldehyde 40b 
In order to synthesize the phenyl neo-confused porphyrin $\mathbf{3 6} \mathbf{b}$, it was first necessary to prepare 5-phenylpyrrole-3-carbaldehyde 40b from acetophenoneoxime55 (Scheme 21). Acetophenoneoxime 55 was prepared using a literature procedure. ${ }^{25}$ Reaction of acetophenoneoxime55 and 1,4-diazabicyclo[2.2.2]octane (DABCO) with ethyl propiolate56 in dichloromethane at room temperature afforded the vinyl oxime57 as a mixture of E:Z-alkene isomers in 85\% yield (Scheme 21). It was found that the optimal temperature for the formation of vinyl oxime 57 was $80^{\circ} \mathrm{C} .{ }^{25}$ The second stage of the synthesis was directed toward the thermal rearrangement of vinyl oxime57 to phenyl pyrrole ester 58. At this stage, higher temperatures were required. In previous research, traditional heating did not afford the desired pyrrole $58 .{ }^{24}$ In order to overcome the activation barrier for the conversion of vinyl oxime 57 to pyrrole $\mathbf{5 8}$, vinyl oxime 57 was heated up in toluene to $170^{\circ} \mathrm{C}$ under microwave irradiation for 45 minutes, which gave the vinyl oxime 57 back. Increasing the temperaure to $180^{\circ} \mathrm{C}$ led to decomposition. However, when the temperature was maintained at $175^{\circ} \mathrm{C}$ and the heating time increased to $2 \mathrm{~h}$, the desired pyrrole $\mathbf{5 8}$ was isolated in $84 \%$ yield. 


\begin{tabular}{|l|l|l|}
\hline Entry & Solvent/Conditions & Results \\
\hline $\mathbf{1}$ & Toluene, microwave, $170^{\circ} \mathrm{C}, 45 \mathrm{~min}$ & $\begin{array}{l}\text { Starting material back } \\
\mathbf{5 7}\end{array}$ \\
\hline $\mathbf{2}$ & Toluene, microwave, $180^{\circ} \mathrm{C}, 45 \mathrm{~min}$ & Decomposition \\
\hline $\mathbf{3}$ & Toluene, microwave, $175^{\circ} \mathrm{C}, 2 \mathrm{~h}$ & Phenyl pyrrole ester $\mathbf{5 8}$ \\
\hline
\end{tabular}

Table 1: Thermal rearrangement of vinyl oxime57 to pyrrole 58.

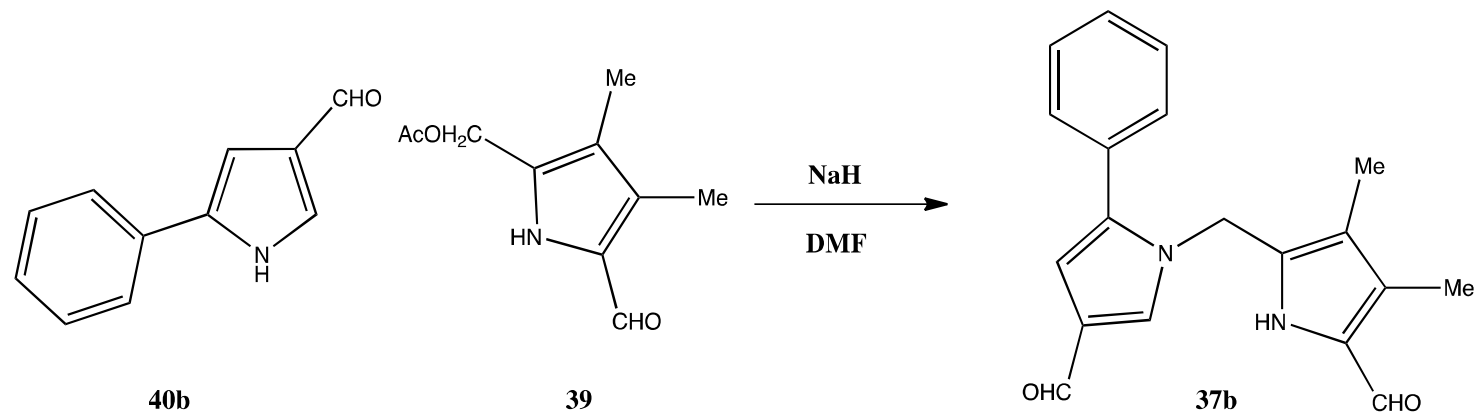

Scheme 22: Synthesis of phenyl neo-confused dipyrrylmethanedialdehyde37b

The next step involved the reduction of the ester group in phenyl pyrrole ester $\mathbf{5 8}$ to an alcohol 59 using DIBAL-H, followed by oxidation using tetra- $n$ propylammoniumperruthenate. This gave the desired phenyl pyrrole aldehyde 40b in $60 \%$ yield. Phenyl pyrrole aldehyde $40 \mathrm{~b}$ was then reacted with acetoxymethylpyrrole aldehyde 39 and sodium hydride in $\mathrm{DMF}$ at $30^{\circ} \mathrm{C}$ to give the dipyrroledialdehyde $37 \mathbf{b}$ in $60 \%$ yield (Scheme 22, Figure 21). 
Phenyl neo-confused porphyrin $\mathbf{3 6} \mathbf{b}$ was prepared from dipyrroledialdehyde37b and dicarboxylic acid $\mathbf{3 8}$ using MacDonald's " $2+2$ " condensation. Following oxidation with $0.2 \%$ aqueous $\mathrm{FeCl}_{3}$ for $1 \mathrm{~h}$, and purification on an alumina column, the neo-confused porphyrin 36b was isolated as a purple powder in $40 \%$ yield (Scheme 23). Attempts to recrystallize 36b were successful, but resulted in substantial losses due to the relatively high solubility of this compound. The phenyl substituent on the neo-confused dipyrrylmethane37b may be responsible of increasing the stability of the system.

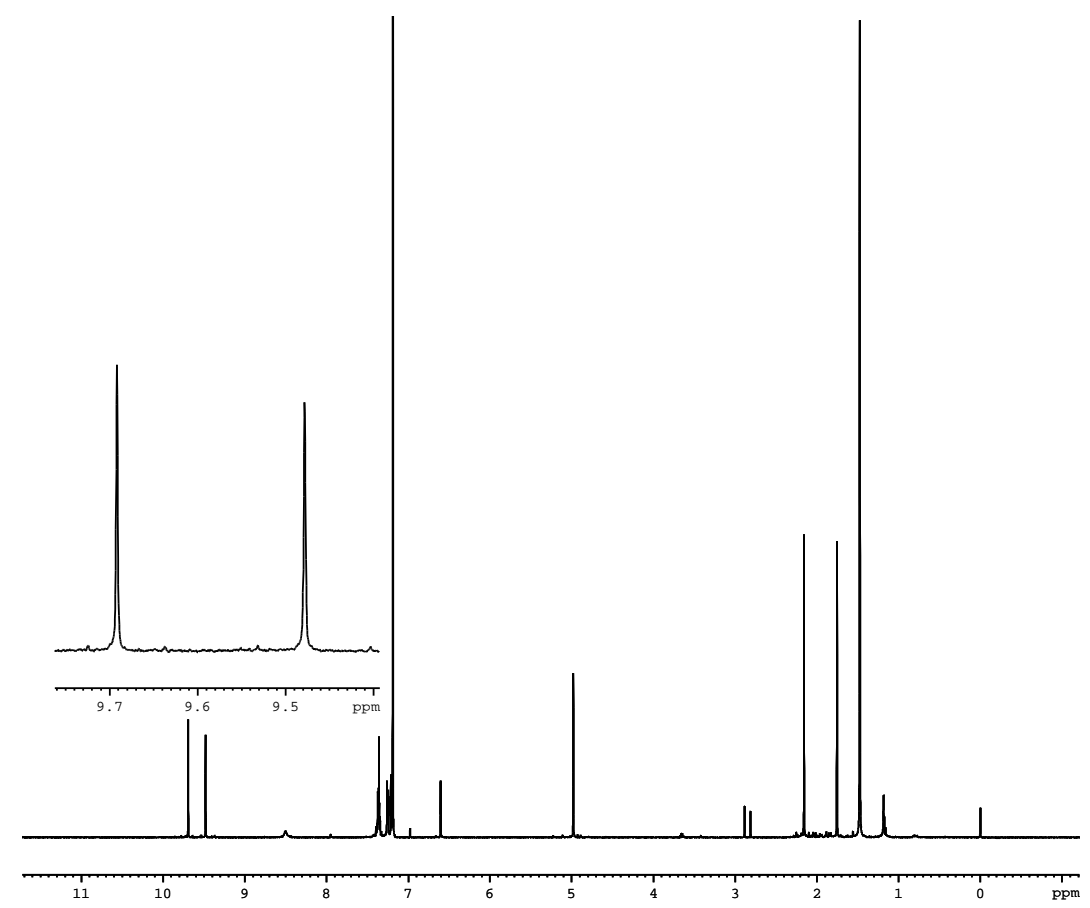

Figure 21: $500 \mathrm{MHz}$ proton NMR spectrum of phenyl neo-confused dipyrrylmethane37b 


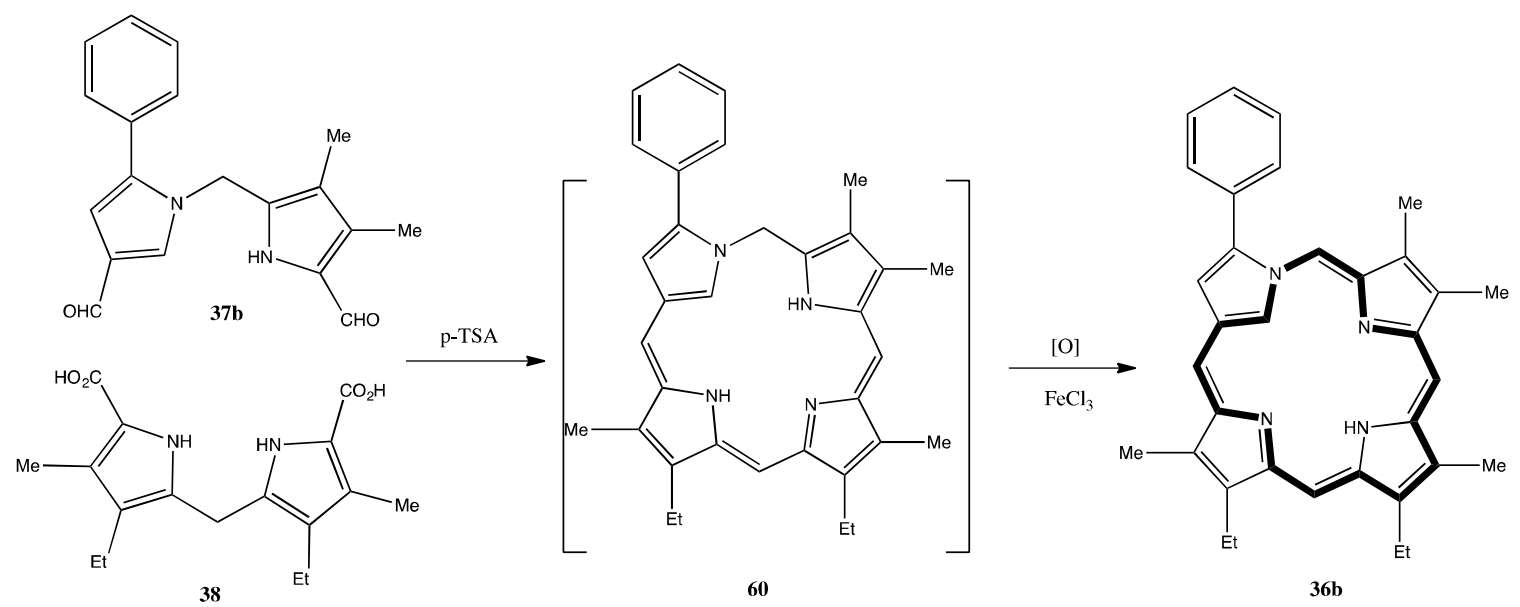

Scheme 23: Synthesis of phenyl neo-confused porphyrin 36b

The meso-protons of 36ashowed up at 8.55, 8.65, 9.12 and $9.41 \mathrm{ppm}$ in the proton NMR spectrum, which was slightly further downfield than had been seen for bromo neo-confused porphyrin 36a. The external pyrrolic hydrogen was observed at 8.67 ppm. Nevertheless, the internal $\mathrm{CH}$ proton gave a peak at $0.057 \mathrm{ppm}$ and the $\mathrm{NH}$ showed up at $-0.036 \mathrm{ppm}$, indicating a reduced upfield shift. (Figure 22). 

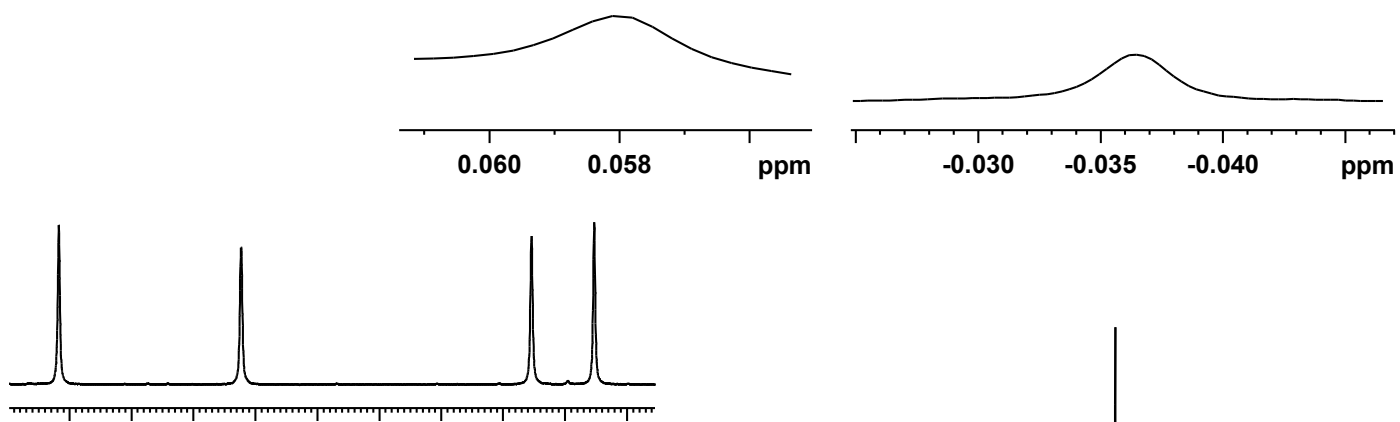

$\begin{array}{llllllllll}9.4 & 9.3 & 9.2 & 9.1 & 9.0 & 8.9 & 8.8 & 8.7 & 8.6 & \text { ppm }\end{array}$

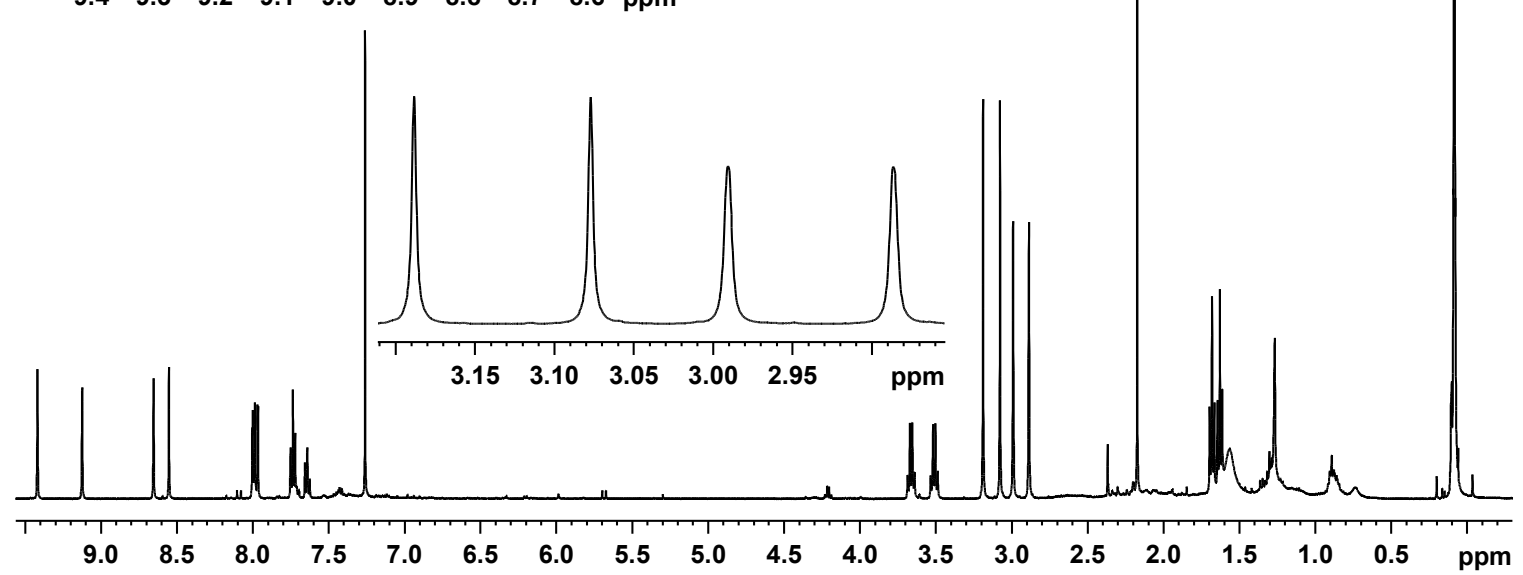

Figure 22: $500 \mathrm{MHz}$ proton NMR spectrum of phenyl neo-confused porphyrin 36b

The UV-vis spectrum of the phenyl neo-confused porphyrin $\mathbf{3 6} \mathbf{b}$ had similar characteristics to true porphyrins. A strong Soret band was present at $392 \mathrm{~nm}$ with several Q bands following at higher wavelengths of 508, 542, 566, 612 and $682 \mathrm{~nm}$ (Figure 23). 


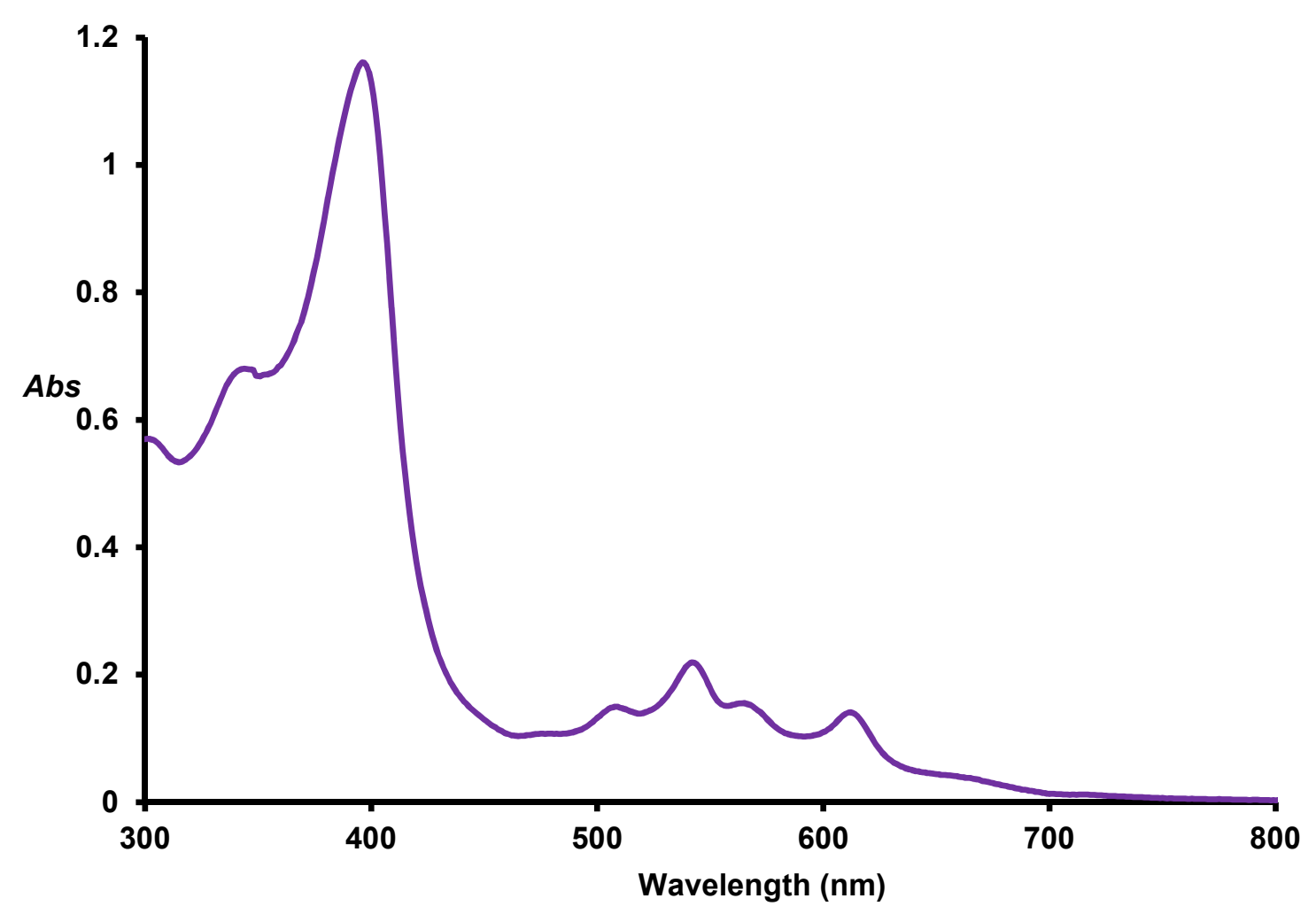

Figure 23: UV-vis spectrum of phenyl neo-confused porphyrin $36 \mathbf{b}$ in $\mathrm{CH}_{2} \mathrm{Cl}_{2}$

In TFA-CDCl 3 , the corresponding dication $36 b_{2}{ }^{2+}$ (Figure 24$)$ showed a substantially enhanced diatropic ring current and the internal $\mathrm{CH}$ shifted upfield to -2.79 ppm, while the meso-proton resonances moved downfield to give four $1 \mathrm{H}$ singlets at 9.14, 9.22, 9.80 and 9.88 ppm (Figure 25). 

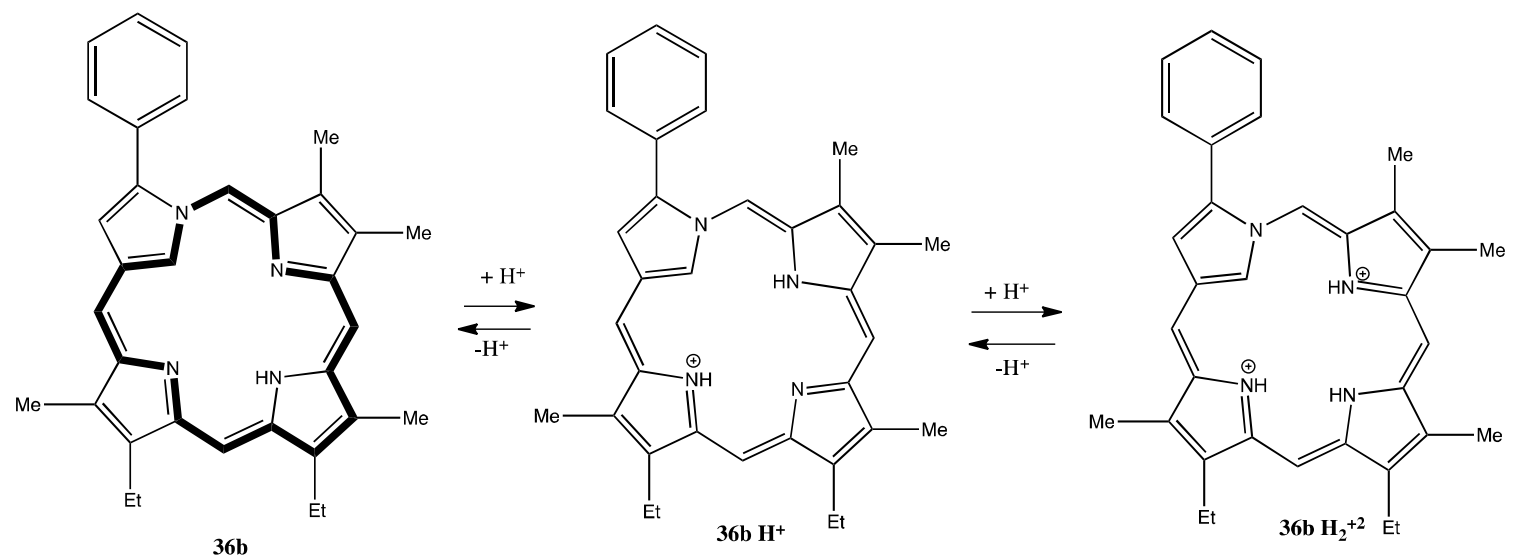

Figure 24: Protonation of phenyl neo-confused porphyrin $36 \mathbf{b H}_{2}{ }^{2+}$

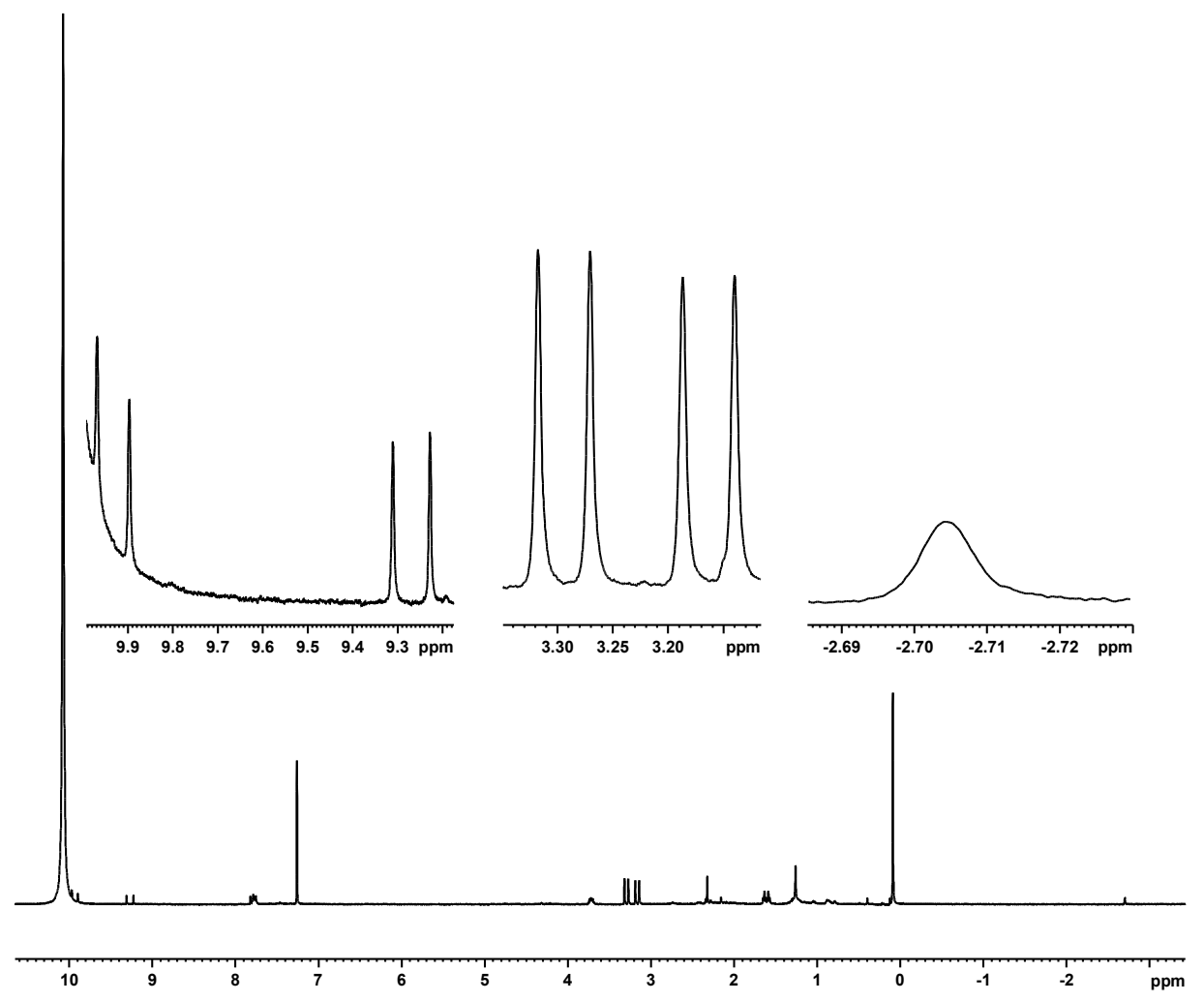

Figure 25: $500 \mathrm{MHz}$ proton NMR spectrum of phenyl neo-confused porphyrin dication $36 \mathbf{b} \mathrm{H}_{2}{ }^{2+}$ in TFA-CDCl 3 


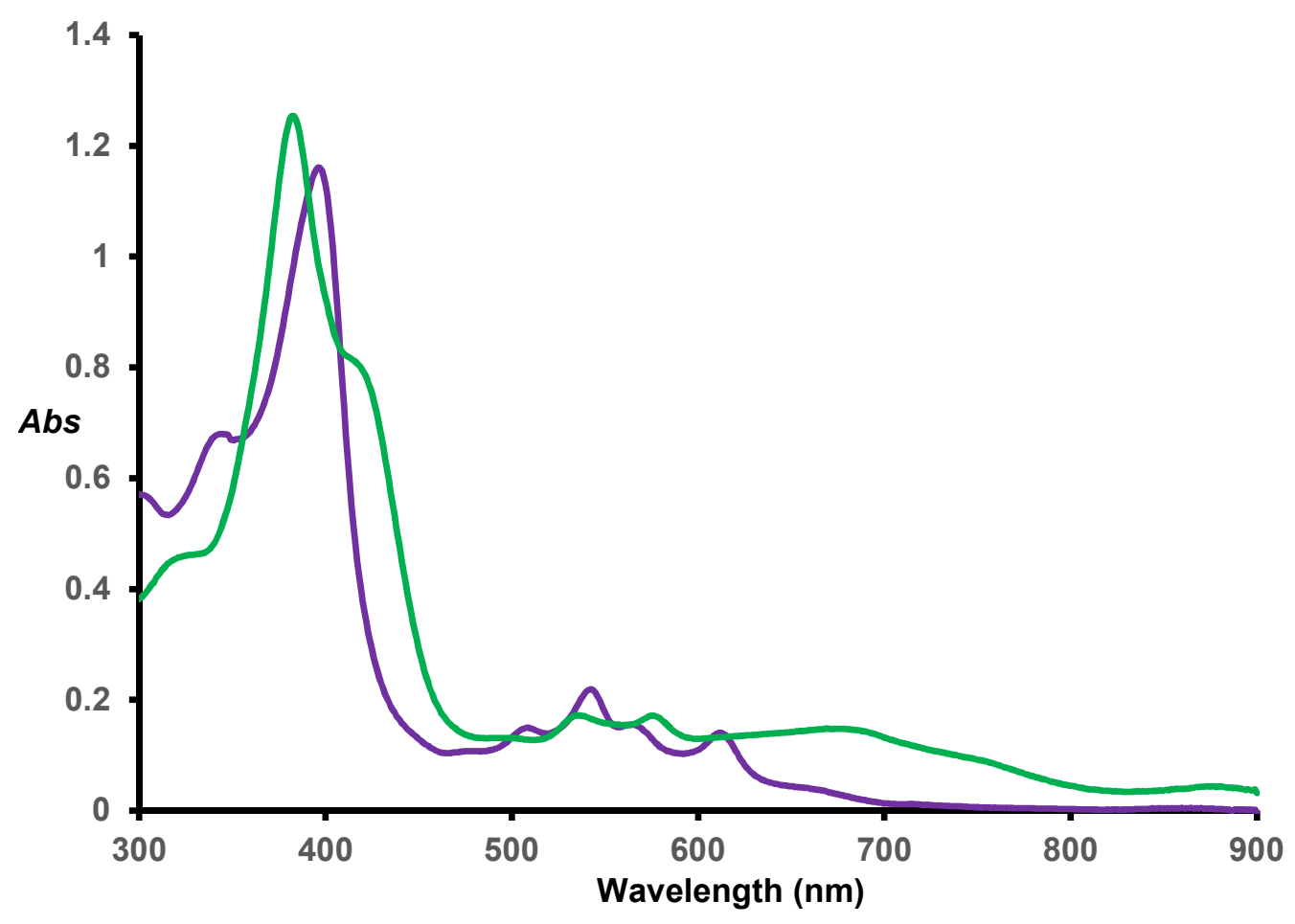

Figure 26: UV-vis spectrum of neo-confused porphyrin $\mathbf{3 6} \mathbf{b}$ in dichloromethane (purple line) and $2 \%$ TFA- $\mathrm{CH}_{2} \mathrm{Cl}_{2}$ (green line)

The UV-vis spectrum of the phenyl neo-confused porphyrin dication $36 \mathbf{b} \mathrm{H}_{2}{ }^{2+}$ gave a strong Soret band at $382 \mathrm{~nm}$ with several Q bands following at higher wavelengths of536, 576 and $677 \mathrm{~nm}$ (Figure 26). 
Metalation of phenyl neo-confused porphyrin $\mathbf{3 6} \mathbf{b}$ was also investigated. Reaction of $\mathbf{3 6} \mathbf{b}$ with palladium(II) acetate in refluxing acetonitrile for 1 hour afforded the palladium(II) derivative $\mathbf{6 1}$ (Scheme 24). The proton NMR spectrum for $\mathbf{6 1}$ showed that the metal complex had a slight increase in diatropic character compared to the free base form of neo-confused porphyrin $\mathbf{3 3 b}$. The meso-protons were shifted slightly downfield. In addition, the external pyrrolic proton showed up as a singlet because there is no longer an internal $\mathrm{CH}$ to couple to this unit. As the internal $\mathrm{NH}$ and $\mathrm{CH}$ units are no longer present, there are no longer any upfield resonances (Figure 27).
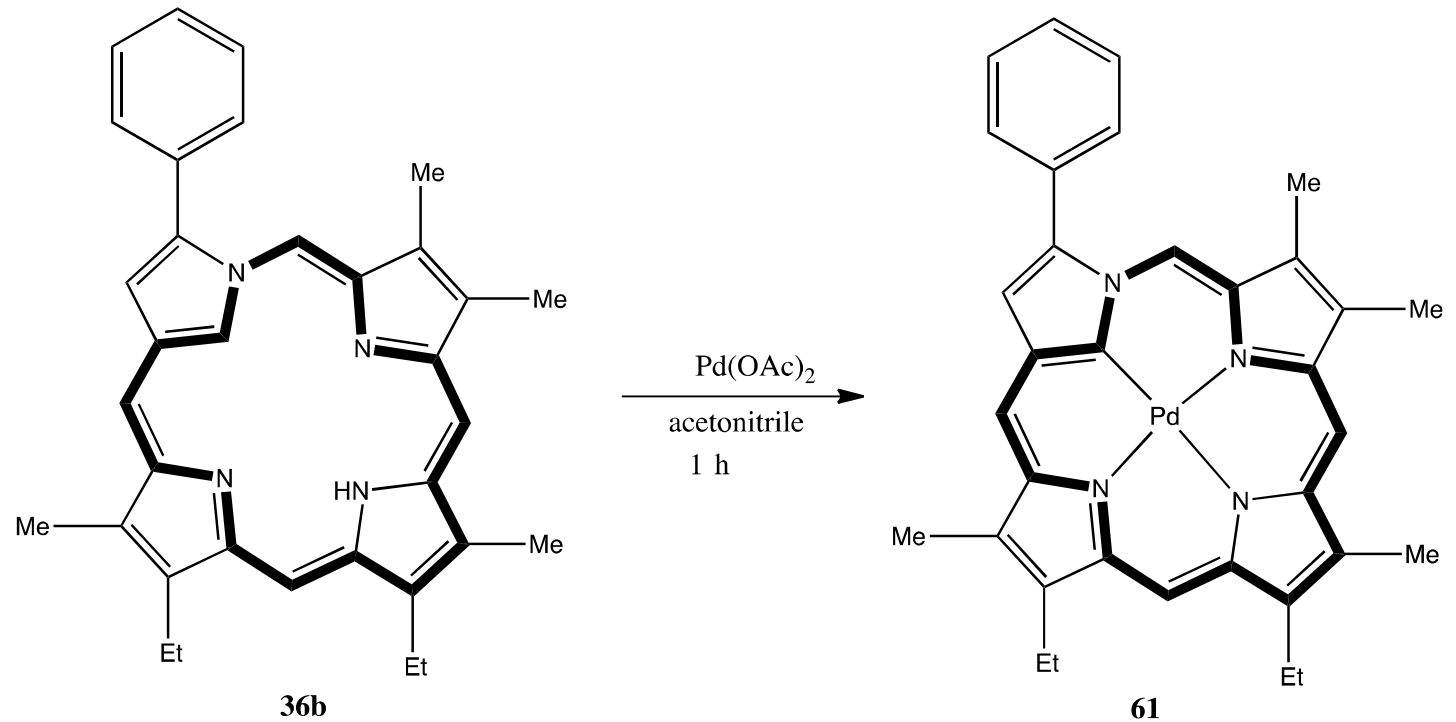

Scheme 24: Synthesis of palladium(II) complex 61 


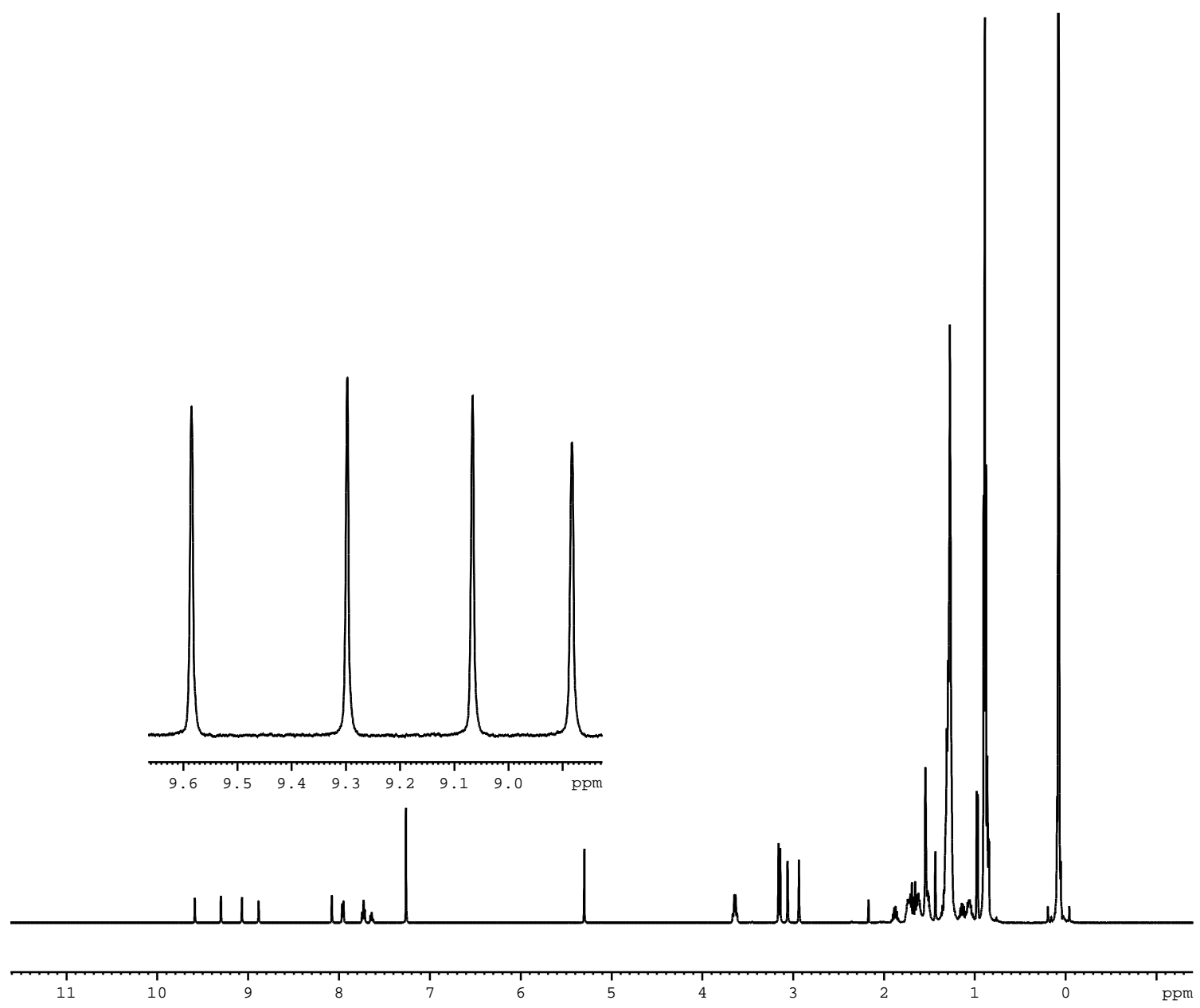

Figure 27: $500 \mathrm{MHz}$ proton NMR spectrum of palladium(II) complex 61 in $\mathrm{CDCl}_{3}$ 


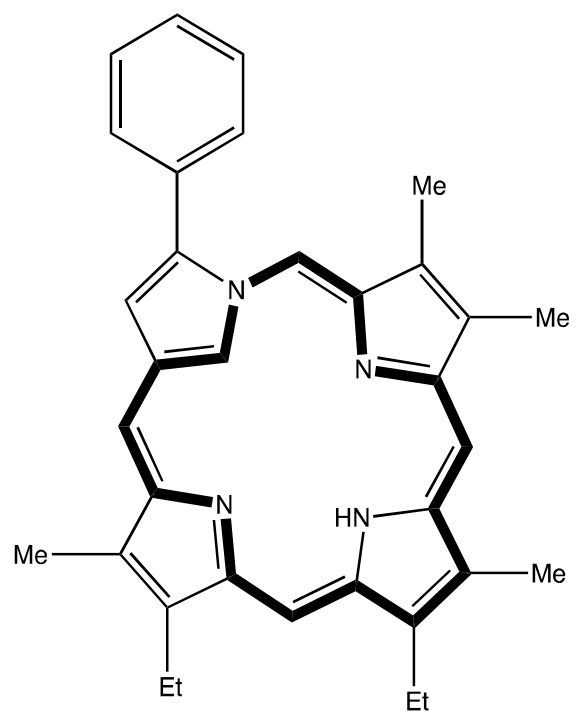

36b

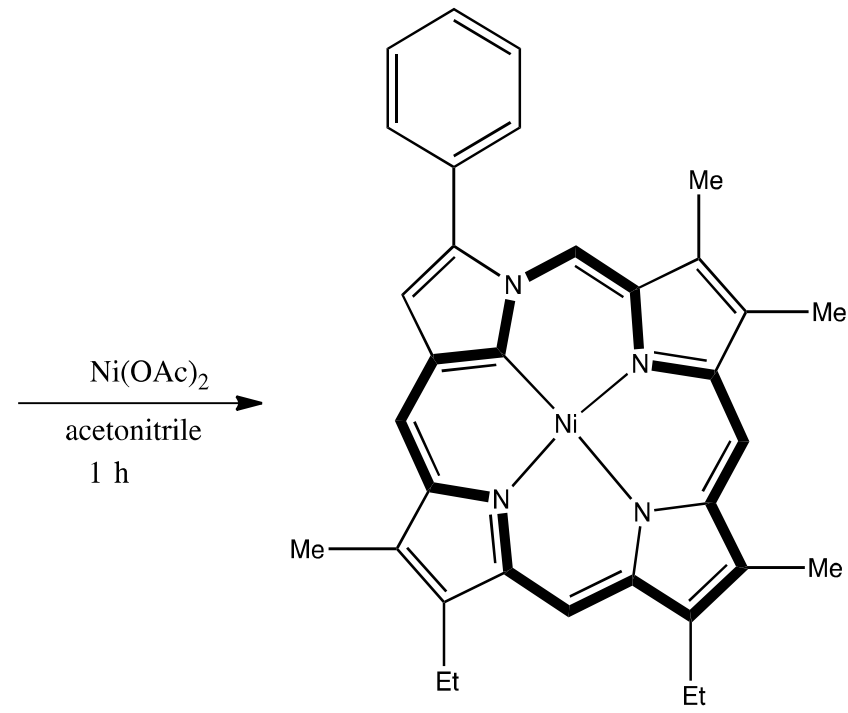

62

Scheme 25: Synthesis of nickel(II) neo-confused porphyrin 62

The nickel(II) complex of phenyl neo-confused porphyrin 36b was also investigated. Reaction of $\mathbf{3 6} \mathbf{b}$ with nickel(II) acetate in refluxing acetonitrile for 1 hour afforded the nickel(II) derivative 62 (Scheme 25). Following purification on an alumina column, the nickel complex 62 was isolated in $60 \%$ yield as brown solid. The proton NMR spectrum for $\mathbf{6 2}$ showed that the metal complex had similar diatropic character to the free base form of neo-confused porphyrin $\mathbf{3 6 b}$, although the meso-protons were shifted slightly upfield. In addition, the external pyrrolic proton shows up as a singlet because there is no longer an internal $\mathrm{CH}$ to couple to this unit. As the internal $\mathrm{NH}$ and $\mathrm{CH}$ units are no longer present, there are no longer any upfield resonances (Figure 28). 


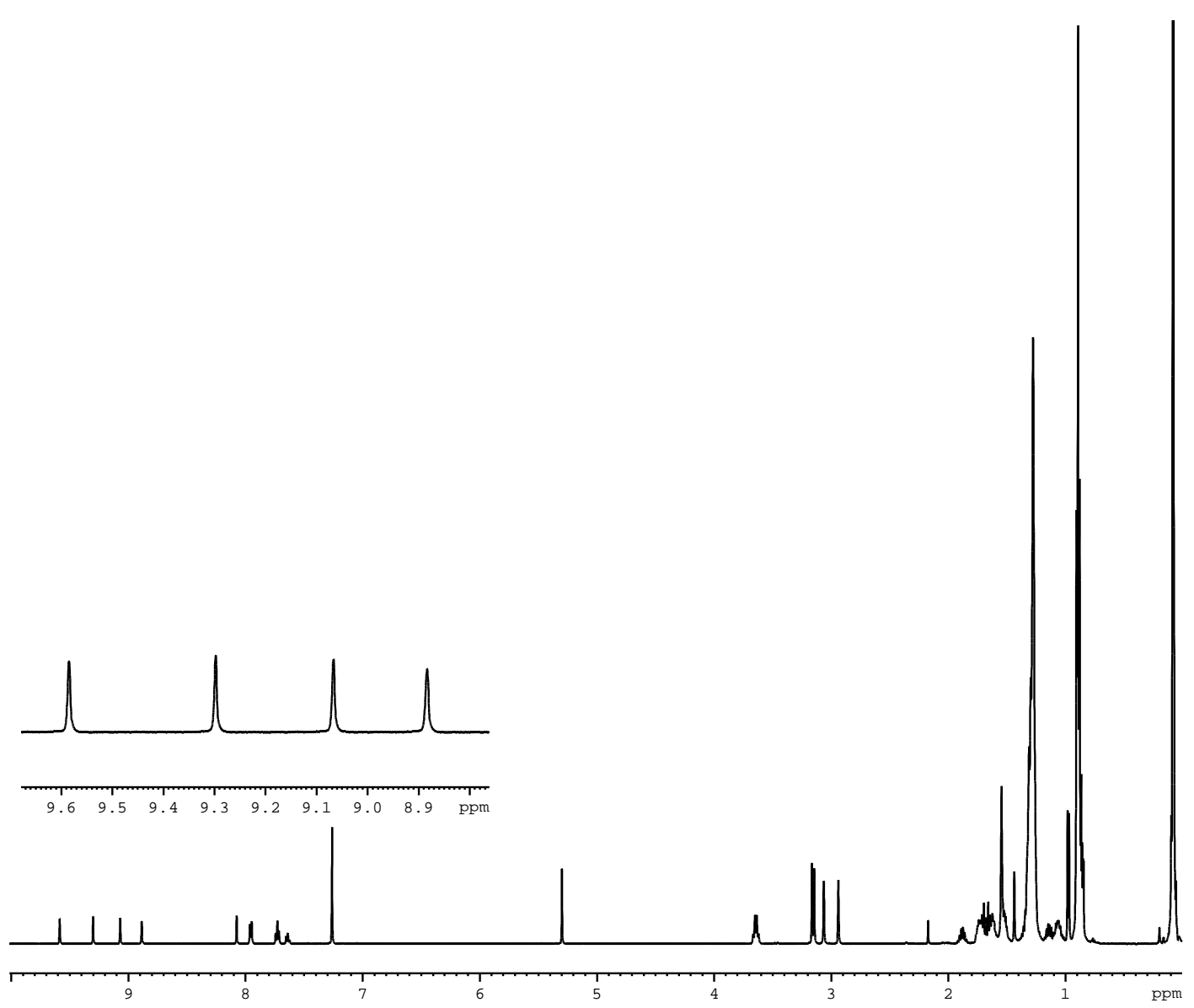

Figure 28: $500 \mathrm{MHz}$ proton NMR spectrum of nickel(II) complex 62 in $\mathrm{CDCl}_{3}$

The synthesis of an interesting aza-neo-confused system was also targeted (Scheme 26). In this system, the neo-confused pyrrole unit has been replaced by an imidazole moiety. Initially, commercially available imidazole-3-carbaldehyde and acetoxymethylpyrrole aldehyde39 were reacted with $\mathrm{NaH}$ in $\mathrm{DMF}$, but this did not give the desired dipyrroledialdehyde63. However, when THF was used as a solvent instead of DMF, pyrrolylmethylimidazoledialdehyde63as shown by proton NMR(Figure 29) was isolated in $60 \%$ yield. Azadipyrrylmethanedialdehyde63 was reacted with 
dipyrrylmethanedicarboxylic acid $\mathbf{3 8}$ in the presence of $p$-toluenesulfonic acid using MacDonald's " $2+2$ " condensation method, followed by an oxidation step. However, no macrocyclic products could be identified (Scheme 26).

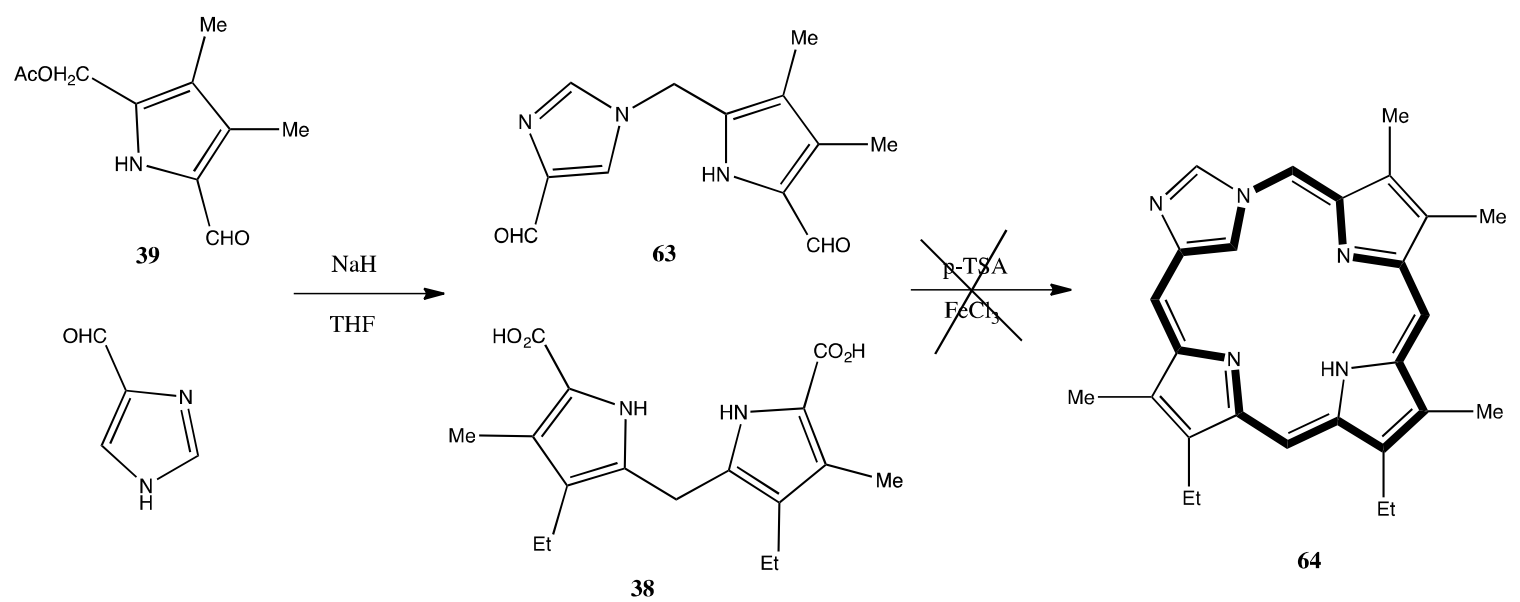

Scheme 26: Attempted synthesis of aza neo-confused porphyrin 64 


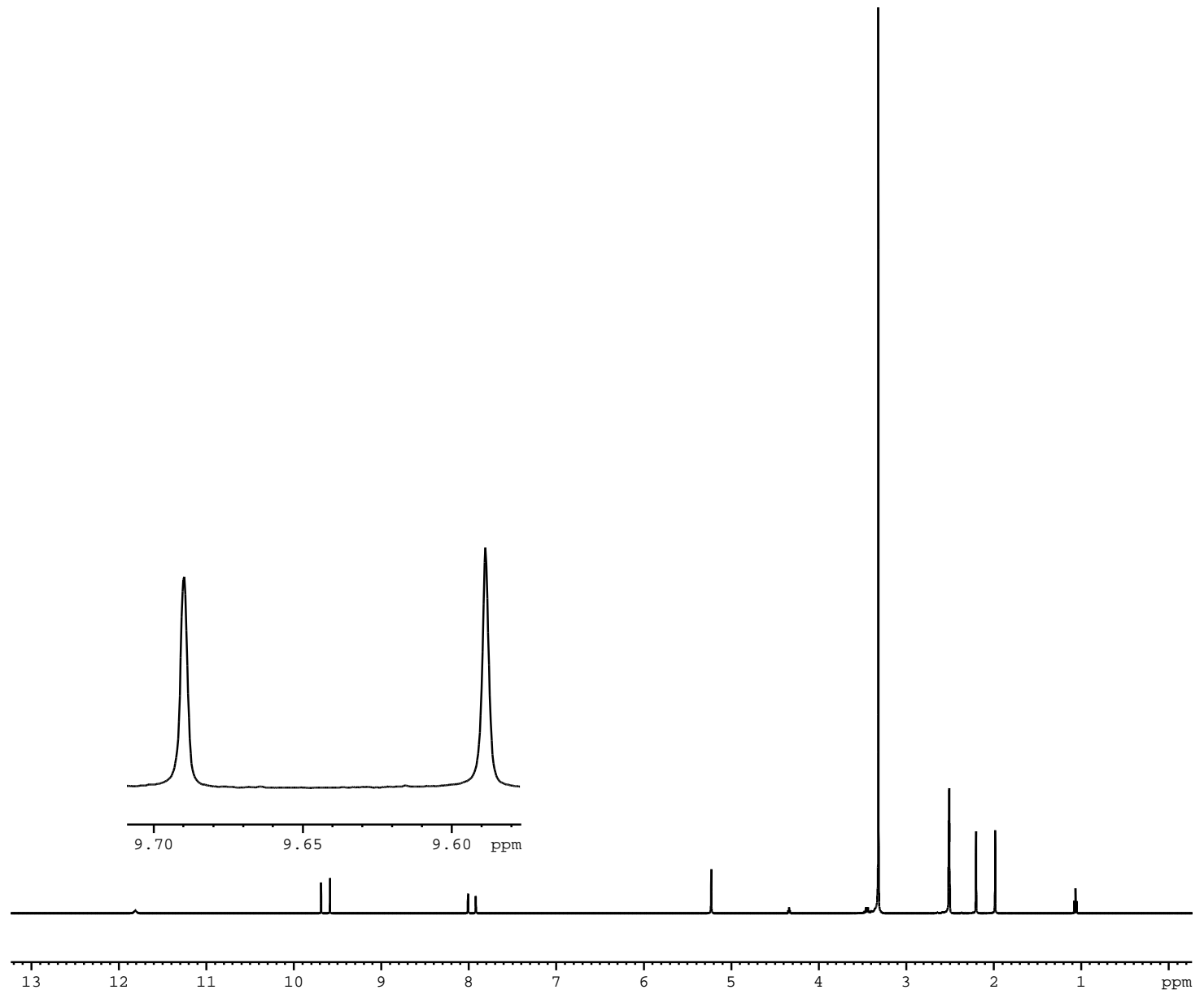

Figure 29: $500 \mathrm{MHz}$ proton NMR spectrum of aza neo-confused dipyrrylmethane63 in $\mathrm{CDCl}_{3}$ 
In an attempt to increase the reactivity of the aza neo-confused dipyrrylmethane, a methyl-substituted imidazole aldehyde $\mathbf{6 9}$ was also targeted. The synthesis of methyl imidazole aldehyde 69 initially involved a protection step where 2-methyl imidazole was reacted with dimethylsulfamoyl chloride to give 67. Subsequent treatment with $n$ butyllithium, followed by addition of DMF and hydrolysis, afforded the deprotected aldehyde 69 (Scheme 27). ${ }^{26}$

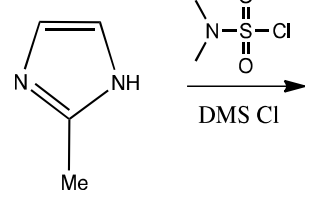

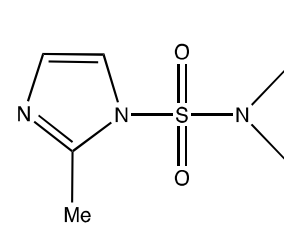

67

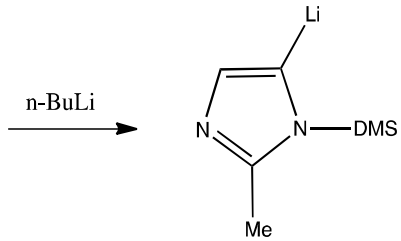

68

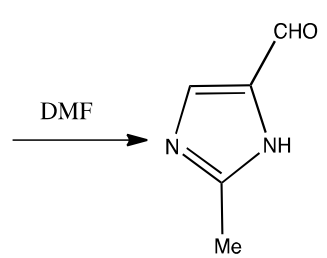

69

Scheme 27: Synthesis of methyl formyl imidazole 69

Aldehyde 69 was reacted with acetoxymethylpyrrolealdehyde39 and NaH in THF, which successfully gave the methyl aza neo-confused dipyrrylmethane70as shown by NMR in 65\% yield (Figure 30). The dialdehyde $\mathbf{7 0}$ and dicarboxylic acid $\mathbf{3 8}$ were reacted in the presence of $p$-toluenesulfonic acid, followed by oxidation with $\mathrm{FeCl}_{3}\left(\mathrm{Scheme}_{28}\right)$. Alternative condensation conditions were also investigated. Unfortunately, all attempts to synthesize aza-neo-confused porphyrin $\mathbf{7 1}$ were unsuccessful. It is unclear why the problem was encountered, but it may be that aza neo-confused porphyrins are unstable. 

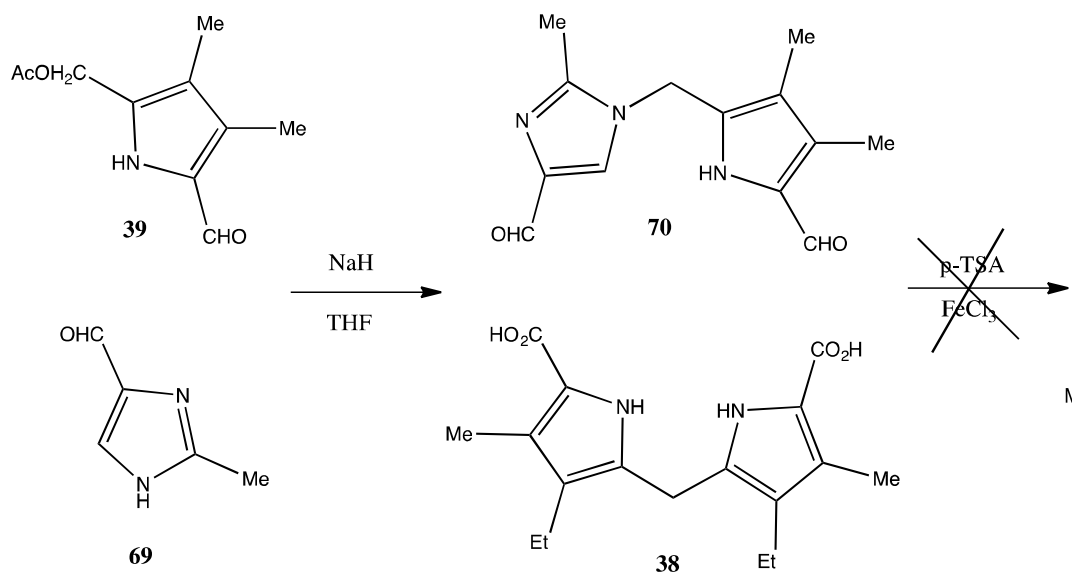

69

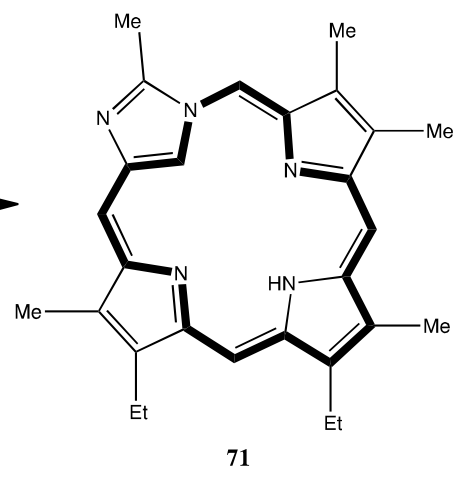

Scheme 28: Attempted synthesis of methyl aza neo-confused porphyrin 71

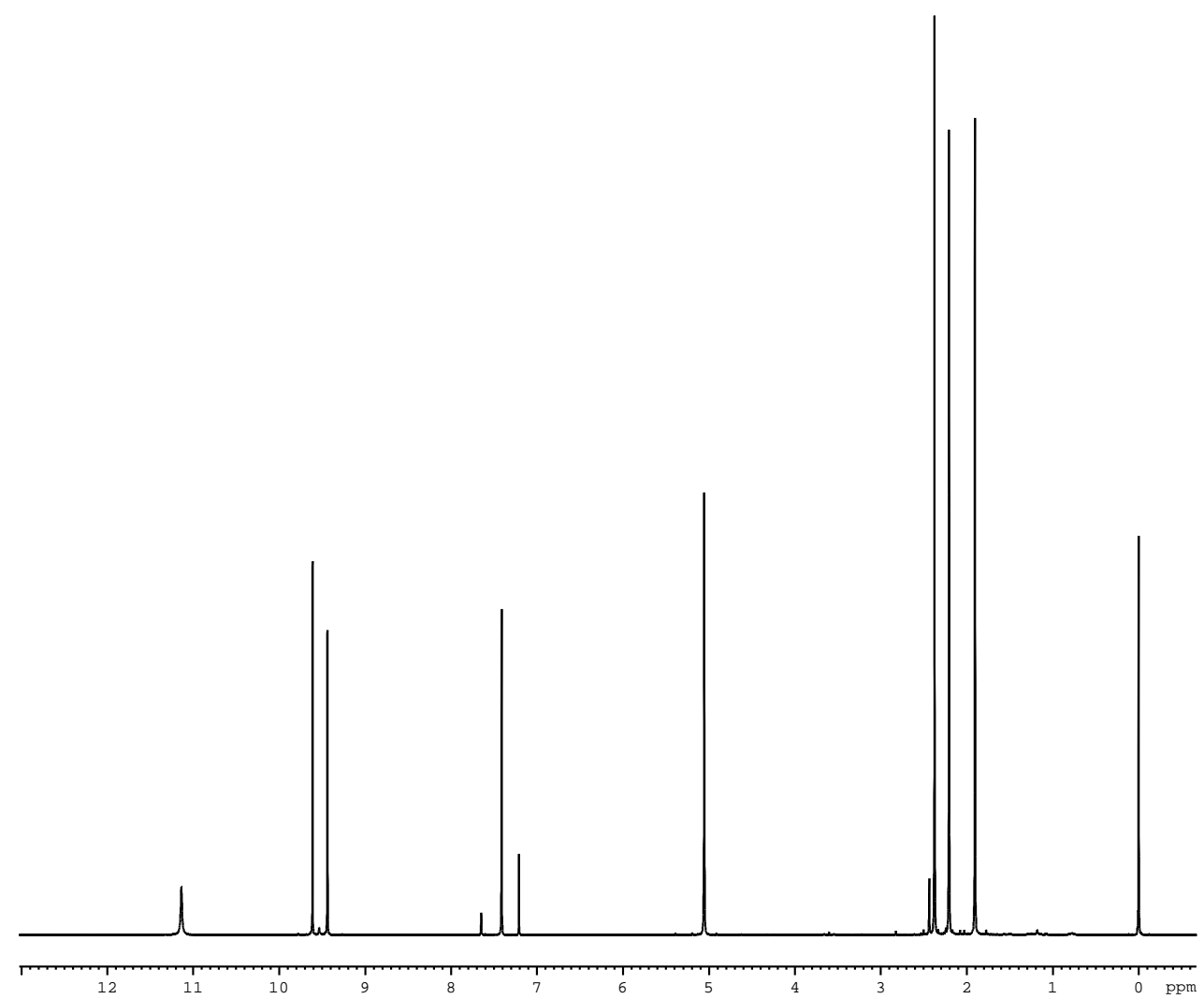

Figure 30: $500 \mathrm{MHz}$ proton NMR spectrum of methyl aza neo-confused dipyrrylmethane 70 in $\mathrm{CDCl}_{3}$ 


\section{Conclusions}

Two examples of neo-confused porphyrins have been synthesized in good yields. These neo-confused porphyrins were shown to retain aromatic character, but this was somewhat reduced compared to benzo-fused neo-confused porphyrins. The observed diatropic character is believed to be due to the presence of a 17 -atom $18 \pi$ electron delocalization pathway. The UV-vis spectra for neo-confused porphyrins also gave porphyrin-like characteristics with a strong Soret band and several Q absorptions. Addition of TFA to solutions of neo-confused porphyrins led to the formation of diprotonateddications that exhibited greatly enhanced diatropicity. Reaction with nickel(II) or palladium(II) acetate gave nickel(II) or palladium(II) organometallic derivatives, and these showed similar diatropic character to free base neo-confused porphyrins. The synthesis of aza neo-confused porphyrins 64 and 71 have also been investigated, but no macrocyclic products could be isolated. It remains to be seen whether this type of neo-confused porphyrin can be accessed by the " $2+2$ " methodology. However, the results from this study demonstrate that neo-confused porphyrins have unique spectroscopic properties. Therefore, this work provides the foundations for further studies into these interesting porphyrin analogues. 


\section{CHAPTER III}

\section{EXPERIMENTAL}

All chemicals were purchased from Acros Organic or Sigma Aldrich. Silica gel and grade III basic alumina were used for column chromatography. All ${ }^{1} \mathrm{H}$ and ${ }^{13} \mathrm{NMR}$ spectra were obtained on a BrukerAvance III 400 or $500 \mathrm{MHz}$ NMR spectrometer at 25 ${ }^{\circ} \mathrm{C}$. Chemical shifts were recorded in parts per million (ppm) relative to $\mathrm{CDCl}_{3}$ (residual chloroform at $\delta 7.26 \mathrm{ppm}$ ) in proton NMR spectra and the $\mathrm{CDCl}_{3}$ triplet at $\delta 77.23 \mathrm{ppm}$ in carbon-13 NMR spectra; for $\mathrm{d}_{6}$-DMSO, the proton NMR spectrum was calculated relative to the $\mathrm{d}_{5}$-DMSO pentet at $2.51 \mathrm{ppm}$, while the septet at $39.5 \mathrm{ppm}$ was used as a standard for carbon-13 NMR. UV-Vis spectra were collected on a Cary 100 Bio spectrophotometer. Melting points were collected with a Mel-Temp apparatus. Mass spectrometry data wereobtained from the Laboratory for Biological Mass Spectrometry at Texas A\&M University. 


\section{Ethyl Isocyanoacetate (42)}

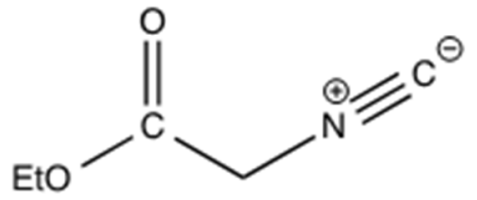

$N$-Formylglycine ethyl ester (70 g, 0.618 moles), triethylamine (135 g, 1.33 moles), and dichloromethane $(550 \mathrm{ml})$ were placed in $2 \mathrm{~L}$ three neck round bottom flask, and was purged with nitrogen and cooled down to $0^{\circ} \mathrm{C}$ with the aid of a salt-ice bath. Freshly distilled phosphorus oxychloride ( $81.8 \mathrm{~g}$ ) was added dropwise to the solution, keeping the temperature at $0-2{ }^{\circ} \mathrm{C}$, and the mixture was stirred for a further $1 \mathrm{~h}$. Sodium carbonate (106 $\mathrm{g}$ in $425 \mathrm{ml}$ of water) was added dropwise to the mixture, maintaining the temperature below $25^{\circ} \mathrm{C}$. Waterwas added to bring the total aqueous layer to a volume of $1 \mathrm{~L}$, and two layers separated. The aqueous layer was back extracted with dichloromethane $(2 \times 250 \mathrm{ml})$. The combined organic layers were washed twice with brine and dried over potassium carbonate. The solvent was removed under vacuum and the residue was vacuum distilled to yield ethyl isocyanoacetate $(36.50 \mathrm{~g}, 0.322 \mathrm{~mol}, 60.4$ \%) as a yellow oil, bp 95-100 ${ }^{\circ} \mathrm{C}$ at $20 \mathrm{mmHg} ;{ }^{1} \mathrm{H}$ NMR $\left(500 \mathrm{MHz}, \mathrm{CDCl}_{3}\right): \delta 1.28(3 \mathrm{H}, \mathrm{t}$, $\left.-\mathrm{CH}_{2} \mathrm{CH}_{3}\right), 4.15\left(2 \mathrm{H}, \mathrm{s},-\mathrm{CH}_{2} \mathrm{CH}_{3}\right), 4.25\left(2 \mathrm{H}, \mathrm{q},-\mathrm{OCH}_{2}\right)$. 
Ethyl 3,4-dimethylpyrrole-2-carboxylate (44)

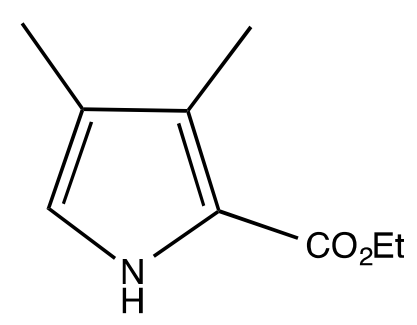

In a round bottom flask was placed ethyl isocyanoacetate ( $74 \mathrm{~g}, 0.654 \mathrm{~mol})$, and tetramethylguanidine $(150 \mathrm{~g}, 1.30 \mathrm{~mol})$. After the flask was cooled in an ice-water bath, a solution of 3-acetoxy-2-nitrobutane (100 g, $0.62 \mathrm{~mol})$ in THF (100 ml) and 2-propanol $(100 \mathrm{ml})$ was added dropwise over $30 \mathrm{~min}$ at $0^{\circ} \mathrm{C}$. The mixture was stirred at room temperature for $20 \mathrm{~h}$. The solvent was removed under reduced pressure. The residue was taken up by dichloromethane $(1250 \mathrm{ml})$ and washed with water $(3 \times 200 \mathrm{ml}), 5 \% \mathrm{HCl}(3 \times$ $200 \mathrm{ml})$, water $(200 \mathrm{ml})$, saturated sodium bicarbonate $(200 \mathrm{ml})$ and saturated sodium chloride $(200 \mathrm{ml})$. After drying over sodium sulfate and evaporating the solvent under vacuum, the residue was crystallized from dichloroethane/hexane to afford the pyrrole (50.82 g, $0.303 \mathrm{~mol}, 49 \%$ ) as a white solid, mp $93-95{ }^{\circ} \mathrm{C}$ (lit. mp 94-95 $\left.{ }^{\circ} \mathrm{C}\right) .{ }^{1} \mathrm{H}$ NMR $\left(500 \mathrm{MHz}, \mathrm{CDCl}_{3}\right): \delta 1.36$ (t, 3H, $\left.J=7.4 \mathrm{~Hz}\right), 2.01(\mathrm{~s}, 3 \mathrm{H}), 2.27$ (s, 3H), 4.33 (q, $J=7.4$ $\mathrm{Hz}), 6.65(\mathrm{~d}, J=2.91 \mathrm{~Hz}), 8.73(\mathrm{~s}, \mathrm{NH}) \mathrm{ppm}$. 


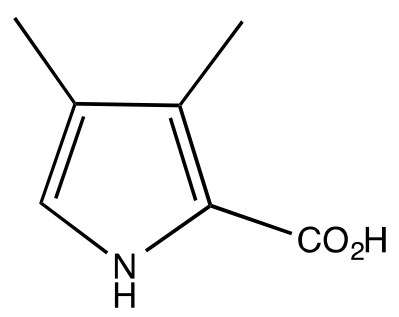

Ethyl 3,4-dimethylpyrrole-2-carboxylate (3.6 g, $0.02 \mathrm{~mol})$ was suspended in $2 \mathrm{ml}$ of $95 \%$ ethanol, then a $30 \%$ solution of potassium hydroxide $(400 \mathrm{ml})$ was added. The mixture was stirred at reflux for $2 \mathrm{~h}$, and then cooled down to room temperature and placed in ice-water bath. To the resulting brown solution, concentrated $\mathrm{HCl}$ was added dropwise, keeping the temperature below $10^{\circ} \mathrm{C}$, to give white precipitate. After filtration, the white solid was washed with water $(\times 10)$ to remove all traces of acid. The white solid was vacuum dried to give the carboxylic acid (2.99 g, $0.021 \mathrm{~mol}, 96 \%) .{ }^{1} \mathrm{H}$ NMR (500 MHz, acetone-d 6 ): $\delta 1.95(\mathrm{~s}, 3 \mathrm{H}), 2.11(\mathrm{~s}, 3 \mathrm{H}), 6.61(\mathrm{~d}, 1 \mathrm{H}, J=3.0 \mathrm{~Hz}), 10.06(\mathrm{~s}$, 1H) ppm. 


\section{3,4-Dimethyl-2,5-pyrroledicarbaldehyde (46)}

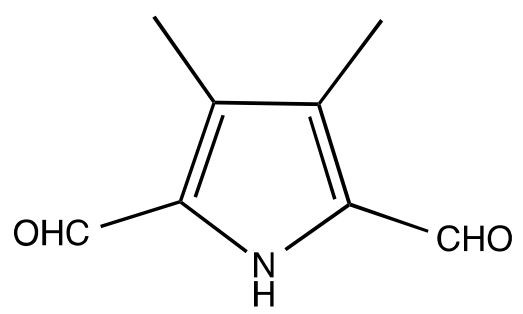

3,4-Dimethylpyrrole-2-carboxylic acid (2.00 g, $0.014 \mathrm{~mol})$ was dissolved in THF (30 ml) and purged with $\mathrm{N}_{2}$ for $5 \mathrm{~min}$ in the dark while cooling the flask in a salt-ice bath. When the solution reached $-5^{\circ} \mathrm{C}$, triethylorthoformate $(32 \mathrm{ml})$ was added quickly, keeping the temperature below $10^{\circ} \mathrm{C}$. After the mixture stirred at $10^{\circ} \mathrm{C}$ for $1 \mathrm{~h}$, the mixture was poured into water $(100 \mathrm{ml})$. The solution was neutralized by the addition of sodium hydroxide ( $20 \mathrm{~g}$ in $80 \mathrm{ml}$ water). The mixture was extracted with dichloromethane $(\times 4)$ and the combined organic layers were washed with brine and dried over magnesium sulfate. The solvent was removed under reduced pressure, and residue was recrystallized from chloroform/hexanes to afford the dialdehyde $(1.95 \mathrm{~g}, 12.9 \mathrm{mmol}$, 97.3\%) as a brown solid, mp $157-159^{\circ} \mathrm{C}\left(\right.$ lit. $\left.\mathrm{mp}^{21} 157-158^{\circ} \mathrm{C}\right) .{ }^{1} \mathrm{H}$ NMR $(500 \mathrm{MHz}$, $\left.\mathrm{CDCl}_{3}\right): \delta 2.24(6 \mathrm{H}, \mathrm{s}), 9.41(2 \mathrm{H}, \mathrm{s}), 9.86(1 \mathrm{H}, \mathrm{br}) \mathrm{ppm}$. 


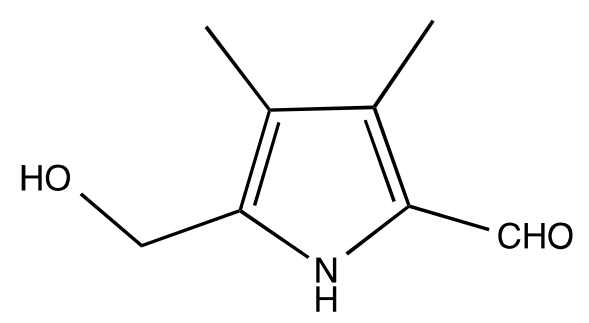

A solution of 3,4-dimethylpyrrole-2,5-dicarbaldehyde (564 $\mathrm{mg}, 3.73 \mathrm{mmol})$ in methanol $(18 \mathrm{ml})$ was cooled to $0^{\circ} \mathrm{C}$ in an ice-salt bath. Sodium borohydride $(36 \mathrm{mg}, 0.93$ mmol) was added and the mixture was allowed to stir for $10 \mathrm{~min}$. Brine $(21 \mathrm{ml})$ was added and the mixture stirred for $15 \mathrm{~min}$. The mixture was extracted with ethyl acetate $(\times 5)$, and the combined organic layers were dried over $\mathrm{MgSO}_{4}$. After filtration and evaporation of the solvent, the residue was recrystallized from chloroform/hexanes to give the carbinol (560 mg, $3.66 \mathrm{mmol}, 98 \%)$, mp $125-126{ }^{\circ} \mathrm{C} ;{ }^{1} \mathrm{H}$ NMR $(500 \mathrm{MHz}$, $\left.\mathrm{CDCl}_{3}\right): \delta 1.89(3 \mathrm{H}, \mathrm{s}), 2.19(3 \mathrm{H}, \mathrm{s}), 3.43(1 \mathrm{H}, \mathrm{br}), 4.66(2 \mathrm{H}, \mathrm{s}), 9.38(1 \mathrm{H}, \mathrm{s}), 10.08(1 \mathrm{H}$, br) ppm. 


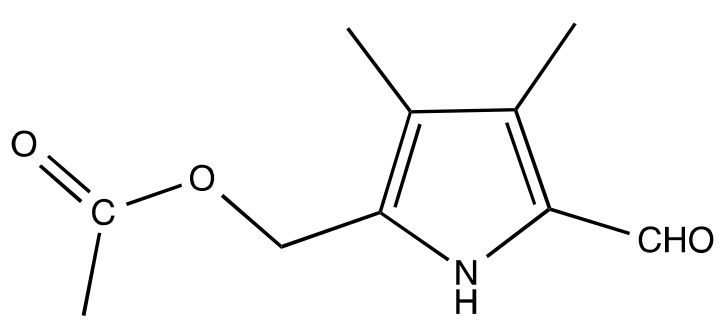

Acetic anhydride $(7.5 \mathrm{~mL})$ was added to a solution of the foregoing pyrrole carbinol (350 $\mathrm{mg}, 2.28 \mathrm{mmol})$ in pyridine $(7.5 \mathrm{~mL})$ at $-3^{\circ} \mathrm{C}$ using a salt-ice bath, and the mixture was stirred for $1 \mathrm{~h}$. The mixture was dispersed between dichloromethane and water, and the organic layer was separated. The aqueous layer was further extracted with dichloromethane (x 3) and the combined organic solutions were dried over sodium sulfate. The solvent was removed under reduced pressure and the dark brown residue was recrystallized from chloroform-hexane to give the acetoxymethylpyrrole $(380 \mathrm{mg}, 1.94$ mmol, $85 \%$ yield) as a brown solid, mp 123-124 ${ }^{\circ} \mathrm{C}$; ${ }^{1} \mathrm{H}$ NMR (500 MHz, $\mathrm{CDCl}_{3}$ ): $\square 1.95$ $(3 \mathrm{H}, \mathrm{s}), 2.01(3 \mathrm{H}, \mathrm{s}), 2.19(3 \mathrm{H}, \mathrm{s}),, 4.98(2 \mathrm{H}, \mathrm{s}),, 9.14(1 \mathrm{H}, \mathrm{br}), 9.54(1 \mathrm{H}, \mathrm{s}) \mathrm{ppm}$. 
Pyrrole-3-carboxaldehyde (49)

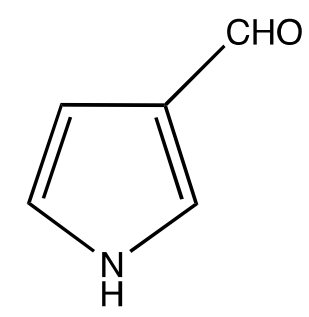

To a suspension of sodium hydride $(60 \%$ in mineral oil, $13.7 \mathrm{~g}, 285 \mathrm{mmol})$ in THF $(450 \mathrm{ml})$ was slowly added pyrrole $(17.4 \mathrm{~g}, 259 \mathrm{mmol})$ at $0^{\circ} \mathrm{C}$. The mixture was stirred at the same temperature for $1.5 \mathrm{~h}$. Triisopropylsilylchloride $(50 \mathrm{~g}, 259 \mathrm{mmol})$ was added to the mixture slowly at $0^{\circ} \mathrm{C}$. The mixture was then stirred for another $1.5 \mathrm{~h}$. Ice water $(20 \mathrm{ml})$ was added, and the mixture was extracted with diethyl ether. The extract was washed with water, dried over anhydrous sodium sulfate and concentrated under reduced pressure to give 1-(triisopropylsilyl)pyrroles ( $57 \mathrm{~g}, 0.255 \mathrm{~mol}$, quantitative yield). A solution of 1-(triisopropylsilyl)pyrrole $(25.0 \mathrm{~g}, 112 \mathrm{mmol})$ in dichloromethane $(20 \mathrm{ml})$ was added to a stirred mixture of DMF $(10 \mathrm{ml}, 129 \mathrm{mmol})$ and oxalyl chloride $(10.0 \mathrm{ml}$, $118 \mathrm{mmol})$ in dichloromethane $(510 \mathrm{ml})$ at $0{ }^{\circ} \mathrm{C}$. The mixture then was placed in an oil bath preheated to $60^{\circ} \mathrm{C}$. The solid dissolved for a moment then formed again. The mixture was refluxed for $30 \mathrm{~min}$, then cooled to $0^{\circ} \mathrm{C}$, and the resulting precipitate was collected by filtration. The solid was washed with dry ether several times, then vacuum dried to giveN,N-dimethylpyrrole-3-formiminium chloride as a white powder $(17.0 \mathrm{~g}$, 97\%). This material was taken on to the next step without further purification. N,Ndimethylpyrrole-3-formiminium chloride $(2.10 \mathrm{~g}, 13.2 \mathrm{mmol})$ was added to a $5 \%$ sodium hydroxide solution $(200 \mathrm{ml})$ and the mixture stirred at room temperature for $4 \mathrm{~h}$. The solution was extracted with dichloromethane, dried over potassium carbonate and 
concentrated under reduced pressure. The residue was purified by flash chromatography on silica gel, using hexanes/ethyl acetate (3:1 to 1:1) as the eluent,to yield pyrrole-3carboxaldehyde ( $9.4 \mathrm{~g}, 0.099 \mathrm{~mol}, 38 \%$ ) as a brown solid, $\mathrm{mp} 62-64^{\circ} \mathrm{C}$ (lit. $\mathrm{mp}^{24} 60-61$ $\left.{ }^{\circ} \mathrm{C}\right) .{ }^{1} \mathrm{H}$ NMR $\square \square 6.61(1 \mathrm{H}, \mathrm{m}), 6.78(1 \mathrm{H}, \mathrm{m}), 6.93(1 \mathrm{H}, \mathrm{dd}), 9.59(1 \mathrm{H}, \mathrm{br}), 9.74(1 \mathrm{H}, \mathrm{s})$ ppm.

\section{5-Bromopyrrole-3-carbaldehyde (40a)}

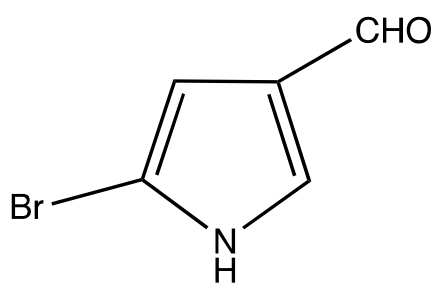

To a solution of pyrrole-3-carboxaldehyde $(0.88 \mathrm{~g}, 9.25 \mathrm{mmol})$ in THF (13.82 ml) was slowly added a solution of NBS (1.64 g) in DMF (4.60 ml) while maintaining the temperature at $-70{ }^{\circ} \mathrm{C}$ with the aid of a dry ice-acetone bath, and the mixture was stirred at the same temperature for $1 \mathrm{~h}$ and then allowed to warm to $-10{ }^{\circ} \mathrm{C}$ over $2 \mathrm{~h}$. After the mixture was stirred at the same temperature for $30 \mathrm{~min}$, ice-water was added and the mixture was extracted with ethyl acetate. The extract was washed with an aqueous citric acid solution (10\%), sodium bicarbonate $(6 \%)$ and brine, dried over anhydrous sodium sulfate, and the solvent removed under reduced pressure. The residue was washed with diisopropyl ether $(20 \mathrm{ml})$ to give the bromo pyrrole $(0.81 \mathrm{~g}, 4.6 \mathrm{mmol}, 51 \%)$ as pale brown solid, mp $124-126^{\circ} \mathrm{C}\left(\right.$ lit $\left.\mathrm{mp}^{24} 125-128^{\circ} \mathrm{C}\right) .{ }^{1} \mathrm{H}$ NMR $\left(500 \mathrm{MHz}, \mathrm{CDCl}_{3}\right) \delta$ 6.59(1H, s), $7.32(1 \mathrm{H}, \mathrm{s}), 8.94(1 \mathrm{H}, \mathrm{br}), 9.64(1 \mathrm{H}, \mathrm{s}) \mathrm{ppm}$. 
Ethyl 3-(1-phenylethylideneaminooxy)acrylate(57)

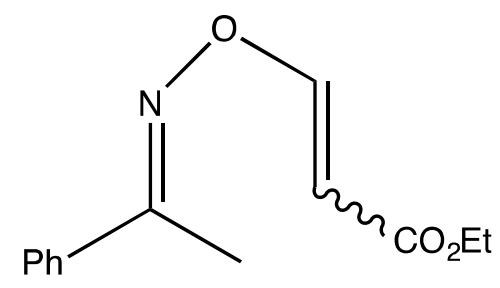

Acetophenoneoxime (800 mg, $5.9 \mathrm{mmol})$ and 1,4-diazabicyclooctane (72 mg) were dissolved in dichloromethane $(16 \mathrm{ml})$ and stirred to $-10{ }^{\circ} \mathrm{C}$. At the same temperature, a mixture of ethyl proiolate $(0.56 \mathrm{ml})$ in dichloromethane was added dropwise over $10 \mathrm{~min}$. The reaction was warmed to room temperature and stirred for $20 \mathrm{~h}$. The mixture was concentrated down under reduced pressure and purified by flash chromatography on silica gel using 9:1 petroleum ether/ethyl acetate to give the product (11.04 g, 47.34

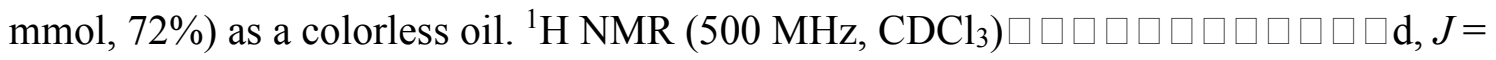
$12.5 \mathrm{~Hz}), 7.69-7.72(2 \mathrm{H}, \mathrm{m}), 7.40-7.51(3 \mathrm{H}, \mathrm{m}), 5.71(1 \mathrm{H}, \mathrm{d}, J=12.5 \mathrm{~Hz}), 4.23(2 \mathrm{H}, \mathrm{q})$, $2.37(3 \mathrm{H}, \mathrm{s}), 1.30(3 \mathrm{H}, \mathrm{t}) \mathrm{ppm}$. 
Ethyl 5-phenylpyrrole-3-carboxylate (58)

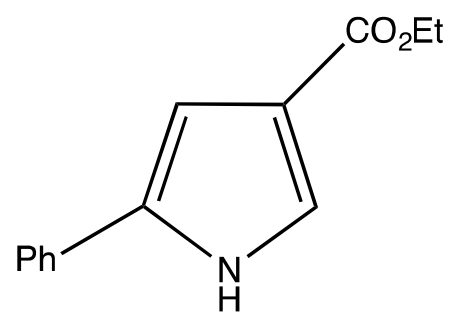

A solution of ethyl 3-(1-phenylethylideneaminooxy) acrylate (300 mg, $1.28 \mathrm{mmol})$ in toluene $(7.5 \mathrm{ml})$ was heated to $175^{\circ} \mathrm{C}$ for $2 \mathrm{~h}$ under microwave irradiation. The solution was then concentrated down and purified over silica gel (3:1 petrolium ether/ethyl acetate) to yield the pyrrole ester (216 $\mathrm{mg}, 1.003 \mathrm{mmol}, 84 \%)$ as an orange oil. ${ }^{1} \mathrm{H}$ NMR $\square \square 8.83$ (1H, br s), 7.47-7.50 (3H, m), 7.37-7.40 (2H,m), 7.24-7.27 (1H, m), 6.91-6.92 (1H, m), $4.31(2 \mathrm{H}, \mathrm{q}, J=7.1 \mathrm{~Hz}), 1.38(3 \mathrm{H}, \mathrm{t}, J=7.1 \mathrm{~Hz}) \mathrm{ppm}$. 


\section{5-Phenylpyrrole-3-carbaldehyde (40b)}

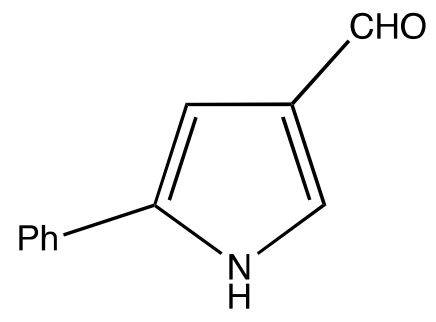

To a solution of ethyl 5-phenylpyrrole-3-carboxylate $(2.16 \mathrm{~g}, 10.03 \mathrm{mmol})$ in THF $(100 \mathrm{ml})$ was added dropwise a $1.0 \mathrm{M}$ solution of DIBAL-H in toluene $(24 \mathrm{ml})$ over 10 min while maintaining the temperature at $-78^{\circ} \mathrm{C}$, and the mixture was stirred for $1 \mathrm{~h}$. After warming the solution to room temperature over $1 \mathrm{~h}$, water $(1.4 \mathrm{ml})$ was added dropwise over $2 \mathrm{~min}$, and stirring was continued for a further $1 \mathrm{~h}$. Celite and magnesium sulfate were added to the mixture, then filtered off and filtrate was evaporated down under reduced pressure to give 5-phenylpyrrole-3-ylmethanol (1.05 g, $6.06 \mathrm{mmol}, 85 \%)$ as an orange oil. ${ }^{1} \mathrm{H}$ NMR $\left(500 \mathrm{MHz}, \mathrm{DMSO}_{-} \mathrm{d}_{6}\right) \delta 4.35(2 \mathrm{H}, \mathrm{d}, J=5.3 \mathrm{~Hz}), 4.59(1 \mathrm{H}, \mathrm{t}, J$ $=5.3 \mathrm{~Hz}), 6.45-6.46(1 \mathrm{H}, \mathrm{m}), 6.74-6.75(1 \mathrm{H}, \mathrm{br} \mathrm{m}), 7.11-7.15(1 \mathrm{H}, \mathrm{m}), 7.31-7.35(2 \mathrm{H}$, m), 7.57-7.59 $(2 \mathrm{H}, \mathrm{m}), 11.04(1 \mathrm{H}, \mathrm{brs}) \mathrm{ppm}$. To a solution of foregoing carbinol (1.05 $\mathrm{g}$, $6.06 \mathrm{mmol})$ in acetonitrile $(23.3 \mathrm{ml})$ was added tetra- $n$-propylammoniumperruthenate (0.32 g), $N$-methylmorpholine N-oxide (1.64 g), and $4^{\circ} \mathrm{A}$ molecular sieves (3.3 g), and the mixture was stirred for $1.5 \mathrm{~h}$. The mixture was filtered off through Celite, and the solvent was evaporated under reduced pressure. The residue was purified on a silica gel column (hexanes/ethyl acetate $4: 1)$ to give the aldehyde $(0.60 \mathrm{~g}, 3.5 \mathrm{mmol}, 60 \%)$ as a pale yellow solid, mp 138-140 $\mathrm{C}\left(\right.$ lit $\left.\mathrm{mp}^{24} 137-139^{\circ} \mathrm{C}\right) .{ }^{1} \mathrm{H} \mathrm{NMR}\left(\mathrm{CDCl}_{3}\right) \delta 6.88(1 \mathrm{H}$, 
m), 7.21-7.25 (1H, m), 7.33-7.37 (2H, m), 7.40-7.44(3H, m), $8.85(1 \mathrm{H}, \mathrm{br}), 9.78(1 \mathrm{H}, \mathrm{s})$ ppm.

4(5)-Formyl-2-methylimidazole (69)

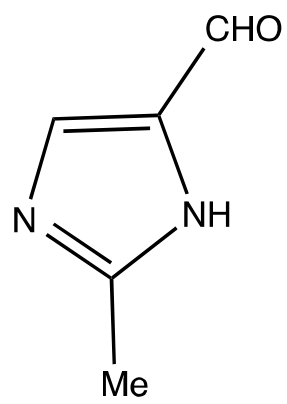

To a solution of 2-methylimidazole $(5.0 \mathrm{~g}, 0.045 \mathrm{moles})$ in dichloroethane $(70 \mathrm{ml})$ was added $\mathrm{N}, \mathrm{N}$-dimethylsulfamoyl chloride $(13 \mathrm{ml})$ and $\mathrm{Et}_{3} \mathrm{~N}(70 \mathrm{ml})$, and the mixture was stirred at room temperature for $20 \mathrm{~h}$. After filtration, the solid was washed with dichloroethane, and the combined organic solutions were washed with saturated sodium carbonate, dried over magnesium sulfate, and evaporated down. Distillation $\left(95-110^{\circ} \mathrm{C}\right)$ afforded 2-methyl-1-1-( $N, N$-dimethylsulfamoyl)imidazole (10.0 g, $52.84 \mathrm{mmol}, 90 \%$ ) as a colorless oil. A solution of the foregoing intermediate $(5.5 \mathrm{~g})$ in THF (200 ml) was cooled to $-76{ }^{\circ} \mathrm{C}, n$-butyllithium ( $30 \mathrm{ml}, 1.6 \mathrm{M}$ in hexanes) was added while keeping the temperature at $-76^{\circ} \mathrm{C}$. The mixture was stirred at the same temperature for a further 30 min. DMF $(21 \mathrm{ml})$ was added dropwise and the mixture stirred at $-78^{\circ} \mathrm{C}$ for $1 \mathrm{~h}$. The mixture was allowed to warm up to room temperature over $1 \mathrm{~h}$ and stirred for $30 \mathrm{~min}$. The $\mathrm{pH}$ was adjusted to 1 with concentrated hydrochloric acid, and the resulting mixture was stirred for $2 \mathrm{~h}$. The $\mathrm{pH}$ was then adjusted to 8 with saturated $\mathrm{NaHCO}_{3}$, and the THF 
was removed under reduced pressure. The residue was extracted with ethyl acetate $(3 \times$ $150 \mathrm{ml}$ ), the combined organic layers dried over magnesium sulfate, and the solvent evaporated to give the aldehyde $(2.6 \mathrm{~g}, 23.61 \mathrm{mmol}, 82 \%)$ as a faint yellow solid. ${ }^{1} \mathrm{H}$ NMR $(500$ Hz, DMSO-d $) \delta 12.06(1 \mathrm{H}, \mathrm{br}), 9.66(1 \mathrm{H}, \mathrm{s}), 7.99(1 \mathrm{H}, \mathrm{s}), 2.54(3 \mathrm{H}, \mathrm{s}) \mathrm{ppm}$.

\section{2-Bromo-3',4'-dimethyl-1,2'-dipyrrylmethane-4,5'-dicarbaldehyde (37a)}

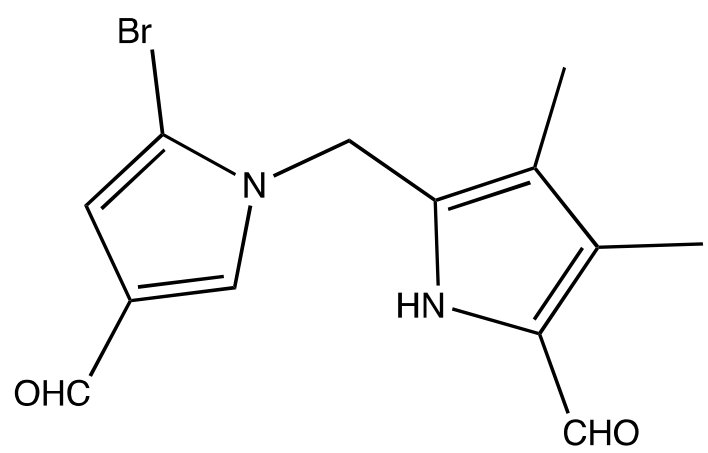

Sodium hydride ( $60 \%$ in mineral oil, $48 \mathrm{mg}, 0.5 \mathrm{mmol}$ ) was added to a solution of 5-bromo-3-pyrrolecarbaldehyde (144 mg, $0.827 \mathrm{mmol})$ in DMF $(30 \mathrm{ml})$ and the mixture was stirred for $30 \mathrm{~min}$ at room temperature. To the mixture, a solution of acetoxymethylpyrrole aldehyde39 (171 $\mathrm{mg}, 0.875 \mathrm{mmol})$ in DMF (15 ml) was added dropwise over $10 \mathrm{~min}$, and the mixture was stirred for $18 \mathrm{~h}$ at $30^{\circ} \mathrm{C}$. The mixture was then diluted with ether and washed with water. The aqueous phase was back extracted with ether (x3) and the combined organic layers dried over sodium sulfate. After suction filtration, the solvent was evaporated down under reduced pressure. Recrystallization from ethanol gave the dipyrrylmethane $(190 \mathrm{mg}, 0.615 \mathrm{mmol}, 65 \%)$ as a pale brown solid. mp 196-198 ${ }^{\circ}$; ${ }^{1} \mathrm{H}$ NMR $\left(500 \mathrm{~Hz}, \mathrm{CDCl}_{3}\right) \delta 1.95(3 \mathrm{H}, \mathrm{s}), 2.21(3 \mathrm{H}, \mathrm{s}), 5.01(2 \mathrm{H}$, 
s), $6.63(1 \mathrm{H}, \mathrm{d}, J=1.9 \mathrm{~Hz}), 7.15(1 \mathrm{H}, \mathrm{d}, J=1.9 \mathrm{~Hz}), 8.98(1 \mathrm{H}, \mathrm{br}), 9.53(1 \mathrm{H}, \mathrm{s}), 9.56$

$(1 \mathrm{H}, \mathrm{s}) \mathrm{ppm} .{ }^{13} \mathrm{C} \mathrm{NMR}\left(\mathrm{CDCl}_{3}\right): \delta 8.50,8.81,43.88,105.72,111.0,120.34,126.96$, $128.84,129.50,130.04,131.94,177.65,184.15 \mathrm{ppm}$.

2-Phenyl-3',4'-dimethyl-1,2'-dipyrrylmethane-4,5'-dicarbaldehyde (37b)

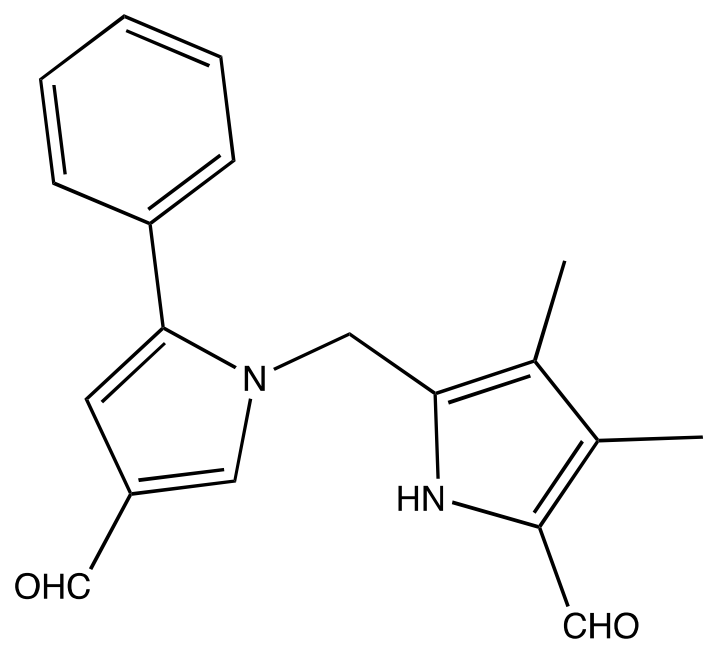

Sodium hydride (60\% in mineral oil, $44 \mathrm{mg}$ ) was added to a solution of 5-phenyl-3pyrrolecarbaldehyde $(147 \mathrm{mg}, 0.479 \mathrm{mmol})$ in DMF $(27.55 \mathrm{ml})$ and the mixture was stirred for $30 \mathrm{~min}$ at room temperature. To the mixture, a solution of acetoxymethylpyrrole aldehyde $(156 \mathrm{mg}, 0.799 \mathrm{mmol})$ in DMF $(13.8 \mathrm{ml})$ was added dropwise over $10 \mathrm{~min}$, and the mixture was stirred for $18 \mathrm{~h}$ at $30^{\circ} \mathrm{C}$. The mixture was then diluted with ether and washed with water. The aqueous phase was back extracted with ether (x3) and the combined organic layers dried over sodium sulfate. After suction filtration, the solvent was evaporated down under reduced pressure. Recrystallization from ethanol gave the dipyrrylmethane $(185 \mathrm{mg}, 0.603 \mathrm{mmol}, 60 \%)$ as a brown 
solid,mp202-204 ${ }^{\circ} \mathrm{C} ;{ }^{1} \mathrm{H}$ NMR $\left(500 \mathrm{~Hz}, \mathrm{CDCl}_{3}\right) \delta 1.79(3 \mathrm{H}, \mathrm{s}), 2.15(3 \mathrm{H}, \mathrm{s}), 5.00(2 \mathrm{H}, \mathrm{s})$, $6.61(1 \mathrm{H}, \mathrm{d}, J=1.7 \mathrm{~Hz}), 7.19(1 \mathrm{H}, \mathrm{d}, J=1.7 \mathrm{~Hz}), 7.24-7.27(2 \mathrm{H}, \mathrm{m}), 7.35-7.38(3 \mathrm{H}, \mathrm{m})$, $8.57(1 \mathrm{H}, \mathrm{br}), 9.47(1 \mathrm{H}, \mathrm{s}), 9.69(1 \mathrm{H}, \mathrm{s}) \mathrm{ppm}$.

$\underline{\text { 1(5-Formyl-3',4'-dimethyl-2-pyrrolylmethyl)imidazole-4-carbaldehyde }}(\mathbf{6 3})$

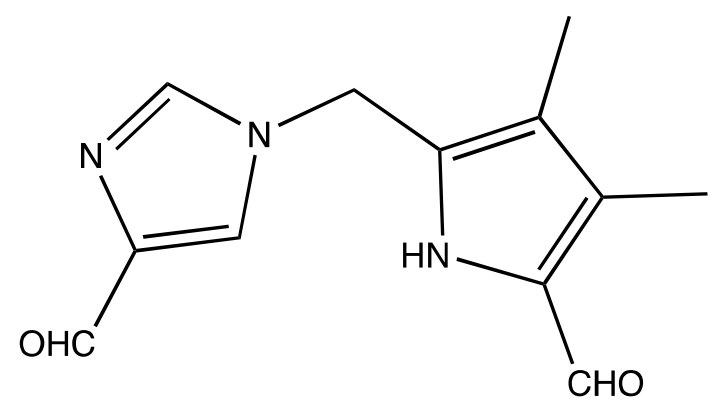

Sodium hydride (60\% in mineral oil, $26 \mathrm{mg}$ ) was added to a solution of formyl imidazole ( $87 \mathrm{mg}, 0.905 \mathrm{mmol})$ in THF $(16.3 \mathrm{ml})$ and the mixture was stirred for $30 \mathrm{~min}$ at room temperature. To the mixture, a solution of acetoxymethylpyrrole aldehyde (92 $\mathrm{mg}, 0.471 \mathrm{mmol})$ in THF $(8.2 \mathrm{ml})$ was added dropwise over $10 \mathrm{~min}$, and the mixture was stirred for $18 \mathrm{~h}$ at $30^{\circ} \mathrm{C}$. The mixture was then diluted with ether and washed with water. The aqueous phase was back extracted with ether (x3) and the combined organic layers dried over sodium sulfate. After suction filtration, the solvent was evaporated down under reduced pressure. Recrystallization from ethanol gave the dipyrrylmethane (109 mg, $0.471 \mathrm{mmol}, 60 \%)$ as a brown solid,mp $198-200{ }^{\circ} \mathrm{C} ;{ }^{1} \mathrm{H}$ NMR $(500 \mathrm{~Hz}$, DMSO-d $) \delta 1.98$ $(3 \mathrm{H}, \mathrm{s}), 2.20(3 \mathrm{H}, \mathrm{s}), 5.23(2 \mathrm{H}, \mathrm{s}), 7.92(1 \mathrm{H}, \mathrm{s}), 8.01(1 \mathrm{H}, \mathrm{s}), 9.58(1 \mathrm{H}, \mathrm{s}), 9.69(1 \mathrm{H}, \mathrm{s})$, $11.83(1 \mathrm{H}, \mathrm{br}) \mathrm{ppm}$. 


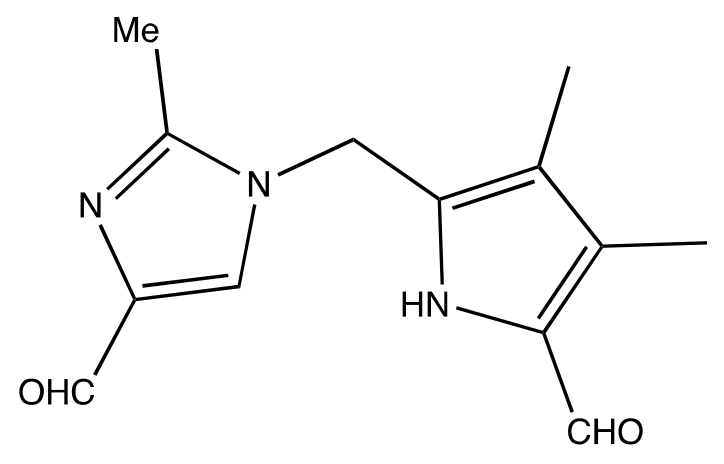

Sodium hydride (60\% in mineral oil, $48 \mathrm{mg}$ ) was added to a solution of 4(5)formyl-2-methylimidazole (104 mg, $0.944 \mathrm{mmol})$ in THF $(21.5 \mathrm{ml})$ and the mixture was stirred for $30 \mathrm{~min}$ at room temperature. To the mixture, a solution of acetoxymethylpyrrole aldehyde 39(122 mg, $0.624 \mathrm{mmol})$ in THF (10.72 ml) was added dropwise over $10 \mathrm{~min}$, and the mixture was stirred for $18 \mathrm{~h}$ at $30^{\circ} \mathrm{C}$. The mixture was then diluted with ether and washed with water. The aqueous phase was back extracted with ether $(\mathrm{x} 3)$ and the combined organic layers dried over sodium sulfate. After suction filtration, the solvent was evaporated down under reduced pressure. Recrystallization from ethanol gave the dipyrrylmethane $(78 \mathrm{mg}, 0.320 \mathrm{mmol}, 60 \%)$ as a brown solid,mp 200-202 ${ }^{\circ} \mathrm{C} ;{ }^{1} \mathrm{H}$ NMR (500 Hz, DMSO-d 6 ) $\delta 1.90$ (3H, s), 2.20 (3H, s), 2.37 (3H, s), 5.05 $(2 \mathrm{H}, \mathrm{s}), 7.20(1 \mathrm{H}, \mathrm{s}), 7.64(1 \mathrm{H}, \mathrm{s}), 9.43(1 \mathrm{H}, \mathrm{s}), 9.60(1 \mathrm{H}, \mathrm{s}), 11.15(1 \mathrm{H}, \mathrm{br}) \mathrm{ppm} .{ }^{13} \mathrm{C}$ NMR (DMSO-d $): \delta 8.50,8.91,13.38,41.73,120.25,126.62,129.54,130.50,140.06$, $147.23,177.96,185.25$. 


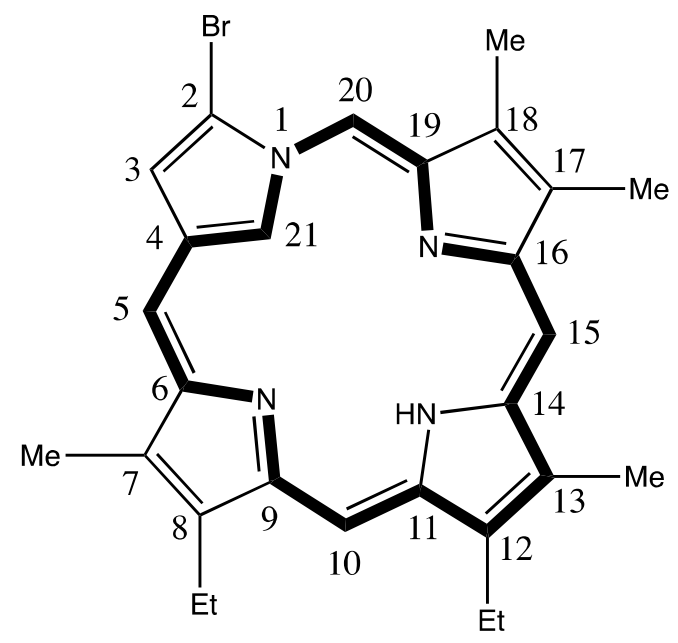

$p$-Toluenesulfonic acid $(56 \mathrm{mg})$ in methanol $(6 \mathrm{~mL})$ was added dropwise to a stirred mixture of dialdehyde37a (31 mg, $0.10 \mathrm{mmol})$ and dipyrrylmethanedicarboxylic acid $\mathbf{3 8}$ (32 $\mathrm{mg}, 0.10 \mathrm{mmol})$ in dichloromethane $(50 \mathrm{~mL})$ and methanol $(6 \mathrm{~mL})$. The resulting mixture was allowed to stir for $16 \mathrm{~h}$ at room temperature. The solution was shaken with a $0.2 \%$ aqueous ferric chloride solution for $1 \mathrm{~h}$ to oxidize the phlorin intermediate. The organic phase was separated and the aqueous solution back extracted with dichloromethane. The combined organic solutions were washed with water and 5\% aqueous sodium bicarbonate solution, and the solvent was removed under reduced pressure. The residue was purified by column chromatography on grade 3 alumina 
eluting with hexanes and dichloromethane (3:1). The neo-confused porphyrin was collected as a pink-purple fraction. Recrystallization from chloroform-hexane gave the neo-confused porphyrin 36a (20.4 $\mathrm{mg}, 0.040 \mathrm{mmol}, 45 \%)$ as a purple powder, $\mathrm{mp}>300$ ${ }^{\circ} \mathrm{C}$. UV-vis $\left(1 \% \mathrm{Et}_{3} \mathrm{~N}-\mathrm{CH}_{2} \mathrm{Cl}_{2}\right): \square \max (\log \square) 338$ (sh, 4.53), 392 (4.81), 508 (3.82), 542 (4.03), 564 (3.74), 613 (3.66), $682 \mathrm{~nm}(3.75)$; UV-vis (2\% TFA- $\left.\mathrm{CH}_{2} \mathrm{Cl}_{2}\right): \square \max (\log \square)$ 377 (4.74), 403 (4.75), 533 (3.73), 576 (3,78), $664 \mathrm{~nm}(3.86) .{ }^{1} \mathrm{H}$ NMR (500 Hz, $\left.\mathrm{CDCl}_{3}\right)$ $\delta 1.25(1 \mathrm{H}, \mathrm{s}), 1.60(3 \mathrm{H}, \mathrm{t}, J=7.8 \mathrm{~Hz}), 1.66(3 \mathrm{H}, \mathrm{t}, J=7.8 \mathrm{~Hz}), 2.17(1 \mathrm{H}, \mathrm{s}), 2.97(3 \mathrm{H}, \mathrm{s})$, $3.00(3 \mathrm{H}, \mathrm{s}), 3.02(3 \mathrm{H}, \mathrm{s}), 3.14(3 \mathrm{H}, \mathrm{s}), 3.47(2 \mathrm{H}, \mathrm{q}, J=7.8 \mathrm{~Hz}), 3.64(2 \mathrm{H}, \mathrm{q}, J=7.8 \mathrm{~Hz})$, 7.91(1H, d, $J=1.6 \mathrm{~Hz}), 8.46(1 \mathrm{H}, \mathrm{s}), 8.54(1 \mathrm{H}, \mathrm{s}), 8.90(1 \mathrm{H}, \mathrm{s}), 9.46(1 \mathrm{H}, \mathrm{s}) \mathrm{ppm} .{ }^{1} \mathrm{H}$ NMR (dication36a ${ }_{2}^{2+}, 500 \mathrm{MHz}$, TFA-CDCl 3$) \delta-2.28(1 \mathrm{H}, \mathrm{s}), 1.47(3 \mathrm{H}, \mathrm{t}, J=7.9 \mathrm{~Hz})$, $1.52(3 \mathrm{H}, \mathrm{t}, J=7.9 \mathrm{~Hz}), 3.08(3 \mathrm{H}, \mathrm{s}), 3.12(3 \mathrm{H}, \mathrm{s}), 3.15(3 \mathrm{H}, \mathrm{s}), 3.20(3 \mathrm{H}, \mathrm{s}), 3.52-3.60$ (4H, overlapping quartets), $7.68(1 \mathrm{H}, \mathrm{s}), 9.00(1 \mathrm{H}, \mathrm{s}), 9.08(1 \mathrm{H}, \mathrm{s}), 9.64(1 \mathrm{H}, \mathrm{s}), 10.03$ $(1 \mathrm{H}, \mathrm{s}) \mathrm{ppm} .{ }^{13} \mathrm{C}$ NMR $\left(500 \mathrm{~Hz}, \mathrm{CDCl}_{3}\right) \delta 10.82,16.48,16.65,19.14,93.29,93.90$, $108.91,110.16,112.80,118.57,119.55,122.70,134.80,135.44,140.04,140.78,141.61$, 141.74, 143.10, $161.00 \mathrm{ppm} .{ }^{13} \mathrm{C}$ NMR $\left(500 \mathrm{~Hz}, \mathrm{TFA}-\mathrm{CDCl}_{3}\right) \delta 10.76,11.04,11.21$, $11.60,15.49,19.17,19.47,94.43,96.16,108.81,114.44,118.71,126.01,132.83,136.70$, $140.07, \quad 142.20, \quad 142.51, \quad 144.16, \quad 146.12, \quad 147.69, \quad 150.68, \quad 154.45 \quad$ ppm. 


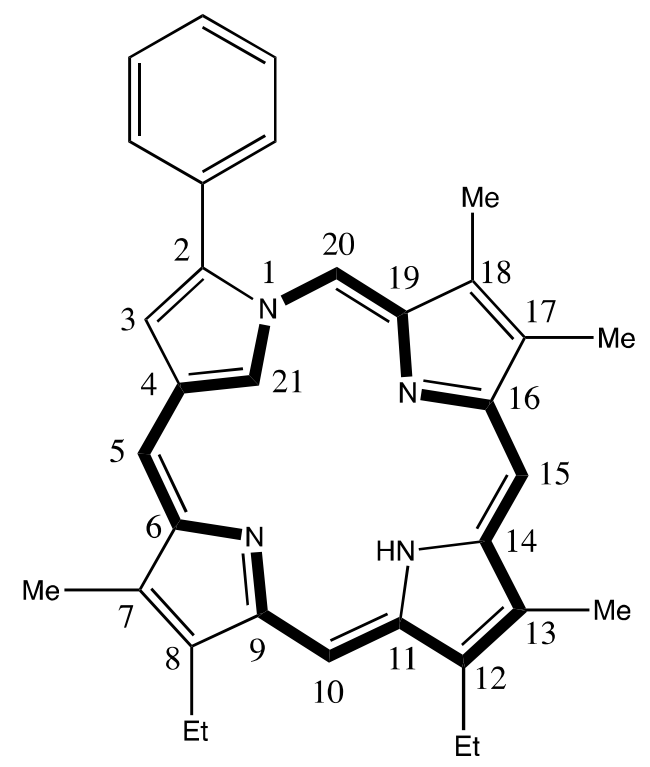

$p$-Toluenesulfonic acid $(56 \mathrm{mg})$ in methanol $(6 \mathrm{~mL})$ was added dropwise to a stirred mixture of dialdehyde 36b (29 mg, $0.946 \mathrm{mmol})$ and dipyrrylmethanedicarboxylic acid $\mathbf{3 8}$ (30 $\mathrm{mg}, 0.942 \mathrm{mmol})$ in dichloromethane $(50 \mathrm{~mL})$ and methanol $(6 \mathrm{~mL})$. The resulting mixture was allowed to stir for $16 \mathrm{~h}$ at room temperature. The solution was stirred with a $0.2 \%$ aqueous ferric chloride solution for $1 \mathrm{~h}$ to oxidize the phlorin intermediate. The organic phase was separated and the aqueous solution back extracted with dichloromethane. The combined organic solutions were washed with water and 5\% aqueous sodium bicarbonate solution, and the solvent was removed under reduced 
pressure. The residue was purified by column chromatography on grade 3 alumina eluting with hexane and dichloromethane (3:1). The neo-confused porphyrin was collected as a pink-purple fraction. Recrystallization from chloroform-hexane gave the neo-confused porphyrin $\mathbf{3 6 b}(19.5 \mathrm{mg}, 0.0391 \mathrm{mmol}, 40 \%)$ as a purple powder, mp $>300^{\circ} \mathrm{C}$. UV-vis $\left(1 \% \mathrm{Et}_{3} \mathrm{~N}-\mathrm{CH}_{2} \mathrm{Cl}_{2}\right): \square \max (\log \square) 344$ (4.49), 396 (4.72), 508 (3.83), 542 (3.99), 602 (3.84), $612 \mathrm{~nm}$ (3.80); UV-vis (2\% TFA- $\left.\mathrm{CH}_{2} \mathrm{Cl}_{2}\right)$ : $\square \max (\log \square) 382$ (4.75), 417 (sh, 4.56), 536 (3.89), 576 (3.89), $677 \mathrm{~nm}(3.82) .{ }^{1} \mathrm{H} \mathrm{NMR}\left(500 \mathrm{~Hz}, \mathrm{CDCl}_{3}\right) \delta$ $1.23(1 \mathrm{H}, \mathrm{s}), 1.61(3 \mathrm{H}, \mathrm{t}, J=7.4 \mathrm{~Hz}), 1.67(3 \mathrm{H}, \mathrm{t}, J=7.4 \mathrm{~Hz}), 2.14(1 \mathrm{H}, \mathrm{br}), 2.86(3 \mathrm{H}, \mathrm{s})$, $2.79(3 \mathrm{H}, \mathrm{s}), 3.04(3 \mathrm{H}, \mathrm{s}), 3.17(3 \mathrm{H}, \mathrm{s}), 3.50(2 \mathrm{H}, \mathrm{q}, J=7.7 \mathrm{~Hz}), 3.66(2 \mathrm{H}, \mathrm{q}, J=7.7 \mathrm{~Hz})$, 7.58-7.63 (1H, m), 7.69-7.73 (2H, m) , 7.93-7.98 (3H, m), $8.54(1 \mathrm{H}, \mathrm{s}), 8.63(1 \mathrm{H}, \mathrm{s}), 9.10$ $(1 \mathrm{H}, \mathrm{s}), 9.40(1 \mathrm{H}, \mathrm{s}) \mathrm{ppm} .{ }^{1} \mathrm{H}$ NMR (dication36b $\left.{ }_{2}{ }^{2+}, 500 \mathrm{MHz}, \mathrm{TFA}-\mathrm{CDCl}_{3}\right) \delta-2.78$ $(1 \mathrm{H}, \mathrm{s}), 1.60(3 \mathrm{H}, \mathrm{t}, J=7.8 \mathrm{~Hz}), 1.65(3 \mathrm{H}, \mathrm{t}, J=7.8 \mathrm{~Hz}), 3.13(3 \mathrm{H}, \mathrm{s}), 3.18(3 \mathrm{H}, \mathrm{s}), 3.27$ $(3 \mathrm{H}, \mathrm{s}), 3.31(3 \mathrm{H}, \mathrm{s}), 3.67-3.75(4 \mathrm{H}, 2$ overlapping quartets), 7.75-7.80 $(5 \mathrm{H}, \mathrm{m}), 7.84$ $(1 \mathrm{H}, \mathrm{s}), 9.22(1 \mathrm{H}, \mathrm{s}), 9.30(1 \mathrm{H}, \mathrm{s}), 9.89(1 \mathrm{H}, \mathrm{s}), 9.96(1 \mathrm{H}, \mathrm{s}) \mathrm{ppm} .{ }^{13} \mathrm{C}$ NMR $(500 \mathrm{MHz}$, $\left.\mathrm{CDCl}_{3}\right): \delta 11.1,16.58,16.91,19.29,92.66,93.76,111.44,114.02,117.62,119.90$, $122.69,128.33,128.90,131.32,132.25,133.59,135.20,139.23,139.73,140.52,140.99$, 141.47, 142.25, 143.08, 144.01, 153.86, 159.92, 161.33 ppm. ${ }^{13} \mathrm{C}$ NMR (500 MHz, TFA$\left.\mathrm{CDCl}_{3}\right): \delta 10.68,11.04,11.17,11.44,15.47,19.25,19.50,94.39,95.89,107.95,114.35$, $114.93,119.64,126.14,128.44,129.59,130.40,131.90,132.82,136.61,139.95,141.04$ $142.13,142.54,145.87,146.79,147.37,149.50,153.41 \mathrm{ppm}$. 


\section{$\underline{\text { Neo-confused porphyrin nickel complex } \mathbf{5 3}}$}

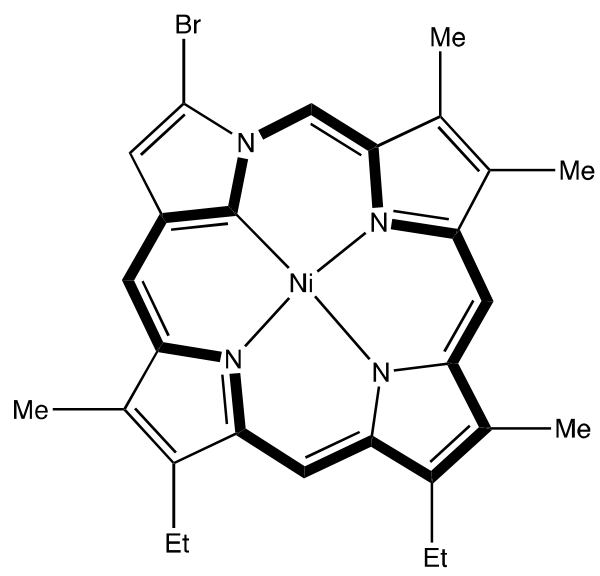

Neo-confused porphyrin 36a $(15.0 \mathrm{mg}, 0.023 \mathrm{mmol})$ was dissolved in pyridine (15 $\mathrm{ml}$ ) along with nickel(II) acetate $(15.0 \mathrm{mg})$ and the mixture was stirred under reflux for 1 h. The mixture was diluted with dichloromethane, washed with water and the aqueous solution back extracted with dichloromethane.The combined organic solutions were evaporated under reduced pressure. The residue was purified by column chromatography on grade 3 alumina eluting with 3:1 hexanes/dichloromethane to give the nickel neoconfused porphyrin $(10.0 \mathrm{mg}, 0.018 \mathrm{mmol}, 60 \%)$ as a brown powder, $\mathrm{mp}>300{ }^{\circ} \mathrm{C}$; UVvis $\left(\mathrm{CH}_{2} \mathrm{Cl}_{2}\right)$ : $\square$ max $(\log \square) 334$ (4.67), 382 (5.08), 435 (sh, 4.49), 524 (4.03), 629 (3.72), $676 \mathrm{~nm}(3.69) .{ }^{1} \mathrm{H} \mathrm{NMR}\left(500 \mathrm{~Hz}, \mathrm{CDCl}_{3}\right) \delta 1.60(6 \mathrm{H}, 2$ overlapping triplets), $2.91(3 \mathrm{H}, \mathrm{s})$, 
$2.93(3 \mathrm{H}, \mathrm{s}), 3.01(3 \mathrm{H}, \mathrm{s}), 3.06(3 \mathrm{H}, \mathrm{s}), 3.57(4 \mathrm{H}, 2$ overlapping quartets), $7.81(1 \mathrm{H}, \mathrm{s})$,

$8.57(1 \mathrm{H}, \mathrm{s}), 8.87(1 \mathrm{H}, \mathrm{s}), 8.98(1 \mathrm{H}, \mathrm{s}), 9.43(1 \mathrm{H}, \mathrm{s}) \mathrm{ppm}$.

\section{$\underline{\text { Neo-confused porphyrin nickel complex } \mathbf{6 2}}$}

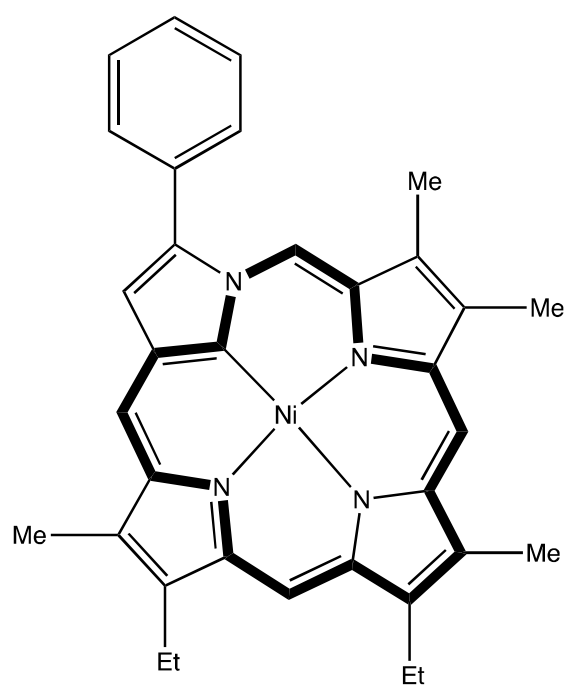

Neo-confused porphyrin $\mathbf{3 6} \mathbf{b}(15.0 \mathrm{mg}, 0.030 \mathrm{mmol})$ was dissolved in acetonitrile $(15 \mathrm{ml})$ along with nickel(II) acetate $(15.0 \mathrm{mg})$ and the mixture was stirred under reflux for $1 \mathrm{~h}$. The mixture was diluted with dichloromethane, washed with water and the aqueous solution was back extracted with dichloromethane.The combined dichloromethane solutions was evaporated under reduced pressure, and the residue purified by column chromatography on grade 3 alumina eluting with $3: 1$ hexanes/dichloromethane to give the nickel neo-confused porphyrin $(11 \mathrm{mg}, 0.012 \mathrm{mmol}$, $60 \%)$ as a brown powder,mp $>300{ }^{\circ} \mathrm{C} ;{ }^{1} \mathrm{H}$ NMR $\left(500 \mathrm{~Hz}, \mathrm{CDCl}_{3}\right) \delta 1.60(6 \mathrm{H}, 2$ overlapping triplets), $2.94(3 \mathrm{H}, \mathrm{s}), 3.06(3 \mathrm{H}, \mathrm{s}), 3.14(3 \mathrm{H}, \mathrm{s}), 3.16(3 \mathrm{H}, \mathrm{s}), 3.64(4 \mathrm{H}, \mathrm{q}, J$ 
$=7.6 \mathrm{~Hz}), 7.64(1 \mathrm{H}, \mathrm{t}, J=7.6 \mathrm{~Hz}), 7.73(2 \mathrm{H}, \mathrm{t}, J=7.5 \mathrm{~Hz}), 7.96(1 \mathrm{H}, \mathrm{d}, J=7.6 \mathrm{~Hz}), 8.08$ $(1 \mathrm{H}, \mathrm{s}), 8.88(1 \mathrm{H}, \mathrm{s}), 9.06(1 \mathrm{H}, \mathrm{s}), 9.30(1 \mathrm{H}, \mathrm{s}), 9.58(1 \mathrm{H}, \mathrm{s}) \mathrm{ppm}$.

$\underline{\text { Neo-confused porphyrin palladium complex } 54}$

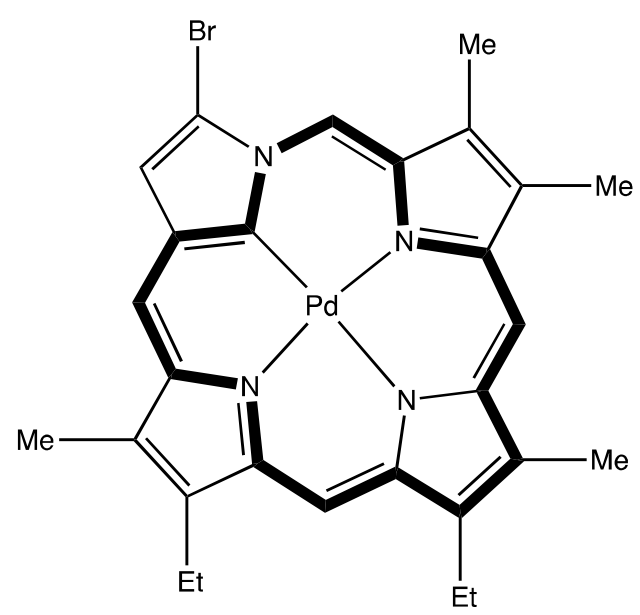

Neo-confused porphyrin 36a $(10.0 \mathrm{mg}, 0.019 \mathrm{mmol})$ was dissolved in acetonitrile $(10 \mathrm{ml})$ along with palladium(II) acetate $(10.0 \mathrm{mg})$ under reflux conditions for $1 \mathrm{~h}$. The mixture was diluted with dichloromethane, and washed with water. The organic solution was evaporated under reduced pressure and the residue was purified by column chromatography on grade 3 alumina eluting with 3:1 hexanes/dichloromethane to give the palladium neo-confused porphyrin $(8.0 \mathrm{mg}, 0.013 \mathrm{mmol}, 80 \%)$ as a green solid,mp $>300{ }^{\circ} \mathrm{C}$; UV-vis $\left(\mathrm{CH}_{2} \mathrm{Cl}_{2}\right): \square \max (\log \square) 370$ (4.42), 500 (3.73), 531 (3.72), 602 (3.50), 646 (3.45), $856 \mathrm{~nm}(3.71) .{ }^{1} \mathrm{H} \mathrm{NMR}\left(500 \mathrm{~Hz}, \mathrm{CDCl}_{3}\right) \delta 1.60$ (6H, 2 overlapping triplets), 2.91(3H, s), $2.93(3 \mathrm{H}, \mathrm{s}), 3.01(3 \mathrm{H}, \mathrm{s}), 3.06(3 \mathrm{H}, \mathrm{s}), 3.57(4 \mathrm{H}, 2$ overlapping quartets), $7.81(1 \mathrm{H}, \mathrm{s}), 8.57(1 \mathrm{H}, \mathrm{s}), 8.87(1 \mathrm{H}, \mathrm{s}), 8.98(1 \mathrm{H}, \mathrm{s}), 9.43(1 \mathrm{H}, \mathrm{s}) \mathrm{ppm}$. 


\section{$\underline{\text { Palladium complex of neo-confused porphyrin (61) }}$}

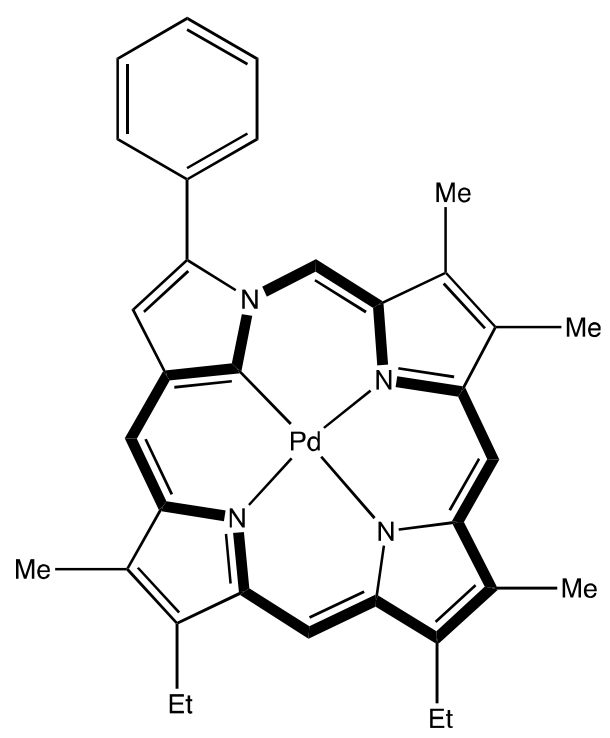

Neo-confused porphyrin 36a $(20.0 \mathrm{mg}, 0.040 \mathrm{mmol})$ was dissolved in acetonitrile $(10 \mathrm{ml})$ along with palladium(II) acetate $(20 \mathrm{mg})$ under reflux conditions for $1 \mathrm{~h}$. The mixture was diluted with dichloromethane, and washed with water. The organic solution was evaporated under reduced pressure and the residue was purified by column chromatography on grade 3 alumina eluting with 3:1 hexanes/dichloromethane to give the palladium neo-confused porphyrin (19 $\mathrm{mg}, 0.0315 \mathrm{mmol}, 78 \%)$ as a green solid,mp $>300{ }^{\circ} \mathrm{C} ;{ }^{1} \mathrm{H}$ NMR $\left(500 \mathrm{~Hz}, \mathrm{CDCl}_{3}\right) \delta 1.02$ (6H, 2 overlapping triplets), 3.03 $(3 \mathrm{H}, \mathrm{s}), 3.15(3 \mathrm{H}, \mathrm{s}), 3.20(3 \mathrm{H}, \mathrm{s}), 3.25(3 \mathrm{H}, \mathrm{s}), 3.65-3.74(4 \mathrm{H}, 2$ overlapping quartets), $7.66(1 \mathrm{H}, \mathrm{t}, J=7.6 \mathrm{~Hz}), 7.76(2 \mathrm{H}, \mathrm{t}, J=7.6 \mathrm{~Hz}), 8.03(2 \mathrm{H}, \mathrm{d}, J=7.6 \mathrm{~Hz}), 8.08$ (1H, s), $9.00(1 \mathrm{H}, \mathrm{s}), 9.16(1 \mathrm{H}, \mathrm{s}), 9.44(1 \mathrm{H}, \mathrm{s}), 9.70(1 \mathrm{H}, \mathrm{s}), 9.89(1 \mathrm{H}, \mathrm{s}) \mathrm{ppm}$. 


\section{REFERENCES}

[1] Milgrom, L. R. The Colours of Life, Oxford University Press: New York; 1997 [2] Porphyrins and Metalloporphyrins. Smith, K. M., ed.; Elsevier Scientific Pub.Co., 1975.

[3] Lash, T. D. J. Porphyrins Phthalocyanines.2011, 15, 1093-1115.

[4] Fischer, H.; Klarer, J. Synthese des Ätioporphyrins, Ätiohämins und Ätiophyllins.Liebigs Ann. Chem. 1926,448, 178; Fischer, H.; Zeile, K. Synthese des Hämatoporphyrins, Protoporphyrins und Hämins.Justus Liebigs Ann. Chem 1929,468, 98.

[5] Wilson B. C. Photodynamic therapy for cancer: principles. Canadian Journal of Gastroenterology.2002, 16, 393-396.

[6] Kadish, K. M.; Smith, K. M.; Guilard, R. The Porphyrin Handbook; Academic Press: New York, 2000; Vol. 1-10.

[7] Adler, A. D.; Longo, F. R.; Shergalis. W. Mechanistic Investigations of Porphyrin Syntheses. I. Preliminary Studies on ms-Tetraphenylporphin.J. Am. Chem Soc. 1964,86, 3145; Adler, A. D.; Longo, F. R.; Sklar, L.; Finarelli, J. D.; Finarelli, M. G.Syntheses of meso-Substituted Porphodimethenes and Porphyrins with Exocyclic Ring Systems.J. Heterocyclic Chem. 1968,5, 669. 
[8] Rothemund, P. A New Porphyrin Synthesis.The Synthesis of Porphin.J. Am. Chem. Soc. 1936,58, 625.

[9] Lindsey, J. S.; Schreiman, I. C.; Hsu, H. C.; Kearney, P. C.; Marguerettaz, A. M. Rothemund and Adler-Longo reactions revisited: synthesis of tetraphenylporphyrins under equilibrium conditions.J. Org. Chem. 1987,52, 827.

[10] Arsenault, G. P.; Bullock, E.; MacDonald, S. F. Pyrromethanes and Porphyrins Therefrom.J. Am. Chem. Soc. 1960,82, 4384.

[11] Sessler, J. L.; Johnson, M. R.; Lynch, V. Synthesis and crystal structure of a novel tripyrrane-containing porphyrinogen-like macrocycle.J. Org. Chem. 1987,52, 4394. [12] Lash, T. D. Oxybenziporphyrin, an aromatic semiquinone porphyrin analog with pathways for $18 \pi$-electron delocalization. Angew. Chem. Int. Ed. Engl.1995, 34, 25332535.

[13] Lash, T. D.; Chaney, S. T.; Richter, D. T. Conjugated macrocycles related to the porphyrins. Part 12. Oxybenzi- and Oxypyriporphyrins: Aromaticity and Conjugation in Highly Modified Porphyrinoid Structures. J. Org. Chem. 1998, 63, 9076-9088. [14] Furuta, H.; Asano, T.; Ogawa, T. N-confused porphyrin - a new isomer of tetraphenylporphyrin.J. Am. Chem. Soc. 1994,116, 767-768.

[15] P. J. Chmielewski, L. Latos-Grazynski, K. Rachlewicz, T. Glowiak, Angew. Chem., Int. Ed. Engl.1994, 33, 779-781.

[16] Furuta, H.; Ishizuka, T.; Osuka, A.; Ogawa, T. J. Am. Chem. Soc. 2000, 122, 57485757. 
[17] Fujino, K.; Hirata, Y.; Kawabe, Y.; Morimoto, T.;Srinivasan, A;Toganoh, M.;

Miseki, A.; Kudo, Y.; Furuta, H. Confusion and Neo-Confusion: Corrole Isomers with an NNNC Core. Angew. Chem. 2011, 123, 6987-6991.

[18] Lash, T. D.; Lammer, A. D.; Ferrence, G. M. Neo-Confused Porphyrins, a New Class of Porphyrin Isomers. Angew. Chem. Int. Ed. 2011, 50, 9718-9721.

[19] Li, R.; Lammer, A.D; Ferrence, G.H; Lash, T. D.Synthesis, Structural Characterization, Aromatic Characteristics, and Metalation of Neo-Confused Porphyrins, a Newly Discovered Class of Porphyrin Isomers. J. Org. Chem.2014, 79, 4078-4093. [20] AbuSalim, D. I.; Lash, T. D. Aromatic Character and relative stability of neoconfused porphyrin tautomers and related compounds.Org. Biomol. Chem. 2013, 11, 8306-8323.

[21] Tardieux, C.; Bolze, F.; Gros, P. C.; Guilard, R. New one-step synthesis of 3,4disubstituted pyrrole-2,5-dicarbaldehyde, Synthesis, 1998, 267-268.

[22] Sonnet, P. E. Synthesis of the trail marker of the taxas leaf-cutting ant, J. Med. Chem. 1971, 15, 97-98.

[23] Vilsmeier, A.; Haack, A. Ber.Dtsch. Chem. Ges. 1927, 60, 119.

[24] Yasuyoshi, A.; Haruyuki, N. Discovery of a Novel Pyrrole Derivative 1-[5-(2Fluorophenyl)-1-(pyridine-3-ylsulfonyl)-1H-pyrrol-3-yl]-NmethylmethanamineFumarate (TAK-438) as a Potassium-Competetive Acid Blocker (PCAB). J. Med. Chem.2012, 55, 4446-4456. 
[25] Madsen, C.; Jensen, A.; Hansen, C. 5-Substituted Imidazole4-acetic Acid Analogues: Synthesis, Modeling, and Pharmacological Characterization of a Series of Novel $\gamma$-Aminobutyric Acid C Receptor Agonists. J. Med. Chem. 2007, 50, 4147-4161. 
APPENDIX

SELECTED NMR SPECTRA 


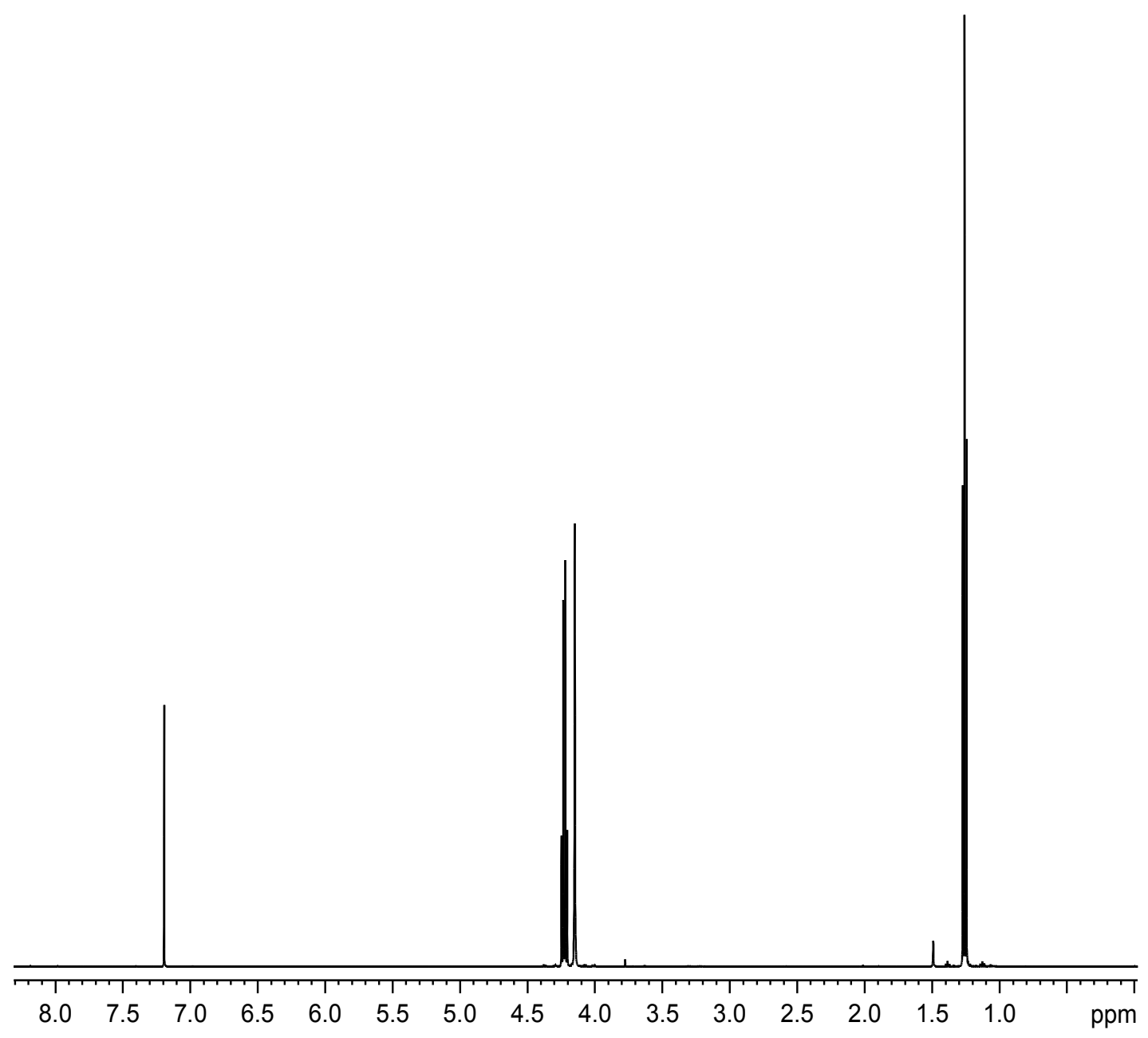

Figure A 1: $500 \mathrm{MHz}$ proton NMR spectrum of ethyl isocyanoacetate42 in $\mathrm{CDCl}_{3}$ 


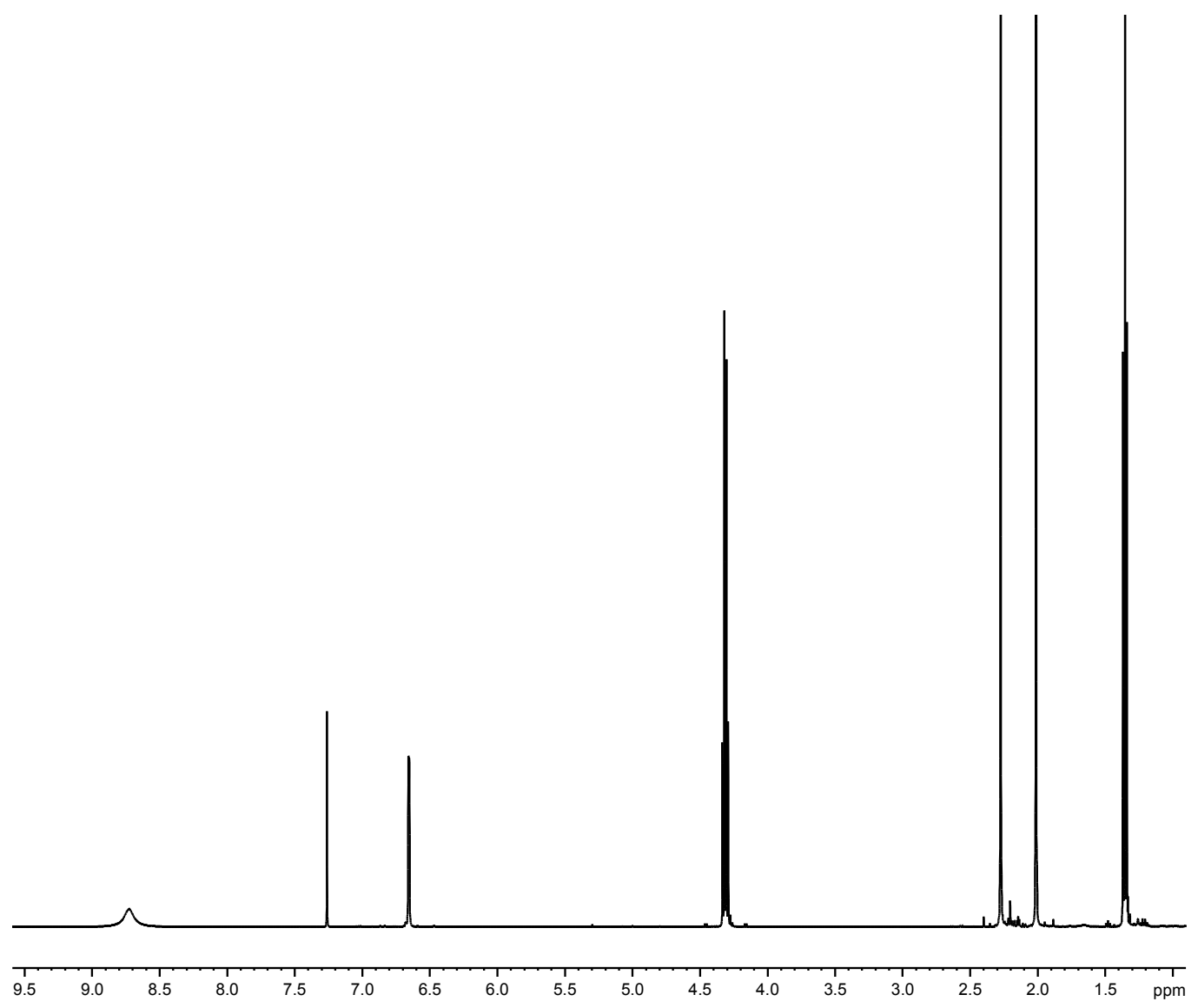

Figure A 2: $500 \mathrm{MHz}$ proton NMR spectrum of ethyl 4-ethyl-3,5-dimethylpyrrole-2carboxylate 44 in $\mathrm{CDCl}_{3}$ 


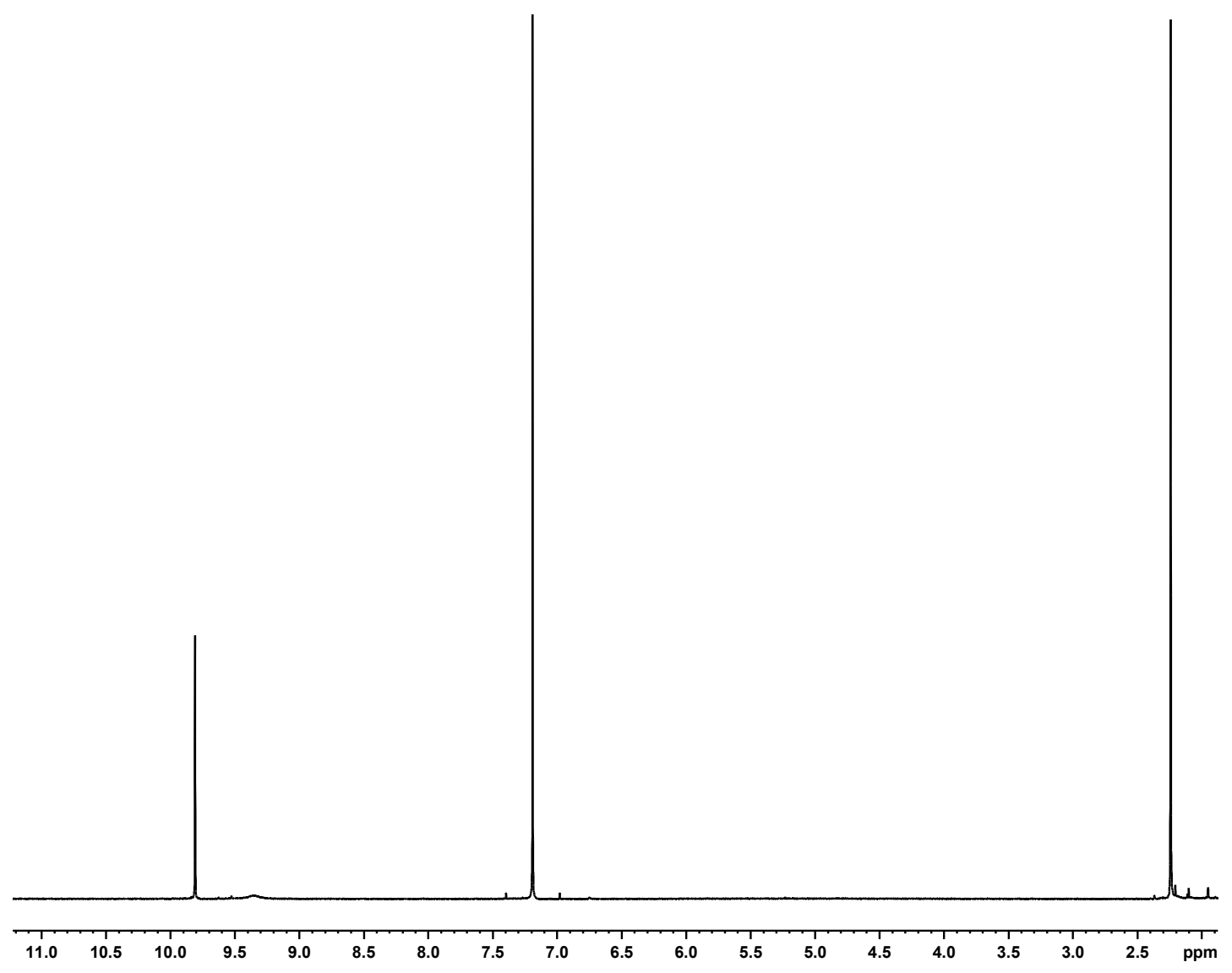

Figure A 3: $500 \mathrm{MHz}$ proton NMR spectrum of 3,4-dimethylpyrrole-2-carboxylic acid in acetone- $\mathrm{d}_{6}$. 


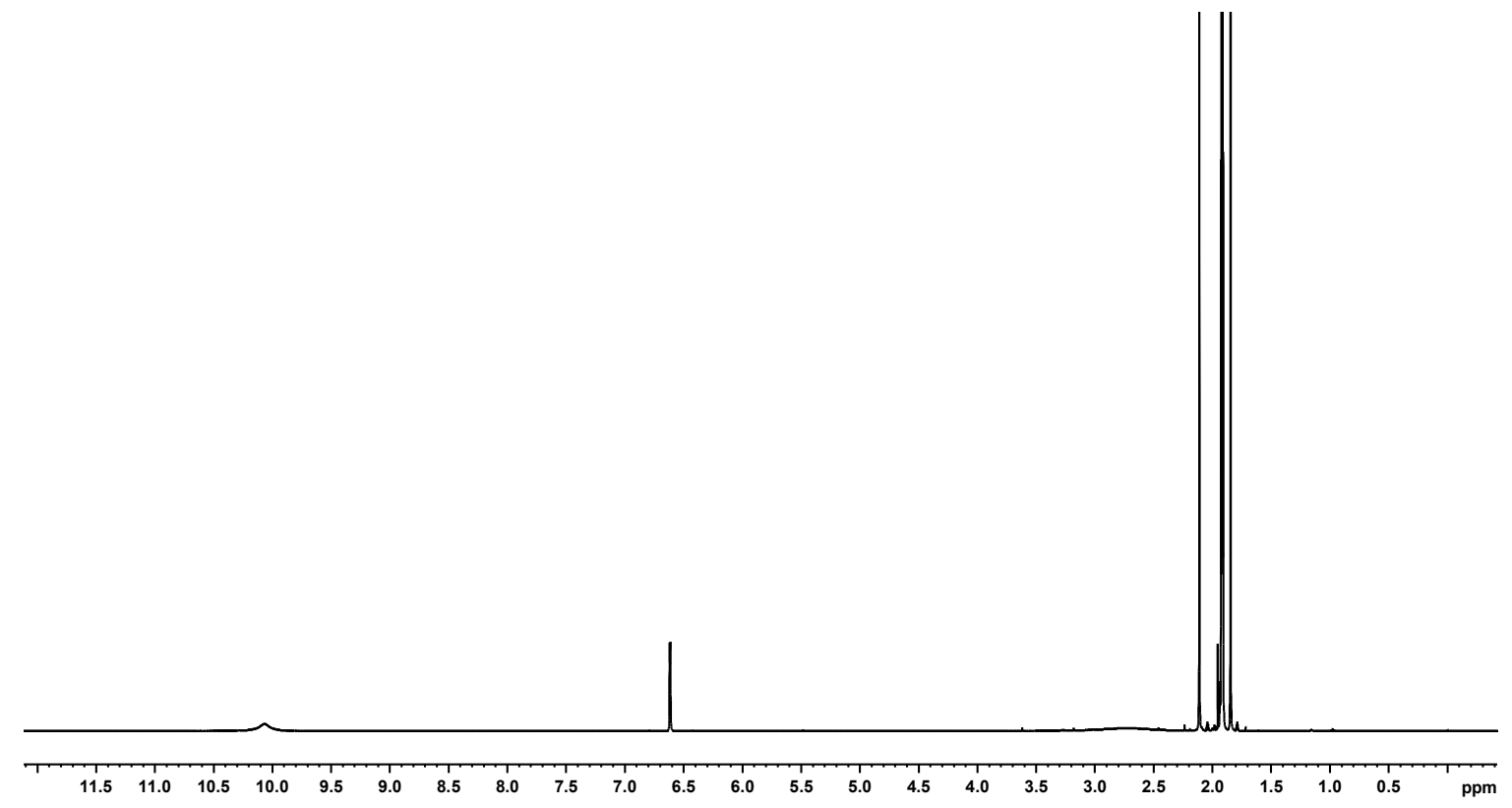

Figure A 4: $500 \mathrm{MHz}$ proton NMR spectrum of 3,4-dimethyl-2,5-pyrroledicarbaldehyde in $\mathrm{CDCl}_{3}$ 


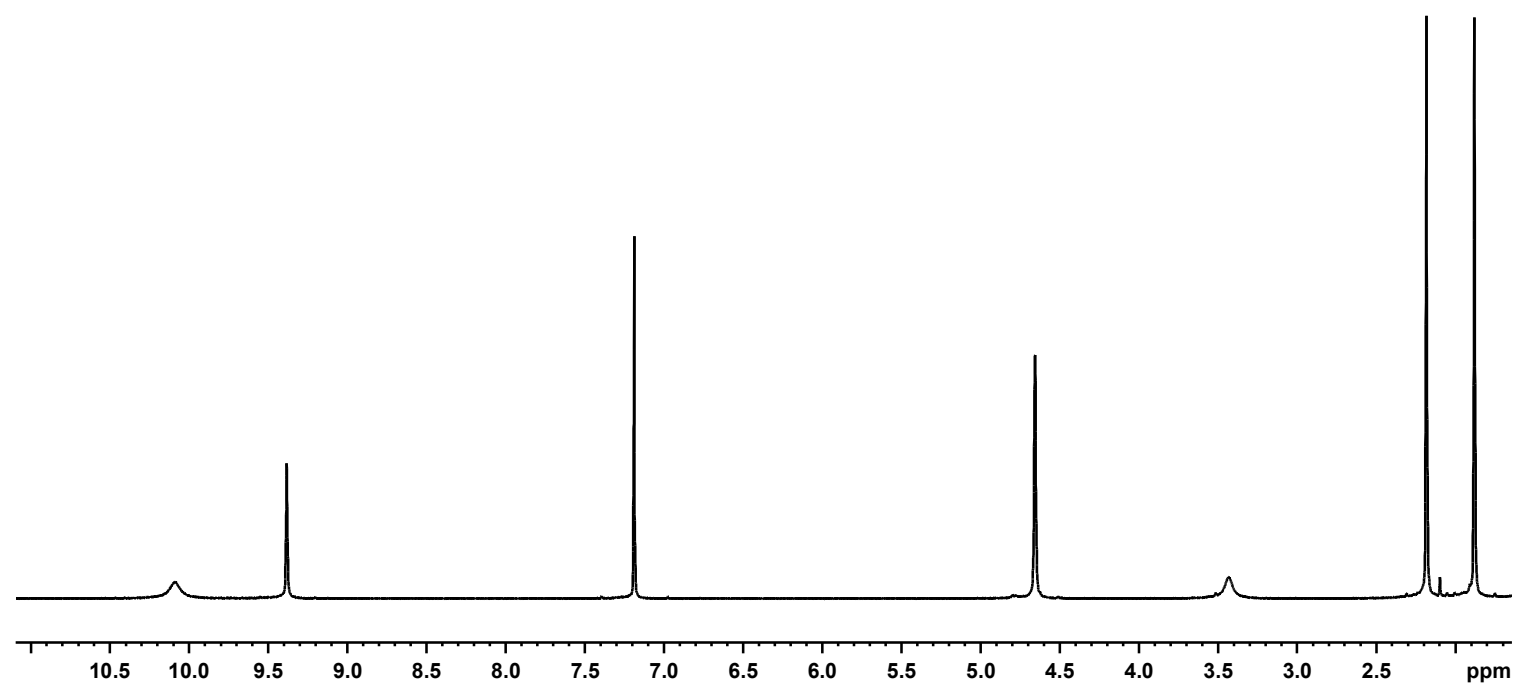

Figure A 5: $500 \mathrm{MHz}$ proton NMR spectrum of 5-hydroxymethyl-3,4dimethylpyrrole-2-carbaldehyde in $\mathrm{CDCl}_{3}$ 


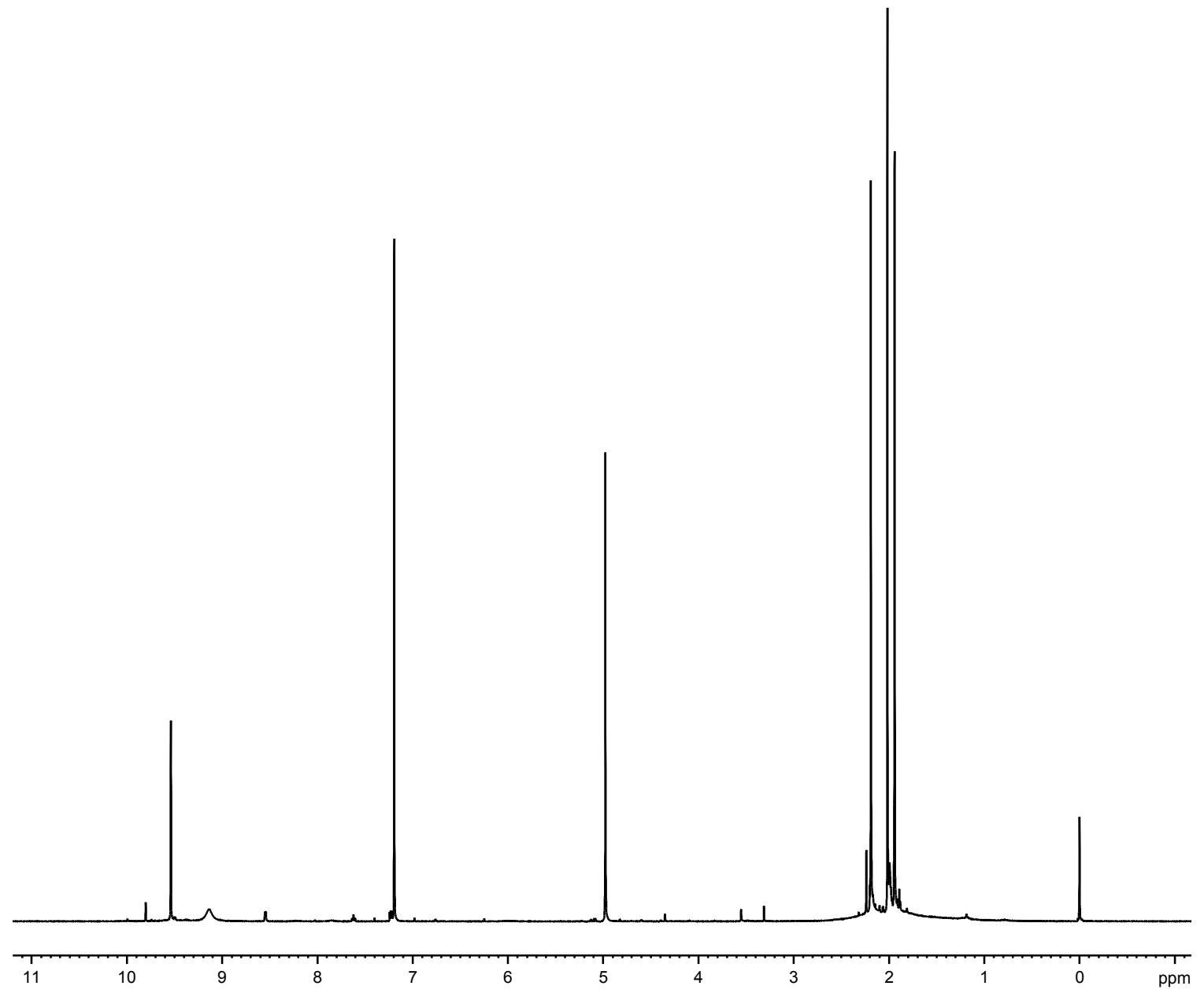

Figure A 6: $500 \mathrm{MHz}$ proton NMR spectrum of 5-acetoxymethyl-3,4-dimethylpyrrole-2carbaldehyde in $\mathrm{CDCl}_{3}$. 


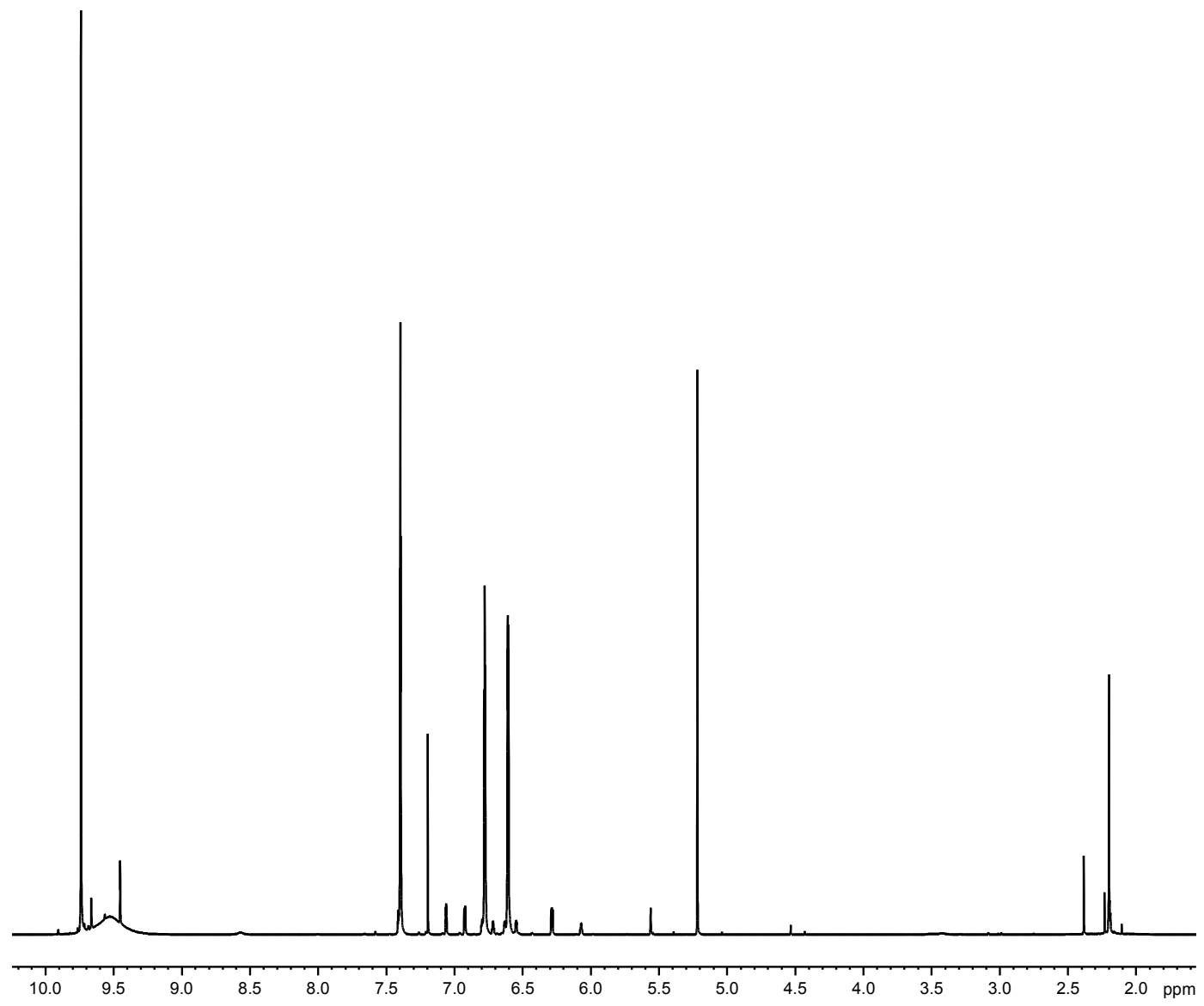

Figure A 7: $500 \mathrm{MHz}$ proton NMR spectrum of pyrrole-3-carboxaldehyde in $\mathrm{CDCl}_{3}$ 


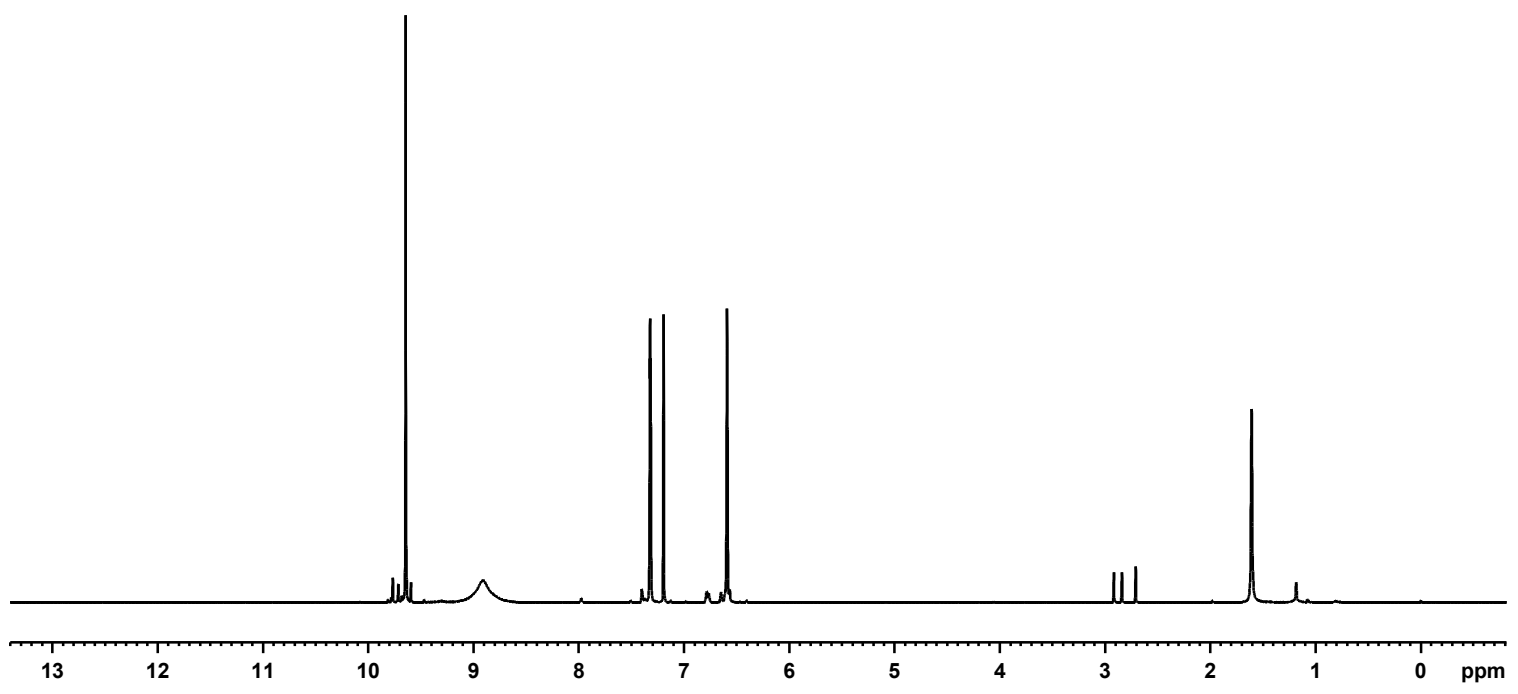

Figure A 8: $500 \mathrm{MHz}$ proton NMR spectrum of 5-bromo-3-pyrrolecarbaldehyde in $\mathrm{CDCl}_{3}$. 


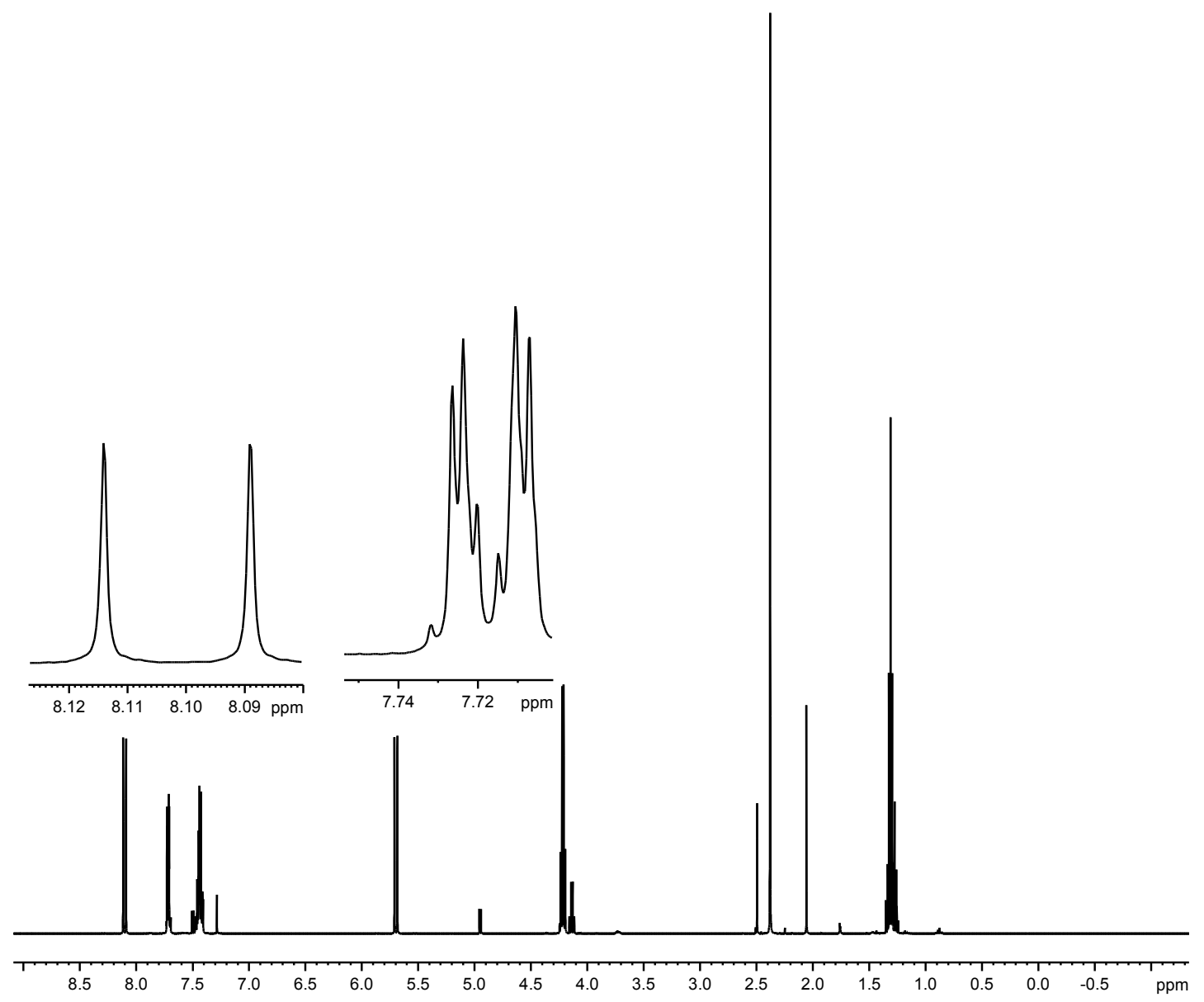

Figure A 9: $500 \mathrm{MHz}$ proton NMR spectrum of acrylate57 in $\mathrm{CDCl}_{3}$ 


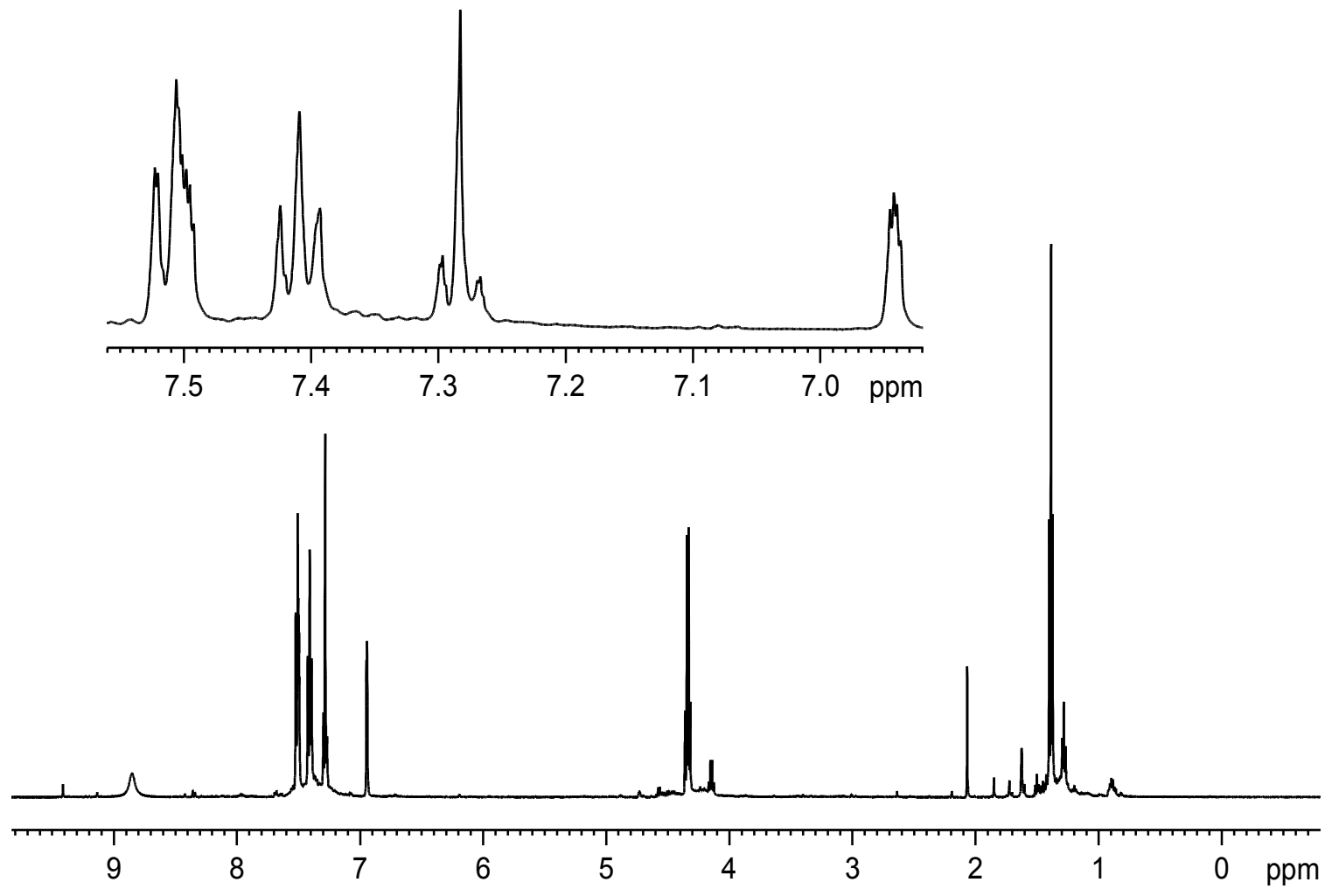

Figure A 10: $500 \mathrm{MHz}$ proton NMR spectrum of ethyl 5-phenyl-3-carboxylate in $\mathrm{CDCl}_{3}$ 


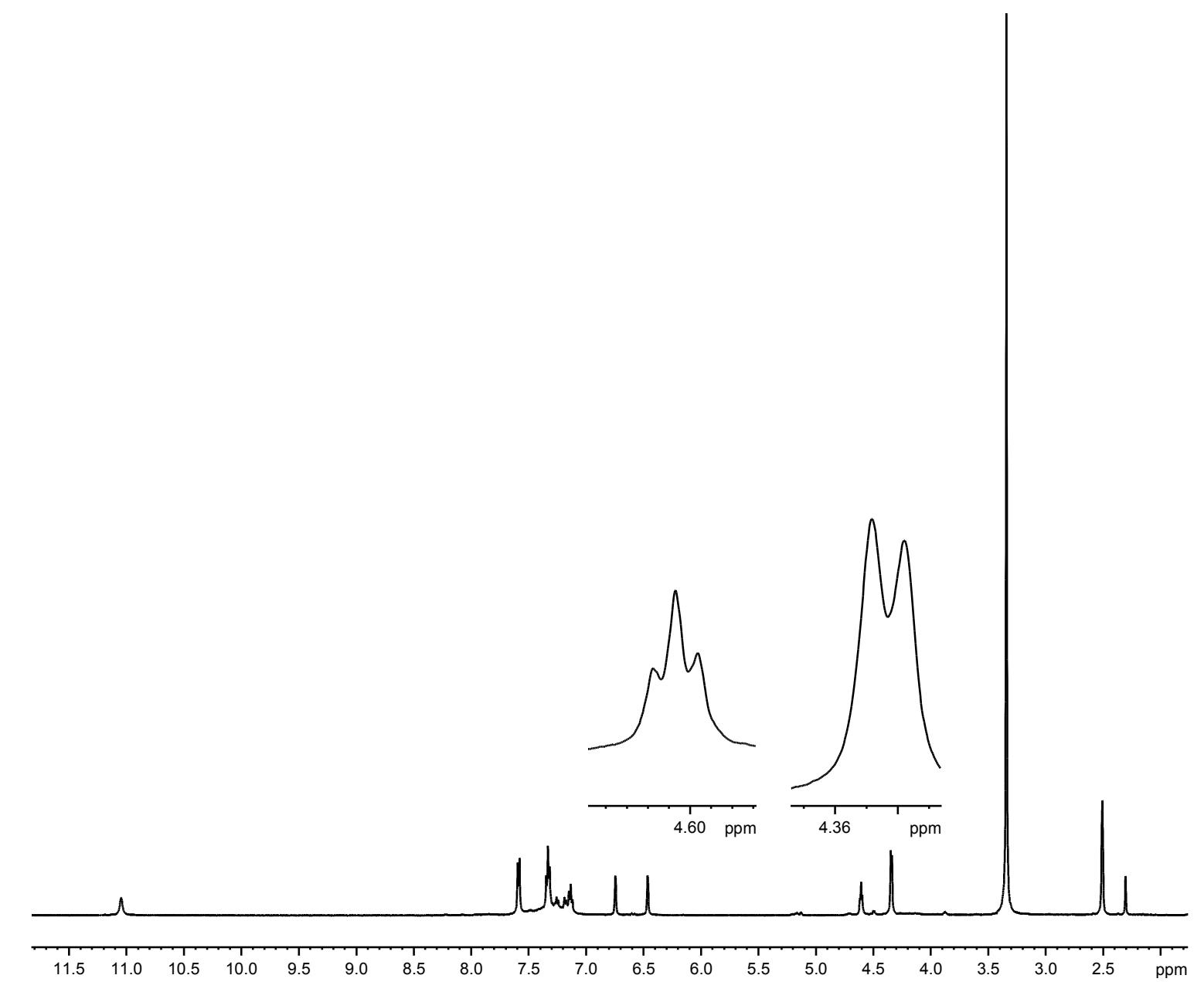

Figure A 11: $500 \mathrm{MHz}$ proton NMR spectrum of phenyl pyrrole carbinol59 in DMSO-d6. 


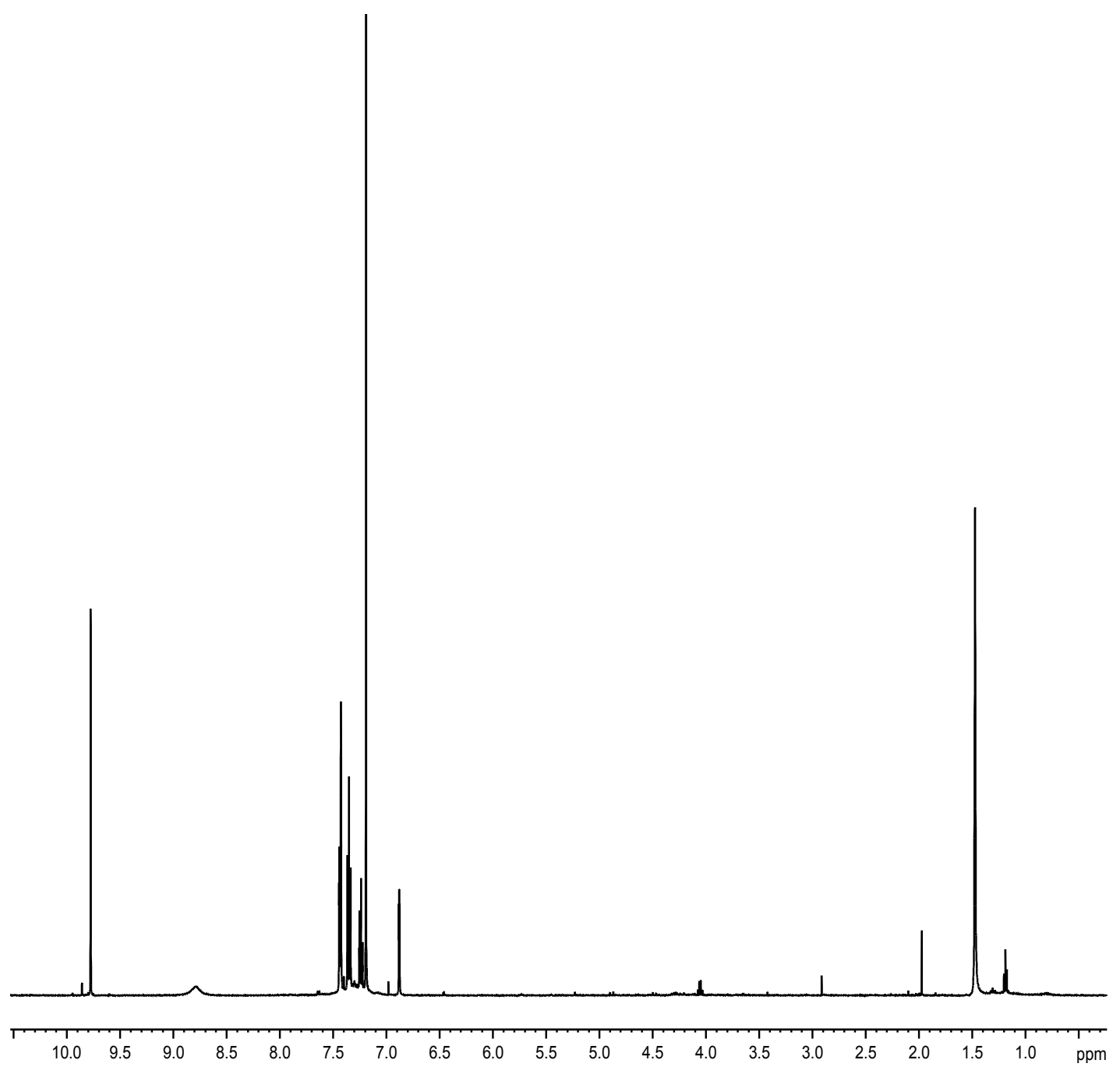

Figure A 12: $500 \mathrm{MHz}$ proton NMR spectrum of phenyl pyrrole aldehyde 40b in $\mathrm{CDCl}_{3}$. 


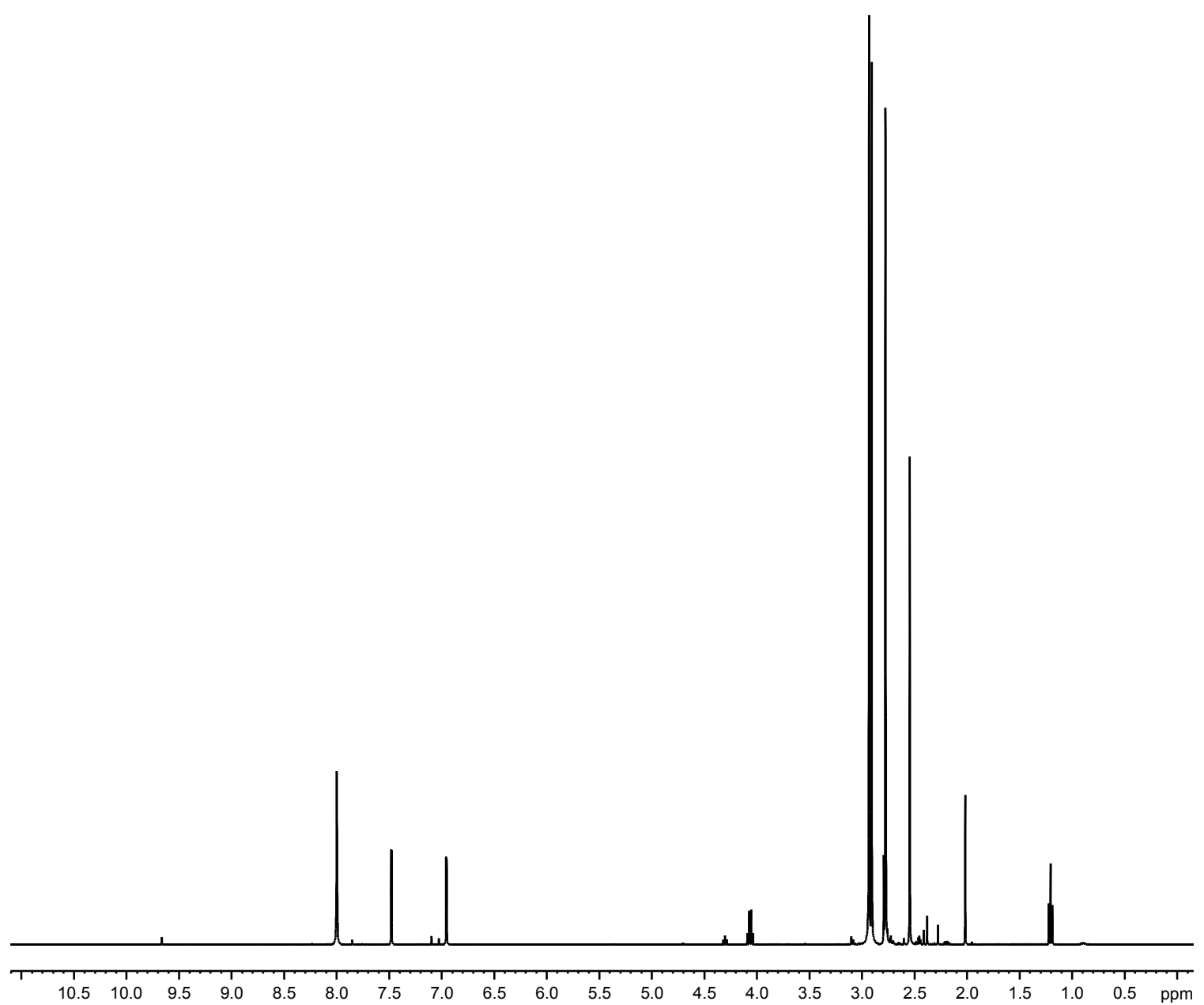

Figure A 13: $500 \mathrm{MHz}$ proton NMR spectrum of 4-formyl-2-methylimidazole in $\mathrm{CDCl}_{3}$. 


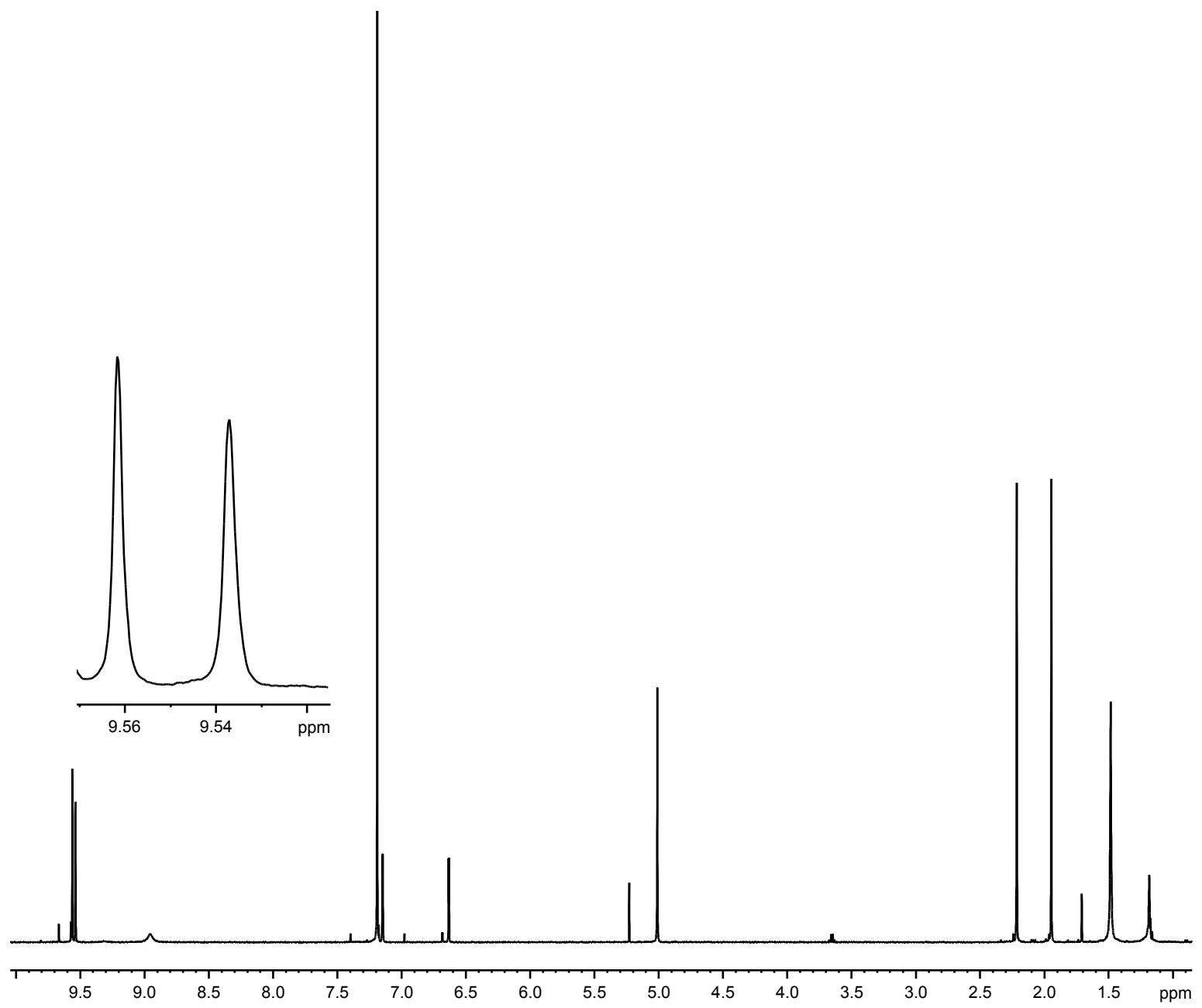

Figure A 14: $500 \mathrm{MHz}$ proton NMR spectrum of bromo neo-confused dipyrrylmethane37a in $\mathrm{CDCl}_{3}$. 


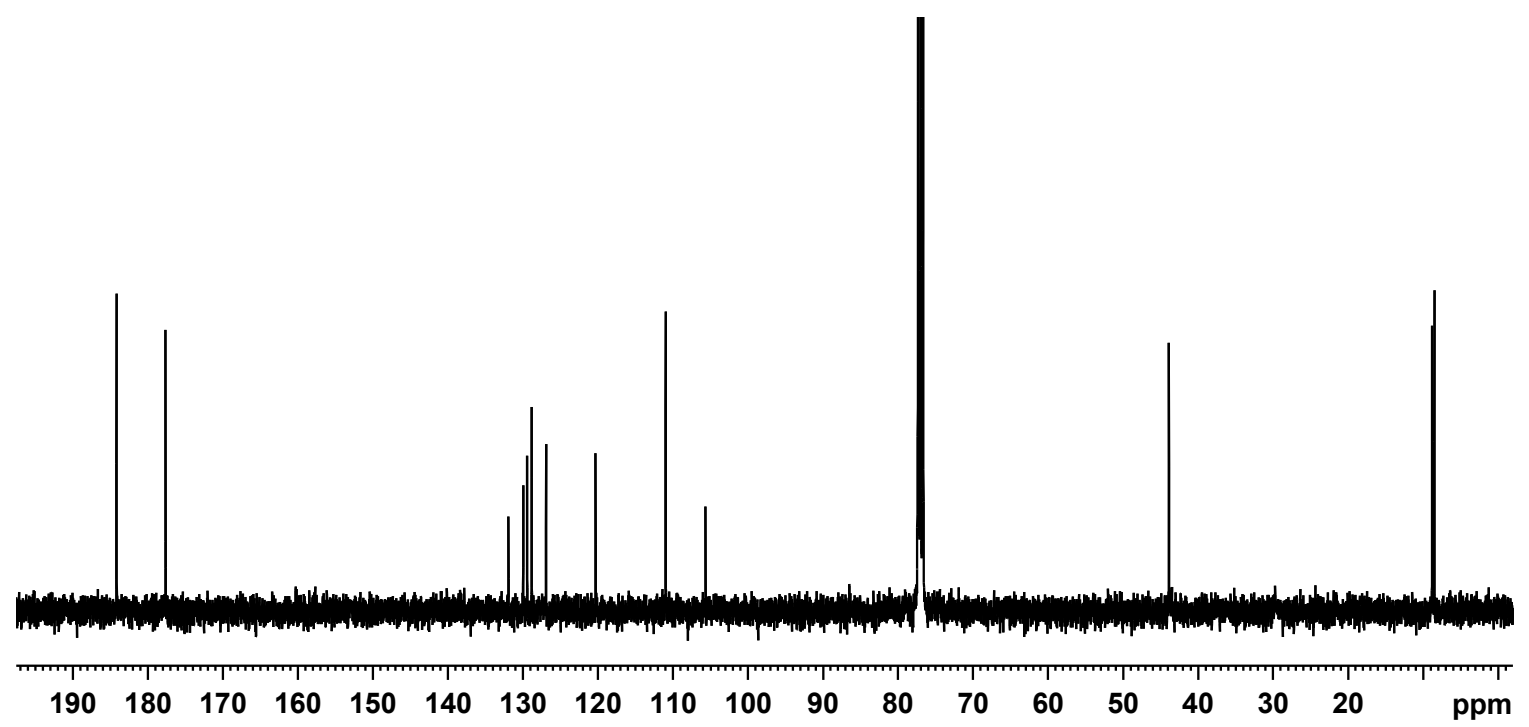

Figure A 15: $125 \mathrm{MHz}$ carbon-13 spectrum of bromo neo-confused dipyrrylmethane37a in $\mathrm{CDCl}_{3}$. 


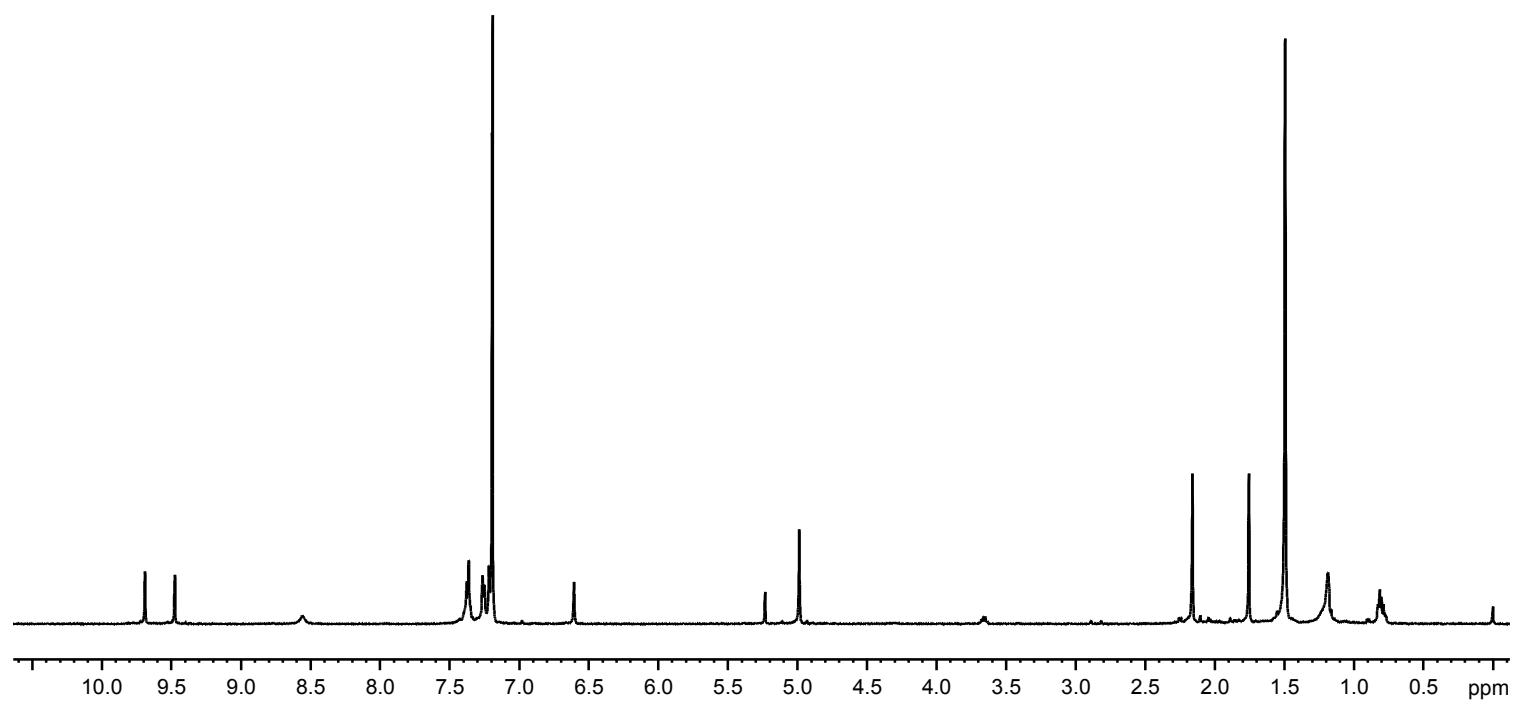

Figure A 16: $500 \mathrm{MHz}$ proton NMR spectrum of phenyl neo-confused dipyrrylmethane37b in $\mathrm{CDCl}_{3}$. 


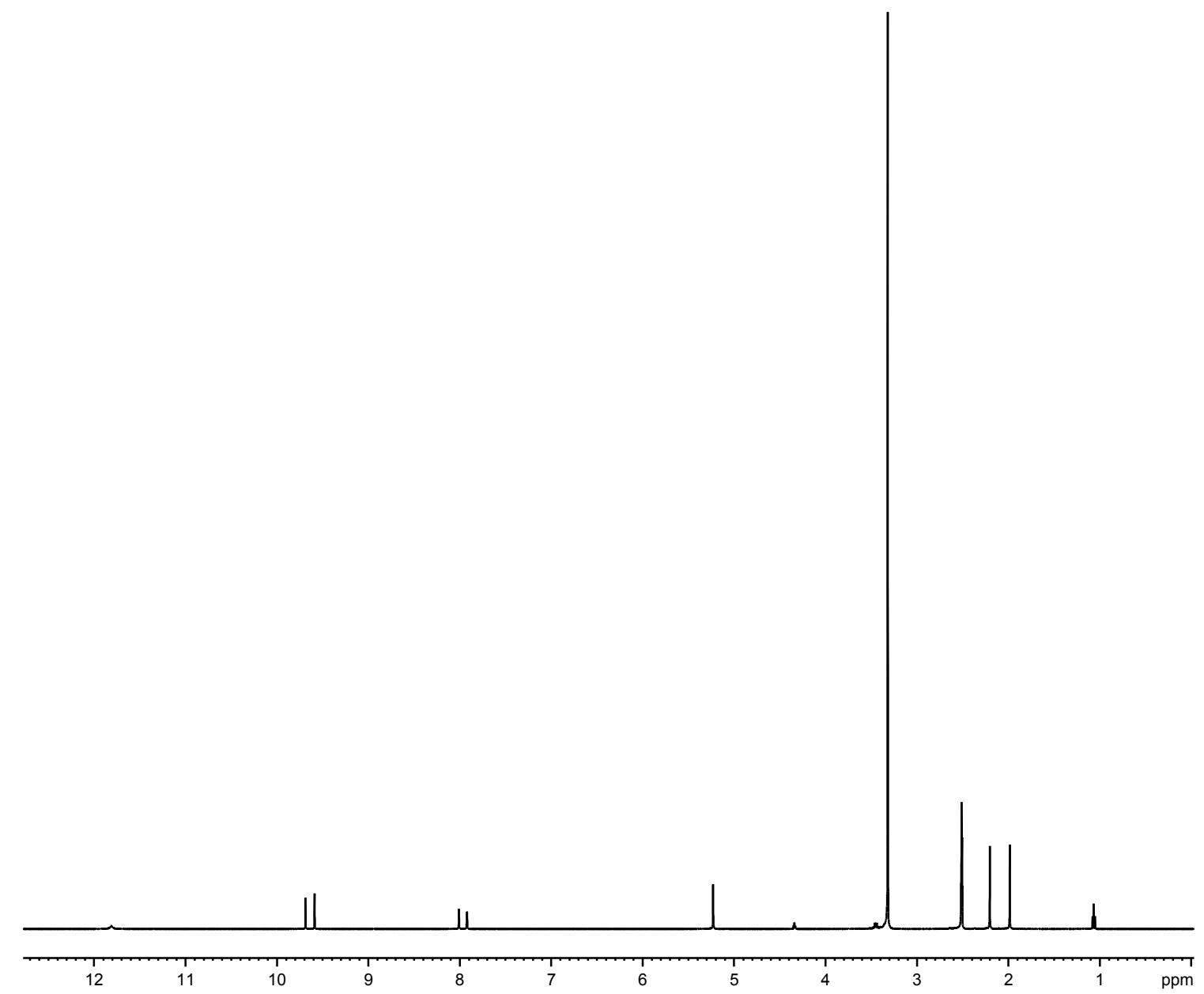

Figure A 17: $500 \mathrm{MHz}$ proton NMR spectrum of formyl imidazole dipyrrylmethane63 in DMSO-d ${ }_{6}$. 


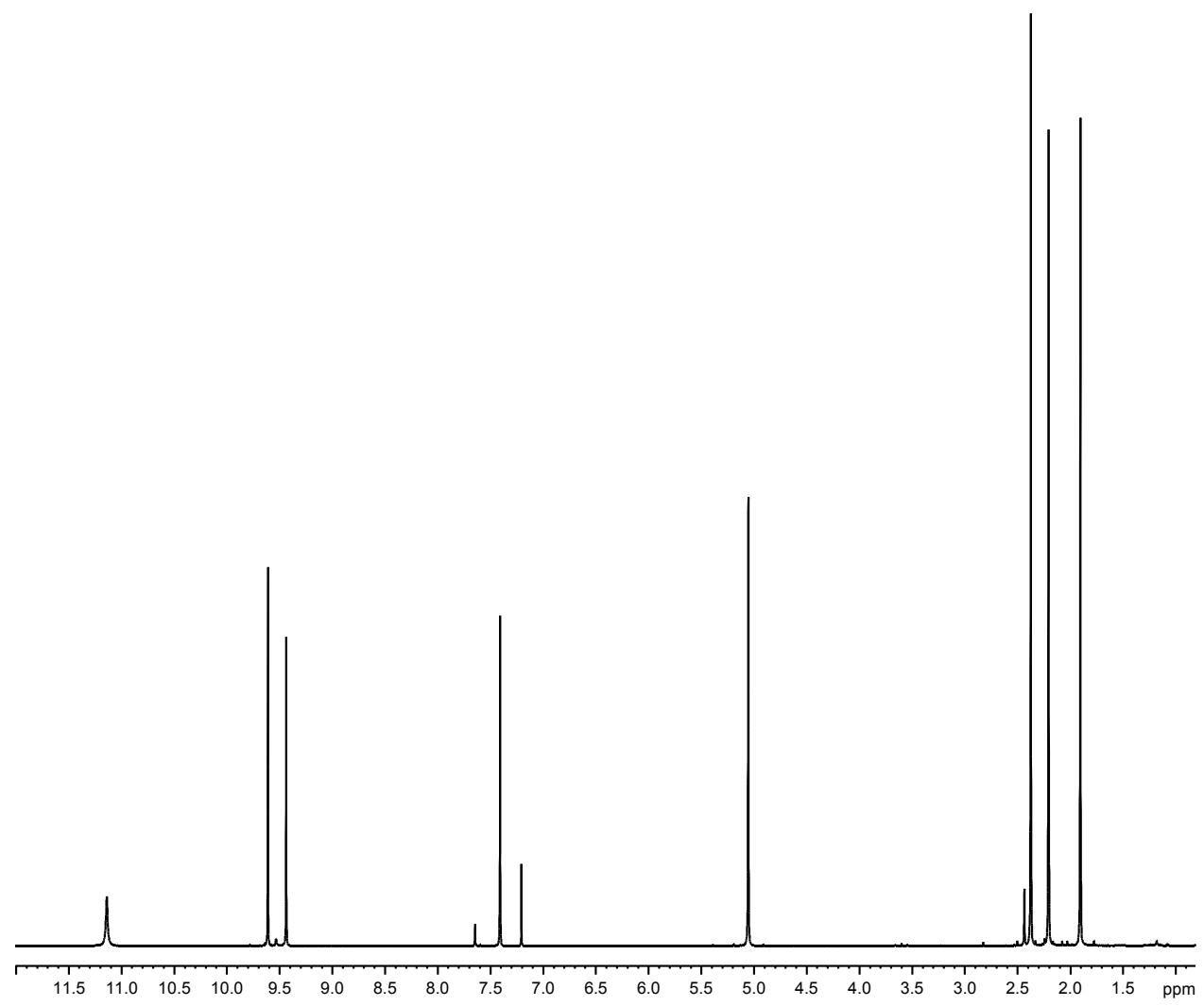

Figure A 18: $500 \mathrm{MHz}$ proton NMR spectrum of methyl formyldipyrrylmethane70 in DMSO- $\mathrm{d}_{6}$. 


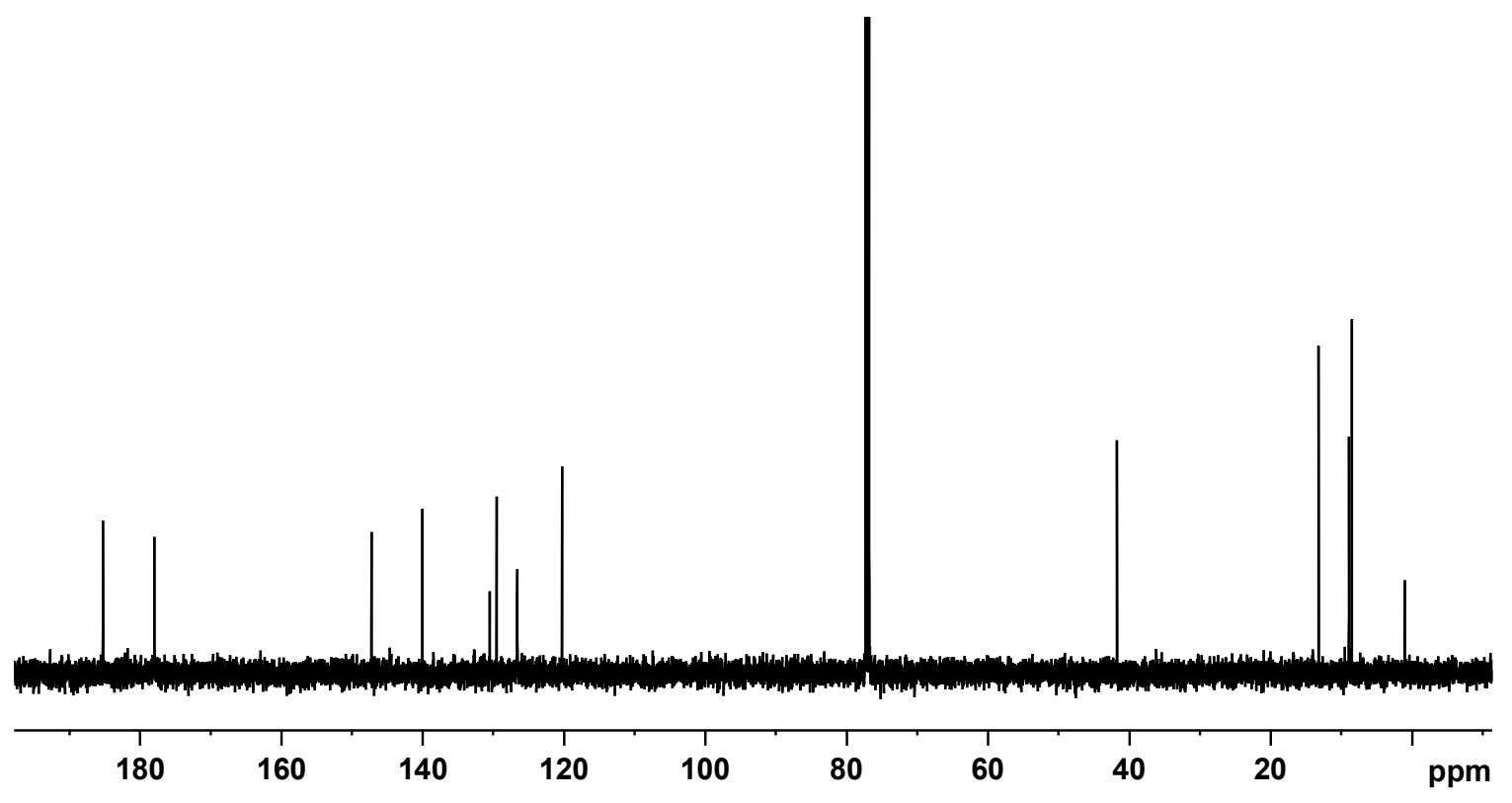

Figure A 19: $125 \mathrm{MHz}$ carbon-13 spectrum of methyl formylimidazoledipyrrylmethane 70 in DMSO- $\mathrm{d}_{6}$. 


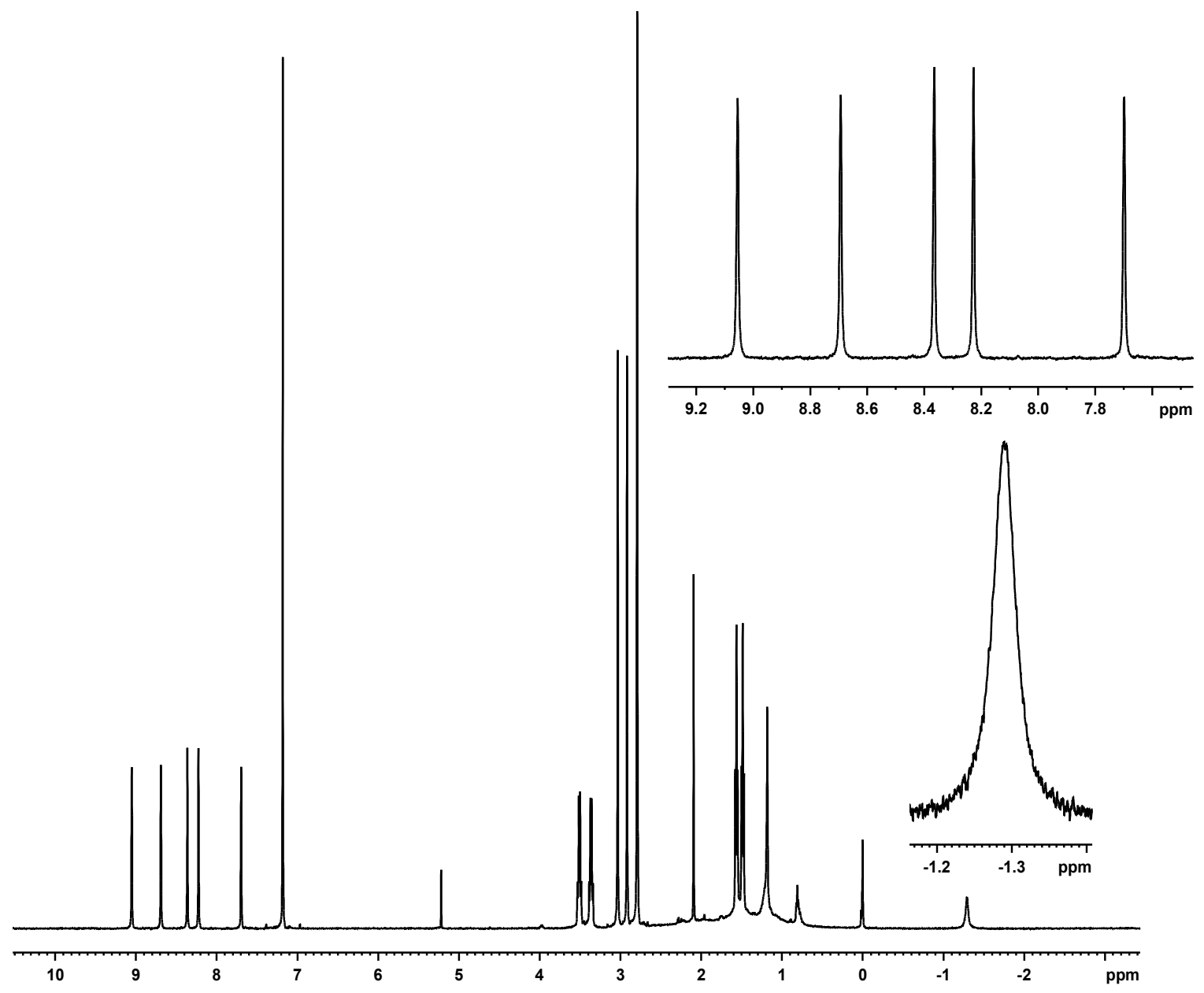

Figure A 20: $500 \mathrm{MHz}$ proton NMR spectrum of neo-confused porphyrin 36a in $\mathrm{CDCl}_{3}$. 


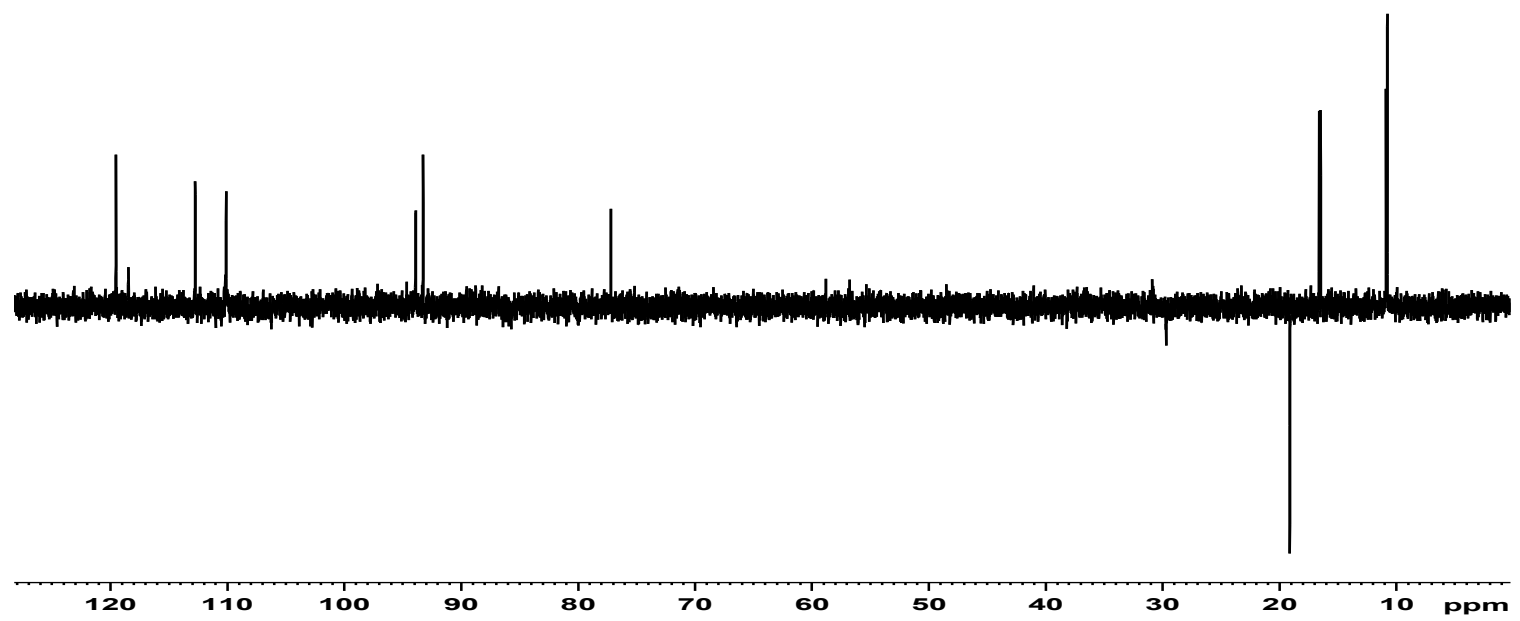

Figure A 21: DEPT-135 NMR spectrum of neo-confused porphyrin 36a in $\mathrm{CDCl}_{3}$.

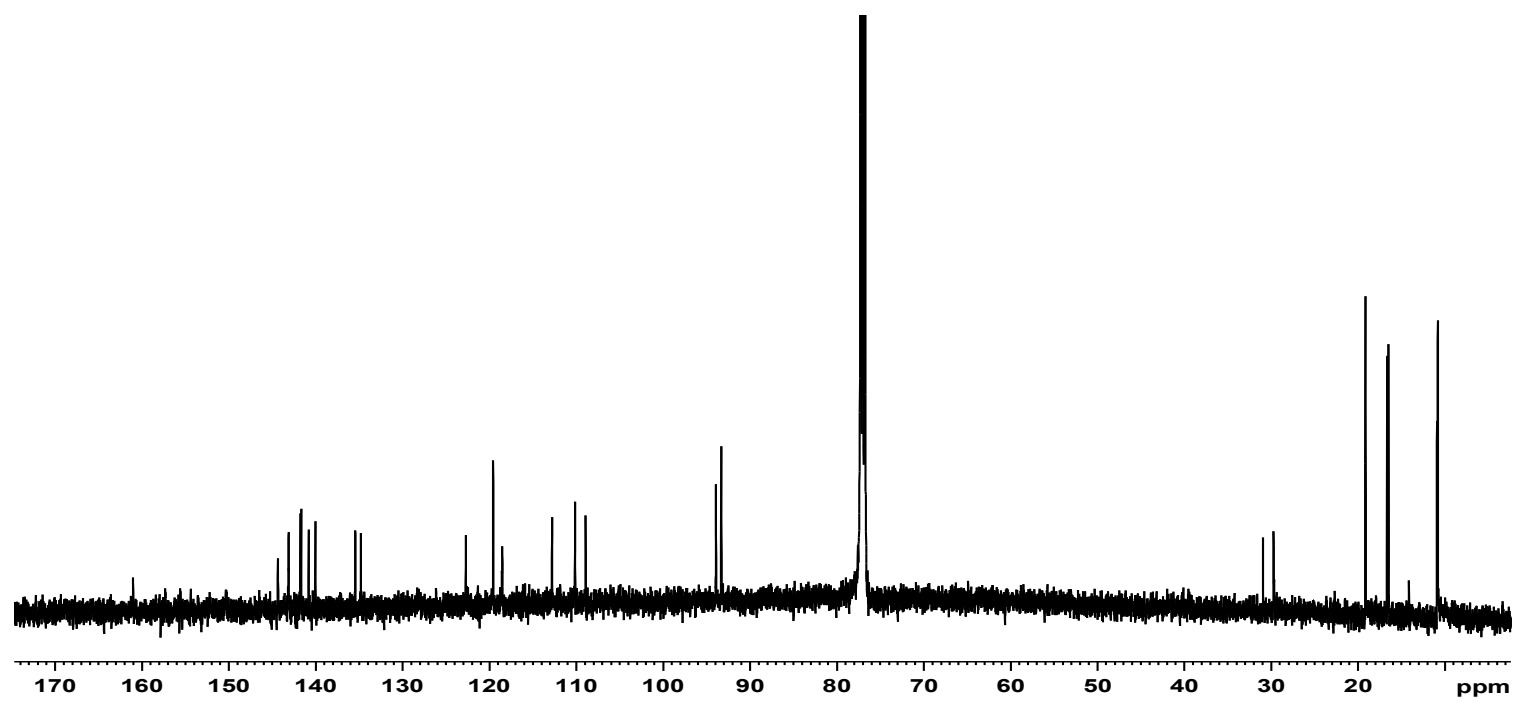

Figure A 22: $125 \mathrm{MHz}$ carbon-13 NMR spectrum of neo-confused porphyrin 36a in $\mathrm{CDCl}_{3}$. 


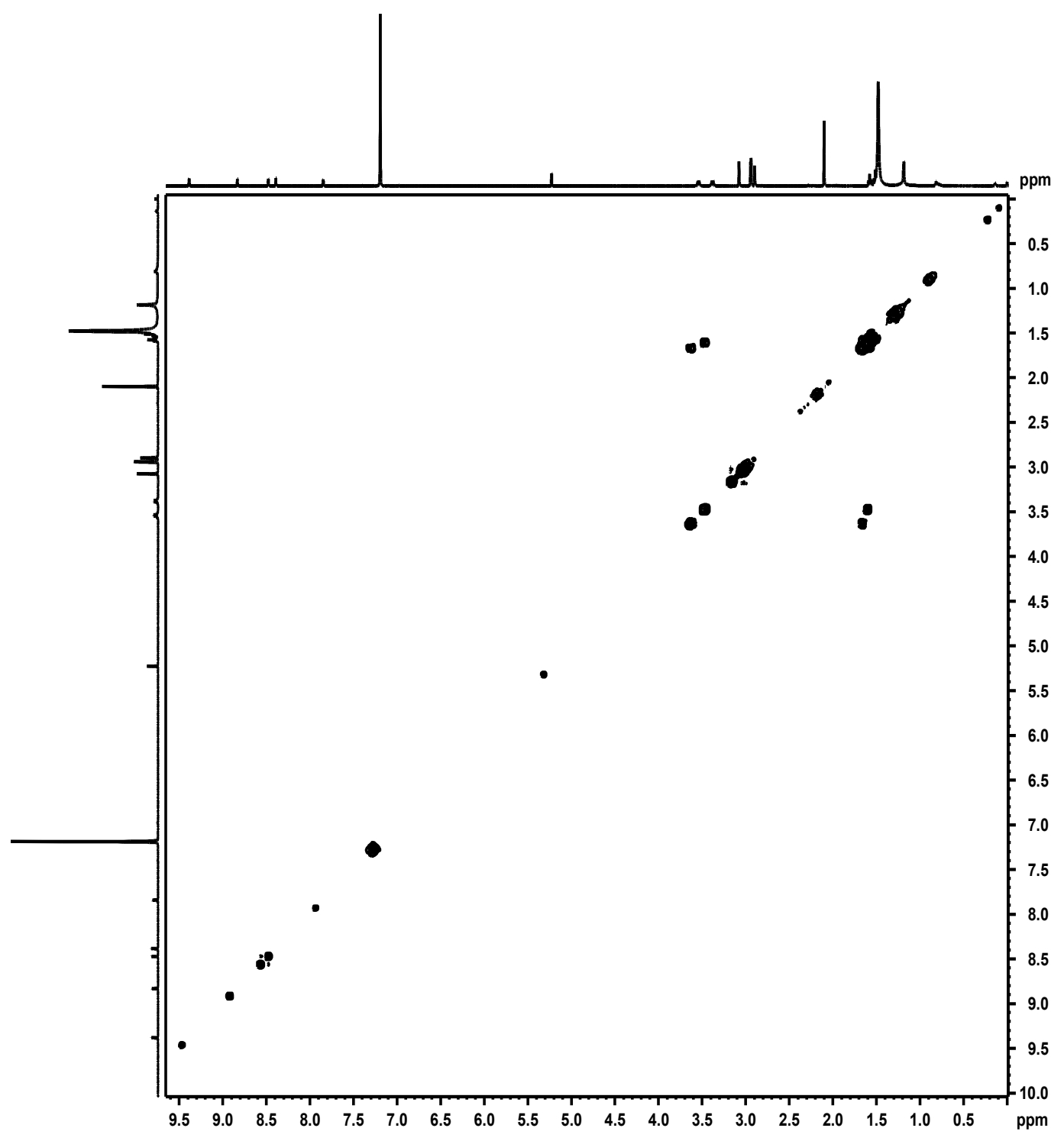

Figure A 23: ${ }^{1} \mathrm{H}-{ }^{1} \mathrm{H}$ COSY NMR spectrum of neo-confused porphyrin 36a in $\mathrm{CDCl}_{3}$. 


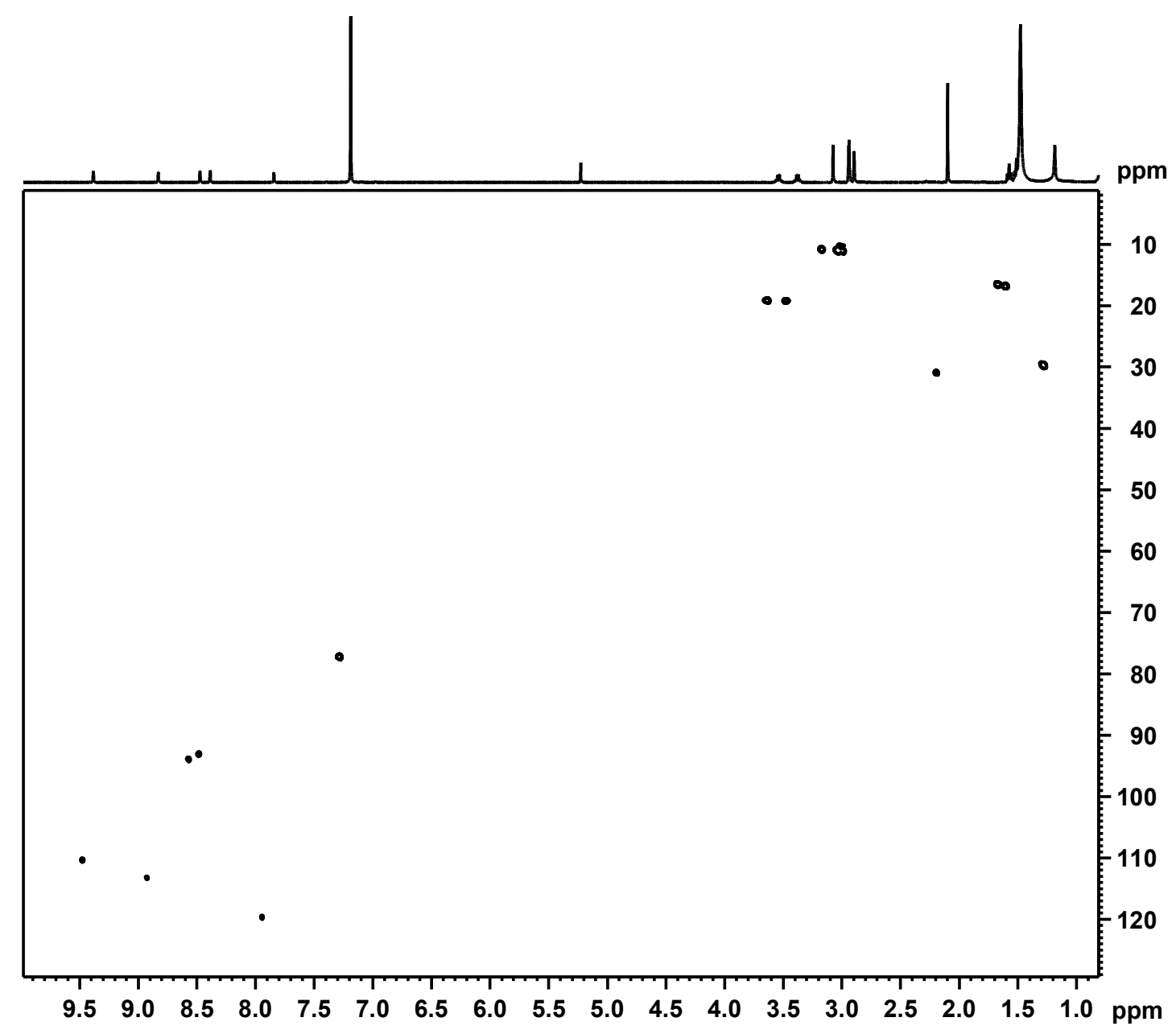

Figure A 24: HSQC NMR spectrum of neo-confused porphyrin 36a in $\mathrm{CDCl}_{3}$. 


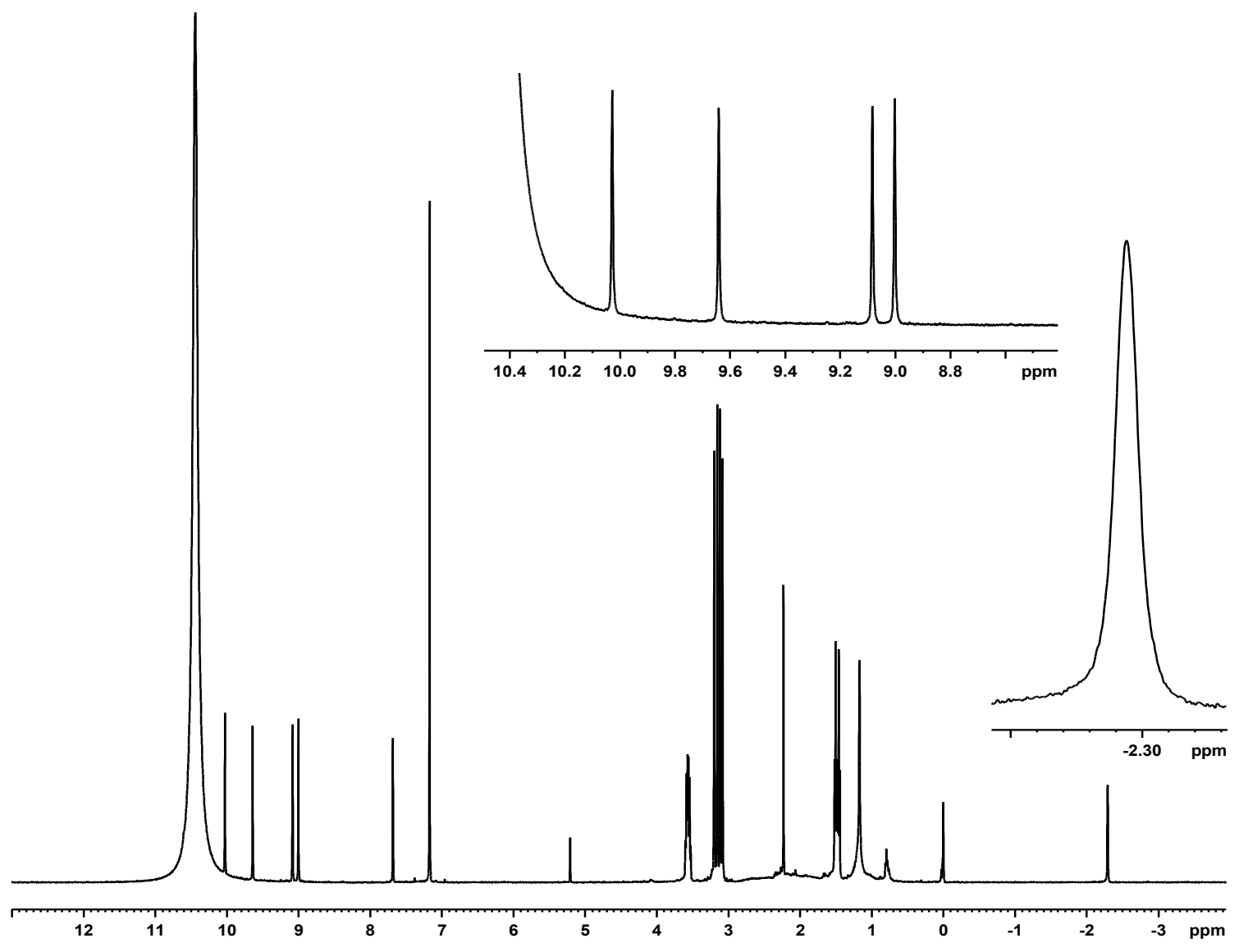

Figure A 25: $500 \mathrm{MHz}$ proton NMR spectrum of neo-confused porphyrin dication $36 \mathrm{aH}_{2}{ }^{2+}$ in TFA-CDCl 3 . 


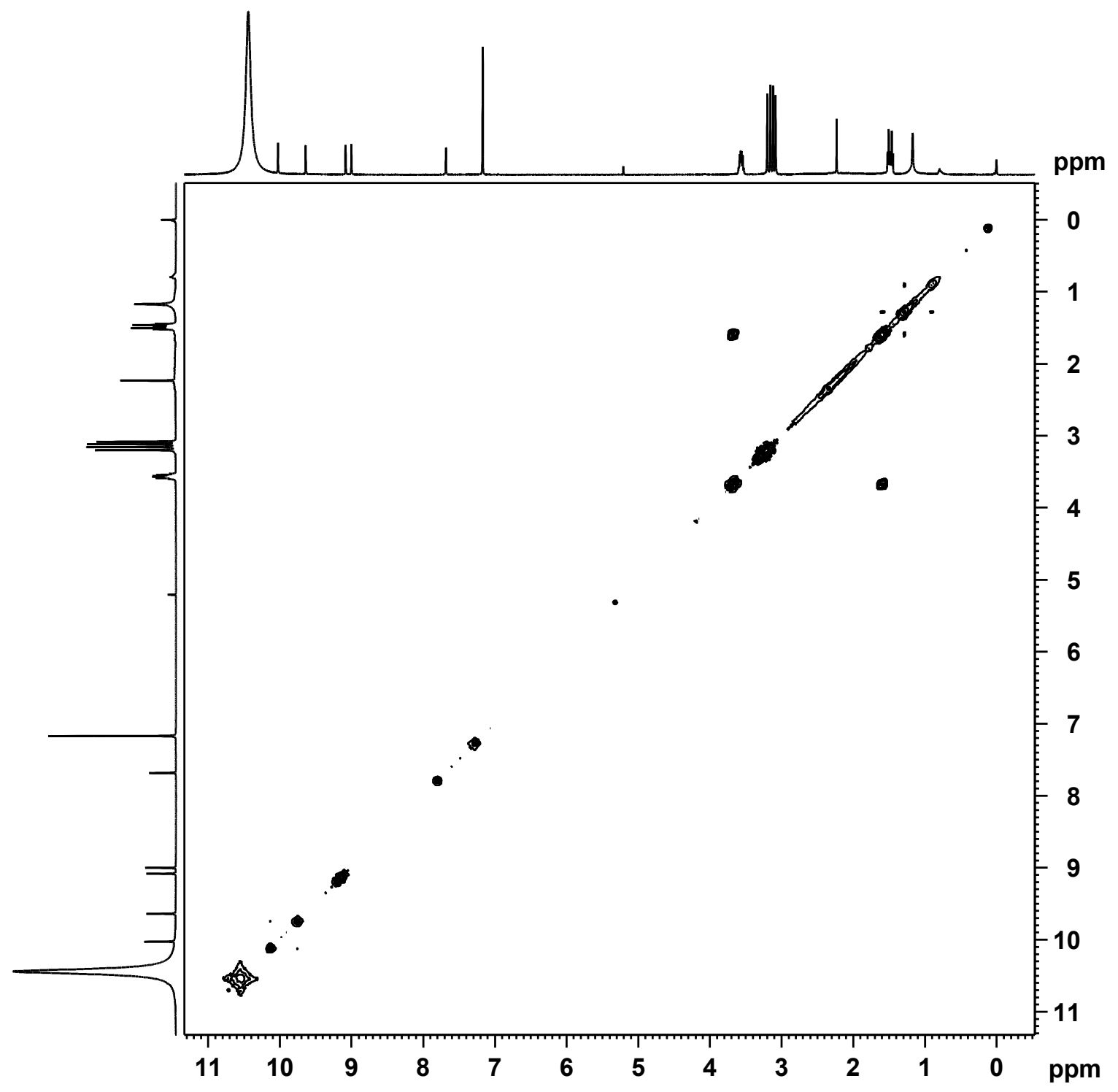

Figure A 26: ${ }^{1} \mathrm{H}-{ }^{1} \mathrm{H}$ COSY NMR spectrum of neo-confused porphyrin dication $36 \mathbf{a} \mathrm{H}_{2}{ }^{2+}$ in TFA-CDCl ${ }_{3}$. 


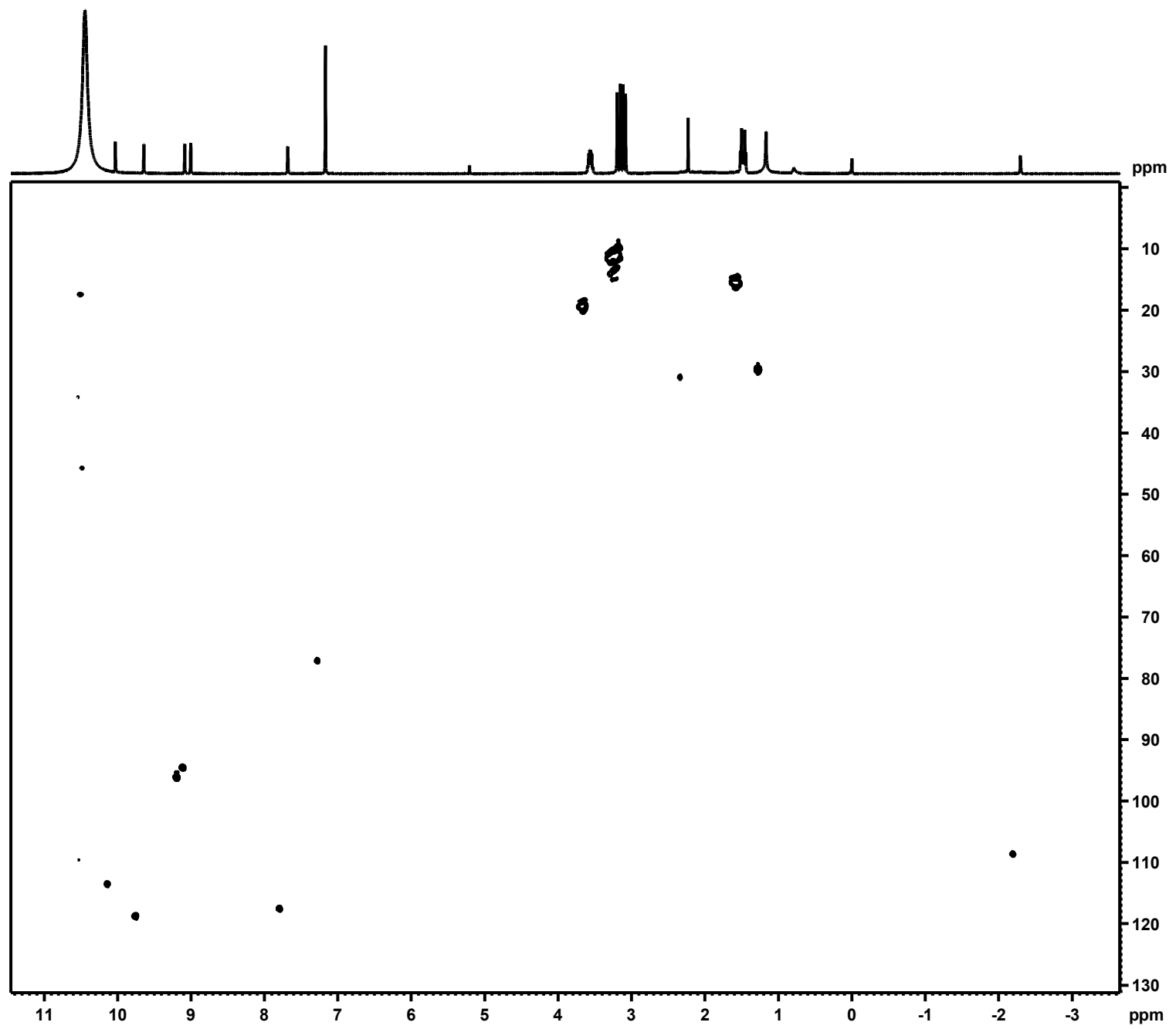

Figure A 27: HSQC NMR spectrum of neo-confused porphyrin $\mathbf{3 6} \mathbf{a H}_{2}{ }^{2+}$ in TFA-CDCl ${ }_{3}$. 


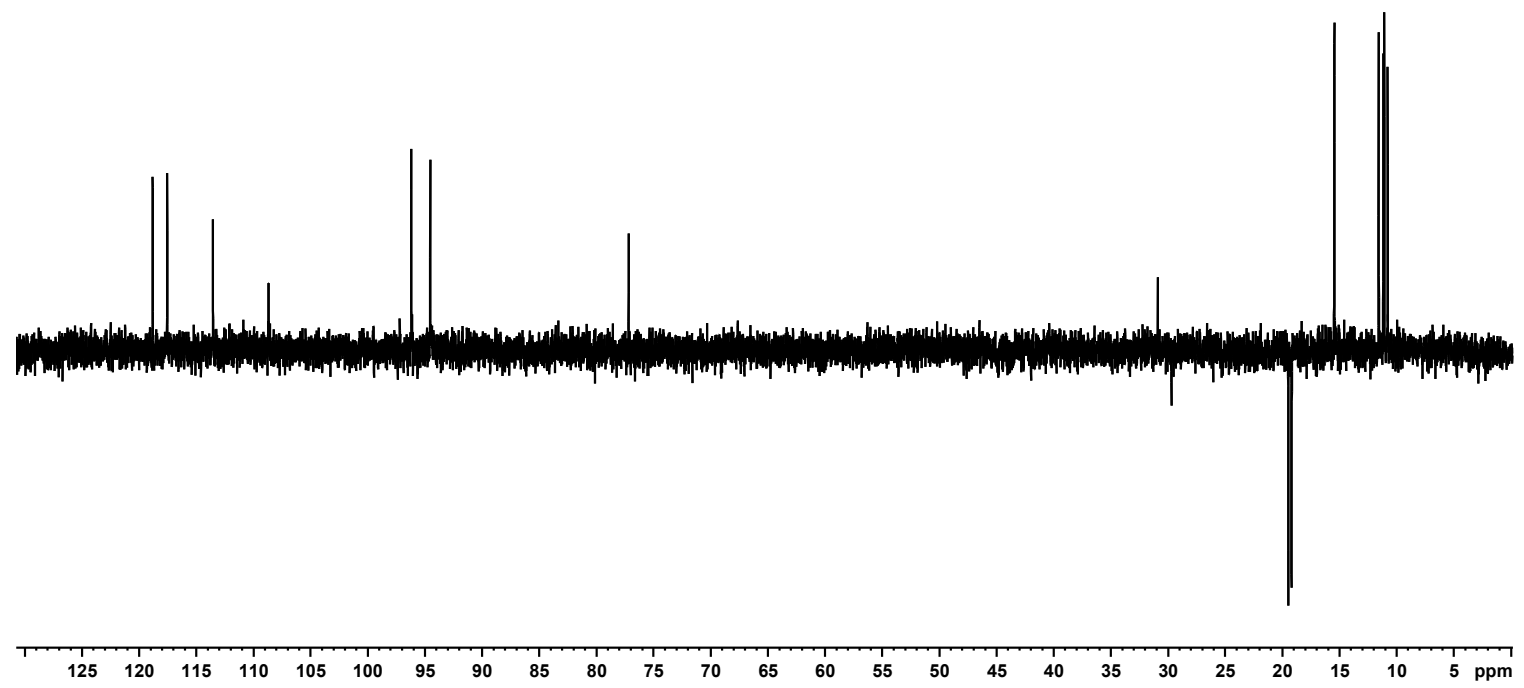

Figure A 28: DEPT-135 NMR spectrum of neo-confused porphyrin $\mathbf{3 6} \mathbf{a H}_{2}{ }^{2+}$ in TFA$\mathrm{CDCl}_{3}$.

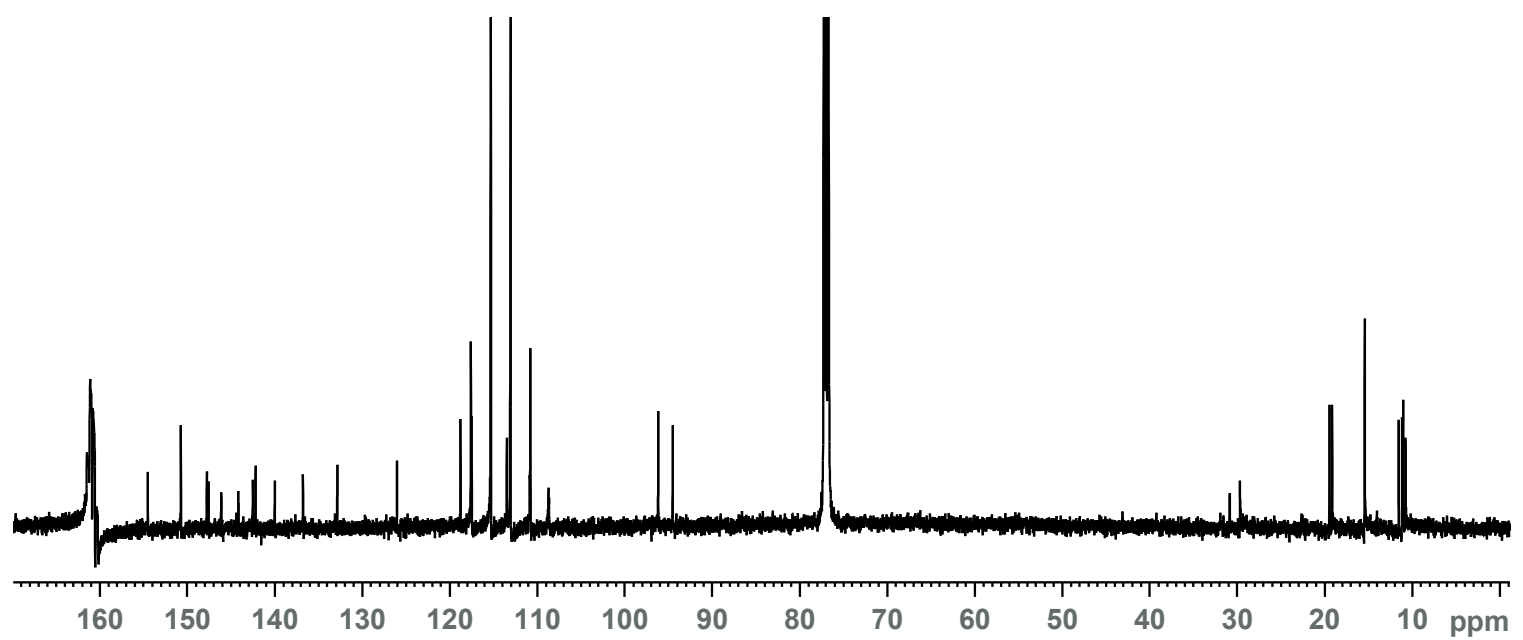

Figure A 29: $125 \mathrm{MHz}$ carbon-13 NMR spectrum of neo-confused porphyrin $\mathbf{3 6}_{\mathbf{6}} \mathbf{H}_{2}{ }^{\mathbf{2 +}}$ in TFA-CDCl ${ }_{3}$. 


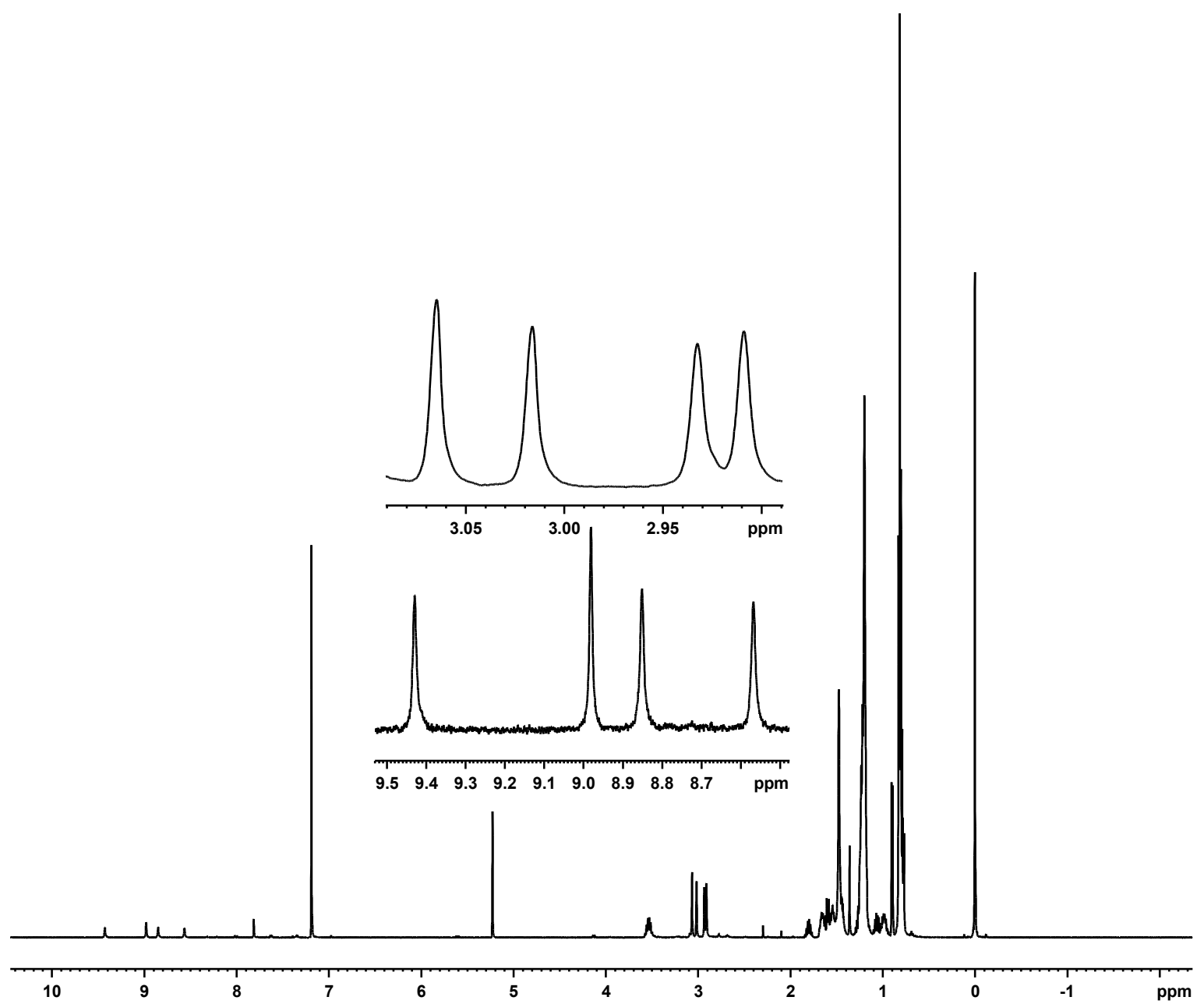

Figure A 30: $500 \mathrm{MHz}$ proton NMR spectrum of palladium complex 54 in $\mathrm{CDCl}_{3}$. 


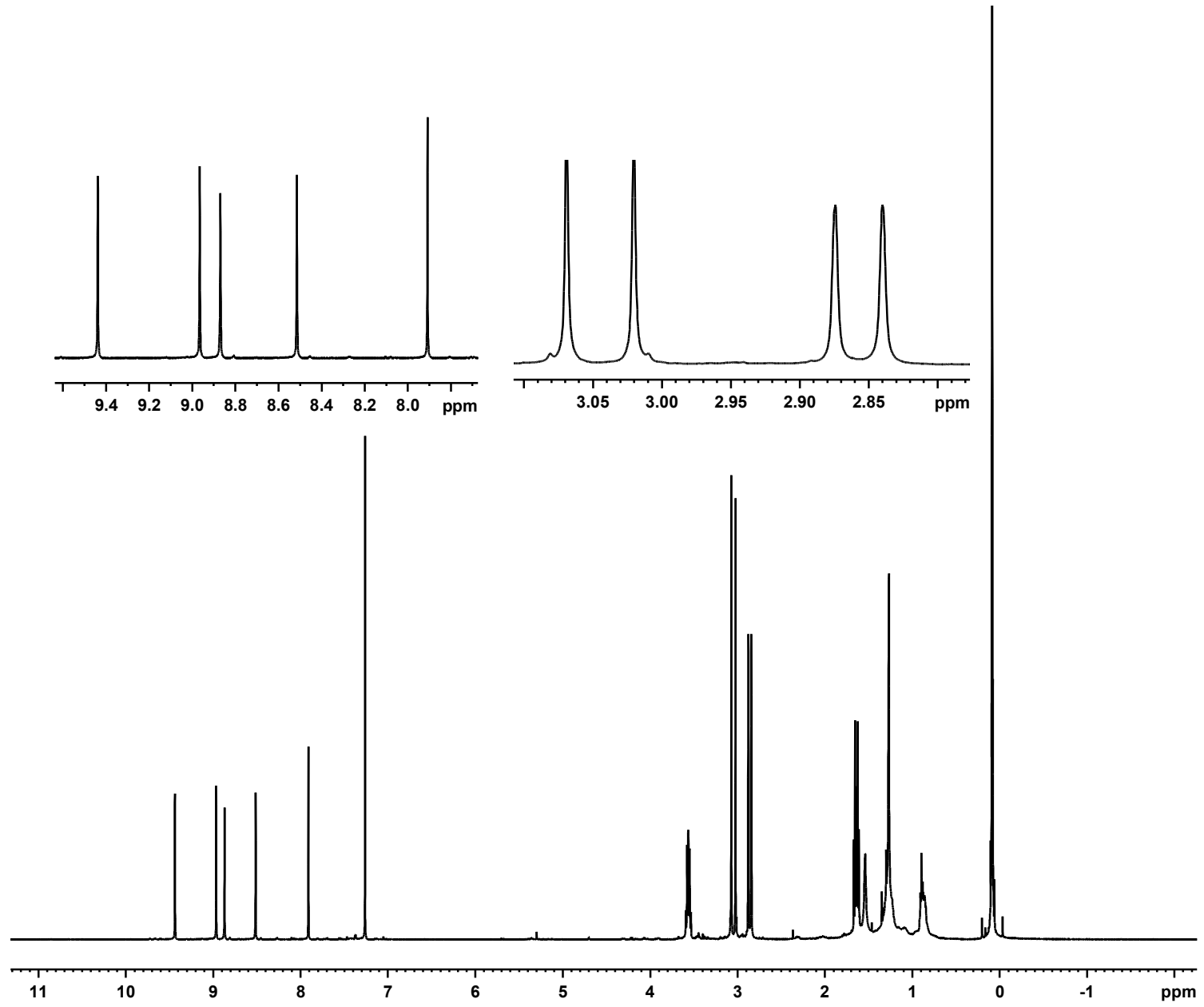

Figure A 31: $500 \mathrm{MHz}$ proton NMR spectrum of nickel complex 53 in $\mathrm{CDCl}_{3}$. 


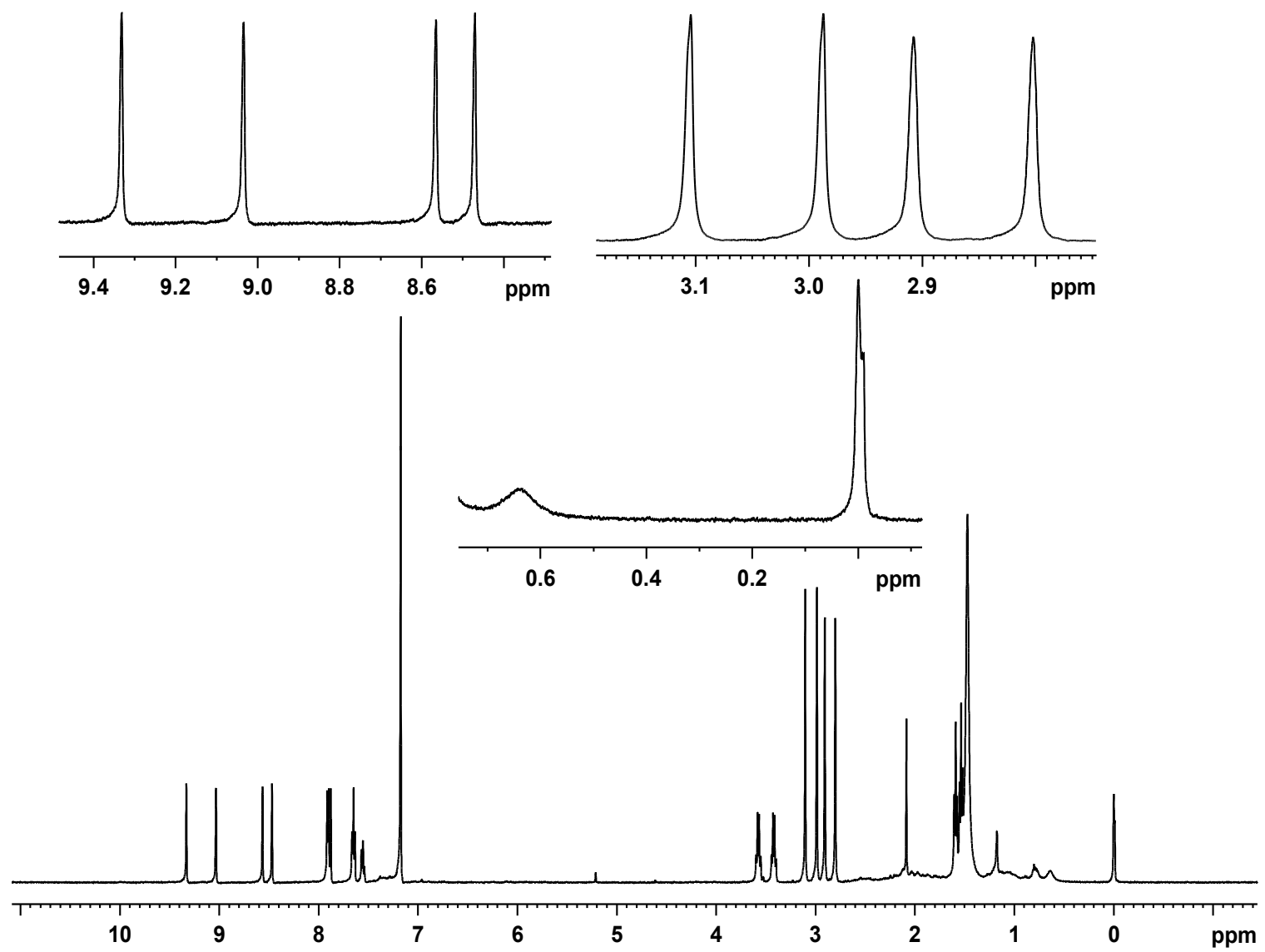

Figure A 32: $500 \mathrm{MHz}$ proton NMR spectrum of neo-confused porphyrin $\mathbf{3 6} \mathbf{b}$ in $\mathrm{CDCl}_{3}$. 


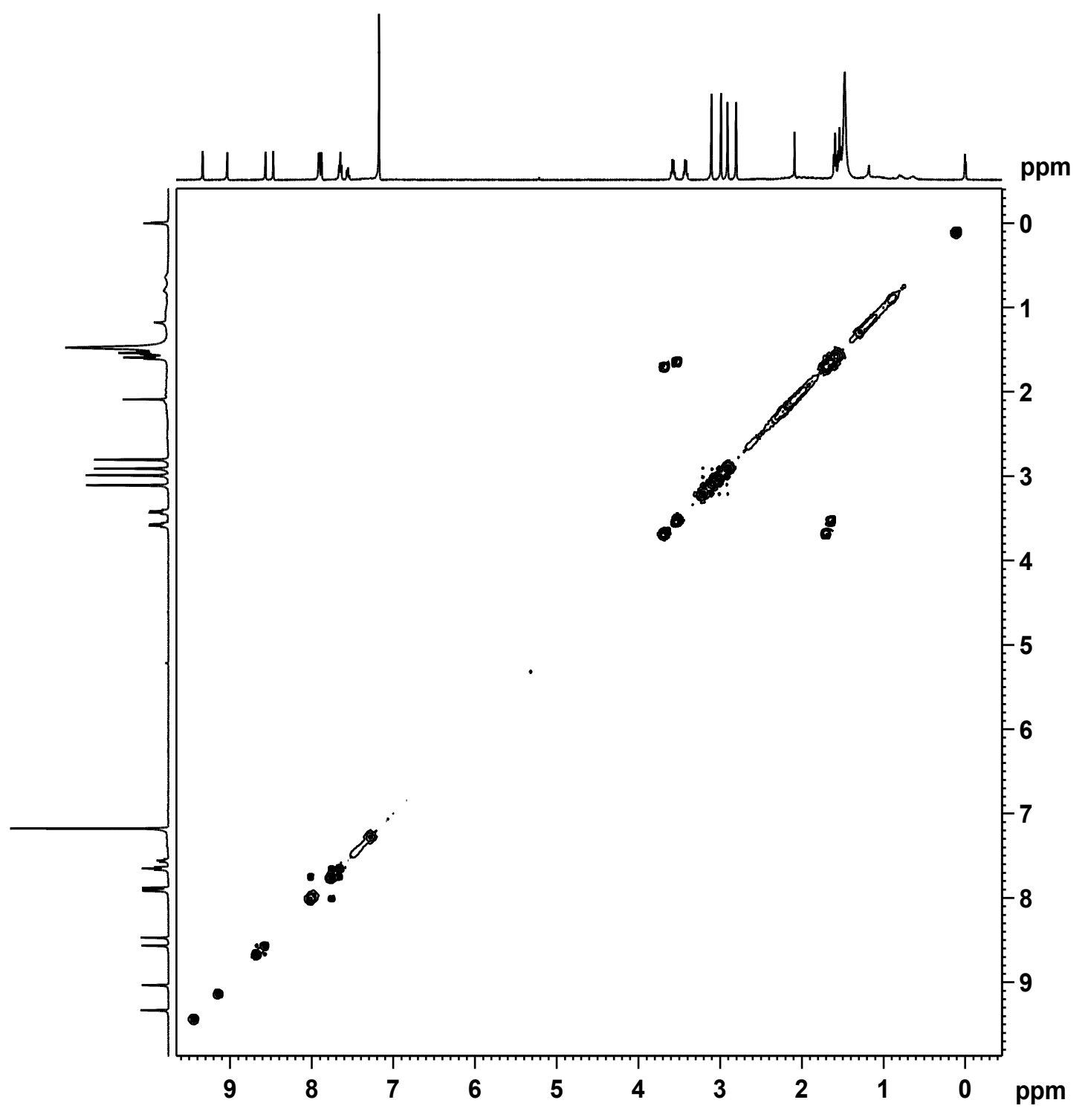

Figure A 33: ${ }^{1} \mathrm{H}-{ }^{1} \mathrm{H}$ COSY NMR spectrum of neo-confused porphyrin $\mathbf{3 6} \mathbf{b}$ in $\mathrm{CDCl}_{3}$. 


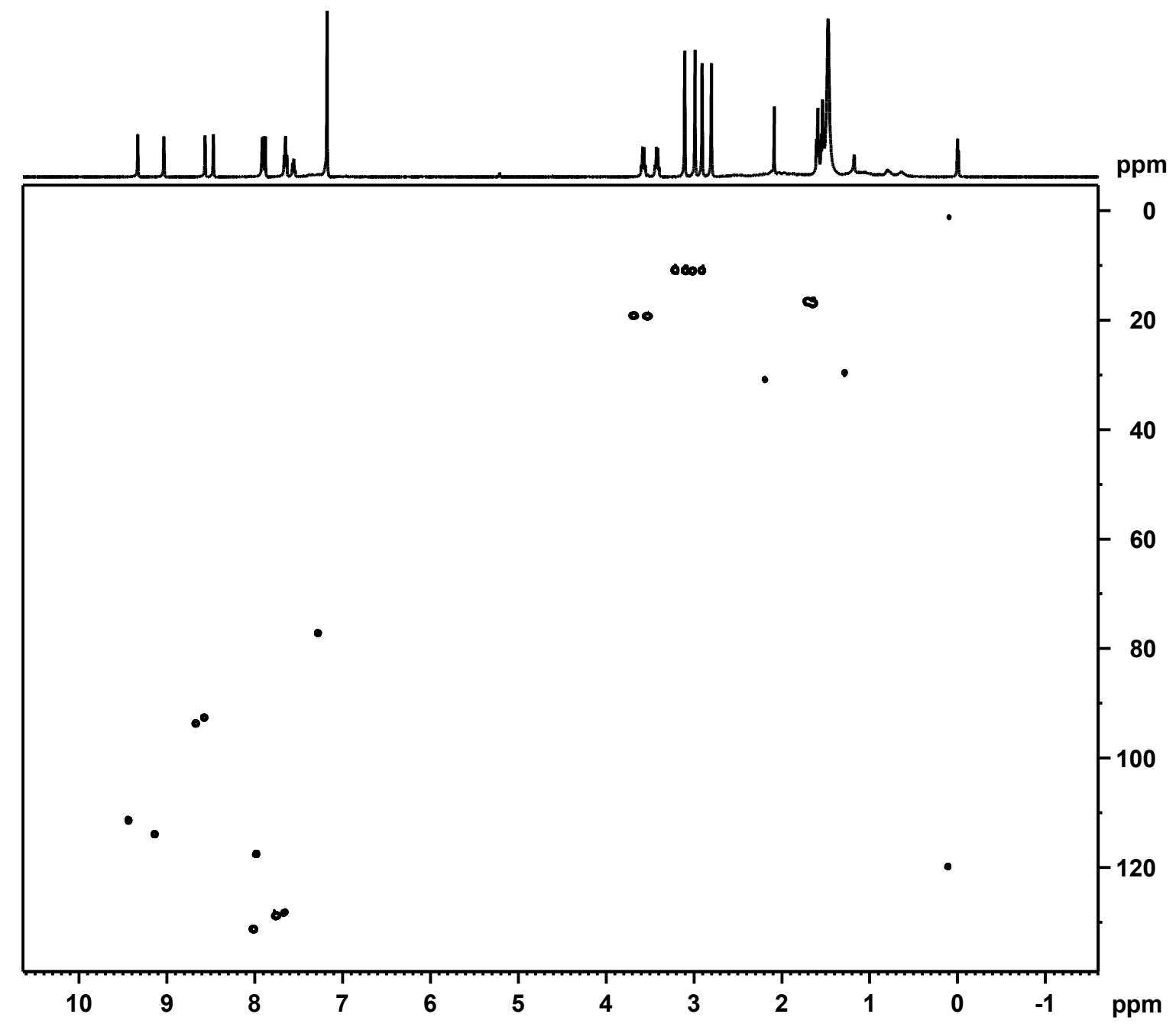

Figure A 34: HSQC NMR spectrum of neo-confused porphyrin 36b in $\mathrm{CDCl}_{3}$. 


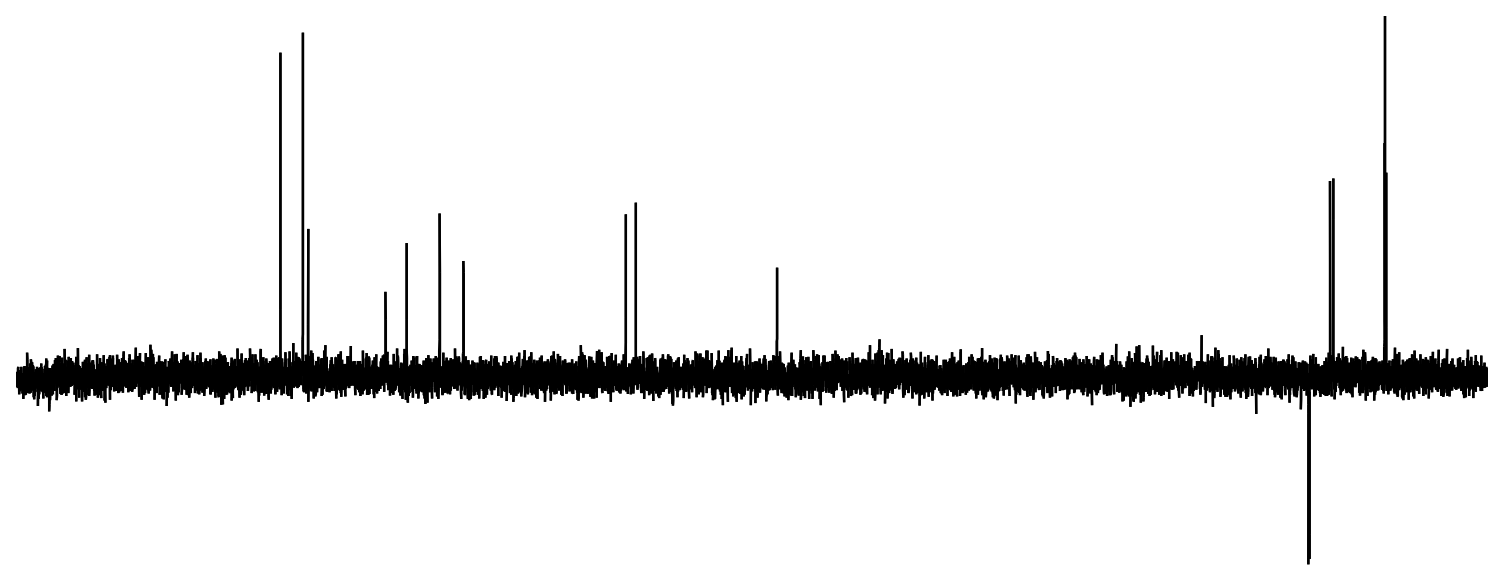

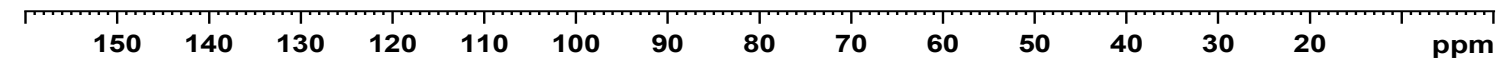

Figure A 35: DEPT-135 NMR spectrum of neo-confused porphyrin $\mathbf{3 6} \mathbf{b}$ in $\mathrm{CDCl}_{3}$.

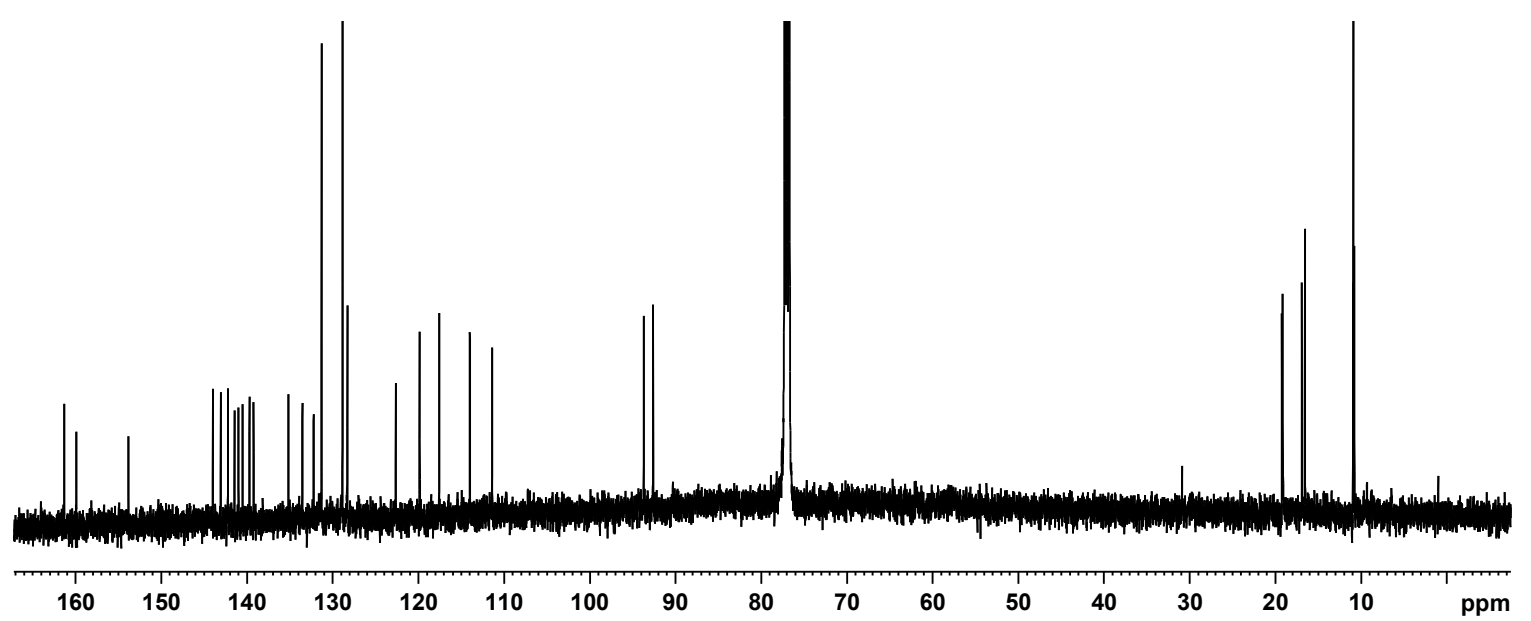

Figure A 36: $125 \mathrm{MHz}$ carbon-13 NMR spectrum of neo-confused porphyrin $36 \mathbf{b}$ in $\mathrm{CDCl}_{3}$. 


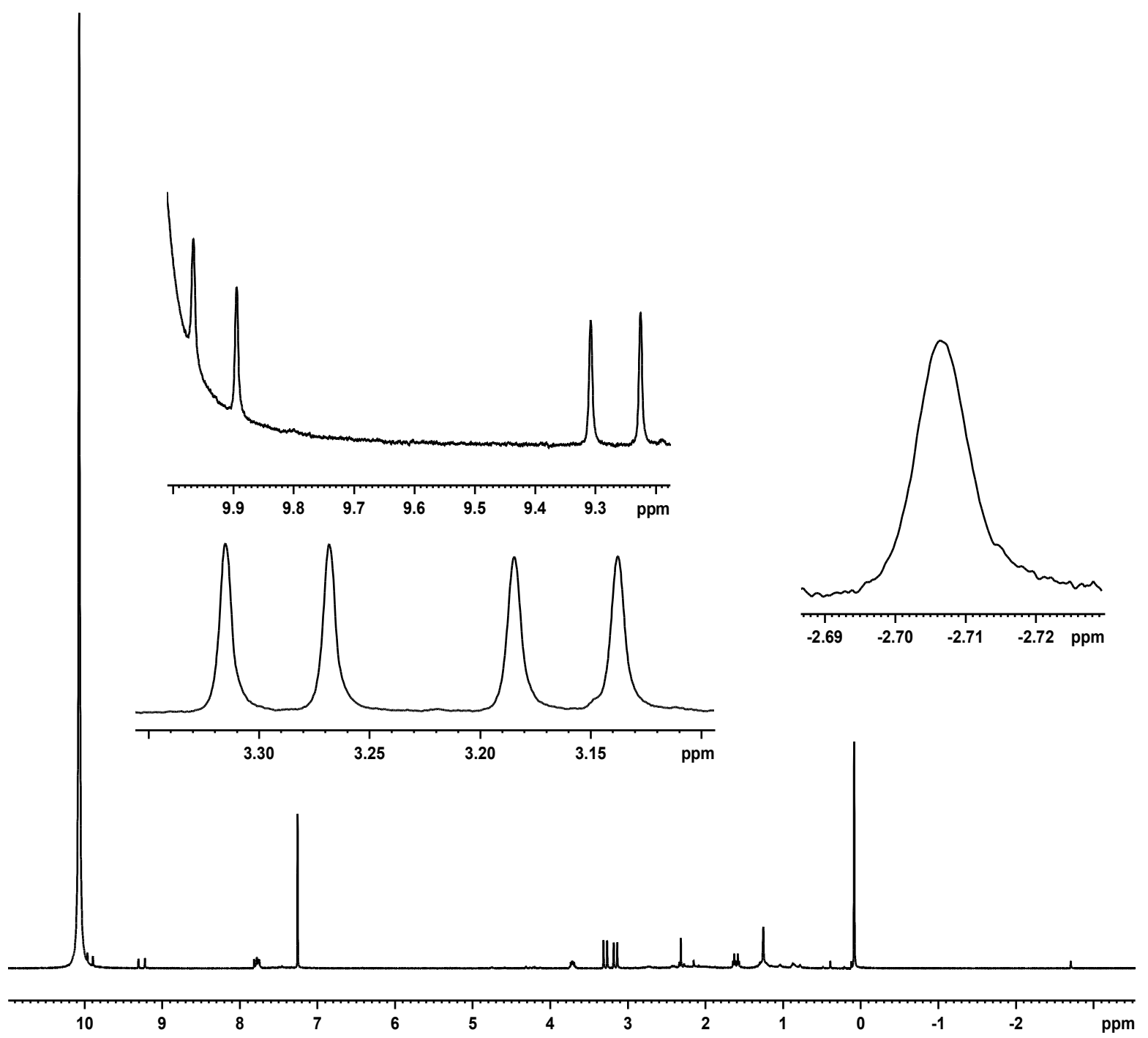

Figure A 37: $500 \mathrm{MHz}$ proton NMR spectrum of neo-confused porphyrin dication36b $\mathrm{H}_{2}{ }^{2+}$ in TFA-CDCl 3 . 


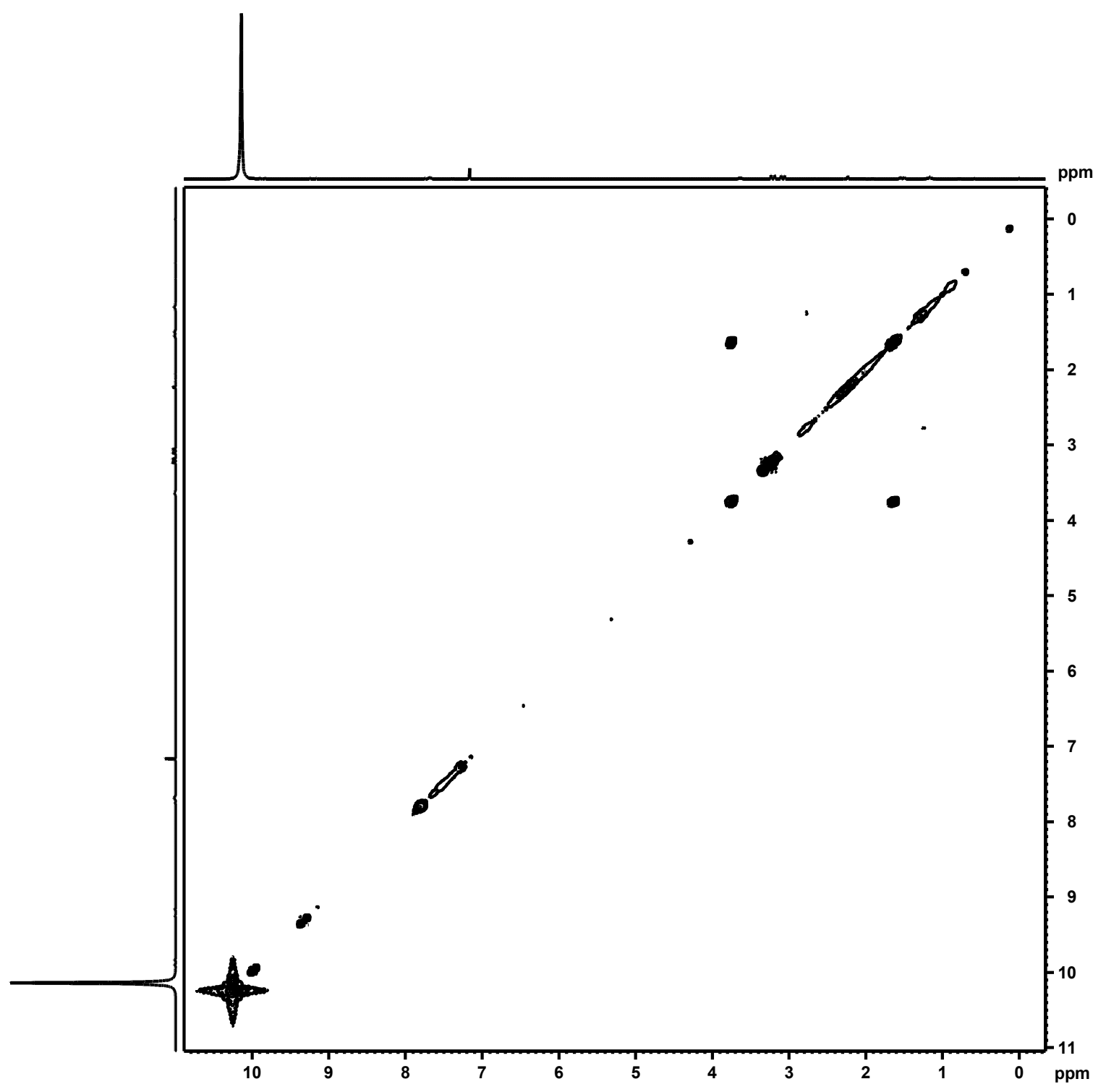

Figure A 38: ${ }^{1} \mathrm{H}-{ }^{1} \mathrm{H}$ COSY NMR spectrum of phenyl neo-confused porphyrin $\mathbf{3 6} \mathbf{b H}_{2}{ }^{2+}$ in TFA-CDCl ${ }_{3}$. 


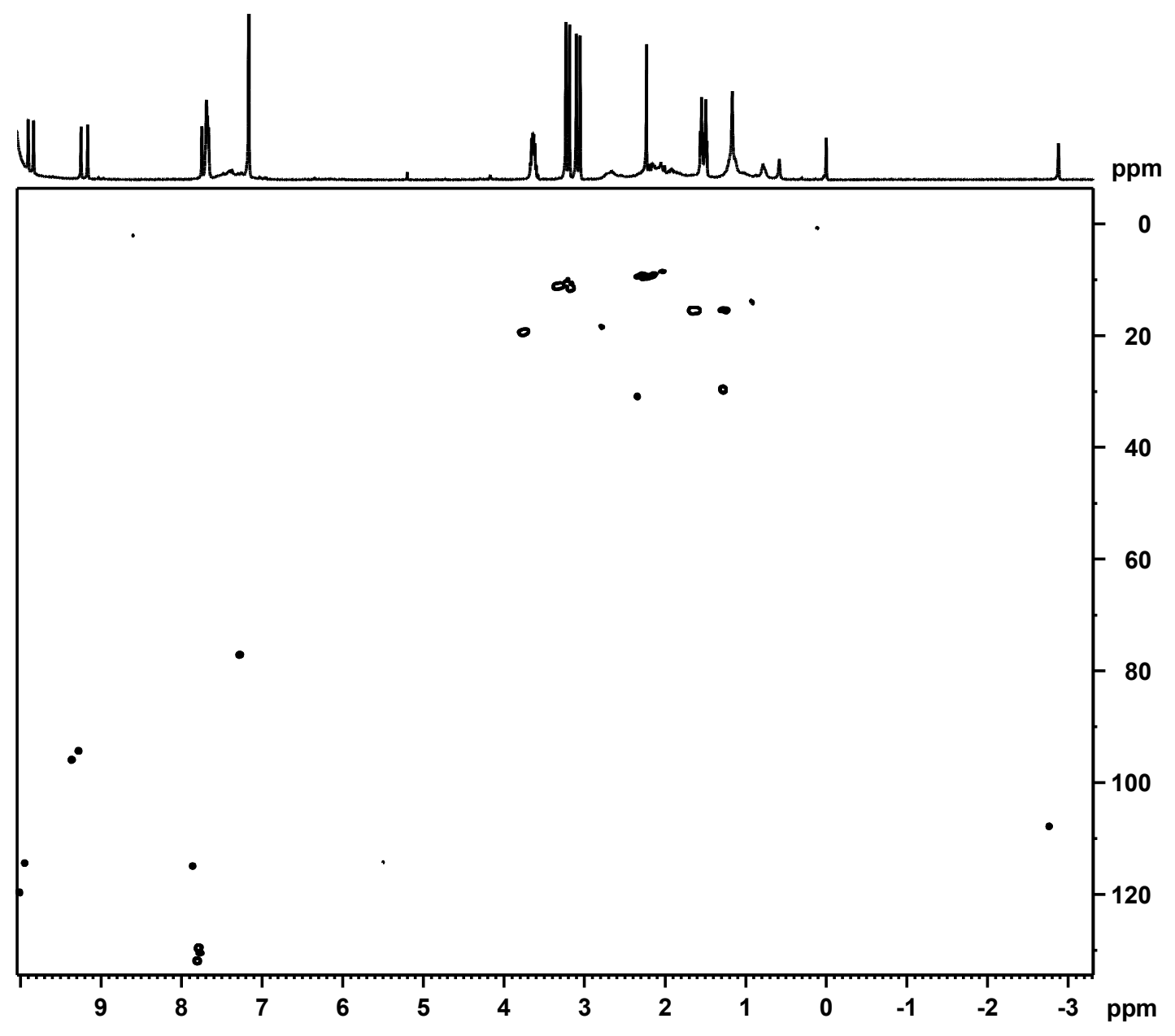

Figure A 39: HSQC NMR spectrum of phenyl neo-confused porphyrin $\mathbf{3 6} \mathbf{b} \mathrm{H}_{2}{ }^{2+}$ in TFA$\mathrm{CDCl}_{3}$. 


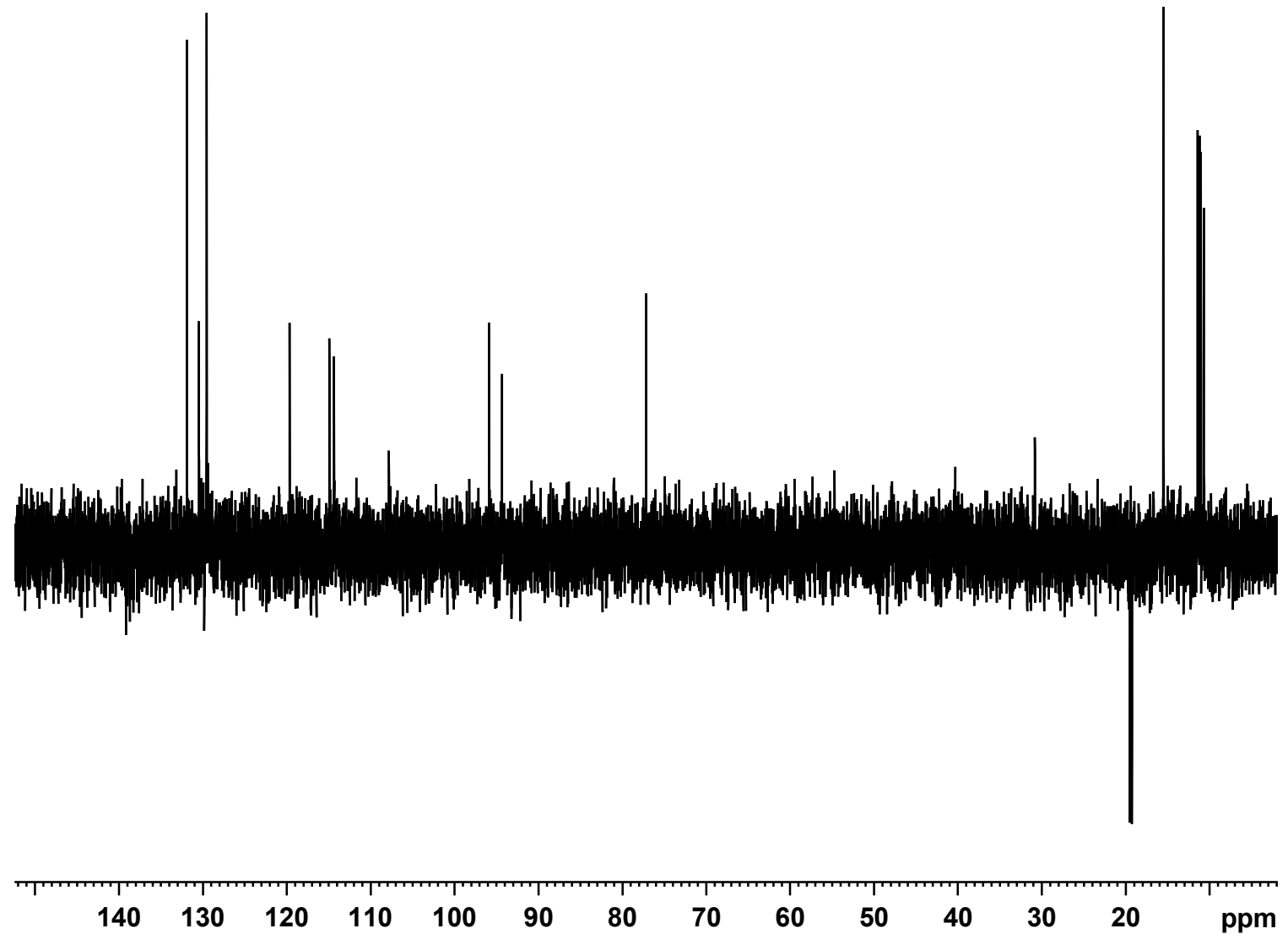

Figure A 40: DEPT-13 NMR spectrum of phenyl neo-confused porphyrin $36 \mathbf{b H}_{2}{ }^{2+}$ in TFA-CDCl ${ }_{3}$. 


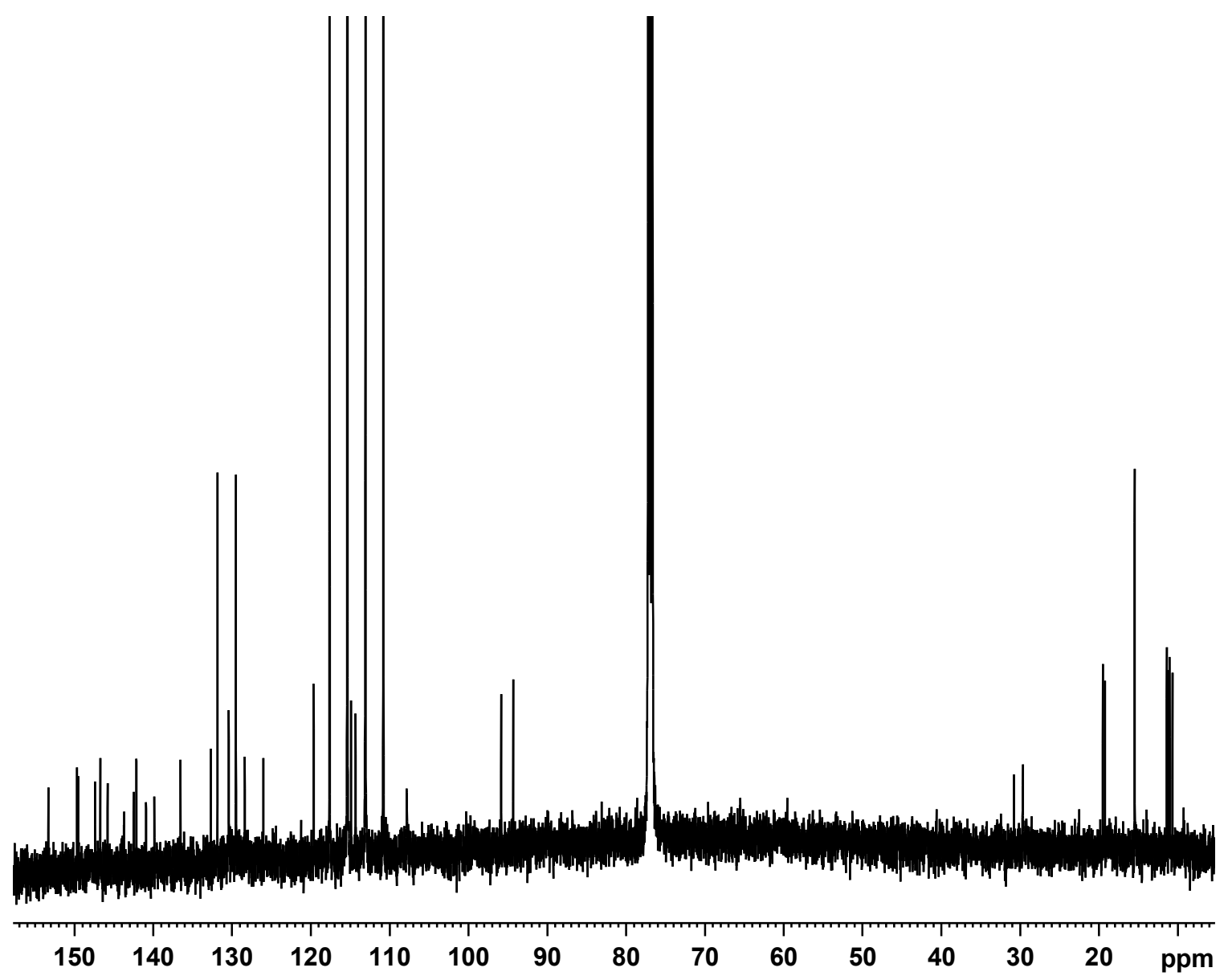

Figure A 41: $125 \mathrm{MHz}$ carbon-13 NMR spectrum of neo-confused porphyrin $\mathbf{3 6} \mathbf{b} \mathrm{H}_{2}{ }^{2+}$ in TFA-CDCl ${ }_{3}$ 


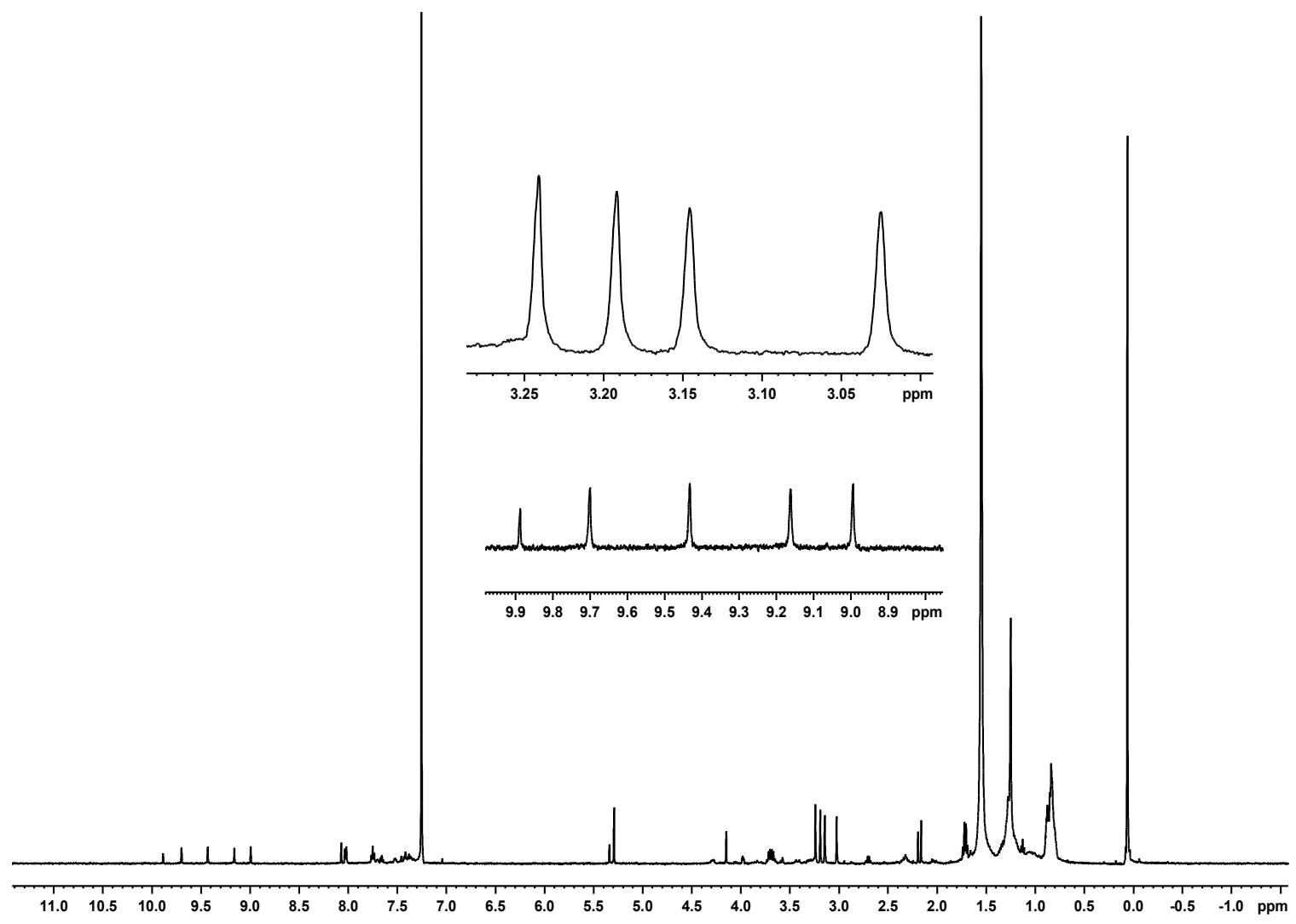

Figure A 42: $500 \mathrm{MHz}$ proton NMR spectrum of palladium complex 61 in $\mathrm{CDCl}_{3}$. 


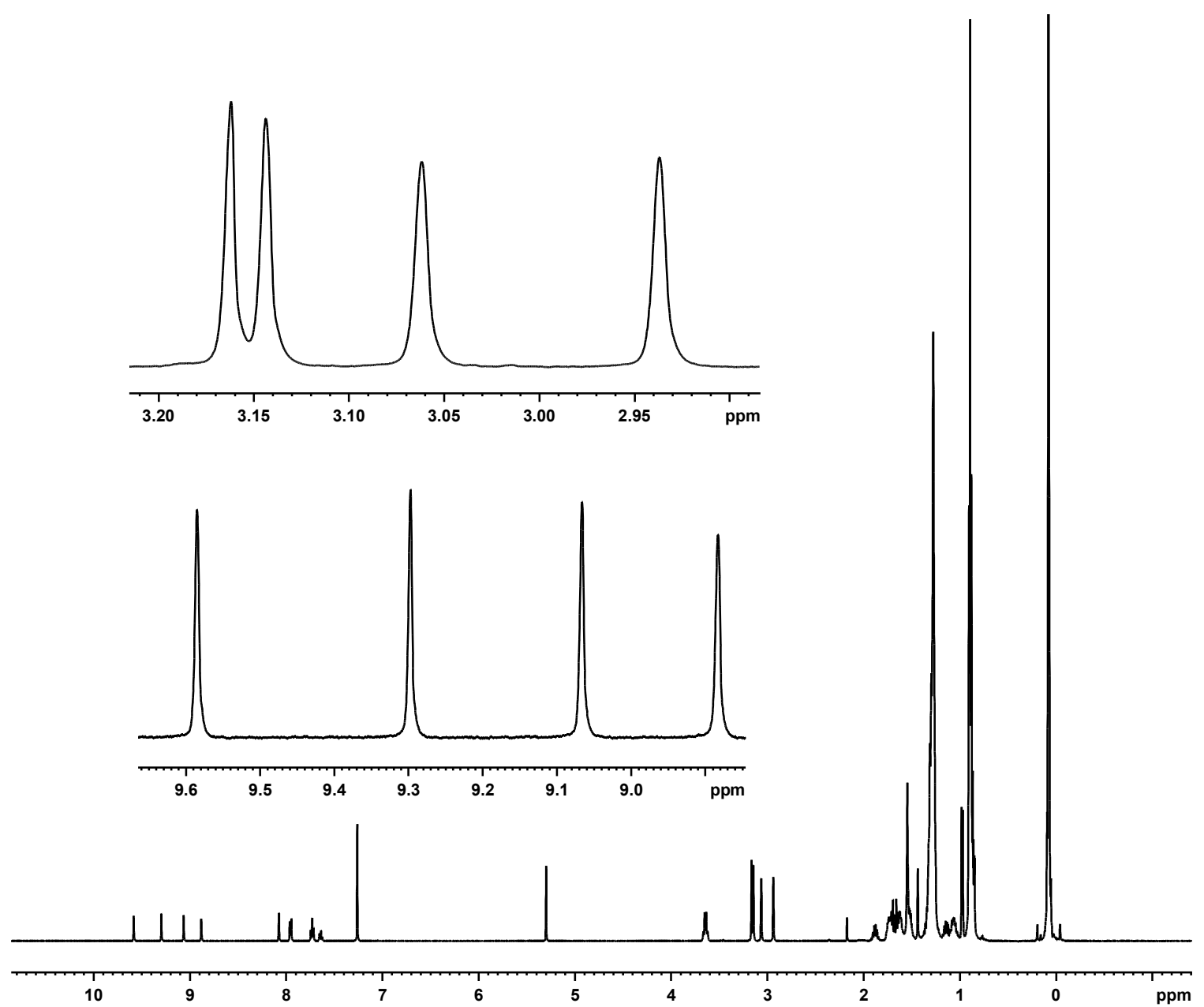

Figure A 43: $500 \mathrm{MHz}$ proton NMR spectrum of nickel complex 62 in $\mathrm{CDCl}_{3}$ 